AUTARQUIA ASSOCIADA À UNIVERSIDADE DE SÃO PAULO

\title{
VALIDAÇÃO DOS MÉTODOS DE ANÁLISE POR ATIVAÇÃO DO LABORATÓRIO DE ANÁLISE POR ATIVAÇÃO NEUTRÔNICA DO IPEN - CNEN/SP VISANDO A PRODUÇÃO DE MATERIAIS DE REFERÊNCIA CERTIFICADOS
}

Robson Petroni

Dissertação apresentada como parte dos requisitos para obtenção do Grau de Mestre em Ciências na Área de Tecnologia Nuclear - Aplicações

Orientador:

Prof. Dr. Edson Gonçalves Moreira 


\title{
INSTITUTO DE PESQUISAS ENERGÉTICAS E NUCLEARES
}

Autarquia associada à Universidade de São Paulo

\begin{abstract}
Validação dos métodos de análise por ativação do laboratório de Análise por Ativação Neutronica do IPEN - CNEN/SP visando a produção de materiais de referência certificados
\end{abstract}

Robson Petroni

Dissertação apresentada como parte dos requisitos para obtenção do Grau de Mestre em Ciências na Área de Tecnologia Nuclear - Aplicações

Orientador:

Prof. Dr. Edson Gonçalves Moreira

Versão Corrigida

São Paulo 
Dedico aos meus pais,

irmãos e familiares 
Aurora do Mundo****************

Quem teve os amores que tive na vida É gente entendida na mágoa e na dor E sabe por certo que um doce carinho Às vezes é espinho em forma de flor Estando sofrendo aqui na cidade A louca saudade de um certo amor Busquei o remédio pra mente saudosa $\mathrm{Na}$ vida gostosa do interior

Cruzei os cerrados, chapadas e serras Pro lado das terras de Minas Gerais Vi campos floridos e belos cenários

Ouvi os canários nos macaubais

Fumaça distante no azul do horizonte Na encosta do monte, formando espirais

Vi tudo que amo na tranquilidade Mas minha saudade ainda era mais

Passei uma noite no Rancho Amizade E vi na saudade o começo do fim A chuva caía naquele tugúrio Num triste murmúrio por sobre o capim A noite avançava e eu não dormia Agora sabia que amar era assim Por fim entreguei-me ao sono profundo E a aurora do mundo caiu sobre mim

Voltei pra cidade, fiquei na agonia Até que um dia meu bem reencontrei

Beijei a menina com todo carinho

E aquele rostinho acariciei Cantando seguiu-me na linha da vida Na estrada florida que eu lhe mostrei Porque ela sabe que agora é só minha És minha rainha eu sou o seu rei 
\#momentopoetico

Tempestade

Quando o mais frio dos ventos sul interpola a quente brisa do mar os sentimentos se confundem, histórias são relembradas... O amor a uma pessoa não é medido pelo espaço que ela ocupa em nosso coração. Mas pelo vazio que ela nos deixa, quando está distante. A saudade é como o vento... castiga, destrói, maltrata, ... e passa ... só então o ínfimo mar se acalma. E a quente brisa, enfim volta a soprar!

(Robson Petroni) 


\section{AGRADECIMENTOS}

Agradeço primeiramente a Deus, por minha saúde, alegria e pelo dom da vida. Agradeço aos meus pais Dona Luzia e Sr. José e aos meus irmãos Rodrigo e Ricardo por todo incentivo e apoio para a realização de mais este projeto. Amo vocês.

Agradeço ao grande amigo, incentivador e super-orientador Dr. Edson Gonçalves Moreira por ter me aceitado como seu primeiro aluno de mestrado e por ter me ajudado muito durante a elaboração do plano de trabalho, artigos, publicação, apresentações e por ter viabilizado minha participação em vários congressos. Muito obrigado mesmo!

Agradeço ao grande amigo, pessoa que admiro muito e que sem dúvidas é o maior incentivador de minha carreira acadêmica, M. Sc. Francisco Jorge Ferreira, gerente do ELAI da CETESB.

Agradeço a todos os membros da banca de defesa, Dra. Mitiko Saiki (IPEN - CNEN/SP), Dr. Silvio Miranda Prada (UNIFIEO), Dr. Olívio Pereira de Oliveira Júnior (SRC), Dr. José Eduardo Bevilacqua (CETESB) e Dr. Paulo Sérgio Cardoso da Silva (IPEN CNEN/SP) por aceitarem meu convite e pela valiosa contribuição.

Agradeço aos amigos feitos durante o mestrado os quais vivenciaram e fizeram parte do meu dia-a-dia nestes últimos três anos.

Agradeço aos pesquisadores, funcionários e colaboradores do LAN, por toda amizade, colaboração e apoio para a realização deste estudo.

Agradeço a Dra. Deborah Inês Teixeira Favaro por ter me apresentado ao Dr. Edson Gonçalves Moreira, na época, ainda enquanto eu era candidato a aluno de mestrado.

Agradeço a gerência do CRPq pela abertura das portas do Centro para a realização deste trabalho de mestrado.

Agradeço a Comissão de Pós Graduação do IPEN - CNEN/SP pela oportunidade de realização deste trabalho de mestrado.

Agradeço a Secretaria de Pós Graduação, em especial a Ana Claudia Martinelli Feher por toda atenção, cordialidade e pela ajuda nas questões burocráticas relacionadas a Pós Graduação.

Agradeço ao Conselho Nacional de Desenvolvimento Científico e Tecnológico (CNPq) pela bolsa de estudos concedida para a realização deste trabalho de mestrado e pela verba referente a auxílios para participação e apresentação de trabalhos em dois congressos. 


\section{RESUMO}

\section{Validação dos métodos de análise por ativação do laboratório de análise por ativação neutrônica do IPEN - CNEN/SP visando a produção de materiais de referência certificados}

\section{Robson Petroni}

Este trabalho de mestrado teve como objetivo realizar a validação formal para quatro métodos de medição do Laboratório de Ativação Neutrônica (LAN) do IPEN CNEN/SP por Análise por Ativação com Nêutrons Instrumental (INAA). Os mensurandos foram a concentração total de As em tecido de mexilhão (método-BIO-1), a concentração total de $\mathrm{Co}, \mathrm{Cr}, \mathrm{Fe}, \mathrm{Rb}, \mathrm{Sc}, \mathrm{Se}$ e $\mathrm{Zn}$ em tecido de mexilhão (método-BIO-2), a concentração total de As e $\mathrm{Sb}$ em sedimento marinho (método-GEO-1) e a concentração total $\mathrm{Co}, \mathrm{Cr}, \mathrm{Fe}, \mathrm{Sc}$ e $\mathrm{Zn}$ em sedimento marinho (método-GEO-2). Em um primeiro momento, foi realizado um estudo univariado para investigar a influência causada ao resultado final em diferentes configurações no preparo dos padrões sintéticos e no tempo de medição da atividade do mensurando no padrão sintético. Outras variáveis, como o tempo de medição da atividade do mensurando na amostra, distância entre amostra e detector e tempo de decaimento para medição da amostra foram estudadas em um processo multivariado, por meio da realização de um Planejamento Fatorial $2^{3}$ completo (DOE). Os parâmetros de desempenho estudados para a validação dos métodos de medição em INAA foram: seletividade, exatidão (precisão e veracidade), linearidade, faixa de trabalho, seletividade, limite de detecção, limite de quantificação, robustez e incerteza de medição. Os métodos foram validados de acordo com as recomendações do Guia de validação do INMETRO DOQ-CGCRE-008. A estimativa das fontes de incertezas foi realizada de acordo com as recomendações do Guia para a expressão da incerteza de medição (ISO GUM) com o uso do método simulado.

Palavras-chave: INAA, MRC, validação, planejamento fatorial, ABNT ISO 17025 


\section{ABSTRACT \\ Validation of the Neutron Activation Analysis methods of the Neutron Activation \\ Laboratory at IPEN-CNEN/SP aiming the production of certified reference materials}

\section{Robson Petroni}

The objective of this study was the validation of four measurement methods by Instrumental Neutron Activation Analysis (INAA) at the Neutron Activation Laboratory (LAN) of IPEN - CNEN/SP. The measurands were: mass fraction of As in biological matrix sample (método-BIO-1), mass fraction of $\mathrm{Co}, \mathrm{Cr}, \mathrm{Fe}, \mathrm{Rb}, \mathrm{Sc}, \mathrm{Se}$ and $\mathrm{Zn}$ in biological matrix sample (método-BIO-2), mass fraction of As and $\mathrm{Sb}$ in geological matrix sample (método-GEO-1) and mass fraction of $\mathrm{Co}, \mathrm{Cr}, \mathrm{Fe}, \mathrm{Sc}$ and $\mathrm{Zn}$ in geological matrix sample (método-GEO-2). First, a univariate method optimization was performed to investigate the influence of the the preparation of synthetic standard (monoelemental standard and/or multielemental standard) and standard measurement times. In a second step, a multivariate method optimization was carried to verify the influence of sample measurement time, sample decay time and sample distance to detector by means of a $2^{3}$ full factorial design (DOE). Investigated method performance characteristics were: selectivity, accuracy (trueness and precision), linearity, work range, selectivity, limit of detection, limit of quantification, robustness and measurement uncertainty. The methods were validated according to recommendations of INMETRO DOQ-CGCRE-008 Validation Guide. The estimate of uncertainty sources was carried out according to recommendations of Guide to the expression of uncertainty in measurement (ISO GUM) using the simulated method.

key-words: INAA, CRM, method validation, experimental design, ISO/IEC 17025 


\section{SUMÁRIO}

1. INTRODUÇÃO........................................................................................ 19

2. SISTEMA DE GESTÃO DA QUALIDADE................................................... 21

2.1. Termos e definições relacionadas à Qualidade.......................................... 22

2.2. A série de normas ABNT NBR ISO 9000............................................. 23

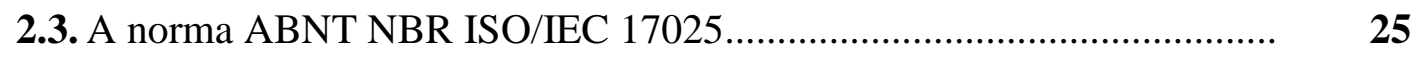

2.4. BPL: Boas Práticas para Laboratório...................................................... 27

2.5. Metodologias auxiliares ao Sistema de Gestão da Qualidade.................... $\quad 28$

2.6. O Sistema de Gestão da Qualidade no LAN.............................................. $\quad 30$

2.7. Garantia da Qualidade para resultados de medição.................................... 32

3. OBJETIVOS............................................................................................. 35

4. VALIDAÇÃO DOS MÉTODOS DE MEDIÇÃÕ.................................... 36

4.1. Validação pelo método de avaliação indireta.......................................... 37

4.1.1. Exatidão................................................................................ 38

4.1.2. Precisão....................................................................... 40

4.1.3. Veracidade .......................................................................... 43

4.1.4. Seletividade ............................................................................ 43

4.1.5. Limite de detecção e limite de quantificação.................................... 44

4.1.6. Robustez............................................................................ 46

4.1.7. Linearidade ........................................................................... 46

4.1.8. Faixa de trabalho..................................................................... 47

4.1.9. Incerteza de medição............................................................... 47

4.2. Validação pelo método de avaliação direta................................................ 52

4.2.1. Análise de material de referência certificado................................... 53

4.2.2. Estudo de comparação interlaboratorial......................................... $\quad 54$

4.2.3. Ensaio de recuperação............................................................. 55

5. PLANEJAMENTO FATORIAL_............................................................... 57

6. ANÁLISE POR ATIVAÇÃ̃ COM NÊUTRONS.......................................... 64

6.1. Principais aplicações do método comparativo de INAA........................... 75 
7. PARTE EXPERIMENTAL..................................................................... $\quad 77$

7.1. Delineamento dos mensurandos e matrizes.......................................... 77

7.2. Delineamento dos métodos de medição................................................... $\quad \mathbf{7 8}$

7.3. Delineamento dos MRCs................................................................... $\quad \mathbf{7 8}$

7.4. Ensaios preliminares.................................................................... $\quad \mathbf{7 9}$

7.4.1. Verificação da calibração dos balões volumétricos........................ 79

7.4.2. Verificação da calibração de micropipetas.................................... 81

7.5. Preparo das amostras e padrões sintéticos................................................ 82

7.5.1. Lavagem e confecção dos invólucros de polietileno........................ 82

7.5.2. Preparo das amostras.................................................................. $\quad 83$

7.5.3. Preparo dos padrões sintéticos................................................... 84

7.6. Montagem do experimento para irradiaçãa............................................... 87

7.7. Montagem das amostras após a irradiação................................................... $\quad 88$

7.8. Otimização dos métodos de medição....................................................... $\quad 90$

7.8.1. Otimização univariada na medição dos padrões

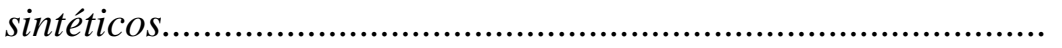

7.8.2. Otimização multivariada para os parâmetros de detecção (Planejamento Fatorial, DOE)................................................... $\quad 91$

7.9. Validação dos métodos de medição..................................................... 93

7.9.1. Delineamentos importantes para o processo de validação dos métodos de medição..................................................................... 93

7.9.2. Pico analítico de cada mensurando para a medição de raios gama.....

7.9.3. Precisão.

7.9.4. Veracidade

7.9.5. Seletividade.

7.9.6. Limite de detecção e limite de quantificação.

7.9.7. Robustez.

7.9.8. Linearidade.

7.9.9. Faixa de trabalho.

7.9.10. Incerteza de medição. 
8. RESULTADOS E DISCUSSÃO............................................................... 97

8.1. Delineamento dos mensurandos e matrizes.......................................... 97

8.2. Ensaios preliminares.......................................................................... 99

8.2.1. Verificação da calibração de balões volumétricos.......................... 99

8.2.2. Verificação da calibração de micropipetas.................................... 101

8.3. Estudo dos picos analíticos em INAA.................................................... 105

8.4. Otimização dos métodos de medição..................................................... 111

8.4.1. Otimização univariada na medição dos padrões sintéticos............. 111

8.4.2. Otimização multivariada para os parâmetros de detecção (Planejamento Fatorial, DOE)............................................... 115

8.5. Validação dos métodos de medição........................................................ 119

8.5.1. Delineamento das condições específicas para os métodos de medição........................................................................ 119

8.5.2. Linearidade, seletividade e faixa de trabalho................................. 121

8.5.3. Método-BIO-1 e Método-GEO-1................................................. 128

8.5.4. Método-BIO-2 e Método-GEO-2.................................................. 138

9. CONCLUSÕES.................................................................................. 149

\section{SECÇÃO DE ANEXOS}

ANEXO 1. Carta formulário........................................................................... 151

ANEXO 2. Trabalho apresentado no 2013 International Nuclear Atlantic

Conference (INAC)

ANEXO 3. Trabalho apresentado no 4th International Nuclear Chemistry Congress (INCC).

ANEXO 4. Trabalho apresentado no $14^{\circ}$ Congresso RESAG_ENQUALAB 2014.. 195

ANEXO 5. Documentos da Qualidade ............................................................ 202

REFERÊNCIAS BIBLIOGRÁFICAS........................................................... 251 


\section{LISTA DE ABREVIATURAS}

ABNT - Associação Brasileira de Normas Técnicas

ANVISA - Agência Nacional de Vigilância Sanitária

BPL- Boas Práticas de Laboratórios

CNEN - Comissão Nacional de Energia Nuclear

CQI - Controle da Qualidade Interno

CRPq - Centro do Reator de Pesquisa

DGNAA - Análise por Ativação com Nêutrons de raios gama retardados

DMAIC - sigla para os termos Definir, Medir, Analisar, Melhorar e Controlar

DOE - Design of Experiments, Planejamento Fatorial

DP - desvio padrão para a média de $n$ medições

EI - Estudo de comparação interlaboratorial

En - Erro normalizado

ER - Erro relativo

ER $(\%)$ - Erro relativo percentual

FAPESP - Fundação de Amparo à Pesquisa do Estado de São Paulo

FWHM - largura referente à metade da altura do pico analítico

GUM- Guia para expressão da incerteza de medição

HPGe - Detector semi condutor de germânio hiperpuro

IAEA - Agência Internacional de Energia Atômica

IEA-R1 - Instituto de Energia Atômica - Reator 1

INAA - Análise por Ativação com Nêutrons Instrumental

INMETRO - Instituto Nacional de Metrologia, Qualidade e Tecnologia

IPEN - Instituto de Pesquisas Energéticas e Nucleares

ISO - Organização Internacional para a Padronização

LAN - Laboratório de Análise por Ativação Neutrônica

LD- Limite de detecção

LMN - Laboratório de Metrologia Nuclear

LQ- Limite de quantificação

MCA- Analisador de multi canais 
MR - Material de Referência

MRC - Material de Referência Certificado

NAA - Análise por Ativação com Nêutrons

NRCC - National Research Council Canada, Conselho Nacional de Pesquisa do Canadá

NIST - National Institute of Standards and Technology, Instituto Nacional de Padrões e

Tecnologia dos Estados Unidos

OECD - Organização para a Cooperação e Desenvolvimento Econômico

PDCA - sigla para os termos Planejar, Fazer, Verificar e Agir

PI- Precisão intermediária

PGNAA - Análise por Ativação com Nêutrons de raios gama prontos

QUAM - Guia para a quantificação da incerteza nas medições analíticas

r - Limite de repetitividade

$\mathrm{R}$ - Limite de reprodutibilidade

SGQ - Sistema de Gestão da Qualidade

TP - Programa Interlaboratorial de Teste de Proficiência

$\mathrm{t}_{1 / 2}$ - tempo de meia vida para a atividade do radionuclídeo

VIM - Vocabulário Internacional de Metrologia 


\section{LISTA DE FIGURAS}

Figura 4.1. Diagrama de Ishikawa para a propagação de incertezas em INAA........ 50

Figura 6.1. Diagrama com a sequência de eventos típicos de uma reação $(n, \gamma)$...... 66

Figura 6.2. Principais elementos que podem ser quantificados por DGNAA.............

Figura 7.1. Representação da adição de $\mathrm{H}_{2} \mathrm{O}$ no balão volumétrico para o procedimento de verificação.

Figura 7.2. Representação do processo de confecção dos papéis filtro. 86

Figura 7.3. Representação do processo de preparo dos padrões sintéticos. 87

Figura 7.4. Representação da montagem de um experimento para irradiação. 88

Figura 7.5. Representação da montagem das amostras e/ou padrões sintéticos para o processo de detecção.

Figura 8.1. Contribuição das fontes de incerteza no processo de verificação de balões volumétricos.

Figura 8.2. Comparação dos valores de ER (\%) e DPR (\%) com os valores informados nos certificados de calibração para cada micropipeta.

Figura 8.3. Resultados com incerteza expandida $(k=2)$ obtidos para o uso de diferentes picos analíticos em Tecido de Mexilhão, IPEN TM-1, $n=3\left(\mathrm{mg} \mathrm{kg}^{-1}\right) \ldots .$.

Figura 8.4. Resultados com incerteza expandida $(k=2)$ obtidos para o uso de diferentes picos analíticos em Sedimento Marinho NRCC MESS 3, $n=3\left(\mathrm{mg} \mathrm{kg}^{-1}\right)$.

Figura 8.5. Resultados de linearidade para cada mensurando

Figura 8.6. En obtido para cada ensaio (método-BIO-1)

Figura 8.7. En obtido para cada ensaio (método-GEO-1).

Figura 8.8. Gráfico da distribuição dos resultados obtidos para En (método-BIO-1).

Figura 8.9. Gráfico da distribuição dos resultados obtidos para En (método-GEO-1).

Figura 8.10. Contribuição relativa das principais fontes de incerteza para As (método-BIO-1).

Figura 8.11. Contribuição relativa das principais fontes de incerteza para As e Sb (método-GEO-1). 
Figura 8.12. En obtido para cada ensaio (método-BIO-2) ................................. 143

Figura 8.13. En obtido para cada ensaio (método-GEO-2)................................. 143

Figura 8.14. Contribuição relativa das principais fontes de incerteza para $\mathrm{Co}, \mathrm{Cr}$, $\mathrm{Fe}, \mathrm{Rb}, \mathrm{Sc}$, Se e Zn (método-BIO-2)..

Figura 8.15. Contribuição relativa das principais fontes de incerteza para $\mathrm{Co}, \mathrm{Cr}$, $\mathrm{Fe}, \mathrm{Sc}$ e Zn (método-BIO-2). 


\section{LISTA DE TABELAS}

Tabela 4.1. Parâmetros de avaliação indireta para métodos quantitativos................ 38

Tabela 5.1. Matriz experimental típica para o DOE $2^{3}$ completo.............................

Tabela 7.1. MRCs para matriz biológica e geológica........................................... $\quad 83$

Tabela 7.2. Lista dos MRCs utilizados na confecção dos padrões sintéticos............. $\quad \mathbf{8 5}$

Tabela 7.3. Massa dos mensurandos contida nos padrões sintéticos........................ $\quad \mathbf{8 7}$

Tabela 7.4. Delineamento experimental para o método-BIO-1............................ 91

Tabela 7.5. Delineamento experimental para o método-BIO-2............................. 91

Tabela 7.6. Delineamento experimental para o método-GEO-1............................. 91

Tabela 7.7. Delineamento experimental para o método-GEO-2............................ 92

Tabela 7.8. Configuração experimental aplicada à todos os métodos de medição no processo de validação analítica..................................................................... 94

Tabela 7.9. Pico de energia e tempo de meia-vida de cada mensurando.................. $\quad 94$

Tabela 8.1. Média dos resultados e desvio padrão obtidos para a verificação da calibração de balões volumétricos $(n=10)$.

Tabela 8.2. Componentes de incerteza para a estimativa da incerteza de medição em balões volumétricos

Tabela 8.3. Resultado para a estimativa da incerteza de medição para a verificação de balões volumétricos

Tabela 8.4. Especificações da Eppendorf da máxima porcentagem para erro sistemático e aleatório para as micropipetas

Tabela 8.5. Resultados do procedimento de verificação para as diferentes micropipetas (média \pm desvio padrão, $n=10$ ).

Tabela 8.6. Resultado para a estimativa da incerteza de medição para a verificação de micropipetas $(\mu \mathrm{L})$.

Tabela 8.7. Importância relativa de cada um dos fatores para a estimativa da incerteza de medição

Tabela 8.8. Resultados obtidos com o uso de diferentes picos analíticos Tecido de Mexilhão, IPEN TM-1, $n=3\left(\mathrm{mg} \mathrm{kg}^{-1}\right)$. 
Tabela 8.9. Resultados obtidos com o uso de diferentes picos analíticos para amostras de Sedimento Marinho NRCC MESS $3, n=3\left(\mathrm{mg} \mathrm{kg}^{-1}\right)$

Tabela 8.10. Pico analítico e tempo de meia-vida de cada radionuclídeo.

Tabela 8.11. Média dos resultados $\left(\mathrm{mg} \mathrm{kg}^{-1}\right)$ com incerteza expandida, $k=2$, obtidos para o uso de padrões de configuração monoelementar e multielementar para a análise de Tecido de Mexilhão IPEN TM-1 $(n=2)$.

Tabela 8.12. Média dos resultados $\left(\mathrm{mg} \mathrm{kg}^{-1}\right)$ com incerteza expandida, $k=2$, obtidos para o uso de padrões de configuração monoelementar e multielementar para a análise de Sedimento Marinho NRCC MESS $3(n=2)$.....

Tabela 8.13. Média dos resultados $\left(\mathrm{mg} \mathrm{kg}^{-1}\right)$ com incerteza expandida, $k=2$, obtidos para diferentes tempos de medição da atividade dos mensurandos do padrão sintético para amostras de Tecido de Mexilhão IPEN TM-1 $(n=2)$.

Tabela 8.14. Média dos resultados $\left(\mathrm{mg} \mathrm{kg}^{-1}\right)$ com incerteza expandida, $k=2$, obtidos para diferentes tempos de medição da atividade dos mensurandos do padrão sintético para amostras de Sedimento Marinho NRCC MESS $3(n=2) \ldots \ldots .$.

Tabela 8.15. Resultados obtidos nos experimentos do Planejamento Fatorial $2^{3}$ para amostras de Tecido de Mexilhão IPEN TM-1

Tabela 8.16. Resultados obtidos nos experimentos do Planejamento Fatorial $2^{3}$ para amostras de Sedimento de Estuário NIST SRM 1646a.

Tabela 8.17. Efeitos principais (A; B; C) e contrastes (A:B; A:C; B:C; A:B:C) em INAA para amostras de Tecido de Mexilhão IPEN TM-1.

Tabela 8.18. Efeitos principais (A; B; C) e contrastes (A:B; A:C; B:C; A:B:C) em INAA para amostras de Sedimento de Estuário NIST SRM 1646a.

Tabela 8.19. Delineamento das condições padrão para cada método de medição....

Tabela 8.20. Resultados obtidos para os experimentos de linearidade utilizando-se padrões multielementar preparados por diluição $(\mu \mathrm{g})$.

Tabela 8.21. Resultados obtidos para os experimentos de linearidade para a análise de diferentes MRCs $\left(\mathrm{mg} \mathrm{kg}^{-1}\right)$.

Tabela 8.22. Faixa de trabalho para cada mensurando em INAA

Tabela 8.23. Resultados de validação para o método-BIO-1

Tabela 8.24. Resultados de validação para o método-GEO-1

Tabela 8.25. Conjunto de resultados utilizados para verificação sobre a normalidade dos resultados obtidos para As (método-BIO-1) e As e Sb (método-GEO-1). 
Tabela 8.26.Resultados para a razão $r$ / PI (método-BIO-1 e método-GEO-1).........

Tabela 8.27. Resultados de validação para o método-BIO-2.................................. 139

Tabela 8.28. Resultados de validação para o método-GEO-2................................ 141

Tabela 8.29.Resultados para a razão $r$ / PI (método BIO-2 e método GEO-2).......... 144

Tabela 8.30. Conjunto de resultados utilizados para verificação sobre a normalidade dos resultados obtidos para o método-BIO-2 e método-GEO-2............. 


\section{INTRODUÇÃO}

Uma das premissas necessárias para que um laboratório produza resultados com o grau de qualidade requerido é a implementação e a adequação de um Sistema de Gestão da Qualidade que satisfaça as suas necessidades e que atenda aos requisitos exigidos por seus clientes. De acordo com a norma ABNT NBR ISO/IEC 17025, a norma mais importante para a Qualidade em laboratórios de medição, todos os métodos utilizados pelo laboratório devem, dentre outros fatores, serem devidamente validados e documentados, visando assegurar que os resultados produzidos nos experimentos sejam adequados à intenção de uso (ABNT, 2006).

O Laboratório de Análise por Ativação (LAN) é uma subdivisão do Centro do Reator de Pesquisas (CRPq) do Instituto de Pesquisas Energéticas e Nucleares (IPEN - CNEN/SP). Desde 2010, uma nova política da Qualidade vem sendo implementada no Laboratório, visando a adequação das atividades desenvolvidas no com os requisitos exigidos pela norma NBR ISO/IEC 17025. A adequação do sistema da qualidade é absolutamente indispensável para o LAN que nos últimos anos tem desenvolvido diversos materiais de referência em matrizes ambientais. Neste contexto, a validação dos métodos de medição trata-se de uma entre uma série de ações à serem tomadas visando a adequação das atividades desenvolvidas pelo Laboratório com as exigências da norma NBR ISO/IEC 17025. Dentro deste cenário, este trabalho foi idealizado e realizado em função de uma grande necessidade do LAN: a validação dos métodos de medição.

Este trabalho descreve o processo formal de validação para quatro métodos de medição de Análise por Ativação com Nêutrons Instrumental (INAA). Os mensurandos estudados foram a concentração total de As, Co, Cr, Fe, Rb, Sc, Se e Zn em matriz biológica e a concentração total de $\mathrm{As}, \mathrm{Co}, \mathrm{Cr}$, Sb, Sc e $\mathrm{Zn}$ em matriz geológica. O grande objetivo foi dar continuidade ao processo de adequação do LAN de acordo com as exigências da norma NBR ISO/IEC 17025, visando uma futura acreditação do Laboratório como produtor de Materiais de Referência Certificado 
(MRC) junto ao Instituto Nacional de Metrologia, Qualidade e Tecnologia (INMETRO).

Para um melhor entendimento, o trabalho foi apresentado em nove capítulos mais anexos. Este texto corresponde ao capítulo 1. O capítulo 2 apresenta as principais normas de Sistema de Gestão da Qualidade, dentre elas a série de normas NBR ISO 9000, a NBR ISO/IEC 17025 e a Boas Práticas de Laboratório (BPL), suas peculiaridades, pontos em comum e no que diferem uma das outras. Também são apresentadas algumas das mais importantes metodologias auxiliares ao Sistema de Gestão da Qualidade, com a 5S, a 6 sigma e a Just in time. Ainda no capítulo 2 é introduzida a importância da obtenção de resultados com qualidade, da validação de métodos de medição e do cenário atual existente no LAN quanto à implementação do Sistema de Gestão da Qualidade NBR ISO/IEC 17025.

O capítulo 3 apresenta formalmente os objetivos deste trabalho. No capítulo 4 são apresentadas as diferentes estratégias utilizadas para a validação de métodos de medição através dos métodos de avaliação direta e indireta, de acordo com recomendações do Guia DOQ-CGCRE-008 do INMETRO e da Resolução nº 899 da Agência Nacional de Vigilância Sanitária, a ANVISA (BRASIL, 2003; INMETRO, 2012b).

O capítulo 5 apresenta de forma sucinta o modelo de Planejamento Fatorial $2^{\mathrm{k}}$, utilizado para a otimização dos métodos de medição submetidos ao processo de validação. Além de apresentar toda a metodologia, definir os termos técnicos e equações, ainda apresenta as vantagens do uso desta técnica frente a uma otimização univariada. O capítulo 6 é uma revisão bibliográfica sobre a técnica de Análise por Ativação com Nêutrons, definindo o método, aplicações e particularidades. O capítulo 7 apresenta a descrição de toda parte experimental do trabalho.

No capítulo 8 são apresentados e discutidos todos os resultados obtidos para os diferentes estudos realizados nesse trabalho. Algumas novas interpretações são sugeridas, dificuldades são apresentadas e perspectivas para um futuro próximo são introduzidas. Por fim, o capítulo 9 apresenta as conclusões, retomando aos objetivos deste trabalho e apontando paranov as perspectivas. 


\section{SISTEMA DE GESTÃO DA QUALIDADE}

$\mathrm{Na}$ área da química, especialmente para os laboratórios de medição (laboratórios analíticos), a implementação de um Sistema de Gestão da Qualidade é absolutamente indispensável para a demonstração da aptidão da qualidade analítica para os resultados gerados. Por meio dos processos de habilitação, certificação e acreditação, o laboratório pode demonstrar que possui instalações, equipamentos e métodos de medição adequados para um ou mais propósitos (ANVISA, 2005).

Sistemas de Gestão da Qualidade (SGQ) são métodos gerenciais que se baseiam na busca pela qualidade por meio de uma metodologia sistêmica e globalizada dentro de uma organização. Nestes sistemas, a qualidade final do produto é relacionada ao resultado e competência técnica do trabalho de todos os membros que participam direta ou indiretamente dos processos desenvolvidos. Além disso, está intimamente relacionada com a tecnologia empregada e o desenvolvimento dos recursos humanos, devendo ser abordada de maneira a vislumbrar a constante melhoria do processo da qualidade como um todo (INMETRO, 2011a; ABNT, 2005).

Neste contexto, o termo "melhoria do processo da qualidade" não está necessariamente relacionado com a qualidade final do produto ou serviço, mas sim ao grau de eficácia para o atendimento dos requisitos exigidos pelo cliente. Estes sistemas devem ser constantemente avaliados, uma vez que devem estar em constante aprimoramento e adequação, visando satisfazer as exigências do cliente e/ou legislação. Desta forma, não existe SGQ melhor ou pior, e sim sistemas mais ou menos eficazes e adaptados.

A implementação de um SGQ pode ser realizada por meio da adequação da rotina do laboratório a uma ampla série de normas, documentos técnicos e protocolos de recomendações, dependendo da natureza das atividades desenvolvidas. Para laboratórios que realizam ensaios de medição em química, a norma ABNT NBR ISO/IEC 17025 (ABNT, 2006) é a de maior reconhecimento e importância no cenário atual. Esta pode 
ser referência para qualquer tipo e tamanho de organização, sendo bastante adaptável aos critérios e necessidades pré-estabelecidas pela gerência da qualidade do laboratório.

O SGQ não trata diretamente da garantia do resultado obtido em uma medição. É muito mais do que isso. Trata-se de uma metodologia aplicada ao planejamento das atividades a serem desenvolvidas em uma organização, e isso inclui uso dos recursos, mão de obra, matéria prima, equipamentos, procedimentos, critérios de aceitação, metas e um plano para a melhoria dos processos, visando o reconhecimento da excelência de como as atividades são desenvolvidas. Desta forma, a garantia da qualidade é consequência de todo o processo organizacional desempenhado pelo Sistema de Gestão da Qualidade.

A série de normas da família ISO 9000 (ABNT, 2002; ABNT, 2005; ABNT, 2009; ABNT, 2010) e os Princípios das Boas Práticas de Laboratórios, BPL (INMETRO, 2011b) são outros exemplos de metodologias aplicadas à gestão da qualidade de uma organização. Ainda, a implementação de conceitos como o $5 \mathrm{~s}$ (RIBEIRO, 2006), Just in Time (HIRANO, 2009; CHENG \& PODOLSKY, 1996) e Lean Six sigma (JONES, 2014) tendem a auxiliar o processo de Gestão e Garantia da Qualidade visando a maximização da produtividade, segurança e controle dos processos, com diversas orientações que podem ser aplicadas na rotina de laboratórios de medição.

\subsection{Termos e definições relacionados à Qualidade}

Antes de prosseguir com a apresentação das normas mais importantes para a implementação de um SGQ em laboratórios de medição, faz-se importante definir o significado dos termos que foram e serão utilizados no decorrer deste texto, com referência à norma ABNT NBR ISO/IEC17025 (ABNT, 2006) e ao Vocabulário Internacional de Metrologia, VIM (INMETRO, 2012a).

Organização: grupo de instalações com um conjunto de responsabilidades, autoridades e relações. Pode ser um laboratório de medição;

Produto: o resultado de um processo;

Processo: conjunto de atividades inter-relacionadas ou interativas que transforma insumos em produtos; 
Qualidade: grau no qual um conjunto de características inerentes satisfaz a requisitos;

Requisito: necessidade ou expectativa que é expressa, geralmente, de forma implícita ou obrigatória;

Sistema: conjunto de elementos inter-relacionados ou interativos;

Sistema de gestão: sistema para estabelecer políticas e objetivos, e para atingir estes objetivos;

Sistema de gestão da qualidade: sistema de gestão para dirigir e controlar uma organização no que diz respeito à qualidade;

Gestão da qualidade: atividades coordenadas para dirigir e controlar uma organização no que diz respeito à qualidade;

Melhoria contínua: atividade recorrente para aumentar a capacidade de atender aos requisitos;

Eficácia: extensão na qual as atividades planejadas são realizadas e os resultados planejados, alcançados;

Cliente: organização ou pessoa que recebe o produto;

Fornecedor: organização ou pessoa que fornece um produto (insumo).

\subsection{A série de normas ABNT NBR ISO 9000}

Este conjunto de normas descreve de forma sucinta e de fácil entendimento a importância do SGQ para uma organização, independentemente da natureza que esta venha ter. Estes sistemas são importantes ferramentas para o planejamento das atividades, foco, diretrizes e estabelecimento de metas de uma organização que vislumbre a satisfação e o pleno atendimento dos requisitos exigidos por seus clientes.

Constituído pelas normas ABNT NBR ISO 9000 que define os termos relacionados à Qualidade, ABNT NBR ISO 9001 que especifica sobre os requisitos fundamentais, foco e diretrizes de um sistema de Gestão da Qualidade, ABNT NBR ISO 9004 que descreve orientações para a otimização da eficiência e eficácia do SGQ e ABNT NBR ISO 19011 que apresenta as diretrizes relacionadas aos processos de auditoria (ABNT, 2002; ABNT, 2005; ABNT, 2009; ABNT, 2010).

A ABNT NBR ISO 9000 define formalmente o significado dos termos técnicos.De acordo com a norma, um SGQ deve ser idealizado e estabelecido com base 
em oito princípios: foco no cliente, liderança, envolvimento das pessoas, abordagem de processo, abordagem sistêmica de gestão, melhoria contínua, abordagem factual para a tomada de decisões e na relação de benefício mútuo com o fornecedor (ABNT, 2005).

Interpretando esses princípios para o cenário de um laboratório de medição, pode-se dizer que o SGQ, antes de tudo, deve ser idealizado para atender às necessidades requeridas pelos clientes do laboratório. Este deve ter uma missão, metas e objetivos bem definidos de modo a motivar e envolver todas as pessoas da organização, com o objetivo de garantir a manutenção da qualidade dos serviços prestados acompanhado de um melhoramento contínuo da gestão.

Existe a recomendação para que o processo de gestão seja realizado de maneira sistêmica e fundamentado em uma abordagem factual, ou seja, identificando e gerenciando todas as etapas e processos de forma inter-relacionada, como se cada processo fosse uma engrenagem para o bom funcionamento da máquina - que é o SGQ. Ainda, deve-se ter sempre em vista que uma organização e seus fornecedores são interdependentes, ou seja, uma vez agregados valores mútuos a esta relação, ela tende a trazer benefícios para ambas às partes.

A implementação de um SGQ deve ser realizada como uma opção estratégica para a garantia da qualidade dos produtos desenvolvidos e dos serviços prestados, visando estabelecer um controle interno aos processos desenvolvidos, a obtenção de certificações junto aos órgãos competentes e/ou por fatores econômicos e contratuais. Desta forma, a gestão da qualidade deve ser desenvolvida de maneira eficaz, coerente e adaptável, visando o pleno atendimento dos requisitos almejados pelos clientes da organização (ABNT, 2009).

Os processos, declarações, diretrizes e objetivos devem ser mensuráveis e consistentes com a política da qualidade e devidamente documentados para assegurar o cumprimento do planejamento e controle das operações. Todos os aspectos operacionais que venham a contribuir para a tomada de decisões também devem ser documentados e disponibilizados para o cliente e/ou órgão regulamentador para assegurar a existência da conformidade de que os requisitos exigidos estão sendo atendidos. O manual da qualidade deve conter a descrição da interação entre os diversos processos subordinados do SGQ, um escopo do planejamento com detalhes e justificativas e a referência para os procedimentos estabelecidos (ABNT, 2009). 
A ABNT NBR ISO 9004 descreve as principais estratégias que devem ser adotadas por uma organização visando o "sucesso sustentado" com ênfase no planejamento do SGQ. Esta norma de caráter orientativo - e não regulador - define e apresenta os principais fatores relacionados às estratégias que devem ser adotadas por uma organização para que esta realize os objetivos definidos para longo prazo (ABNT, 2010). A ABNT NBR ISO 9004 é direcionada para a avaliação de desempenho, cumprimento e estabelecimento de metas, foco nas necessidades do cliente e na manutenção de um ambiente de trabalho produtivo e motivador, vislumbrando com isso a manutenção e o aprimoramento constante do SGQ.

Outra ferramenta muito importante para a avaliação do desempenho de um SGQ é o processo de auditoria. Neste cenário, a norma ABNT NBR ISO 19011 foi estabelecida visando definir e estabelecer as diretrizes destes processos e sobre as recomendações direcionadas ao auditor. Os programas de auditoria devem ser idealizados como peças fundamentais para o desenvolvimento do SGQ. Através destes, faz-se possível a verificação da conformidade dos processos com as obrigações legislativas e contratuais, da habilitação e/ou acreditação em uma norma de sistema de gestão e da definição das estratégias necessárias para o aprimoramento do SGQ (ABNT, 2002).

\subsection{A norma ABNT NBR ISO/IEC 17025:2005}

A norma ABNT NBR ISO/IEC 17025 dispõe sobre os requisitos necessários para que laboratórios de ensaio e calibração possam demonstrar sua competência técnica, capacidade de produção de resultados tecnicamente confiáveis e que possuem instalações e equipamentos adequados para o desenvolvimento das atividades e processos. Em sua composição, a norma é dividida em 6 partes: Objetivo, Referência Normativa, Termos e Definições, Requisitos de Direção, Requisitos Técnicos e os Anexos Normativos (ABNT, 2006).

Uma vez implementada na rotina de uma organização, existirá automaticamente a adequação a todas as exigências da norma ABNT NBR ISO 9001. Além disso, a ABNT NBR ISO/IEC 17025 apresenta abrangência tanto na área técnica quanto na área administrativa da organização sendo muito flexível para atender a qualquer área do laboratório, com intuito de demonstrar a competência técnica para 
gerar resultados válidos. Para isso, especifica os requisitos gerais para a realização de ensaios e/ou calibrações - genericamente tratadas aqui nesta dissertação como medições - utilizando métodos normalizados, não normalizados e métodos desenvolvidos pelo próprio laboratório. Inclui ainda orientações genéricas para o procedimento de validação desses métodos, incluindo o processo de amostragem.

A estimativa das incertezas do processo de medição deve ser realizada visando à aplicabilidade do resultado da medição para um uso específico. Isso se faz necessário, pois um mesmo método de medição, dependendo dos equipamentos, instalações, conhecimento e experiência do analista poderá gerar resultados apropriados ou não para uma norma ou legislação, em função da incerteza associada ao mesmo. Desta forma, o processo de estimativa das incertezas de medição para um respectivo método deve ser o mais abrangente possível, visando-se a representatividade do mesmo.

Deve-se citar que a norma não especifica um nível de aceitação para os valores das incertezas de medição, uma vez que estes são relacionados a diversos fatores característicos para a técnica, para o método de medição e com os requisitos dos clientes.

A ABNT NBR ISO/IEC 17025 acrescenta ainda a exigência quanto à validação de software utilizado e das etapas de coleta, transporte e armazenamento das amostras. O SGQ deve estar em constante aprimoramento e todos os processos de não conformidade devem ser registrados, investigados e solucionados de acordo com procedimento descrito na norma (ABNT, 2006).

Deve haver um plano de calibração dos instrumentos e equipamentos do laboratório, os reagentes devem estar dentro do período de validade e deve haver registro sobre quais equipamentos e reagentes foram utilizados em determinado experimento. Todas essas etapas fazem parte de um amplo processo para a garantia e rastreabilidade do resultado.

Faz-se importante citar que um SGQ, seja para um laboratório de medição ou para qualquer outra atividade, é uma complexa ferramenta de controle dos processos e serviços. Ainda que dois laboratórios optem por estabelecer os SGQs sob as exigências de uma mesma norma, isto não significa que os resultados gerados por ambos serão comparáveis e que os serviços prestados apresentarão um mesmo grau de qualidade. Vale aqui reafirmar o que já foi dito, de que não existe um SGQ melhor ou 
pior, e sim sistemas mais ou menos eficazes e adaptados às necessidades do laboratório e de seus clientes.

\subsection{BPL: Boas Práticas para Laboratórios}

A BPL é uma norma criada pela OECD (Organization for Economic Cooperation and Development) que compreende tanto o processo organizacional quanto as condições nas quais os estudos são planejados, desenvolvidos, monitorados, registrados, arquivados e relatados. Ela tem como objetivo testar substâncias para determinar suas propriedades e com isso obter um perfil de segurança com relação à saúde humana e ao meio ambiente (INMETRO, 2011b).

Resumidamente, "trata-se de um sistema da qualidade que abrange o processo organizacional e as condições nas quais estudos não-clínicos relacionados à saúde e à segurança ao meio ambiente são planejados, desenvolvidos, monitorados, registrados, arquivados e relatados" (INMETRO, 2014).

A BPL não foi idealizada para as operações gerais do laboratório e sim especificamente para o estudo feito neste e por ele. Ela é uma garantia de qualidade, integridade e segurança dos dados apresentados pelo estudo. Alguns pontos que são exclusivos para a BPL são a garantia de cuidado com animais, o monitoramento constante das instalações e atividades e a obrigatoriedade de um plano de estudos para cada projeto (ENGELHARD et al., 2003; FOX, 2003).

Há princípios que são comuns tanto para a NBR ISO IEC 17025 quanto para a BPL, principalmente no que diz respeito à gestão e organização. Ambas definem responsabilidades, necessidade de procedimentos padrões para calibração e manutenção de equipamentos, além de apontar a necessidade de treinamento do pessoal e o uso de métodos e relatórios de teste e estudo devidamente validados. Não é possível comparar e dizer qual é a melhor, pois cada uma apresenta características próprias. Além disso, não se pode afirmar que um sistema engloba o outro, mas sim que um complementa o outro. 


\subsection{Metodologias auxiliares ao Sistema de Gestão da Qualidade}

Muitas vezes ter um SGQ acreditado em uma norma específica não é o suficiente para manter a harmonia entre as diversas peças da máquina que se chama Qualidade. Neste sentido, diversas metodologias auxiliares foram desenvolvidas ao longo dos anos e hoje são praticamente indispensáveis para o bom funcionamento de qualquer SGQ. Estas metodologias têm como objetivo reduzir desperdícios e aumentar a produtividade da organização. Dentre as principais podem ser citadas: 5s (RIBEIRO, 2006), Just in Time (HIRANO, 2009; CHENG \& PODOLSKY, 1996) e Lean Six sigma (JONES, 2014).

Etapa inicial e base para implantação de qualquer SGQ, a metodologia 5S é assim chamada devido a primeira letra de 5 palavras japonesas: Seiri (utilização), Seiton (arrumação), Seiso (limpeza), Seiketsu (normalizar) e Shitsuke (disciplina). O principal objetivo do $5 \mathrm{~S}$ é mobilizar, motivar e conscientizar a organização sobre a importância da manutenção do SGQ, através da organização e da disciplina no local de trabalho.

Os propósitos da metodologia $5 \mathrm{~S}$ são de melhorar a eficiência através da destinação adequada de materiais (separar o que é necessário do desnecessário), organização e limpeza do ambiente de trabalho, identificação de materiais e espaços (cada equipamento e reagente tem o seu lugar na bancada ou prateleira) e a manutenção e melhoria do próprio 5S (a metodologia nunca deve ser imutável, pelo contrário, deve se adaptar as novas necessidades da organização).

Os cinco principais conceitos da metodologia $5 \mathrm{~S}$ levam à maior produtividade pela redução da perda de tempo típica para a organização da bancada, procura por reagentes e/ou equipamentos (pois só fica no ambiente o que é necessário e ao alcance da mão); a redução de despesas e o melhor aproveitamento de materiais (uma vez que a acumulação excessiva tende a causar problemas de armazenamento e perdas por deterioração); a melhoria da qualidade de produtos e serviços; a redução do número de acidentes no ambiente de trabalho e maior satisfação e motivação das pessoas que fazem parte da organização (com um ambiente organizado, limpo e agradável, as pessoas perdem menos tempo com atividades desnecessárias e tendem a trabalhar melhor e produzir mais).

O conceito Lean Six sigma, ou somente Six sigma foi idealizado visando o bom funcionamento do controle da qualidade para processos e produtos. O Six sigma 
visa identificar os pontos falhos ao longo da cadeia produtiva, reduzindo as perdas e aumentando a uniformidade dentro de um lote de produção. É apoiado sobre duas metodologias complementares: o DMAIC (define - measure - analyse - improve control) e o PDCA (plan - do - check - act).

A metodologia DMAIC apresenta as ferramentas necessárias para que a organização defina um problema a partir da opinião dos fornecedores e clientes, investigue a relação de causa-efeito do problema identificado em relação a qualidade final do produto, realize a análise dos dados e o mapeamento para a identificação da causa-raiz dos defeitos, melhore e otimize os processos de produção e implemente um sistema de controle da qualidade adaptado ao monitoramento em cada uma das etapas de produção.

O Six sigma é desenvolvido sobre o controle estatístico dos processos do quadro de produção. A metodologia PDCA é entendida como o planejamento das medidas a serem tomadas no âmbito do controle da qualidade visando a execução das ações necessárias para a melhoria do processo produtivo a médio e longo prazo, embasado em dados estatísticos do processo de produção. Ele abrange não só o tratamento estatístico, mas também, o alinhamento do SGQ com as estratégias da organização com ênfase na relação custo-benefício dos projetos de melhoria.

Outra metodologia cujo conceito está muito difundido no mercado é a Just in time. Trata-se de umsistema de administraçãoda produção que determina que nada deve ser produzido, transportado ou comprado antes da hora certa. É uma metodologia muito eficiente quanto executada de forma correta, uma vez que favorece o sistema de produção em fluxo contínuo e que nada permanece em estoque (produto ou matéria prima) diminuindo o custo com a manutenção dos ambientes e com a logística do transporte.

Em teoria, a matéria prima só será entregue quando houver a previsão de entrega do produto. Existe um planejamento embasado nos resultados estatísticos da produção em função da demanda de mercado e, a partir disso, são traçados planos de dimensionamento da produção. Nada é produzido sem que haja uma demanda. Deve haver uma relação de cooperação fornecedor-organização-cliente, visto que esta metodologia só pode ser implementada numa cadeia produtiva onde todos os integrantes conheçam e pratiquem os conceitos Just in time. 
Dentre todas as metodologias aqui citadas, a 5S é a mais utilizada e a de mais fácil implementação para laboratórios de medição. Conceitos como o Six sigma e o Just in time, apesar de parecerem distantes do dia-a-dia de um laboratório são bastante úteis para uma melhor organização e administração de um SGQ. Uma vez que o LAN tem buscado a acreditação de seu SGQ visando à produção de MRC, a gerência do laboratório deve investir ao longo dos próximos anos na implementação dessas metodologias ao longo da cadeia produtiva do MRC, com foco no controle estatístico dos processos e no atendimento aos requisitos dos clientes, uma vez que este é um requisito será essencial para o reconhecimento da excelência dos serviços prestados no cenário da produção de MRC.

\subsection{O Sistema de Gestão da Qualidade no LAN}

O LAN é um laboratório pertencente ao Centro do Reator de Pesquisa (CRPq). A base da organização funcional do CRPq é constituída por grupos de trabalho e laboratórios, formados por profissionais que se alternam em diferentes processos, sem níveis hierárquicos, visando alcançar um conjunto de metas pré-estabelecidas. Os grupos de trabalho e laboratórios respondem à gerência do $\mathrm{CRPq}$ por meio das gerências adjuntas. Estas gerências adjuntas são temáticas, isto é, coordenam as atividades de Pesquisa, Ensino, Serviços, Operação e Manutenção do Reator, respectivamente.

Devido à natureza do gerenciamento adjunto, estas áreas estão em constante interação sendo interdependentes uma das outras. Entre as principais instalações do Centro está o IEA-R1 e os laboratórios associados como: o Laboratório de Ativação Neutrônica (LAN), o Laboratório de Metrologia Nuclear (LMN)e os laboratórios e arranjos experimentais para realização de pesquisas em física nuclear, física de nêutrons e física da matéria condensada (IPEN, 2014a).

Dentro do CRPq, o reator IEA-R1 é certificado de acordo com as exigências da norma NBR ISO 9001 (ABNT, 2009), demonstrando excelência para a prestação de serviços. O LAN é um dos laboratórios beneficiados por esse SGQ, uma vez que usufrui dos serviços prestados pelo reator IEA-R1.

A pesquisa acadêmica é e sempre foi a principal atividade desenvolvida pelos membros do LAN. Talvez por esse motivo, o laboratório não possua um SGQ 
implementado na sua rotina diária. No entanto, ao longo da última década, muito tem sido feito buscando a adequação do laboratório de acordo com as exigências da norma NBR ISO/IEC 17025 (ABNT, 2006).

Existe um plano de calibração para instrumentos e equipamentos, sistemas internos de verificação da conformidade em medições, formulários de uso de equipamento, registro de uso dos reagentes, cartas-controle, treinamentos de funcionários e colaboradores, dentre outros requisitos que demonstram que a gerência do laboratório tem dedicado um enorme esforço para a aptidão das atividades com as exigências da norma NBR ISO/IEC 17025.

Como uma última etapa desta adequação, inicia-se a validação formal dos métodos de medição. Este tipo de validação difere um pouco da praticada atualmente (validação direta) pelos membros do laboratório, pois visa a investigação e caracterização das figuras de mérito dos métodos de medição (o capítulo 4 apresenta todas as etapas do processo da validação direta e da validação formal).

Devido a sua trajetória em diversas áreas de pesquisa com a utilização da INAA, o LAN tem grande experiência na obtenção de resultados analíticos com qualidade por utilizar diversas ferramentas de controle, em particular, o uso de MRCs e a participação em Testes de Proficiência (TP), tanto nacionais quanto internacionais.

No período entre 2002 e 2005, o grupo de pesquisadores do LAN participou de projeto FAPESP para a implantação de um sistema de qualidade no laboratório, com resultados muito positivos em relação às práticas de qualidade do laboratório (FAPESP 02/00419-7). No entanto, com a exceção de um trabalho de mestrado defendido por MATSUBARA (2011), as informações de validação de métodos encontram-se de forma difusa em teses e artigos e, para fins de acreditação, devem estar disponíveis de forma mais sistematizada.

A documentação de validação dos métodos, além dos parâmetros de desempenho, traz informações de segurança sobre a utilização dos métodos, equipamentos e reagentes, o objetivo dos métodos e suas limitações, amostragem, calibração, controle de qualidade, procedimentos operacionais, cálculos, referências normativas, definições, princípios analíticos, controle de qualidade e sobre o resultado de medição.

A etapa de validação formal dos métodos de medição, aé uma das evidências necessárias para a certificação e acreditação junto ao INMETRO da norma 
NBR ISO/IEC 17025, visando o reconhecimento da aptidão da estrutura do laboratório para a produção de MRC em matrizes ambientais. Paralelamente a isso, enquanto o processo de acreditação não é concluído, o laboratório demonstra sua excelência por meio da participação em programas interlaboratoriais nacionais e internacionais.

Pelo fato de que diversos estudos realizados pelo LAN envolvem o uso de animais (inclusive para a produção de MRC), vale-se citar que alguns conceitos da BPL podem e devem ser implementados (adaptados à rotina de trabalhos do LAN), visandose o cuidado e a integridade à saúde humana e o respaldo para o trabalho com animais. Os conceitos defendidos pelas metodologias $5 \mathrm{~S}$ e 6 sigma também apresentam caráter indispensável para a excelência das atividades no LAN, sendo metodologias indispensáveis para a melhoria do ambiente físico de trabalho e do controle de processos de medição. Com o objetivo no âmbitoda prestação de serviços, produção e comercialização de MRCs o conceito Just in time parece ser bastante útil.

Isso corrobora as definições pré estabelecidas 10 anos atrás pela norma ABNT NBR ISO 9001 (ABNT, 2005), onde um SGQ, desde sua idealização, deve estar em constante adaptação visando o pleno atendimento das necessidades de seus clientes e a garantia da qualidade dos serviços prestados. Também demonstra que o LAN está no caminho certo, buscando estabelecer o que há de mais moderno e eficiente no cenário atual, no que diz respeito à melhoria e adaptação de seu SGQ, que já existe em alguns laboratórios, mais que ainda está por ser acreditado.

Contudo, o processo de acreditação deve ser minuciosamente planejado, uma vez que requer um detalhado estudo de mercado, projeções estatísticas, planos de marketing e divulgação, estudos de demanda e consumo e extrapolação do preço do produto (seja uma análise de medição ou a venda de um MRC).

\subsection{Garantia da Qualidade para resultados de medição}

Para que um laboratório analítico produza dados com qualidade, este deve estabelecer um SGQ apropriado às suas necessidades e que atendam aos requisitos dos seus clientes (ABNT, 2005). Para tanto, seus métodos analíticos devem ser devidamente documentados e validados, a instrumentação analítica submetida a processos de calibração sistemática, cartas de controle devem ser estabelecidas para assegurar que os procedimentos estejam sob conformidade do ponto de vista do controle estatístico e 
deve haver um eficiente plano de treinamento e avaliação de competência de todos os funcionários e colaboradores que fazem parte das atividades do laboratório (KONIECZKA \& NAMIESNIK, 2009; ABNT, 2006).

Diversos modelos de SGQ e de metodologias auxiliares foram apresentados ao longo do texto, com as particularidades de cada um, visando introduzir a importância de um SGQ para o controle dos processos. Interpretando todas estas para um cenário de um laboratório de medição.Algo que todas têm em comum é a necessidade da realização do processo de validação dos métodos de medição, sendo este processo indispensável para a garantia da qualidade dos resultados gerados. De nada adianta utilizar-se um método primário de medição, se as características do uso deste método são desconhecidas no cenário de um laboratório.

O processo de validação fornece informações do desempenho a ser esperado do método e pode ser realizado uma única vez ou em intervalos frequentes ou não - isso depende do uso pretendido e da política da Qualidade do laboratório. A validação deve ser distinguida das outras medidas para a garantia da qualidade que são o controle de qualidade interno (CQI), a participação em testes de proficiência (TP) e eventualmente a acreditação em relação a uma norma internacional. Destes, o CQI fornece informações sobre o desempenho ao longo do tempo de um método já bem estabelecido enquanto que o TP é oportunidade de avaliação do desempenho do laboratório a partir de agentes externos (THOMPSON et al., 2002).

Do ponto de vista analítico, uma importante estratégia adotada para verificação e confirmação do controle da qualidade dos resultados obtidos por um laboratório de medição em procedimentos do dia-a-dia é a análise de materiais de referência (MR), sendo estes de preferência, de matriz similar à da amostra analisada (MERMET et al., 2004). Esse procedimento é extremamente útil quando se trabalha com matrizes complexas das quais não se conhece a concentração do mensurando na amostra. Por meio do resultado obtido na análise do MR, é possível verificar a conformidade do procedimento realizado, comprovando e garantindo o bom funcionamento dos instrumentos utilizados (bloco digestor, forno de micro-ondas, espectrômetros, cromatógrafos, etc.) e a correta realização de todas as etapas do procedimento de medição. Contudo, não se pode garantir que o resultado gerado para a amostra seja livre de erros aleatórios e interferências analíticas. 
Atualmente, existe a necessidade da demonstração de que os resultados obtidos por um laboratório de medição sejam rastreáveis, confiáveis e com suas respectivas incertezas estimadas de forma correta e representativa (ZSCHUNKE, 2000). E estas características estão diretamente relacionadas com o processo de validação de métodos. Desta forma, o processo de validação se faz fundamental para que os resultados gerados por um método possam contribuir para a tomada de decisões no cenário político, econômico, de proteção ao meio ambiente e à saúde, podendo ser comparados com o de outros estudos ou padrões exigidos por um determinado acordo, orgão ou legislação. 


\section{OBJETIVOS}

Realizar a validação formal para a determinação da concentração de As em amostras de matriz biológica (MÉTODO BIO-1);

Realizar a validação formal para a determinação da concentração de As e Sb em amostras de matriz geológica (MÉTODO GEO-1);

Realizar a validação formal para a determinação da concentração de $\mathrm{Co}, \mathrm{Cr}$, $\mathrm{Fe}, \mathrm{Rb}, \mathrm{Sc}$, Se e Zn em amostras de matriz biológica (MÉTODO BIO-2);

Realizar a validação formal para a determinação da concentração de $\mathrm{Co}, \mathrm{Cr}$, Fe, Sc e Zn em amostras de matriz geológica (MÉTODO GEO-2);

Realizar a otimização dos métodos em função do emprego de Planejamento Fatorial para cada um dos métodos de medição;

Estabelecer um procedimento padrão para a cálculo das incertezas em INAA para os respectivos métodos de medição;

Elaborar os documentos da Qualidade referente a validação dos respectivos métodos de medição. 


\section{VALIDAÇÃO DOS MÉTODOS DE MEDIÇÃO}

O termo validação é definido como a confirmação por meio de estudos sistemáticos que o método seja cientificamente coerente sob as condições em que ele é aplicado. Esta confirmação se dá pelo fornecimento de provas objetivas que demonstram o cumprimento de critérios que levam à aceitação e, assim, provam a aplicabilidade do método para um determinado fim (BRASIL, 2003; ANVISA, 2004; PETERS et al., 2007; STOCKL et al., 2009; INMETRO, 2012a).

O desenvolvimento de um método analítico, a adaptação ou a implementação de um método conhecido, envolvem um processo de avaliação que estime sua eficiência na rotina do laboratório, sendo este denominado de validação. Outras definições sobre validação encontradas na literatura são apresentadas a seguir:

"Validação é o processo de definir uma exigência analítica e confirmar que o método sob investigação tem capacidade de desempenho consistente com o que a aplicação requer" (EURACHEM, 1998);

“Confirmação por testes e apresentação de evidências objetivas de que determinados requisitos são preenchidos para um dado uso intencional" (ABNT, 2006);

"O objetivo da validação consiste em demonstrar que o método analítico é adequado para o seu propósito" (WALSH, 1999);

"Validação é a verificação na qual os requisitos especificados são adequados para um uso pretendido" (INMETRO, 2012a).

A validação demonstra objetivamente a qualidade inerente de um método analítico, pois inclui os possíveis fatores que influenciam o resultado final e possibilita 
o julgamento quanto à consistência e qualidade dos resultados analíticos (PETERS et al., 2007; TAVANIERS et al., 2004).

O termo validação difere do termo verificação, uma vez que a verificação é o fornecimento de evidências que mostram a adequação de um dado item a um requisito específico. Enquanto que um processo de validação é verificar se os requisitos específicos são adequados para o uso pretendido (HUBER, 2007; INMETRO, 2012a).

O processo de validação pode ser realizado por meio do método da avaliação direta e/ou do método de avaliação indireta. Neste trabalho de validação, darse-á ênfase ao método de avaliação indireta, de acordo com recomendações do Guia DOQ-CGCRE-008 (INMETRO, 2010). Os diferentes métodos de validação são apresentados a seguir.

\subsection{Validação pelo método de avaliação indireta}

No processo de validação, a escolha dos parâmetros de desempenho do método a serem avaliados está diretamente relacionada ao tipo de ensaio pretendido. Neste contexto, faz-se importante definir se os resultados terão caráter quantitativo ou qualitativo, e, principalmente, quais os requisitos exigidos pelo cliente ou mesmo pelo órgão regulador (HUBER, 2007; INMETRO, 2010). A validação pode ser realizada tanto para um método qualitativo, baseado na presença ou na ausência do analito na amostra analisada, quanto para um quantitativo, baseado na medição da quantidade do mensurando de interesse na amostra (FELDSINE et al., 2002; INMETRO, 2010).

Via de regra, um método de análise quantitativo pode ser dividido em dois grupos. $\mathrm{O}$ primeiro referente às medições de elementos ditos majoritários (concentração maior que $1 \%$ ), um segundo para medição de elementos dispostos em menor teor $(0,01 \%$ à $1 \%)$ e em concentração traço $(<0,01 \%)$. Para cada tipo de análise há um conjunto de parâmetros de desempenho que são designados para o processo de validação (INMETRO, 2010). Este conjunto de parâmetros serve para qualificar o método de medição quanto as suas características específicas. A Tabela 4.1 apresenta os parâmetros exigidos para a validação de métodos quantitativos, de acordo com a faixa de concentração dos mensurandos na amostra. 
Tabela 4.1. Parâmetros de avaliação indireta para métodos quantitativos

\begin{tabular}{cc}
\hline Faixa de Concentração & Parâmetros de desempenho \\
\hline Elementos majoritários & $\begin{array}{c}\text { Exatidão (Precisão e Veracidade), } \\
(1 \% \text { a } 100 \%)\end{array}$ \\
Seletividade, Robustez, Sensibilidade, \\
Linearidade e Faixa de Trabalho. \\
Elementos de menor teor e traço \\
$(<1 \%)$ \\
Exatidão (Precisão e Veracidade), \\
Seletividade, Robustez, Linearidade, Faixa \\
de Trabalho, Limite de Detecção e Limite \\
de Quantificação.
\end{tabular}

A seguir, são apresentados os conceitos e discutidas as estratégias utilizadas para a estimativa de cada um dos parâmetros de desempenho (figuras de mérito) necessários para a validação formal de elementos de menor teor e traço.

\subsubsection{Exatidão}

Ainda hoje, existe grande confusão sobre quando se fala em exatidão e precisão dos resultados. De acordo com o VIM, a exatidão de uma medição é "o grau de concordância entre um valor medido e um valor verdadeiro dum mensurando", enquanto que a precisão de uma medição é "o grau de concordância entre indicações ou valores medidos, obtidos por medições repetidas no mesmo objeto ou em objetos similares, sob condições especificadas" (INMETRO, 2012a).

Estes dois termos são distintos em sua concepção. Enquanto que a exatidão não é uma grandeza, isto é, não assume função em valor numérico a precisão é uma grandeza e sua avaliação é feita em função de um número obtido para o resultado. Dizse que um método produz resultados mais ou menos exatos que outro. Por outro lado, a precisão é expressa numericamente, normalmente como desvio padrão (DP) que é dependente da variância dos resultados (ISO, 2012; INMETRO, 2012a).

Outro conceito que também gera confusão a muitas pessoas é a correlação dos termos exatidão e veracidade. O VIM define a veracidade com "o grau de 
concordância entre a média dum número infinito de valores medidos repetidos e um valor de referência". Assim como a exatidão, a veracidade não é uma grandeza e por esse motivo não pode ser apresentada como um resultado numérico (INMETRO, 2012a). Contudo, a veracidade é avaliada através de grandezas, como o erro relativo $(E R)$ ou erro relativo percentual $(E R(\%)$ ), o índice- $z$ (ou escore- $z$ ) e o erro normalizado (En) (ISO, 2005; INMETRO, 2010). As Equações 1, 2 e 3 apresentam as fórmulas para o cálculo destas respectivas grandezas.

$$
E R(\%)=\frac{100\left(x-x_{v}\right)}{x_{v}}
$$

onde:

$E R(\%)$ é o erro relativo percentual;

$x$ é o resultado da medição;

$x_{v}$ é o valor de referência.

$$
z=\frac{x-x_{v}}{s_{v}}
$$

onde:

$z$ é o valor do índice- $z$ para a medição;

$x$ é o resultado da medição;

$x_{v}$ é o valor de referência;

$\mathrm{S}_{\mathrm{v}}$ é o desvio padrão do valor de referência.

Quando o índice- $z$ é calculado sobre o resultado da medição de um MRC, o termo $s_{v}$ assume o valor da incerteza combinada do valor de consenso $x_{v}$. De acordo com a norma ABNT NBR ISO/IEC 17043, temos a seguinte forma de classificação dos resultados (ABNT, 2011):

$$
|z| \leq 2 \text { resultado satisfatório; }
$$

$2<|z|<3$ resultado questionável;

$|z| \geq 3$ resultado insatisfatório.

$$
E n=\frac{x-x_{v}}{\sqrt{U^{2}+U_{v}^{2}}}
$$

onde: 
En é o valor para erro normalizado;

$x$ é o resultado da medição;

$x_{v}$ é o valor de referência;

$U$ é a incerteza expandida do resultado;

$U_{v}$ é a incerteza expandida do valor de referência.

Quando $|E n| \leq 1$, o resultado obtido na medição é considerado adequado e satisfatório, do contrário o resultado é considerado insatisfatório (INMETRO, 2010).

A exatidão é o conjunto de parâmetros que serve para avaliar o "potencial analítico" de um método de medição. Ela engloba precisão (repetitividade, precisão intermediária e reprodutibilidade) e veracidade, e, de acordo com os resultados característicos para estes parâmetros, é possível chegar à conclusão sobre o grau de exatidão do método de medição, ou seja, se este é adequado ou não ao uso pretendido.

A seguir, são descritas as definições dos termos que englobam a precisão, como repetitividade, precisão intermediária e reprodutibilidade. Também são apresentadas as estratégias adotadas para a avaliação dos mesmos neste trabalho de validação de métodos.

\subsubsection{Precisão}

$\underline{\text { Repetitividade e limite de repetitividade }}$

A repetitividade é um parâmetro quantitativo que expressa o grau de dispersão obtido para amostras idênticas, sob as mesmas condições analíticas, isto é, em um mesmo local e equipamento, com o uso dos mesmos reagentes, por um mesmo analista, com as repetições realizadas em um menor intervalo possível. O VIM define repetitividade como "a condição de medição num conjunto de condições, as quais incluem o mesmo procedimento de medição, os mesmos operadores, o mesmo sistema de medição, as mesmas condições de operação e o mesmo local, assim como medições repetidas no mesmo objeto ou em objetos similares durante um curto período de tempo" (INMETRO, 2012a).

A repetitividade é avaliada através da estimativa do limite de repetitividade (r). Este é calculado de acordo com a Equação 4. 


$$
r=2,8 s \quad \text { (Eq. } 4)
$$

onde:

$r$ é o valor do limite de repetitividade;

$s$ é o desvio padrão obtido para $n$ medições, $n \geq 7$.

Por meio deste parâmetro é possível avaliar a "competência" do método em gerar um resultado adequado às intenções de uso. Neste contexto, quanto menor o valor típico para $r$, menor dispersão entre dois resultados para amostras idênticas é esperada. Desta forma faz-se possível a estimativa do menor grau de dispersão natural para dois resultados em um método específico (ISO, 2012).

\section{Precisão intermediária}

A precisão intermediária $(P I)$ é a estimativa da precisão dos resultados para ensaios realizados com amostras idênticas, em um mesmo método de medição e um mesmo laboratório (ISO, 2013). De acordo com o VIM, a precisão intermediária é definida como "a precisão de medição sob um conjunto de condições de precisão intermediária" (INMETRO, 2012a).

Para a estimativa de PI é recomendado que os procedimentos sejam realizados integral ou parcialmente por diferentes analistas $(A)$, em diferentes equipamentos $(E)$, com diferentes reagentes $(R)$ em um período de tempo maior que o da repetitividade ( $T$ ) (ISO, 2013; INMETRO, 2010). Seu resultado auxilia no entendimento sobre o grau de variabilidade natural dos resultados sob condições que podem variar no laboratório em um período específico. O valor de PI pode ser calculado de acordo com a Equação 5.

$$
P I=\sqrt{\frac{1}{(n-1)} \sum_{k=1}^{n}\left(x_{k}-\bar{x}\right)^{2}}
$$

onde:

PI é o valor de precisão intermediária;

$n$ é o número de amostras (alíquotas); 
$k$ é o número do ensaio da amostra, $k=1, n$;

$x_{k}$ é o resultado obtido para o ensaio $k$;

$\bar{x}$ é a média dos resultados para $n$ medições.

Com a avaliação da precisão intermediária de um método, é possível a identificação dasvariáveis $(A, E, R$ e $T)$ que mais influenciam na variação natural dos resultados nos ensaios realizados em um respectivo laboratório. Estes resultados individuais,as $A, E, R$ e $T$,podem ser comparados com os resultados obtidos em outros laboratórios visando avaliar a técnica do analista, desempenho dos equipamentos, marcas de reagentes diferentes, entre outros, visto que a variação destes fatores é bastante comum nas diferentes rotinas dos laboratórios. Desta forma, é possível fazer a estimativa da influência referente a cada variável investigada para a variabilidade dos resultados dentro do laboratório.

\section{$\underline{\text { Reprodutibilidade e limite de reprodutibilidade }}$}

A reprodutibilidade é um parâmetro importante para a avaliação do desempenho de um mesmo método quando utilizado em diferentes laboratórios e para estimar o maior grau de variação natural para dois resultados em amostras idênticas (INMETRO, 2010). O VIM define a reprodutibilidade como "a precisão de medição conforme um conjunto de condições de reprodutibilidade" (INMETRO, 2010). Por meio dos ensaios realizados em no mínimo dois laboratórios independentes e para um número mínimo de quinze amostras, é possível calcular o limite de reprodutibilidade $(R)$, conforme descrito na Equação 6 (ISO, 2013; ABNT, 2000).

$$
R=2,8 S \quad \text { (Eq. 6) }
$$

onde:

$R$ é o valor do limite de reprodutibilidade;

$S$ é o desvio padrão associado aos resultados obtidos para $n$ laboratórios participantes, para $n \geq 2, S=\sqrt{s^{2}+\cdots+s_{n}^{2}}$. 


\subsubsection{Veracidade}

A avaliação da veracidade dos resultados ainda é algo que gera grande polêmica e controvérsia em meio aos pesquisadores. No cenário qualitativo, os resultados são ditos exatos ou não. Para estipular um critério de classificação do desempenho deste parâmetro de forma quantitativa, constantemente surgem diferentes métodos de avaliação característicos para cada técnica e/ou natureza do estudo. Neste trabalho, a veracidade dos resultados obtidos foi avaliada quantitativamente por meio do cálculo de En já discutido anteriormente (Eq.3). O En foi adotado para a avaliação quantitativa da veracidade uma vez que este leva em consideração as incertezas advindas tanto do MRC quanto a calculada para o método de medição. Uma vez que foi realizado um estudo específico para a estimativa da contribuição das principais fontes de incerteza em INAA, considerou-se mais coerente o uso do En.

\subsubsection{Seletividade}

De acordo com o VIM, seletividade é "a propriedade de um sistema de medição, utilizado com um procedimento de medição especificado, segundo a qual o sistema fornece valores medidos para um ou vários mensurandos, tal que os valores de cada mensurando sejam independentes uns dos outros ou de outras grandezas associadas ao fenômeno, corpo ou substância em estudo". Ainda, segundo o mesmo, em química, a seletividade de um sistema de medição é obtida geralmente para grandezas associadas aos constituintes selecionados em concentrações dentro de intervalos pré-estabelecidos. (INMETRO, 2012a).

Em outras palavras, a seletividade expressa como um método particular pode ser utilizado para determinar a concentração dos mensurandos sob condições pré-determinadas, na presença de componentes de comportamento similar (interferentes). Via de regra, a seletividade é melhorada quando se utiliza uma propriedade única do mensurando, tal como a absorbância em um comprimento de onda específico ou pela separação do mensurando de outras substâncias presentes na amostra (THOMPSON et al., 2002).

Devido à característica que cada radionuclídeo tem de emitir radiação gama em um comprimento de onda específico (resultando em picos de energia bastante 
particulares, normalmente na região entre 80 e $1600 \mathrm{keV}$ ) e sendo isso associado à alta resolução e alta eficiência dos detectores de germânio hiperpuro, a técnica de INAA pode ser considerada muito seletiva (EHMANN \& VANCE, 1991).

Mesmo no caso de haver coincidência de um mesmo pico de energia de decaimento para dois ou mais radionuclídeos, é provável a existência de outro pico que não seja afetado pelo interferente. Isso porque um radionuclídeo normalmente apresenta diferentes vias de decaimento. Ainda assim, havendo a coincidência, o problema pode ser na maioria das vezes contornado pela espera do decaimento (total ou parcial) da atividade do interferente na amostra, estando isso diretamente relacionado com o tempo de meia vida dos radionuclídeos (EHMANN \& VANCE, 1991).

A seletividade dos métodos foi avaliada por meio da análise de cinco diferentes MRCs de matriz similar. As análises foram realizadas em triplicata para cada MRC avaliado. Ao resultado obtido, calculou-se o valor do En, de acordo com a Equação 3. Desta forma, fez-se uma avaliação da habilidade do método de medição para a quantificação do mensurando na presença de interferentes característicos da matriz de estudo, gerando as evidências necessárias para o suporte e confiabilidade dos resultados (INMETRO, 2010).

\subsubsection{Limite de detecção e limite de quantificação}

PRICHARD e BARWICK (2008) definem o limite de detecção de um método de medição como sendo a menor quantidade de mensurando presente na amostra que pode ser detectado, mas não necessariamente quantificado com um grau de incerteza aceitável, normalmente 95\%. Já o limite de quantificação de um método de medição é a menor quantidade de mensurando presente na amostra que pode ser quantificado com um grau de incerteza aceitável.

De acordo com o VIM, o limite de detecção é o "valor medido, obtido por um dado procedimento de medição, para o qual a probabilidade de declarar falsamente a ausência de um componente em um material é $\beta$, sendo $\alpha$ a probabilidade de declarar falsamente a sua presença" (INMETRO, 2012a). Apesar de ser um dos documentos referência para a definição de termos da metrologia, o VIM não apresenta nenhuma definição para limite de quantificação. 
Tanto o limite de detecção $(L D)$ quanto o limite de quantificação $(L Q)$ apresentam importante papel para a caracterização do desempenho para os métodos de medição. Com o delineamento destes é possível avaliar o potencial do método em detectar e quantificar os mensurandos na faixa de concentração requerida por um estudo ou legislação. O primeiro está relacionado ao valor mínimo que pode ser detectado por um método de medição com $95 \%$ de confiança, enquanto que o segundo representa a menor concentração do mensurando que pode ser quantificada com $95 \%$ de confiança quanto à exatidão dos resultados.

Em INAA, diversos fatores afetam os valores de $L D$ e $L Q$. Desta forma, estes devem sempre ser apresentados associados às informações específicas do método utilizado, a matriz da amostra, as condições de irradiação, de decaimento e de medição, uma vez que são estimados a partir da estatística de contagem referente à radiação de fundo característica para a região de localização do pico correspondente do mensurando (GREENBERG et al., 2011).

Os valores para limite de detecção (Eq. 7) e o limite de quantificação (Eq. 8) foram estimados para uma amostra característica para a matriz em estudo, de acordo com o modelo e fórmula propostos por CURRIE (1999).

$$
L D=3,29 \frac{\sqrt{b}}{t}
$$

onde:

$L D$ é a taxa de contagem correspondente ao limite de detecção do método (cps);

$b$ é o número de contagens da radiação de fundo sob o pico analítico (cps);

$t$ é o tempo real de medição da amostra (s).

Para o limite de quantificação tem-se que:

$$
L Q=10 \frac{\sqrt{b}}{t}
$$

onde:

$L_{Q}$ é a taxa de contagem correspondente ao limite de quantificação do método (cps);

$b$ é o número de contagens da radiação de fundo sob o pico analítico (cps);

$t_{v}$ é o tempo real de medição da amostra (s). 
Os resultados obtidos para $L D$ e $L Q$ são convertidos para $\mathrm{mg} \mathrm{kg}^{-1}$ utilizando a equação geral da ativação neutrônica (Eq. 35), descrita no capítulo 6.

\subsubsection{Robustez}

A robustez de um método de ensaio mede o comportamento que os resultados apresentam frente a pequenas variações das condições padrão do método de medição. Um método é considerado robusto quando apresenta resultados similares frente a pequenas variações que possam ocorrer quando este está a ser executado. Neste contexto, quanto maior a robustez do método, maior a confiança sobre o limite de repetitividade e o limite de reprodutibilidade.

Para a avaliação da robustez foi realizado o delineamento experimental univariado em um nível de observação. Isto significa que cada variável estudada, teve sua influência determinada por meio da comparação do resultado obtido para a medição na condição padrão do método com o resultado obtido em uma condição modificada. As variáveis (fatores) estudadas foram o tempo de decaimento da amostra até o início do processo de medição, distância entre amostra e detector, fluxo de nêutrons térmicos, geometria da amostra e do padrão sintético, massa da amostra. Outros fatores como a configuração do preparo dos padrões sintéticos, tempo de medição para amostra e padrão sintético e uso de diferentes detectores também foram avaliados, porém em outros delineamentos do processo de validação.

\subsubsection{Linearidade}

Em sua teoria, a técnica de INAA é linear para todas as faixas de concentração. Isto quer dizer que independentemente da concentração da amostra, esta apresentará uma correlação linear para a radioatividade induzida com qualquer outro ponto investigado, na faixa de 0 até $1 \mathrm{~kg} \mathrm{~kg}^{-1}$. Isso se deve ao fato de que a radioatividade induzida por um radionuclídeo sempre será proporcional ao número de átomos daquele elemento na amostra, e isso independe da matriz de estudo (EHMANN \& VANCE, 1991; BLAAUW \& GELSEMA, 1999; BODE \& BLAAUW, 2012). 


\subsubsection{Faixa de trabalho}

A faixa de trabalho é o intervalo característico para a concentração dos mensurandos que se pretende quantificar com o emprego de um método de medição específico. A faixa de trabalho deve cobrir a faixa de aplicação para a qual o ensaio vai ser usado e a concentração mais esperada da amostra deve, sempre que possível, se situar no centro da faixa de trabalho (INMETRO, 2010).

Via de regra, o limite inferior consiste no valor para o $L Q$ para o mensurando no método. O limite superior depende das características de cada método de medição, estando correlacionado com a linearidade do método e com a resposta dos equipamentos usados no processo de medição. Contudo, a escolha dos limites da faixa de trabalho é arbitrária, desde que haja uma resposta linear entre os limites estabelecidos.

\subsubsection{Incerteza de medição}

Outro requisito da norma ABNT NBR ISO/IEC 17025 e também apresentado no Guia para a validação de métodos de medição DOQ-CGCRE-008 é a estimativa da contribuição das principais fontes de incerteza de medição (ABNT, 2006; INMETRO, 2010).

A expressão padronizada da incerteza associada a processos de medição tem se tornado requisito indispensável em química analítica, não só por ser exigida na acreditação de laboratórios, mas principalmente por viabilizar a interpretação correta de resultados analíticos.

Segundo recomendações do QUAM:2012 a estimativa da incerteza associada ao resultado deve ser realizada de forma sistematizada de acordo com as seguintes etapas: especificação do mensurando; identificação das fontes de incerteza; quantificação das contribuições de cada fonte de incerteza; combinação das contribuições para o cálculo da incerteza padrão combinada; aplicação do fator de abrangência, $k$, para o cálculo da incerteza padrão expandida, $U$, e finalmente, a apresentação dos resultados (EURACHEM/CITAC, 2012).

O VIM define o termo incerteza de medição como "um parâmetro não negativo que caracteriza a dispersão dos valores atribuídos a um mensurando, com 
base nas informações utilizadas". A incerteza de medição inclui componentes provenientes de efeitos sistemáticos, tais como componentes associadas a correções e a valores atribuídos a padrões, assim como a incerteza definicional que é " $a$ incerteza mínima que se pode obter, na prática, em qualquer medição de um dado mensurando" (INMETRO, 2012a).

A incerteza de medição geralmente engloba muitas componentes. Algumas delas podem ser estimadas por uma avaliação do tipo A da incerteza de medição, a partir da distribuição estatística dos valores provenientes de séries de medições e podem ser caracterizadas como desvio padrão. As outras componentes, as quais podem ser estimadas por uma avaliação do tipo B da incerteza de medição, podem também ser caracterizadas por desvio padrão estimados a partir de funções de densidade de probabilidade baseadas na experiência ou em outras informações. As incertezas tipo B correspondem aos valores publicados por uma autoridade competente, obtidas a partir de um certificado de calibração e documentos correlatos (INMETRO, 2012a).

De acordo com GREENBERG e colaboradores (2011), diversas são as fontes de incerteza em INAA, como por exemplo, anomalias de geometria para amostra e padrão sintético, variações de densidade do material analisado, variação do fluxo e fluência de nêutrons térmicos, presença de elementos absorvedores de nêutrons, perdas do mensurando no momento da irradiação, manuseio e medição, dentre outras. Ainda, pode-se citar a existência de interferências associadas ao software utilizado para integração dos picos, da eletrônica acoplada ao detector e do cálculo de correção do tempo morto das medições.

A estratégia adotada para o dimensionamento das incertezas segue a linha de pesquisa iniciada por MOREIRA e colaboradores (2006), na qual, para o preparo e caracterização de um material de referência de tecido de mexilhão, foi desenvolvido um método de estimativa para o cálculo das incertezas baseados nas recomendações do Guia para a expressão das Incertezas de Medição, ISO GUM (INMETRO, 2012c).

Desta forma, avaliou-se a influência associada à massa da amostra, massa do padrão sintético, atividade do radionuclídeo na amostra, atividade do radionuclídeo no padrão sintético, a constante de decaimento do radionuclídeo e anomalia na geometria da amostra e do padrão sintético. Essas são as fontes de incerteza majoritárias em INAA (BALLA et al., 2004; GREENBERG, 2008; GREENBERG et al., 2011). 
O ISO GUM estabelece que a incerteza de medição deve ser avaliada em função das grandezas de entrada do modelo matemático do método. As grandezas de entrada para o cálculo da concentração dos mensurandos são apresentadas na Equação 9.

$$
C=\frac{m_{p} A_{a} e^{\lambda\left(\operatorname{td}_{\mathrm{a}}-\mathrm{td}_{\mathrm{p}}\right)}}{m_{a} A_{p}}
$$

onde:

$C$ é a concentração do mensurando na amostra $\left(\mathrm{mg} \mathrm{kg}^{-1}\right)$;

$m_{p}$ é a massa do mensurando no padrão (mg);

$A_{a}$ é a taxa de contagem do radionuclídeo na amostra (cps);

$\lambda$ é a constante de decaimento do radionuclídeo $\left(\mathrm{s}^{-1}\right)$;

$t_{d a}$ é o tempo de decaimento do radionuclídeo até o momento inicio da medição da amostra (s);

$t_{d p}$ é o tempo de decaimento do radionuclídeo até o inicio da medição do padrão (s); $m_{a}$ é a massa seca da amostra $(\mathrm{kg})$;

$\mathrm{A}_{\mathrm{p}}$ é a taxa de contagem do radionuclídeo no padrão sintético para tempo de decaimento $t d p$ (cps).

O diagrama de Ishikawa (Figura 4.1) apresenta a propagação das incertezas avaliadas neste trabalho de validação. 


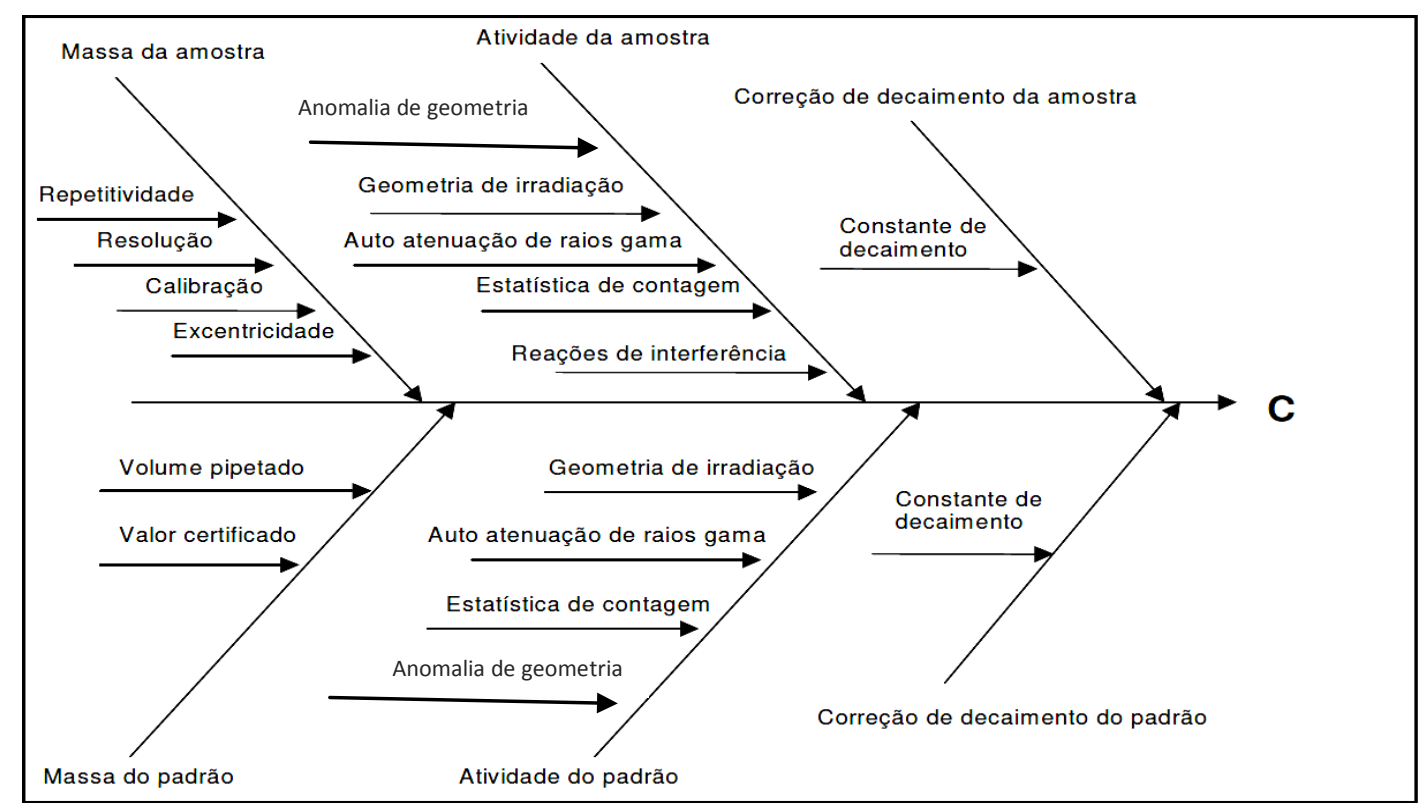

Figura 4.1. Diagrama de Ishikawa para a propagação de incertezas em INAA

De acordo com as recomendações da norma ISO GUM (INMETRO, 2012a) e do QUAM:2012 (EURACHEM/CITAC,2012), a fórmula genérica estipulada para o cálculo da incerteza padrão expandida é descrita na Equação 10.

$$
U=k \sqrt{\left(\frac{u A_{a}}{A_{a}}\right)^{2}+\left(\frac{u A_{p}}{A_{p}}\right)^{2}+\left(\frac{u t d_{a}}{t d_{a}}\right)^{2}+\left(\frac{u t d_{p}}{t d_{p}}\right)^{2}+\left(\frac{u M_{a}}{M_{a}}\right)^{2}+\left(\frac{u M_{p}}{M_{p}}\right)^{2}+\left(\frac{u \lambda}{\lambda}\right)^{2}}
$$

onde:

$U$ é a incerteza expandida para a grandeza;

$u$ corresponde à incerteza combinada para o fator $x$;

$k$ corresponde ao fator de abrangência da incerteza expandida, $k=2,95 \%$ confiança;

$A_{a}$ é a taxa de contagem do radionuclídeo na amostra para tempo de decaimento $t d a$;

$A_{p}$ é a taxa de contagem do radionuclídeo no padrão para tempo de decaimento $t d p$;

$t_{d a}$ é o tempo de decaimento do radionuclídeo para a amostra;

$t_{d p}$ é o tempo de decaimento do radionuclídeo para o padrão;

$M_{a}$ é a massa do mensurando na amostra;

$M_{p}$ é a massa do mensurando no padrão;

$\lambda$ é a constante de decaimento radioativo para o radionuclídeo. 
Para o cálculo da incerteza de medição característica para cada mensurando, foi realizado o procedimento simulado para o cálculo de incertezas (COUTO, 2006; COUTO \& SILVA, 2007; INMETRO, 2012c). Este método, demasiadamente simples, não requer a realização de cálculos complexos baseando-se na relação direta entre a incerteza associada a um componente de entrada $f$ e o resultado da medição. Desta maneira é possível realizar-se um conjunto de experimentos para a simulação numérica para caracterização de uma grandeza $C$. Genericamente tem-se que:

$$
C=\frac{f_{1} f_{2}}{f_{3} f_{4}}
$$

onde:

C é a grandeza de saída que pode ser concentração;

$f_{x}$ são os fatores considerados para o cálculo da incerteza de medição, $x=\{1,2,3,4\}$.

As incertezas $u f_{1}, u f_{2}, u f_{3}$ e $u f_{4}$ referentes aos componentes de entrada $f_{1}, f_{2,} f_{3}$ e $f_{4}$ são estimadas em função do modo que cada fonte de entrada define o mensurando, isto é, o cálculo do mensurando é realizado por meio da variação de cada componente de entrada com sua respectiva incerteza. De acordo com o exemplo, temos que:

$$
\begin{aligned}
& C_{f 1}=\frac{\left(u f_{1} f_{1}\right) f_{2}}{f_{3} f_{4}} \\
& C_{f 2}=\frac{f_{1}\left(u f_{2} f_{2}\right)}{f_{3} f_{4}} \\
& C_{f 3}=\frac{f_{1} f_{2}}{\left(u f_{3} f_{3}\right) f_{4}} \\
& C_{f 4}=\frac{f_{1} f_{2}}{f_{3}\left(u f_{4} f_{4}\right)}
\end{aligned}
$$

Desta forma, cada componente de entrada do cálculo da incerteza de medição pode ter sua incerteza associada facilmente calculada de acordo com a Equação 16. 


$$
\Delta f_{x}=\left|C-C_{f x}\right|
$$

onde:

$\Delta f_{x}$ é a incerteza nominal associada atribuída ao componente de entrada $f_{x}$, onde $x=\{1,2,3,4\}$

$C$ é o valor obtido no resultado original da medição;

$C f_{x}$ é o valor obtido para o resultado levando-se em consideração a incerteza associada ao componente de entrada $f_{x}$.

De acordo com o método simulado, a incerteza padrão expandida do mensurando pode ser calculada conforme a Equação 17.

$$
U C=k \sqrt{\left(\Delta C_{f 1}\right)^{2}+\left(\Delta C_{f 2}\right)^{2}+\left(\Delta C_{f 3}\right)^{2}+\left(\Delta C_{f x}\right)^{2}}
$$

onde:

$U C$ é a incerteza expandida para a grandeza $C$;

$k$ corresponde ao fator de abrangência da incerteza expandida; $k=2 ; 95 \%$ confiança;

$\Delta f_{x}$ é a incerteza nominal associada atribuída ao componente de entrada $f_{x}$, onde $x=\{1,2,3,4\}$

\subsection{Validação pelo método de avaliação direta}

A validação realizada por meio do procedimento de avaliação direta nada mais é do que a avaliação da veracidade dos resultados obtidos para um método de ensaio específico (INMETRO, 2012a). A exatidão de um método é definida como sendo a concordância entre o resultado de um ensaio e o valor de referência aceito como convencionalmente verdadeiro.

A avaliação da exatidão de um método pode ser realizada utilizando-se um material de referência certificado (MRC) de matriz similar à da amostra, pela participação em comparações interlaboratoriais e até mesmo pela realização de ensaios de recuperação. Este tipo de validação faz-se muito comum especialmente no meio acadêmico e trata-se de uma importante ferramenta para estudos de desenvolvimento e 
otimização de métodos, uma vez que fornece resultados sobre o desempenho do novo método necessitando de um número reduzido de análises frente ao processo formal de validação (avaliação indireta).

O número reduzido de análises é a grande vantagem deste tipo de validação. Isso faz com que grande parte dos pesquisadores, especialmente os de universidades, recorram a este método, visto que é bem mais rápido e barato, podendo ser realizado de maneira concomitante com as análises das amostras do estudo. Além disso, a matemática envolvida é demasiadamente simples e praticamente não requer conhecimento prévio em estatística e desenhos experimentais.

O método de avaliação indireta é um requisito para a acreditação do método utilizado no laboratório junto a um órgão regulamentador. Neste método diversos parâmetros devem ser estudados visando à caracterização do método de medição, tornando o processo bem mais trabalhoso, demorado e com maiores custos. Em contra partida, fornece evidências sobre a verdadeira aplicabilidade do método de medição, tornando os resultados gerados mais seguros quanto à existência de erros.

\subsubsection{Análise de Material de Referência Certificado}

Material de Referência (MR), segundo definição do ABNT ISO Guia 30, é "um material ou substância suficientemente homogêneo que tem uma ou mais propriedades bem estabelecidas para ser usado na calibração de um equipamento, na avaliação de um método de medição ou atribuição de valores a materiais" (ABNT, 2000). De acordo com o VIM, um MR é um "material, suficientemente homogêneo e estável em relação a propriedades específicas, preparado para se adequar a uma utilização pretendida numa medição ou num exame de propriedades qualitativas" (INMETRO, 2012a).

O que difere um MR e MRC é o fato de que o MRC vem acompanhado de um certificado contendo todas as propriedades do material, mencionando os valores das grandezas de interesse com suas respectivas incertezas. Outro requisito, é que este certificado seja emitido por um órgão de competência reconhecida (INMETRO, 2012b).

Preferencialmente, sua certificação é realizada utilizando métodos primários de medição ou por meio de estudos colaborativos interlaboratoriais. Contudo, existe uma ampla gama de estratégias que podem ser adotadas para certificar o valor de 
consenso das grandezas (ABNT, 2004; ISO, 2006). Essa dependerá da estratégia adotada pelo produtor, das necessidades dos clientes e das exigências do órgão regulador.

De acordo com definição do VIM, um MRC é "um material de referência acompanhado duma documentação emitida por uma entidade reconhecida, a qual fornece um ou mais valores de propriedades especificadas com as incertezas e as rastreabilidades associadas, utilizando procedimentos válidos" (INMETRO, 2012a).

Por meio da análise de um MRC é possível fazera avaliação sobre o desempenho de um método utilizado por um laboratório específico através da comparação do resultado obtido na medição com o valor certificado, estimando-se a exatidão do resultado.

Uma das premissas deste tipo de validação é que amostra e MRC sejam analisados de forma concomitante, dentro do mesmo procedimento, com os mesmos reagentes, equipamentos e no menor período de tempo possível. Ainda, é desejado que o MRC seja de matriz similar ao das amostras e com a composição físico-química mais semelhante possível, visando-se a minimização de possíveis erros analíticos. Isso é particularmente importante para métodos pouco robustos (MERMET et al., 2004).

Estando em conformidade o resultado obtido na análise do MRC com o seu valor certificado, admite-se a aplicabilidade e a veracidade do método para as amostras de comportamento e características similares, "validando-se" os resultados obtidos para o lote de amostras.

Um ponto falho neste tipo de validação é o fato de que muitas vezes as outras características de desempenho do método não são conhecidas, como linearidade, faixa de trabalho, sensibilidade, interferentes e precisão, podendo ocasionar a existência de erros analíticos elevados, dificultando a interpretação, discussão e conclusão do estudo.

\subsubsection{Ensaios interlaboratoriais}

Nas últimas décadas, tem sido grande a evolução no que diz respeito à harmonização dos requisitos de qualidade aplicados nos ensaios interlaboratoriais (THOMPSON et al., 2002). 
Dentro do cenário da validação de métodos, estes estudos são importantes ferramentas para a avaliação da competência técnica e para monitorar a integridade dos resultados gerados por um método específico em um determinado laboratório, sendo estes similares ou não. Existem ainda estudos que visam avaliar a competência de dois ou mais laboratórios para um único método, sendo estes estudos denominados ensaios de normalização, onde o principal objetivo é a avaliação dos resultados quanto à repetitividade, precisão intermediária e reprodutibilidade. Neste caso, vale reafirmar a abrangência de aplicação dos ensaios é exclusiva a um único método.

Outro desenho de Programa Interlaboratorial é denominado de Teste de Proficiência $(T P)$. Neste tipo de estudo, os resultados enviados por cada participante são confrontados frente a critérios de avaliação pré-estabelecidos. Os ensaios de aptidão constituem um caso particular das comparações interlaboratoriais, em que o objetivo principal é a avaliação do desempenho dos participantes (THOMPSON et al., 2002).

Resumidamente, quando o laboratório pretende avaliar a repetitividade e a reprodutibilidade de um método, demonstrando em simultâneo que tem uma precisão compatível com a de outros laboratórios, pode recorrer a um ensaio do tipo de normalização. Quando tem por objetivo evidenciar a veracidade dos seus resultados, então pode participar em ensaios do tipo de aptidão (testes de proficiência).

Sempre que nos processos de avaliação utilizados não se verifiquem as condições satisfatórias, deverá ser realizada uma análise de causas e elaborado um plano de ações corretivas (se aplicável), de forma a fazer uma reavaliação do ensaio (ANVISA, 2005).

A periodicidade da análise dos EIs deve ser estipulada em função da frequência de análises efetuadas, de estas serem de rotina ou de caráter pontual, do grau de conhecimento das amostras, da complexidade das técnicas e do grau de confiança exigido para o resultado.

\subsubsection{Ensaios de recuperação}

Ensaios de recuperação são realizados a partir da adição à amostra de uma quantidade conhecida de mensurando, isto é, uma fortificação. Neste procedimento, o mensurando deve ser adicionado às amostras em pelo menos três diferentes concentrações, por exemplo, próximo do limite de detecção, próximo da concentração 
máxima permissível e numa concentração próxima da média da faixa de uso do método. A limitação deste procedimento é que o analito adicionado não está necessariamente na mesma forma que o presente na amostra (TAVARES, 2012).

Inicialmente faz-se a medição do mensurando em uma alíquota da amostra. Para outras três alíquotas deve-se adicionar diferentes quantidades conhecidas do mensurando na amostra. Esse é o processo de fortificação. Subtrai-se o valor correspondente ao resultado da amostra do resultado das amostras com fortificação. $\mathrm{O}$ valor resultante desta subtração deverá ser a quantidade de mensurando correspondente à fortificação. Desta forma, através da quantidade de mensurando recuperada, admite-se que não existem interferentes na amostra, validando-se o resultado.

Esta técnica é muito empregada como ferramenta auxiliar para a avaliação de interferências em amostras desconhecidas, cujas matrizes não sejam similares à utilizada no escopo da validação do método para métodos com boa robustez. A quantidade percentual recuperada pelo processo pode ser calculada por meio da Equação 18.

$$
R(\%)=\frac{100\left(C_{3}-C\right)}{C_{2}}
$$

onde:

$R(\%)$ é a recuperação percentual da fortificação;

$C$ é a concentração do mensurando na amostra $\left(\mathrm{mg} \mathrm{kg}^{-1}\right)$;

$C_{2}$ é a concentração do mensurando referente à fortificação $\left(\mathrm{mg} \mathrm{kg}^{-1}\right)$;

$C_{3}$ é a concentração da amostra mais a concentração do mensurando referente à fortificação; $C+C_{2}\left(\mathrm{mg} \mathrm{kg}^{-1}\right)$.

Em casos onde a concentração da amostra for inferior ao limite de detecção do método, recomenda-se calcular a recuperação considerando-se $C=0$, com o resultado sendo expresso na forma de intervalo. Onde $C$ é maior que o limite de detecção, deve-se calcular a média aritmética para os três ensaios com fortificações diferentes expressando-se o resultado como o valor médio.

O critério de aceitação para a recuperação pode variar de acordo com a concentração do mensurando na amostra e até mesmo em função da técnica empregada na análise. De acordo com BRITO (2001), os ensaios de recuperação são considerados satisfatórios, quando obtidos resultados entre $80 \%$ e $120 \%$ para elementos de menor teor e traço e entre $90 \%$ e $110 \%$ para elementos majoritários. 


\section{PLANEJAMENTO FATORIAL}

A busca pelo aperfeiçoamento dos métodos de produção somada às exigências impostas por um mercado cada vez mais competitivo leva as indústrias e prestadores de serviço a adotarem frequentes e rigorosos programas de manutenção da qualidade visando o aperfeiçoamento de seus produtos. Esses projetos de melhoria estão presentes desde a captação da matéria prima até a logística de distribuição, envolvendo toda a cadeia produtiva, passando ainda por todo o processo de produção, estocagem e gerenciamento de resíduos (MELO, 2007).

Como consequência desta busca pelo aprimoramento e excelência, experimentos industriais e/ou laboratoriais são realizados com grande frequência, sob as mais diversas metodologias de tratamento de dados, buscando-se com isso o atendimento dos mais variados objetivos. Na grande maioria dos casos, estes estudos envolvem o emprego de um Planejamento Fatorial, do inglês Factorial Design ou Design of Experiments (DOE) devido à sua simplicidade e eficiência (YE et al.,2001).

Essa necessidade de que indústrias e laboratórios tem em otimizar seus procedimentos faz com que o DOE seja ferramenta muito utilizada e difundida nas mais diversas áreas do conhecimento. Contudo, sua aplicabilidade ainda é muito pequena visando a investigação das variáveis de processo em INAA, tornando a metodologia praticamente desconhecida e muito pouco palpável para grande parte dos pesquisadores da área.

O DOE é uma metodologia multivariada empregada na otimização de métodos e processos. Independente do modelo utilizado, o uso do DOE apresenta uma série de vantagens frente ao uso de uma metodologia univariada (convencional), tais como, a possibilidade da redução no número de rodadas e experimentos, a indicação da variável majoritária do processo investigado e a forma como as mais diversas variáveis se correlacionam entre si (ERIKSSONet al., 2008).

O modelo clássico de otimização univariada consiste na investigação do comportamento atribuído a cada variável através de experimentos individuais, nos quais a configuração da variável de estudo é alterada uma-a-uma, mantendo-se a configuração 
das demais variáveis constantes. Nesta metodologia os resultados são estimados por meio da variação do resultado obtido entre a configuração padrão e as diferentes configurações testadas. Esse método, amplamente utilizado, normalmente além de requerer elevado número de experimentos, se comparado com experimentos de DOE, ainda não leva em consideração a informação sobre a maneira que cada variável se correlaciona com as outras (ZHAG et al., 2014).

Antes de prosseguir com a apresentação da metodologia DOE, faz-se importante definir o significado de alguns termos que facilitarão a compreensão do texto (TEÓFILO \& FERREIRA, 2006; ERIKSSON et al., 2008; CLEWER \& SCANISBRICK, 2011).

Os termos e equações apresentados a seguir são referentes ao DOE com modelo experimental $2^{k}$, que é o mais comum e usual. Desta forma, outros modelos experimentais poderão requerer outros modelos matemáticos para seus respectivos dimensionamentos.

Fator: cada uma das variáveis investigadas em um DOE;

Nível: cada uma das configurações experimentais atribuídas a uma variável de estudo. Um típico DOE normalmente apresenta dois níveis a serem investigados, denominados nível +1 e nível -1 . Procura-se atribuir a cada um desses níveis configurações extremas, ou seja, ao nível +1 atribui-se uma configuração a qual se espera obter resultados muito melhores e ao nível -1 atribui-se uma configuração a qual se espera obter resultados muito piores.

Cabe ressaltar que um resultado melhor ou pior está estritamente relacionado ao objetivo do DOE. Ainda, vale citar que aaleatorização das configurações atribuídas a cada nível (como atribuir a configuração a qual se obtém um melhor resultado aonível -1 e vice-versa) não prejudica o modelo matemático do DOE, apenas pode apresentar um resultado ou uma conclusão pouco representativa. Alguns modelos específicos podem também requerer a informação da configuração dos fatores que é atribuída ao nível padrão, sendo este denominado nível 0.

Efeito: é resultado ocasionado pela alteração de um nível dentro de um fator, e/ou o resultado da interação entre dois ou mais fatores nos mais diversos níveis; 
Efeito Principal $(M E)$ : é resultado da alteração de um ou mais níveis dentro de um fator. É calculado de acordo com a Equação 19.

$$
M E=2 \frac{\sum\left(y^{+1}\right)-\sum\left(y^{-1}\right)}{n}
$$

onde:

$M E$ é o valor para o efeito principal de um fator; $\sum\left(y^{+1}\right)$ and $\sum\left(y^{-1}\right)$ é a somatória dos resultados obtidos para todos os experimentos nos níveis +1 e -1 , considerando-se todas as replicatas;

$n$ é o número total de experimentos incluindo todas as replicatas.

Efeito de Interação ou Contraste (IE): também conhecido como efeito de segunda ordem, efeito de terceira ordem, etc., é a metade da diferença entre o $M E$ de um fator no nível de outro fator. Em outras palavras, trata-se de como a mudança no nível de um fator afeta o resultado obtido em um outro fator (MARTíNEZ, 2013). Pode ser calculado de acordo com a Equação 20. Para tanto, o IE entre os fatores é obtido levando-se em consideração os sinais já atribuídos aos diferentes níveis, como se fosse uma operação matemática de multiplicação. Este modelo para o dimensionamento dos sinais para o cálculo do IE é apresentado mais adiante no texto, na Tabela 5.1.

Erro Padrão de Efeito (ESE): é a incerteza na medição no resultado de um efeito. O valor de ESE é o mesmo para todos os efeitos e/ou interações. Uma das formas para calcular-se o ESE é de acordo com a Equação 20.

$$
E S E=\frac{S}{\sqrt{2^{(z-1)}}}
$$

onde:

ESE é o erro padrão de efeito;

$s$ é o desvio padrão dos resultados obtidos nos experimentos, incluindo replicatas; $z$ é o número de fatores investigados. 
Segundo BUTTON (2001), DOEs são ferramentas indicadas para a fase inicial do desenvolvimento experimental quando há necessidade de se definir os fatores mais importantes e estudar os efeitos sobre a variável resposta escolhida. Também é método bastante útil para um melhor conhecimento sobre um processo pouco estudado e para a otimização de procedimentos de medição. Ainda, "é um modelo de efeitos fixos, isto é, a análise dos efeitos provocados pelos fatores não pode ser transferida para outros níveis que não os analisados no planejamento".

Quando se deseja avaliar o efeito de um fator nas respostas de um produto ou processo, recomenda-se utilizar técnicas completamente aleatorizadas de DOE, podendo estas serem divididas em diferentes blocos experimentais. Conforme proposto por JURAN e colaboradores (1951).

Quando o objetivo do estudo é investigar o efeito provocado nas respostas de dois ou mais fatores, torna-se mais viável o uso de técnicas clássicas de DOE, dentre elas, o DOE completo e o DOE fracionado. Quando a experimentação com réplicas for inviável, uma alternativa viável é recorrer ao uso de experimentos com ponto central (MONTGOMERY, 1991).

O DOE fracionado é normalmente empregado no estágio inicial de processos de investigação, quando o pesquisador deseja testar um número grande de fatores $(z \geq 4)$ e retirar do estudo aqueles que não apresentam efeitos significativos. Em alguns casos, o desenvolvimento do estudo pode envolver dois ou mais estágios, o que levar a dificuldades no processo de aleatorização dos experimentos. Outra situação indesejada ocorre quando os níveis atribuídos a alguns fatores são difíceis de serem modificados enquanto que para outros este processo é relativamente fácil. Nestes casos, são usados planos split-plot ou ainda planos strip-block (BOX et al., 2005).

A modelagem de DOE completo, a mesma empregada neste estudo, é uma das mais simples e compactas metodologias de DOE. Esta é indicada para estudos que envolvem um número pequeno de níveis e fatores estudados. Dependendo do propósito de uso, diferentes configurações desta modelagem de DOE podem ser utilizadas, dentre elas a da família $y^{z}$. Este tipo de delineamento é apropriado para a investigação de modelos experimentais relativamente simples, onde cada um dos $z$ fatores são estudados para $y$ diferentes níveis, emy configurações experimentais (PEREIRA-FILHO et al., 2002; TEÓFILO \& FERREIRA, 2006; REYNIER et al., 2013; IZADYAR et al., 2013). 
O delineamento utilizado neste trabalho foi o $2^{3}$ completo, onde 3 fatores são investigados em 2 diferentes níveis, no qual a um deles se espera obter resultados mais favoráveis (nível +1) e um outro a qual se espera obter resultados menos favoráveis (nível -1) para a exatidão dos resultados em INAA.

Resumidamente, o estudo consiste na análise de uma ou mais amostras típicas em diferentes condições experimentais, visando identificar o grau de influência associado a cada um dos fatores de estudo, o grau de interação destes (entre si e uns com os outros) e a influência provável disso sobre o resultado final (LOPES \& SANTOS, 2008; HAIR et al., 2009).

A matriz experimental do DOE $2^{3}$ completo é apresentada na Tabela 5.1 (TEÓFILO \& FERREIRA, 2006).

Tabela 5.1. Matriz experimental típica para o DOE $2^{3}$ completo

\begin{tabular}{|c|c|c|c|c|c|c|c|c|}
\hline \multirow[t]{2}{*}{ Experimento } & \multirow[t]{2}{*}{${ }^{*}$ Contribuição } & \multicolumn{3}{|c|}{ Efeito Principal } & \multicolumn{4}{|c|}{ Efeito de Interação } \\
\hline & & A & B & $\mathrm{C}$ & $\mathrm{AB}$ & $\mathrm{AC}$ & $\mathrm{BC}$ & $\mathrm{ABC}$ \\
\hline $\mathrm{y}_{1}$ & $\mathrm{a}_{0} \mathrm{~b}_{0} \mathrm{c}_{0}$ & - & - & - & + & + & + & - \\
\hline $\mathrm{y}_{2}$ & $\mathrm{a}_{1} \mathrm{~b}_{0} \mathrm{c}_{0}$ & + & - & - & - & - & + & + \\
\hline $\mathrm{y}_{3}$ & $\mathrm{a}_{0} \mathrm{~b}_{1} \mathrm{c}_{0}$ & - & + & - & - & + & - & + \\
\hline $\mathrm{y}_{4}$ & $\mathrm{a}_{1} \mathrm{~b}_{1} \mathrm{c}_{0}$ & + & + & - & + & - & - & - \\
\hline $\mathrm{y}_{5}$ & $\mathrm{a}_{0} \mathrm{~b}_{0} \mathrm{c}_{1}$ & - & - & + & + & - & - & + \\
\hline $\mathrm{y}_{6}$ & $\mathrm{a}_{1} \mathrm{~b}_{0} \mathrm{c}_{1}$ & + & - & + & - & + & - & - \\
\hline $\mathrm{y}_{7}$ & $\mathrm{a}_{0} \mathrm{~b}_{1} \mathrm{c}_{1}$ & - & + & + & - & - & + & - \\
\hline $\mathrm{y}_{8}$ & $a_{1} b_{1} c_{1}$ & + & + & + & + & + & + & + \\
\hline
\end{tabular}

* onde 0 e 1 representam os diferentes níveis (nível -1 e nível +1, respectivamente)

O modelo matemático do DOE $2^{3}$ completo é representado pela Equação 21 (BOX et al., 2005).

$$
y_{i j k}=\mu+\tau_{i}+\beta_{j}+y_{k}+\left(\tau \beta_{i j}\right)+\left(\tau y_{i k}\right)+\left(\beta y_{j k}\right)+\left(\tau \beta y_{i j k}\right)+\varepsilon_{i j k}
$$


onde:

$\mu$ é a média dos resultados;

$\tau_{i}$ é o efeito principal do fator $A$;

$\beta_{j}$ é o efeito principal do fator $B$

$y_{k}$ é o efeito principal do fator $C$;

$\left(\tau \beta_{i j}\right)$ é o efeito de interação entre os fatores $A$ e $B$;

$\left(\tau y_{i k}\right)$ é o efeito de interação entre os fatores $A$ e $C$;

$\left(\beta y_{j k}\right)$ é o efeito de interação entre os fatores $B$ e $C$;

$\left(\tau \beta y_{i j k}\right)$ é o efeito de interação dos fatores $A, B$ e $C$;

$\varepsilon_{i j k}$ é o erro padrão de efeito.

A maior vantagem do uso de um DOE é a realização de uma otimização multivariada, onde, através dos cálculos de efeito principal e dos efeitos de interação é possível entender como os diferentes fatores são correlacionados e sobre a importância destas correlações para a otimização do método de medição. Desta forma se faz possível avaliar e conhecer o grau importância que um fator carrega no resultado final. Além disso, o método requer um menor número de experimentos quando comparado com a metodologia de otimização univariada. Isso implica em menores gastos e num menor tempo dispensado para a execução do planejamento (ERIKSSON et al., 2008).

Contudo, para uma correta estimativa da influência de cada fator ao resultado final algumas premissas são requeridas, tais como a aleatorização da ordem de execução dos experimentos, a obtenção de resultados independentes (e não interdependentes) e a ocorrência de distribuição normal para os resultados obtidos experimentalmente (ERIKSSONet al., 2008; CLEWER \& SCANISBRICK, 2011; MARTÍNEZ, 2013).

A aleatorização nos experimentos se faz particularmente importante no intuito de balancear (distribuir) os efeitos produzidos por fatores não-controláveis do processo investigativo dentre todos os experimentos - e consequentemente resultados -, buscando-se atender ao principal requisito dos mais diversos métodos estatísticos (dentre eles a Análise de Variância e teste $t$, os quais são empregados para a interpretação dos resultados gerados em um DOE), os quais exigem que as componentes de erro experimental sejam variáveis aleatórias e independentes (BOX et al., 2005; ERIKSSON et al., 2008; CLEWER \& SCANISBRICK, 2011). 
Os fatores avaliados neste estudo de otimização de métodos em INAA foram: tempo de decaimento da atividade da amostra antes do inicio da medição $(A)$, a distância entre amostra e detector $(B)$ e o tempo de medição para amostra $(C)$. Os resultados para a otimização do delineamento experimental mais favorável para a melhoria da exatidão dos resultados em INAA foram calculados utilizando-se a plataforma Action-R 2.6, uma plataforma de livre acesso desenvolvida em $\mathrm{R}$ para Microsoft Excel (PORTAL ACTION, 2015). 


\section{ANÁLISE POR ATIVAÇÃO COM NÊUTRONS}

O método de Análise por Ativação com Nêutrons (NAA) se baseia na produção e posterior identificação de radionuclídeos artificiais a partir de elementos naturalmente estáveis. Esse processo ocorre por meio do bombardeamento com nêutrons no material a ser analisado (amostra), resultando em reações nucleares características para cada elemento. Em NAA, o produto da reação nuclear que é medido é a emissão de raios gama provenientes do decaimento radioativo dos radionuclídeos formados durante o processo de bombardeamento com nêutrons (BODE et al., 2000).

Em outras palavras, em NAA, as amostras são irradiadas sob um fluxo de nêutrons provenientes de um reator nuclear. Esses nêutrons interagem com os núcleos dos nuclídeos dos elementos presentes na amostra formando assim os radionuclídeos. Por sua vez, estes radionuclídeos sofrem processo de decaimento radioativo regido pela constante de decaimento radioativo $(\lambda)$, uma constante relacionada ao tempo de meiavida característico de cada radionuclídeo. O tempo de meia-vida é um parâmetro relacionado unicamente com a configuração nuclear de cada radionuclídeo (disposição de prótons, nêutrons, quarks, etc.). Dependendo da configuração do núcleo, o tempo de meia vida pode ser de milhões de anos ou menor que milissegundo. Os raios gama gerados no processo de decaimento radioativo são medidos em espectrômetro de raios gama (BODE \& GOEIJ, 1998; HAMIDATOU et al., 2013).

No contexto histórico, o primeiro experimento envolvendo a reação de ativação com nêutrons que se tem registro foi realizado por Hevesy e Levi em 1936. Desde então, a NAA progrediu significativamente ao longo dos anos, tornando-se uma técnica analítica de grande versatilidade para grande gama de aplicações (BODE \& GOEIJ, 1998).

Uma das premissas da NAA é a existência de uma fonte geradora de nêutrons. Apesar de alguns isótopos serem excelentes fontes de nêutrons, como por exemplo, o ${ }^{241} \mathrm{Am},{ }^{252} \mathrm{Cf} \mathrm{e}{ }^{235} \mathrm{U}$, as técnicas nucleares obtiveram grande avanço com o desenvolvimento do primeiro grande reator nuclear em meados de 1940. Atualmente é 
impossível pensar-se em NAA sem pensar na existência de um reator nuclear como fonte geradora de nêutrons (HAMIDATOU et al., 2013).

Dentre as principais vantagens do uso de um reator nuclear como fonte geradora de nêutrons para análises de materiais em NAA, tem-se que (IAEA, 2001):

- em um reator nuclear, a taxa de fluência de nêutrons é geralmente alta, fato que favorece a detecção de um grande número de elementos;

- dependendo da posição de irradiação da amostra, diferentes fluxos de nêutrons podem ser obtidos, e estes fluxos podem ser monitorados durante todo o experimento e medidos com boa exatidão;

- existe grande poder de penetração dos nêutrons com fluxo homogêneo em vários tipos de materiais. Desta maneira, materiais de espessura volumosa podem ser analisados;

- a razão entre nêutrons térmicos, epitérmicos e rápidos são muito bem conhecidas em cada uma das posições de irradiação;

- a produção de calor devido às interações sofridas pela amostra é demasiadamente pequena;

- o processo de irradiação das amostras pode ser realizado paralelamente às outras atividades do reator, sem que haja concorrência e/ou ocorrência de interferências.

Genericamente, os nêutrons podem ser classificados de acordo com sua energia como: nêutrons térmicos (cuja energia mais provável de $0,025 \mathrm{eV}$ ), os nêutrons epitérmicos (com energias que vão de $0,55 \mathrm{eV}$ até aproximadamente $1 \mathrm{MeV}$ ) e nêutrons rápidos (com energia maior que $1 \mathrm{MeV}$ ).

Quando o nêutron colide com um núcleo, diversos tipos de reações podem ocorrer, tais como: espalhamento elástico (n, n), espalhamento inelástico (n, n’), captura radioativa $(n, \gamma)$, reações com liberação de partículas $(n, \alpha),(n, p)$ e $(n, 2 n)$, e reações de fissão (n, f). Contudo, os nêutrons térmicos e epitérmicos são os que induzem a reação de captura radioativa $(n, \gamma)$, e por esse motivo são considerados os mais importantes para NAA (IAEA, 2004).

A sequência de eventos que ocorrem numa reação nuclear típica utilizada na análise por ativação com nêutrons se inicia quando um nêutron interage com um núcleo alvo por meio de uma colisão inelástica, formando um núcleo composto num estado excitado. A energia de excitação do núcleo composto é devida à energia de ligação do 
nêutron com o núcleo. O núcleo composto formado quase que instantaneamente adquire uma configuração mais estável por meio da emissão de raios gama prontos. Em muitos casos, esta nova configuração produz um núcleo radioativo que também sofre um decaimento por emissão de raios gama retardados, mas a uma velocidade mais lenta, de acordo com o tempo de meia vida do núcleo radioativo (ALFASSI, 1990).

A Figura 6.1 ilustra a sequência de eventos de uma típica reação de decaimento $(\mathrm{n}, \gamma)$.

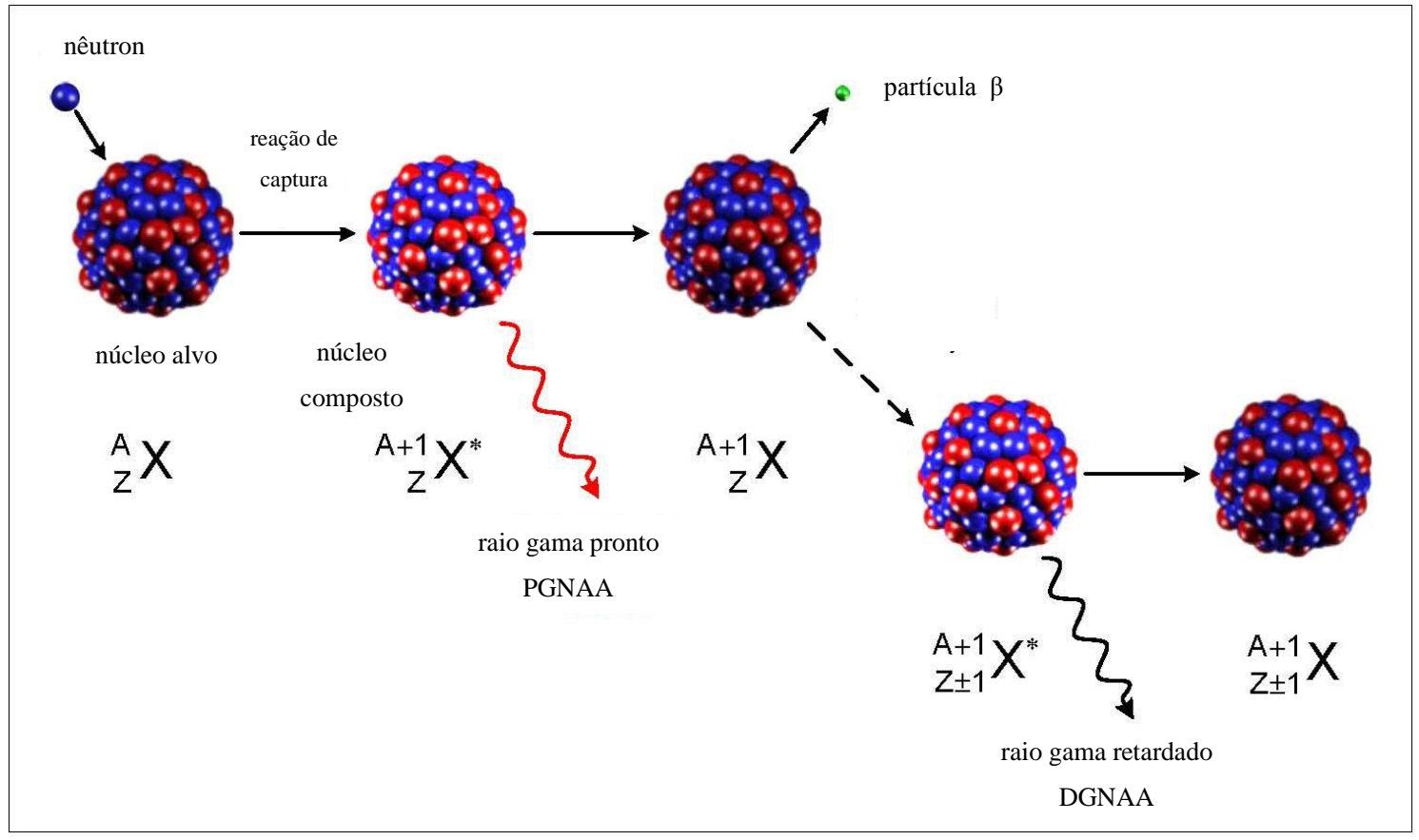

Figura 6.1 Diagrama com a sequência de eventos típicos de uma reação (n, $\gamma)$ (adaptado de HAMIDATOU et al., 2013)

A técnica NAA é sumariamente dividida em função do momento da medição dos raios gama, podendo ser classificada como Análise por Ativação com Nêutrons com detecção por raios gama prontos (PGNAA) ou Análise por Ativação com Nêutrons com detecção por raios gama retardados (DGNAA) ${ }^{1}$. A técnica PGNAA é caracterizada pela necessidade de que a detecção de raios gama seja realizada simultaneamente ao processo de irradiação, uma vez que os raios gama prontos são

\footnotetext{
${ }^{1}$ Do inglês "prompt gamma rays" traduzido como "raios gama prontos" e "delayed gamma rays" traduzido como "raios gama retardados". Neste último caso, também são usados os termos "raios gama atrasados" ou simplesmente "raios gama de decaimento".
} 
gerados milisegundos após a ocorrência da reação de captura (n, $\gamma)$. Por outro lado, análise em DGNAA não possui a necessidade de detecção simultânea, visto que os raios gama retardados, na maioria das vezes, são emitidos por um período de tempo muito maior, sendo este tempo dependente do tempo de meia vida do radionuclídeo gerado (HAMIDATOU et al., 2013).

A técnica PGNAA é geralmente desenvolvida através do uso de um colimador de nêutrons localizado bem próximo ao núcleo do reator. O fluxo típico de um feixe de nêutrons em PGNAA chega a ser da ordem de um milhão de vezes menor que o fluxo obtido em DGNAA. Por esse motivo a técnica PGNAA é mais aplicável para elementos cuja seção de choque de captura para nêutrons seja extremamente alta, como por exemplo para $\mathrm{Cd}, \mathrm{B}, \mathrm{Sm}$ e Gd e para elementos cujo tempo de meia vida impossibilite a análise pelo método DGNAA (HAMIDATOU et al., 2013).

Elementos que produzam apenas um isótopo estável ou que possuem um pico de decaimento por raio gama elevado devem preferencialmente serem analisados por DGNAA. Cerca de $70 \%$ dos elementos da tabela periódica atendem a estes requisitos, podendo ser quantificados com emprego da técnica DGNAA. Isso rotula a técnica como a mais convencional em NAA (HAMIDATOU et al., 2013). Por esse motivo, a técnica DGNAA é muitas vezes citada como somente NAA. A Figura 6.2 ilustra os elementos que podem ser quantificados por DGNAA (elementos com destaque em vermelho).

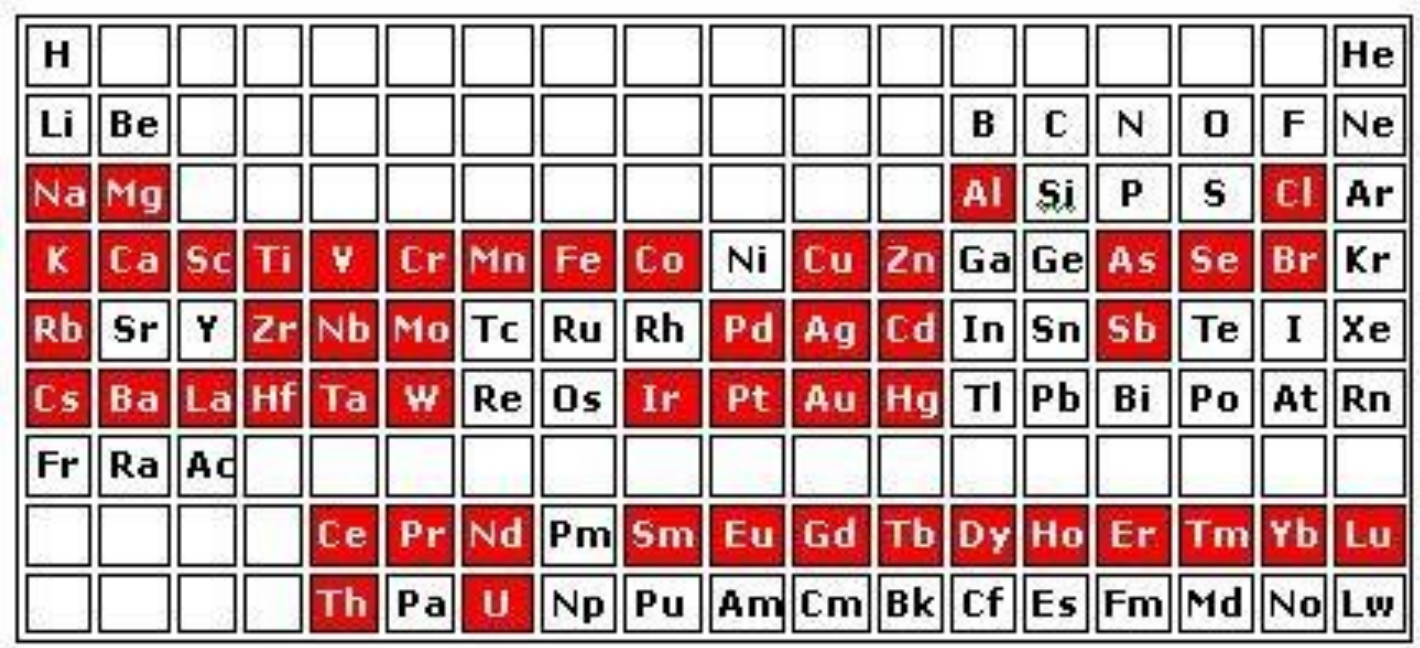

Figura 6.2 Principais elementos (em vermelho) que podem ser quantificados por DGNAA (IPEN, 2015) 
A sensibilidade do método de DGNAA depende do tipo de matriz e dos parâmetros de irradiação (fluxo de nêutrons, tempos de irradiação e de decaimento), condições de medição (tempo de medição e eficiência do detector), parâmetros nucleares dos elementos em estudo (abundância isotópica, seção de choque para nêutrons, meia vida e abundância de raios gama) (BODE et al., 2000).

O sistema de detecção de raios gama é constituído basicamente por um detector semicondutor de germânio hiperpuro (HPGe) associado ao analisador de multi canal (MCA) e a um computador responsável pela análise dos dados obtidos durante o processo de medição, integração da área dos picos analíticos e geração do espectro com os resultados da medição dos raios gama.

Detectores HPGe são bastante úteis para a medição de raios gama com energia entre $60 \mathrm{keV}$ e $3 \mathrm{MeV}$, podendo ser de diversos formatos, dentre os quais o mais comum é o coaxial. As principais características que fizeram do HPGe um dos mais utilizados em NAA dizem respeito à alta resolução e eficiência relativa, que varia entre 20 e $60 \%$. A resolução do detector está relacionada à capacidade em medir e separar os diferentes picos em um menor espaço possível no espectro de raios gama. Normalmente a resolução é avaliada por meio da largura referente à metade da altura do pico analítico (FWHM) para as energias específicas de $122 \mathrm{keV}$ para fonte de ${ }^{57} \mathrm{Co}$ e $1332 \mathrm{keV}$ para fonte de ${ }^{60} \mathrm{Co}$. Para a maioria das aplicações em NAA, um detector com 0,5 keV para a energia $122 \mathrm{keV}$ e 1,8 keV para a energia de $1332 \mathrm{keV}$ reúne características bastante favoráveis para resolução (HAMIDATOU et al., 2013).

Devido a suas características, a técnica de DGNAA foi amplamente difundida em diversos campos de pesquisa, dando origem a diversas outras técnicas que surgiram visando atender a necessidades específicas. Dentre elas, uma assume grande importância para este estudo de validação: a Análise por Ativação com Nêutrons Instrumental (INAA).

INAA é uma técnica multielementar capaz de detectar e quantificar dezenas de elementos em uma única rodada de experimentos, é pouco susceptível à de efeitos de matriz e é considerada técnica não destrutiva, uma vez que não requer processos de digestão das amostras, fato que contribui para a diminuição do risco de contaminação. Apresenta-se ainda uma técnica muito competitiva para a determinação do teor de elementostraço em matrizes ambientais, apresentando elevado nível de exatidão para a medição de muitos elementos (GREENBERG et al., 2011). 
Outra grande vantagem da INAA está no fato da não obrigatoriedade de se analisar o branco analítico, pois não há utilização de reagentes para digestão da amostra, processos de extração ou separação de elementos. Por esse motivo, faz-se seguro afirmar que não há possibilidade de introdução de contaminantes após a irradiação nas amostras, exceto por contaminação de outro material radioativo (HAMIDATOU et al., 2013).

Além disso, outras características importantes da técnica INAA dizem respeito à seletividade e linearidade das medições. Isso porque cada radionuclídeo decai por meio da emissão de radiação gama em um comprimento de onda específico. Além disso, um mesmo radionuclídeo pode possuir diferentes vias de decaimento radioativo, apresentando muitas vezes mais de um pico analítico no espectro de raios gama. Através do uso de dois ou mais picos analíticos, o resultado da medição pode ser comparado para um mesmo radionuclídeo. Havendo ausência de interferências espectrais, o resultado das medições em diferentes picos analíticos para um mesmo radionuclídeo deve sempre coincidir. Estando isso associada à alta resolução característica dos detectores de germânio hiperpuro, a técnica de INAA pode ser considerada muito seletiva (EHMANN \& VANCE, 1991).

A técnica de INAA é linear em todas as faixas de medição, ou seja, independentemente da concentração do mensurando na amostra, esta apresentará correlação linear para a radioatividade induzida com qualquer outro ponto investigado. Isso porque, a radioatividade induzida por um radionuclídeo sempre será proporcional ao número de átomos daquele elemento na amostra. Desta forma, a faixa linear de trabalho em INAA vai 0 até $1 \mathrm{~kg} \mathrm{~kg}^{-1}$ para qualquer mensurando que possa ser quantificado (EHMANN \& VANCE, 1991; BLAAUW \& GELSEMA, 1999; BODE \& BLAAUW, 2012).

Na prática, a linearidade em INAA deixa de ser infinita com a presença de problemas de geometria das amostras e padrões sintéticos, reações interferentes, autoatenuação da radiação gama na amostra, ocorrência de eventos de espalhamento inelástico e pelo fato de que os detectores apresentam diferentes características para a medição de raios gama quando esta apresenta-se próximo ao $L D$ e próximo ao infinito. Podem ocorrer problemas de empilhamento e sobreposição de picos e distorções relacionadas aos efeitos de tempo morto. Desta forma, mesmo em INAA, o correto 
dimensionamento e estudo da faixa linear de trabalho para amostras típicas se faz de grande necessidade.

Outro comentário bastante útil do ponto de vista metrológico é o de que apesar da linearidade comprovada do método de INAA, a incerteza padrão associada a uma faixa de concentração específica pode variar - e muito - ao se comparar os resultados obtidos de uma para outra faixa de concentração. Por isso, especialmente no escopo de validação do método, faz-se de grande importância a definição da faixa de trabalho, ainda que o uso de uma curva analítica não seja requerido.

Entre as desvantagens da técnica estão a dependência da utilização de um reator nuclear, a necessidade de manipulação de material radioativo, a geração de rejeito radioativo e o baixo controle que o analista tem durante o processo experimental, visto que ele só prepara as amostras e padrões e confere os resultados gerados pelo software do cálculo de concentração nas análises. Ainda, pode haver dificuldades no procedimento amostral e na homogeneização das amostras, visto que a técnica requer quantidade pequena de amostra (normalmente entre 0,05 e 0,50 g) para a realização das medições (EHMANN \& VANCE, 1991).

Como limitações da técnica, pode-se citar que alguns elementos de baixo número atômico como $\mathrm{Li}, \mathrm{B}, \mathrm{C}, \mathrm{N}$ e $\mathrm{O}$ apresentam baixa secção de choque para ativação, o que impede sua detecção e quantificação. Ainda, há aquele grupo de elementos caracterizados por tempos de meia vida muito curtos $\left(\mathrm{t}_{1 / 2} \leq 10 \mathrm{~s}\right)$, fato que impossibilita a realização do processo analítico ou requer arranjos experimentais específicos para a obtenção de resultados exatos. Além disso, a técnica INAA não permite a identificação direta da forma química em que um elemento é encontrado na amostra por se tratar de um método baseado em reações que acontecem no nível do núcleo atômico e não de sua eletrosfera (ALFASSI, 1990; HAMIDATOU et al., 2013).

A técnica INAA é dividida em dois métodos distintos: o método absoluto e método comparativo. A medição pelo método absoluto leva em consideração diversos fatores nucleares, tais como fluxo de nêutrons, razão entre nêutrons térmicos / epitérmicos, secção de choque de captura para formação do radionuclídeo, a probabilidade da ocorrência de reações interferentes, a fluência do fluxo de nêutrons, abundância isotópica do núcleo alvo, dentre muitos outros. Greenberg e colaboradores (2011), descrevem passo a passo todos os fatores inclusos no cálculo para a 
determinação da concentração dos mensurandos na amostra por meio do método absoluto em INAA.

A Equação 22 apresenta a relação entre a atividade induzida em INAA e os diversos parâmetros envolvidos no processo de irradiação, sendo utilizada para o cálculo da concentração de um mensurando na amostra por meio do método absoluto de INAA (DE SOETE et al., 1972). Esta fórmula será importante para a definição do método comparativo.

$$
A=\frac{z \emptyset \sigma N m f\left[1-e^{\left(-0,693 \frac{t}{t_{1 / 2}}\right)}\right]}{M}
$$

onde:

$A$ é a atividade induzida do nuclídeo do mensurando na amostra (cps);

$z$ é a eficiência do detector;

$\varnothing$ é o fluxo de nêutrons $\left(\mathrm{m}^{-2} \mathrm{~s}^{-1}\right)$;

$\sigma$ é a secção de choque para captura de nêutrons $\left(\mathrm{m}^{2}\right)$;

$N$ é o número de Avogadro, $\left(6,0210^{23}\right)$;

$m$ é a massa do mensurando na amostra (mg);

$f$ é a abundância isotópica do nuclídeo alvo;

té o tempo de irradiação da amostra (s);

$t_{1 / 2}$ é o tempo de meia vida do radionuclídeo (s);

$M$ é a massa molar do mensurando $\left(\mathrm{mg} \mathrm{mol}^{-1}\right)$.

O método comparativo de INAA, o mesmo utilizado neste trabalho de validação, consiste na irradiação da amostra e do padrão sintético (no qual a concentração do mensurando é conhecida) de maneira simultânea, em um mesma geometria de espaço e de fluxo de nêutrons. Após o período de decaimento apropriado, realiza-se a medição do espectro de raios gama na amostra e no padrão sintético numa mesma configuração de detecção e em um mesmo detector. A determinação da concentração do mensurando na amostra é calculada por meio da comparação da área dos picos (atividade) obtidos para amostra e padrão sintético (EHMANN \& VANCE, 1991). 
A grande dificuldade para a utilização do método absoluto de INAA é a limitação para uma correta estimativa do fluxo de nêutrons incidente na amostra, visto que este parâmetro pode variar durante o período de irradiação e a sua correta estimativa é fundamental para o cálculo preciso da concentração (GREENBERG et al., 2011).

Por outro lado, o método comparativo de INAA independe destes parâmetros cuja estimativa correta ainda é incerta, pois parte do princípio de que a relação entre a atividade da amostra e do padrão sintético depende exclusivamente da massa do mensurando (GREENBERG et al., 2011). Desta forma, obtém-se a seguinte relação exposta nas Equações 23 e 24.

$$
\begin{aligned}
& A_{a}= \frac{z \emptyset \sigma N m_{a} f\left[1-e^{\left(-0,693 \frac{t}{t_{1 / 2}}\right)}\right]}{M} \\
& A_{p}=\frac{z \emptyset \sigma N m_{p} f\left[1-e^{\left(-0,693 \frac{t}{t_{1 / 2}}\right)}\right]}{M}
\end{aligned}
$$

onde:

$A_{a}$ é a atividade induzida do mensurando na amostra (cps);

$m_{a}$ é a massa do mensurando na amostra (mg);

$A_{p}$ é a atividade induzida do mensurando no padrão sintético (cps);

$m_{p}$ é a massa do mensurando no padrão sintético (mg).

Visando facilitar a representação dos próximos passos, assume-se que:

$$
D=\left[1-e^{\left(-0,693 \frac{t}{t_{1 / 2}}\right)}\right]
$$

Fazendo-se a razão das Equações 23 e 24 e substituindo-se o termo da Equação 25 tem-se o seguinte cenário expresso nas Equações 26 e 27: 


$$
\begin{gathered}
\frac{A_{a}}{A_{p}}=\frac{\left(\frac{z \emptyset \sigma N m_{a} f D}{M}\right)}{\left(\frac{z \emptyset \sigma N m_{p} f D}{M}\right)} \\
\frac{A_{a}}{A_{p}}=\frac{z \emptyset \sigma N m_{a} f D M}{M z \emptyset \sigma N m_{p} f D}
\end{gathered}
$$

Nesta etapa, os parâmetros $z, \emptyset, \sigma, N, f, D$ e $M$ se anulam, uma vez que amostra e padrão sintético são irradiados em um único processo e sob as mesmas condições. Desta forma, chega-se a Equação 28.

$$
\frac{A_{a}}{A_{p}}=\frac{m_{a}}{m_{p}}
$$

Reorganizando-se os parâmetros para que a massa do mensurando na amostra fique em evidência, tem-se que:

$$
\begin{gathered}
A_{a} m_{p}=A_{p} m_{a} \\
m_{a}=\frac{A_{a} m_{p}}{A_{p}}
\end{gathered}
$$

De acordo com a lei de decaimento radioativo (Eq.31), e substituindo-se os termos da Equação 31 na Equação 30 é chega-se Equação 32. Esse tipo de arranjo se faz necessário uma vez que o processo de medição da atividade do radionuclídeo na amostra e padrão não pode ser realizado de maneira simultânea, visto que deve ser realizado em um mesmo espectrômetro de raios gama.

$$
\begin{gathered}
A=A_{0} e^{\lambda t} \\
m_{a}=\frac{m_{p} A_{a} e^{\lambda t a}}{A_{p} e^{\lambda t p}}
\end{gathered}
$$

onde: 
$A$ é a atividade para o tempo de decaimento $t(\mathrm{cps})$;

$A_{0}$ é a atividade para o tempo de decaimento $t=0(\mathrm{cps})$;

$A_{\mathrm{a}}$ é a atividade do radionuclídeo na amostra para o tempo de decaimento $t$ (cps);

$A_{\mathrm{p}}$ é a atividade do radionuclídeo no padrão para o tempo de decaimento $t$ (cps);

$\lambda$ é a constante de decaimento do radionuclídeo, $\lambda=\frac{\ln (2)}{\mathrm{t}_{1 / 2}}\left(\mathrm{~s}^{-1}\right)$;

$t_{a}$ é o tempo de decaimento do radionuclídeo até o momento início da medição da amostra (s);

$t_{p}$ é o tempo de decaimento do radionuclídeo até o início da medição do padrão (s); $t$ é o tempo de decaimento no momento da medição (s)

Rearranjando os termos da Equação 32, chega-se a Equação 33.

$$
m_{a}=\frac{m_{p} A_{a} e^{\lambda(t a-t p)}}{A_{p}}
$$

Contudo, não é desejado obter-se a massa de mensurando na amostra, e sim a concentração do mensurando na amostra. Para isso, faz-se necessária a substituição do termo da Equação 34 na Equação 33.

$$
C_{a}=\frac{m_{a}}{M_{a}}
$$

onde:

$C_{a}$ é a concentração do mensurando na amostra $\left(\mathrm{mg} \mathrm{kg}^{-1}\right)$;

$m_{a}$ é a massa do mensurando na amostra (mg);

$M_{a}$ é a massa da amostra $(\mathrm{kg})$;

Substituindo-se a Equação 34 na Equação 33, chega-se a equação fundamental do método comparativo de INAA (Eq. 35).

$$
C_{a}=\frac{m_{p} A_{a} e^{\lambda(t a-t p)}}{A_{p} M_{a}}
$$


onde:

$C$ é a concentração do mensurando na amostra $\left(\mathrm{mg} \mathrm{kg}^{-1}\right)$;

$m_{p}$ é a massa do mensurando no padrão (mg);

$A_{a}$ é a atividade do radionuclídeo na amostra (cps);

$\lambda$ é a constante de decaimento do radionuclídeo $\left(\mathrm{s}^{-1}\right)$;

$t_{a}$ é o tempo de decaimento do radionuclídeo na medição da amostra (s);

$t_{p}$ é o tempo de decaimento do radionuclídeo na medição do padrão (s);

$M_{a}$ é a massa da amostra $(\mathrm{kg})$;

$A_{p}$ é a atividade do radionuclídeo no padrão sintético para tempo de decaimento tp (cps).

\subsection{Principais aplicações do método comparativo de INAA}

As principais aplicações para a técnica de INAA estão relacionadas com estudos que envolvem matrizes ambientais. Contudo, pode-se destacar pelo menos quatro grandes áreas onde a técnica de INAA é empregada (EHMAN \& VANCE, 1991; IAEA, 2001; HAMIDATOU et al., 2013):

- Arqueologia: amostras e objetos, tais como âmbar, ossos, cerâmicas, moedas, jóias, artefatos de metal, esculturas, argamassas, pinturas, pigmentos, matérias-primas, solos, argilas e artefatos de pedra podem ter sua composição investigada pelo emprego do método comparativo de INAA;

- Biomedicina: investigação da composição de tecidos humanos e de animais, análise elementar de componentes biliares, sanguíneos, sangue, osso, cérebro, tecido da mama, tecidos cancerosos, cólon, fluidos de diálise, drogas e medicamentos, olho, fezes, feto, cálculos biliares, cabelo, implantes, rins, fígado, pulmão, plantas medicinais e ervas, leite, músculos, unhas, placenta, caracterização de venenos, tecidos de ratos (normais e doentes), dentes, esmalte dentário, obturações dentárias, entre muitas outras;

- Meio ambiente: análise de monitoramento ambiental (ativo e passivo) no ar, água, solo e sedimento, caracterização de poluentes, poluição de fontes hídricas, estudo de combustíveis fósseis, caracterização de frutos e sementes, estudos de biomonitoramento em pescados, moluscos, insetos, plantas, fungos e líquens, estudos que envolvem a 
dinâmica de poluentes no ar, água, solo e sedimento, precipitação da chuva, dentre outras.

- Qualidade: estudos voltados para a área da Qualidade envolvem o desenvolvimento de novos processos e produtos, caracterização das fontes de incerteza, estabelecimento de padrões de segurança, estudos de fiscalização e conformidade de dados, caracterização do teor de mensurandos na produção de MRC, entre outros.

Ainda, a INAA é empregada para o estudo e caracterização de rochas e artefatos extraterrestres, na construção civil, na indústria aeroespacial, entre outras.

Falando-se exclusivamente da caracterização do teor de mensurando para a produção de MRC, faz-se importante citar que o método comparativo de INAA foi reconhecido pelo Comitê Consultivo para Quantidade de Matéria (CCQM) pelo alto grau de qualidade analítica, tendo sido reconhecido como um potencial método primário de medição (GREENBERG et al., 2011).

Dentro dessa linha de pesquisa, o LAN tem se destacado pela produção de diversos MRC nos últimos anos. Entre 2005 e 2010, MOREIRA (2010) desenvolveu sua tese de doutoramento que consistiu na produção de um MRC de tecido de mexilhão. Entre 2009 e 2013 o grupo de pesquisadores do LAN participou o projeto de cooperação técnica da Agência Internacional de Energia Atômica (IAEA) voltado para a América Latina, o RLA/2/014 (ARCAL XCVII) para produzir um MRC de tecido de peixe (IAEA, 2010).

Atualmente, CASTRO e colaboradores (2014) estão desenvolvendo um trabalho de preparo e caracterização de MRC de rim bovino. Desta forma, este trabalho de mestrado foi idealizado para propiciar parte do suporte técnico necessário para a produção de novos MRCs em matriz biológica e/ou geológica. 


\section{PARTE EXPERIMENTAL}

A parte experimental deste trabalho consistiu no(a):

- Delineamento dos mensurandos e matrizes;

- Delineamento dos métodos de medição;

- Delineamento dos MRCs utilizados nos experimentos do escopo de validação;

- Realização de ensaios preliminares (verificação da calibração das micropipetas e balões volumétricos);

- Preparo das amostras e dos padrões sintéticos;

- Otimização univariada de alguns componentes dos métodos de medição para os mensurandos nas matrizes de interesse (estudo dos padrões sintéticos);

- Otimização multivariada dos métodos de medição para os mensurandos nas matrizes de interesse (DOE);

- Realização dos experimentos do escopo de validação dos métodos de medição;

- Estimativa da contribuição das principais fontes de incerteza em INAA;

- Confecção dos documentos da Qualidade.

\subsection{Delineamento dos mensurandos e matrizes}

Este estudo foi embasado nas respostas dos pesquisadores às perguntas desenvolvidas na carta-formulário (Anexo 1). Foram convidados para participação dez pesquisadores do LAN. O único requisito para a participação neste estudo foi o de que o pesquisador utilizasse rotineiramente a técnica INAA para o desenvolvimento de seus trabalhos. Todos os pesquisadores participantes foram convidados pessoalmente e a cada um deles foi entregue uma cópia em papel da carta-formulário. Uma versão online deste documento também foi disponibilizada.

A partir das respostas informadas por todos os pesquisadores, foi gerado um relatório descrevendo sobre os mensurandos mais importantes, as matrizes mais 
analisadas, as condições experimentais mais utilizadas, as principais dificuldades analíticas e com as sugestões para a realização deste trabalho de validação.

Os resultados obtidos neste questionário serviram como ponto de partida para o delineamento dos métodos de medição. Conhecendo-se os mensurandos mais importantes, as matrizes de maior interesse, dentre outros, buscou-se o desenvolvimento de estratégias que contemplem a real necessidade da maioria dos pesquisadores do LAN que trabalham rotineiramente com INAA.

\subsection{Delineamento dos métodos de medição}

Os métodos de medição a serem submetidos ao processo de validação analítica foram:

- Método-BIO-1: determinação da concentração total de As em amostras de matriz biológica;

- Método-BIO-2: determinação da concentração total de $\mathrm{Co}, \mathrm{Cr}, \mathrm{Fe}, \mathrm{Rb}, \mathrm{Sc}, \mathrm{Se}$ e $\mathrm{Zn}$ em amostras de matriz biológica;

- Método-GEO-1: determinação da concentração total de As e Sb em amostras de matriz geológica;

- Método-GEO-2: determinação da concentração total de $\mathrm{Co}, \mathrm{Cr}, \mathrm{Fe}, \mathrm{Sc}$ e $\mathrm{Zn}$ em amostras de matriz geológica.

\subsection{Delineamento dos MRCs}

O delineamento dos MRCs utilizados foi feito de acordo com alguns critérios:

- O MRC utilizado no escopo de validação do método deverá conter obrigatoriamente todos os mensurandos com o valor para concentração certificado e incerteza expandida de medição $(U, k=2)$;

- A concentração dos mensurandos no MRC deve ser da mesma ordem de grandeza das amostras analisadas pelos pesquisadores do LAN;

- O MRC deve estar à disposição no LAN e em quantidade suficiente para a realização deste trabalho (não havendo a necessidade de compra de um novo MRC);

- O MRC deve estar dentro do prazo de validade; 
- As unidades apresentadas no MRC devem ser rastreáveis ao Sistema Internacional de Medição (SI).

\subsection{Ensaios preliminares}

Todos os equipamentos e instrumentos utilizados possuem o certificado de calibração emitido por um órgão autorizado. De acordo com as exigências da norma ABNT NBR ISO/IEC 17025 (ABNT, 2006), este fato por si só já é suficiente para a comprovação de que o valor de referência atribuído para tal equipamento é correto e garante rastreabilidade ao SI. Contudo, no dia a dia, estes equipamentos estão sujeitos as mais adversas situações, podendo haver a alteração do valor de referência entre um procedimento de calibração e outro. Esta informação é investigada por meio de um procedimento de verificação da calibração do equipamento, que deve ser realizado dentro de intervalos mais curtos, visando a garantia de que o equipamento utilizado atenda às condições descritas pelo certificado de calibração.

\subsubsection{Verificação da calibração dos balões volumétricos}

Realizou-se a verificação da calibração dos balões volumétricos classe A $B V-A L R$ 6830/10 e BV - ALR 6831/10 da marca Pyrex. De acordo com o certificado de calibração, o volume nominal deste balões é $10,00 \pm 0,01 \mathrm{~mL}$.

Os balões volumétricos foram inicialmente submetidos a um procedimento de limpeza. Para isso foram mantidos por 24 horas em solução de $\mathrm{HNO}_{3} 10 \%$ (v/v) e enxaguados em $\mathrm{H}_{2} \mathrm{O}$ destilada. A parte externa foi previamente lavada com detergente neutro $2 \%$ (v/v) (Extran) e enxaguada com $\mathrm{H}_{2} \mathrm{O}$ destilada. Para secagem, os balões foram acondicionados com a boca para baixo dentro de um béquer forrado com papel absorvente por um período entre 48 e 72 horas.

Para a verificação da calibração, efetuou-se uma primeira pesagem do balão volumétrico previamente lavado, seco e vazio em balança analítica Shimadzu AEL-40SM. Anotou-se a massa.

Acondicionou-se cerca de $50 \mathrm{~mL}$ de água deionizada (Milli - Q, Millipore; $18,2 \mathrm{~m} \Omega$ ) em um béquer previamente limpo e seco por um período de 3 horas para a ocorrência do equilíbrio térmico entre água do béquer e a temperatura da sala. 
Posteriormente, o balão volumétrico foi preenchido com água deionizada (Milli - Q, Millipore; 18,2 $\mathrm{m} \Omega$ ) até próximo à marcação do menisco (Figura 7.1). Com o auxílio de um termômetro, mediu-se a temperatura da água e registrou-a para cálculos posteriores. Utilizou-se uma pipeta Pasteur de plástico para completar-se o volume de água até o menisco. Quando necessário, secou-se a área interna do balão acima do menisco com papel absorvente, visando-se remover gotículas de água que pudessem estar adsorvidas à parede interna do balão. Pesou-se o balão volumétrico em balança analítica e anotou-se o valor da massa (KENNEDY, 1990).

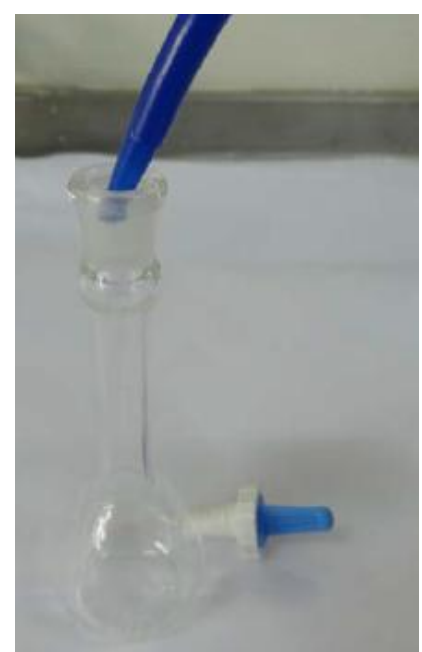

Figura 7.1. Representação da adição de $\mathrm{H}_{2} \mathrm{O}$ no balão volumétrico para o procedimento de verificação

Com exceção à etapa de lavagem, repetiu-se o procedimento por mais nove vezes para cada balão verificado $(n=10)$.

Para o cálculo do volume de verificação (Equação 36), aplicou-se o fator de correção do coeficiente de expansão térmica da água para cada medição obtida (HARRIS, 1996). Calculou-se a média dos valores corrigidos em função da temperatura no momento da medição e expressou-se o resultado como a média \pm desvio padrão dos dez valores corrigidos.

$$
V_{B}=\frac{\left(m_{1} f c_{1}+\cdots m_{n} f c_{n}\right)}{n}
$$

onde:

$V_{B}$ é média dos resultados corrigidos para $n$ verificações; 
$m_{1}$ é a massa de água obtida no experimento 1 ;

$f c_{1}$ é o fator de correção correspondente ao experimento 1 ;

$m_{n}$ é a massa de água obtida no experimento $n$;

$f c_{n}$ é o fator de correção correspondente ao experimento $n$;

$n$ é o número de experimentos realizados $(n=10)$

Os resultados obtidos para cada experimento foram avalidaos em função da média de $n$ medições. Resultados foram considerados outliers quando obtido valor para erro da medição maior que $0,3 \%$.

\subsubsection{Verificação da calibração de micropipetas}

Para a verificação da calibração das micropipetas para diversos volumes, acondicionou-se $\mathrm{H}_{2} \mathrm{O}$ deionizada (Milli - Q, Millipore; 18,2 $\mathrm{m} \Omega$ ) em um béquer de $50 \mathrm{~mL}$ previamente limpo e seco por período de 3 horas para ocorrência do equilíbrio térmico entre água e temperatura da sala. Durante esse período, o béquer permaneceu tampado com um vidro de relógio de $5 \mathrm{~cm}$ de diâmetro.

Os volumes nominais de verificação de interesse foram: $25 \mu \mathrm{L}, 50 \mu \mathrm{L}$, $100 \mu \mathrm{L}, 500 \mu \mathrm{L}, 1000 \mu \mathrm{L}, 2000 \mu \mathrm{L}$ e $4000 \mu \mathrm{L}$, Para a contemplação da utilização nesta ampla faixa de volumes, foi necessária a verificação em três micropipetas diferentes, identificadas como Eppendorf 20-200, Eppendorf 100-1000 e Eppendorf 1000-10000.

A um béquer de $10 \mathrm{~mL}$ adicionou-se aproximadamente $1 \mathrm{~mL}$ de água utilizada no procedimento. Colocou-se o béquer no interior da balança analítica Shimadzu AEL-40SM. Anotou-se a massa correspondente.

Pegou-se a micropipeta e selecionou-se o volume de interesse para realizarse a verificação. Acoplou-se a ponteira adequada a micropipeta, submergiu-a entre $5 \mathrm{~mm}$ e $10 \mathrm{~mm}$ no béquer de $50 \mathrm{~mL}$ contendo água. Pressionou-se o êmbolo da micropipeta até o final e soltou-se de forma adequada para que o líquido fosse recolhido. Repetiu-se por 3 vezes esse procedimento.

Pressionou-se novamente o êmbolo da micropipeta até o final e recolheu-se o volume equivalente. Liberou-se o conteúdo no béquer alocado na balança, fazendo-se escorrer o conteúdo pela parede interna do mesmo. Após o término da operação, manteve-se a ponta da ponteira encostada na parede do béquer por aproximadamente 5 
segundos. Anotou-se a massa correspondente. Para cada volume verificado, repetiu-se por 10 vezes o procedimento descrito $(n=10)$.

A água utilizada teve sua temperatura medida com termômetro durante o processo experimental e sua temperatura registrada ao final de cada ciclo de 10 repetições. Para o cálculo do volume de verificação para cada configuração investigada utilizou-se a Equação 37.

$$
V_{M}=\frac{\left[\left(m_{1}-b\right) f c_{1}+\left(m_{2}-m_{1}\right) f c_{2}+\left(m_{n-1}-m_{n}\right) f c_{n}\right]}{n}
$$

onde:

$V_{M}$ é média dos resultados corrigidos para $n$ verificações;

$m_{1}$ é a massa de água obtida no experimento 1 ;

$b$ é a massa do béquer com aproximadamente $1 \mathrm{~mL}$ de $\mathrm{H}_{2} \mathrm{O}$;

$f c_{1}$ é o fator de correção correspondente ao experimento 1 ;

$m_{2}$ é a massa de água obtida no experimento 2;

$f c_{2}$ é o fator de correção correspondente ao experimento 2;

$m_{n}$ é a massa de água obtida no experimento $n$;

$f c_{n}$ é o fator de correção correspondente ao experimento $n$;

$n$ é o número de experimentos realizados $(n=10)$

\subsection{Preparo das amostras e padrões sintéticos}

\subsubsection{Lavagem e confecção dos invólucros de polietileno}

As folhas de polietileno utilizadas para o preparo dos invólucros dispensados ao acondicionamento das amostras e padrões foram previamente lavadas em solução de $\mathrm{HNO}_{3} 10 \%$ (v/v) por um período de 48 horas, enxaguadas com $\mathrm{H}_{2} \mathrm{O}$ destilada e deionizada (Milli - Q, Millipore; 18,2 $\mathrm{m} \Omega$ ) e secas em temperatura ambiente em capela de fluxo laminar da marca TROX, modelo Technik.

Os invólucros foram confeccionados utilizando-se a seladora SelaPack em geometria retangular de $1 \mathrm{~cm}$ de largura por $1,5 \mathrm{~cm}$ de comprimento selado em todas as extremidades. Os invólucros foram armazenados em frasco devidamente identificado e mantidos ao abrigo da luz solar e emtemperatura ambiente até o momento de sua utilização. 


\subsubsection{Preparo das amostras}

O procedimento para o preparo das amostras consistiu em pesar diversas alíquotas com $155 \pm 10 \mathrm{mg}$ de cada um dos MRCs diretamente no interior do invólucro de polietileno e selar a extremidade aberta com seladora SelaPack. Anotou-se a referência da amostra na parte externa do invólucro utilizando-se uma caneta hidrográfica de tinta azul. Armazenou-o em recipiente plástico devidamente identificado, protegido de luz solar e sob temperatura ambiente até a realização das irradiações. A Tabela 7.1 apresenta os MRCs de matriz biológica e geológica utilizados neste estudo de validação em INAA.

Tabela 7.1.MRCs para matriz biológica e geológica

\begin{tabular}{cc}
\hline Matriz Biológica & Matriz Geológica \\
\hline IPEN TM-1, Tecido de mexilhão & NIST SRM 2702, Marine sediment \\
(IPEN - CNEN/SP) & (NIST) \\
NIST SRM 2976, Mussel tissue & NIST SRM 1646a, Estuarine sediment \\
(NIST) & (NIST) \\
NIST SRM 1566b, Oyster tissue & NRCC MESS 3, Marine sediment \\
(NIST) & (NRCC) \\
IAEA 407, Fish tissue & (NIST) \\
(IAEA) & BIST SRM 8704, Buffalo River sediment \\
NRCC DORM 2, Dogfish Muscle & Estuarine sediment \\
(NRCC)
\end{tabular}

Para a determinação do teor de umidade em cada MRC, levou-se o pesafiltro à estufa Fanem Orion $515 \mathrm{C}$ sob temperatura adequada por 24 horas. Acondicionou-se em dessecador de vidro por 1 hora e pesou-se em balança analítica Shimadzu AEL-40SM. Anotou-se a massa. Pesou-se dentro do pesa-filtro aproximadamente $1 \mathrm{~g}$ de amostra (MRC). Levou-se à estufa em temperatura adequada por 24 horas (A temperatura utilizada no procedimento de determinação do teor de umidade para amostras biológicas foi $85{ }^{\circ} \mathrm{C}$ e para amostras geológicas $105{ }^{\circ} \mathrm{C}$ ). 
Acondicionou-se o sistema pesa-filtro-amostra em dessecador de vidro por 1 hora. Pesou-se em balança analítica Shimadzu AEL-40SM. Anotou-se a massa. O teor de umidade para as amostras foi calculado conforme a Equação 38.

$$
W=\frac{100\left(m_{f}-m_{T}\right)}{\left(m_{i}-m_{T}\right)}
$$

onde:

$W=$ teor de umidade na amostra $(\%)$;

$m_{i}=$ massa antes do procedimento de secagem do $\operatorname{MRC~}(\mathrm{g}) ;$

$m_{f}=$ massa após o procedimento de secagem do MRC (g);

$m_{T}=$ massa de tara do pesa-filtro $(\mathrm{g})$.

O procedimento foi realizado em triplicata para cada MRC utilizado e o resultado final expresso como média \pm desvio padrão das triplicatas.

\subsubsection{Preparo dos padrões sintéticos}

Os padrões foram preparados através da diluição de MRCs monoelementar da marca Spex. Para tanto, retirou-se uma alíquota de cada MRC e pipetou-se a quantidade adequada de solução $(1,0 \mathrm{~mL}$ para $\mathrm{As} ; 0,5 \mathrm{~mL}$ para $\mathrm{Sb} ; 1,0 \mathrm{~mL}$ para $\mathrm{Co} ; 2,0$ $\mathrm{mL}$ para $\mathrm{Cr} ; 3,0 \mathrm{~mL}$ para $\mathrm{Rb}$; 0,1 $\mathrm{mL}$ para Sc; 0,1 mL para Se e 1,0 mL para $\mathrm{Zn}$ ) em um balão volumétrico de 10,00 \pm 0,01 $\mathrm{mL}$. Em seguida, completou-se o volume com $\mathrm{H}_{2} \mathrm{O}$ purificada (Milli - Q, Millipore; 18,2 m ). Para o mensurando Fe, não realizou-se a diluição do MRC, uma vez que se faz necessária uma elevada massa para o mensurando no padrão sintético, visto que a abundância isotópica do ${ }^{58} \mathrm{Fe}$ é de apenas $0,28 \%$ e a

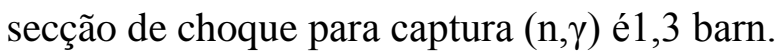

Neste trabalho, optou-se por trabalhar com duas configurações de padrão sintético, uma monoelementar e outra multielementar. Padrões sintéticos multielementares foram preparados de acordo com cada método de medição. Assim sendo, preparou-se um padrão multielementar para o método $B I O-2$, outro para o método GEO-1 e outro para o método GEO-2, cada qual contendo somente os mensurandos pertencentes ao respectivo método de medição. Não foi verificado nenhum problema de homogeneização durante o preparo dos padrões sintéticos e a 
massa de um mensurando contida no padrão sintético é mesma para o respectivo mensurando nos padrões utilizados em diferentes métodos. A Tabela 7.2 apresenta a referência para cada MRC utilizado no preparo e confecção dos padrões sintéticos.

Tabela 7.2. Lista dos MRCs utilizados na confecção dos padrões sintéticos

\begin{tabular}{cccc}
\hline Mensurando & Fabricante & Lote & ${\text { Concentração }\left(\mathrm{mg} \mathrm{L}^{-1}\right)^{*}}^{*}$ \\
\hline $\mathrm{As}$ & Spex & $16-97 \mathrm{AS}$ & $1001 \pm 3,0$ \\
$\mathrm{Co}$ & Spex & $14-41 \mathrm{CO}$ & $1002 \pm 3,0$ \\
$\mathrm{Cr}$ & Spex & $14-93 \mathrm{CR}$ & $1005 \pm 3,0$ \\
$\mathrm{Fe}$ & Spex & AF14-55FE & $10008 \pm 30$ \\
$\mathrm{Rb}$ & Spex & $14-134 \mathrm{RB}$ & $999 \pm 3,0$ \\
$\mathrm{Sb}$ & Spex & $17-64 \mathrm{SB}$ & $1001 \pm 3,0$ \\
$\mathrm{Sc}$ & Spex & $15-63 \mathrm{SC}$ & $1000 \pm 3,0$ \\
$\mathrm{Se}$ & Spex & X11-18SE & $10004 \pm 30$ \\
$\mathrm{Zn}$ & Spex & Y11-84ZN & $10011 \pm 30$ \\
\hline
\end{tabular}

* incerteza corresponde à incerteza expandida, $k=2$

Os papéis de filtro necessários para o preparo dos padrões analíticos foram confeccionados manualmente por meio do recorte de folhas de papel de filtro Whatman $\mathrm{n}^{\circ} 41$. Visando-se obter uma mesma geometria, fez-se os recortes em formato retangular medindo $30 \mathrm{~mm}$ x $16 \mathrm{~mm}$ (Figura 7.2).

Para a realização da pipetagem, papéis de filtro recortados em tamanho adequado foram cuidadosamente posicionados em estruturas chamadas de "estantes". Cada uma das "estantes" foram confeccionadas utilizando-se 2 baguetas de vidro de mesmo tamanho. Para tanto, encosta-se e alinha-se as duas baguetas paralelamente e prende-se cada uma das extremidades (direita e esquerda) com um pedaço de fita adesiva. A seguir, pipetou-se nos recortes de papel-filtro entre $25 \mu \mathrm{L}$ e $50 \mu \mathrm{L}$ da solução de trabalho com os mensurandos de interesse ${ }^{2}$.

\footnotetext{
${ }^{2}$ Pipetou-se o volume de $25 \mu \mathrm{L}$ para a solução preparada com o(s) mensurando(s) por meio de diluição em balão volumétrico e pipetou-se o volume de $50 \mu \mathrm{L}$ para solução não diluída do MRC de Fe (nos padrões sintéticos em que este se faz necessário).
} 


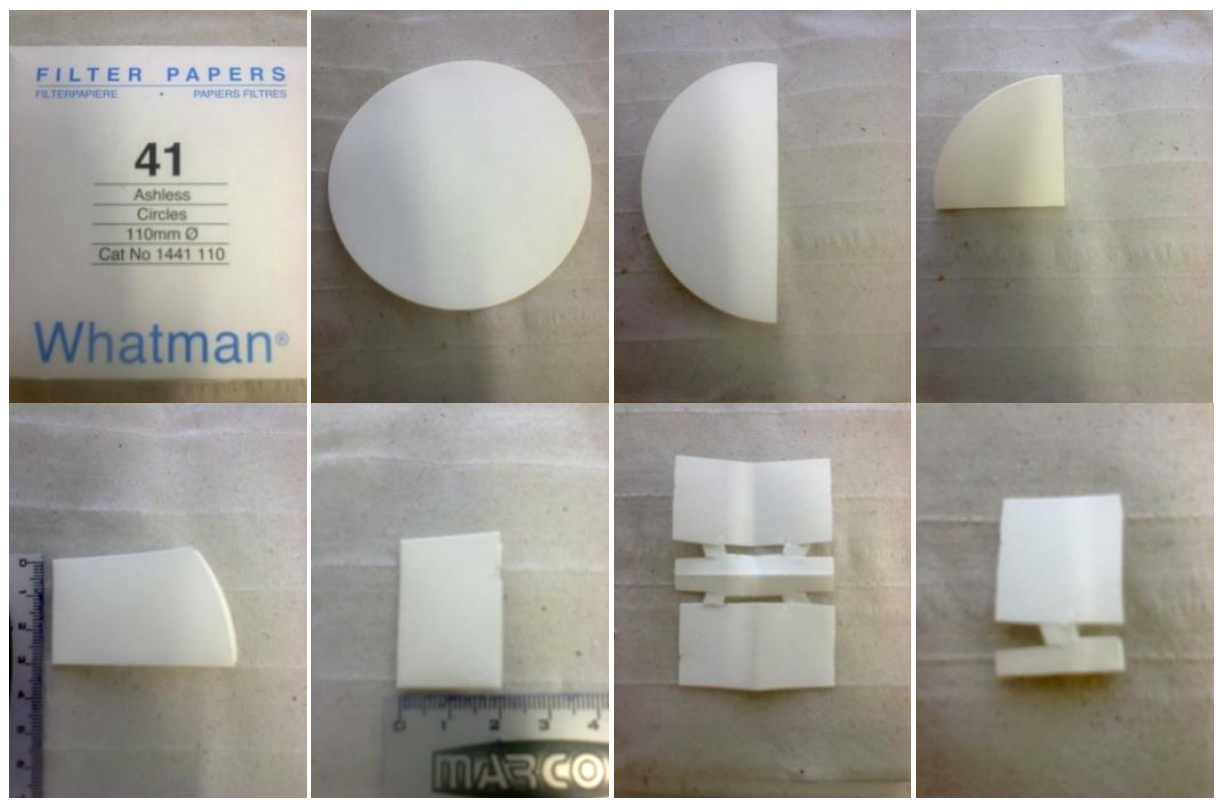

Figura 7.2. Representação do processo de confecção dos papéis filtro

Aguardou-se um período entre $4 \mathrm{~h}$ e $12 \mathrm{~h}$ para a total evaporação do solvente (água). Nesse período, os padrões analíticos foram mantidos nas estantes no interior de uma capela de fluxo laminar, ao abrigo da luz solar e sob temperatura ambiente.

Com o auxílio de uma pinça com as extremidades protegidas com película plástica (Parafilm) para não entrarem em contato direto com o papel de fitro, retirou-se o papel-filtro da estante, recortou-se cerca de $10 \mathrm{~mm}$ da parte inferior (mais próxima da base da estante) e descartou-a. O papel foi dobrado ao meio uma vez no sentido vertical e uma vez no sentido horizontal, resultando em uma geometria de volume de $10 \mathrm{~mm} \times 8$ $\mathrm{mm} \times 1 \mathrm{~mm}$. Introduziu-se o papel de filtro dobrado a um invólucro de polietileno previamente preparado e selou-o em seladora SelaPack. Os padrões foram armazenados em recipientes plásticos devidamente identificados, protegidos da luz solar e sob temperatura ambiente até momentos antes da análise. A Tabela 7.3 apresenta a massa dos mensurandos contida nos padrões sintéticos. 

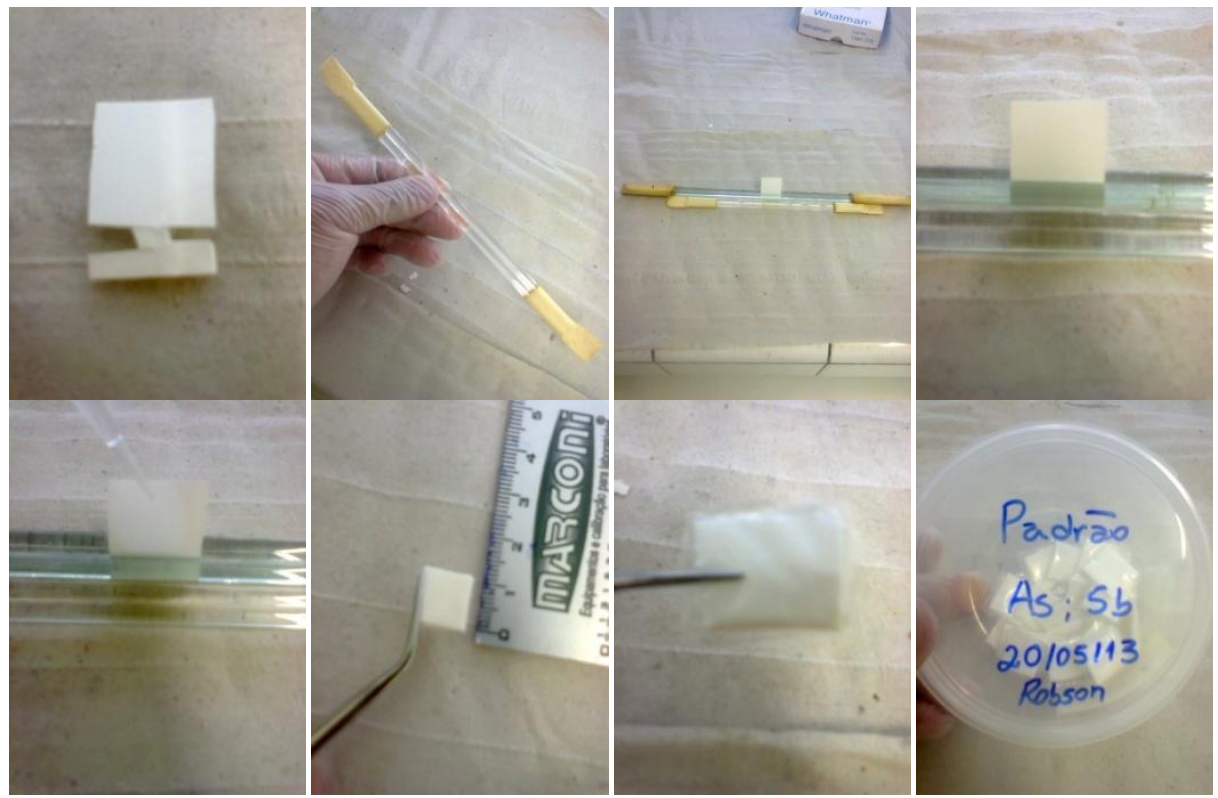

Figura 7.3. Representação do processo de preparo dos padrões sintéticos

Tabela 7.3.Massa dos mensurandos contida nos padrões sintéticos

\begin{tabular}{cc}
\hline Mensurando & Massa $(\mu \mathrm{g})^{*}$ \\
\hline $\mathrm{As}$ & $2,471 \pm 0,062$ \\
$\mathrm{Co}$ & $2,473 \pm 0,060$ \\
$\mathrm{Cr}$ & $5,02 \pm 0,13$ \\
$\mathrm{Fe}$ & $503 \pm 11$ \\
$\mathrm{Rb}$ & $7,44 \pm 0,19$ \\
$\mathrm{Sb}$ & $1,233 \pm 0,032$ \\
$\mathrm{Sc}$ & $0,251 \pm 0,013$ \\
$\mathrm{Se}$ & $2,51 \pm 0,14$ \\
$\mathrm{Zn}$ & $24,71 \pm 0,62$ \\
\hline
\end{tabular}

* incerteza corresponde à incerteza expandida, $U, k=2$

\subsection{Montagem do experimento para irradiação}

Amostras e padrões sintéticos de mesma geometria tiveram a parte externa limpa com um papel embebido em álcool etílico grau P.A. e, em seguida, com outro papel embebido emágua deionizada (Milli - Q, Millipore; 18,2 $\mathrm{m} \Omega$ ). Secou-se a parte externa do invólucro com papel absorvente. 
Com o auxílio de duas pinças, amostras e padrões sintéticos foram envolvidos (individualmente) por uma folha de alumínio denominada invólucro externo. Os códigos de identificação de cada amostra e padrão foram anotados na parte externa dos invólucros externos. A seguir, todas as amostras e padrões do experimento foram organizados um sobre o outro de maneira aleatória e envolvidas por uma nova camada de papel alumínio (sanduíche). O código de identificação do experimento foi anotado na parte externa do sanduíche.

Inseriu-se o sanduíche de amostras e padrões dentro de um cilindro de alumínio denominado coelho. Juntamente com a ficha de solicitação de irradiação, entregou-se o coelho para o setor responsável pelo procedimento de irradiação do experimento. A Figura 7.4 apresenta o processo de montagem do experimento para irradiação.
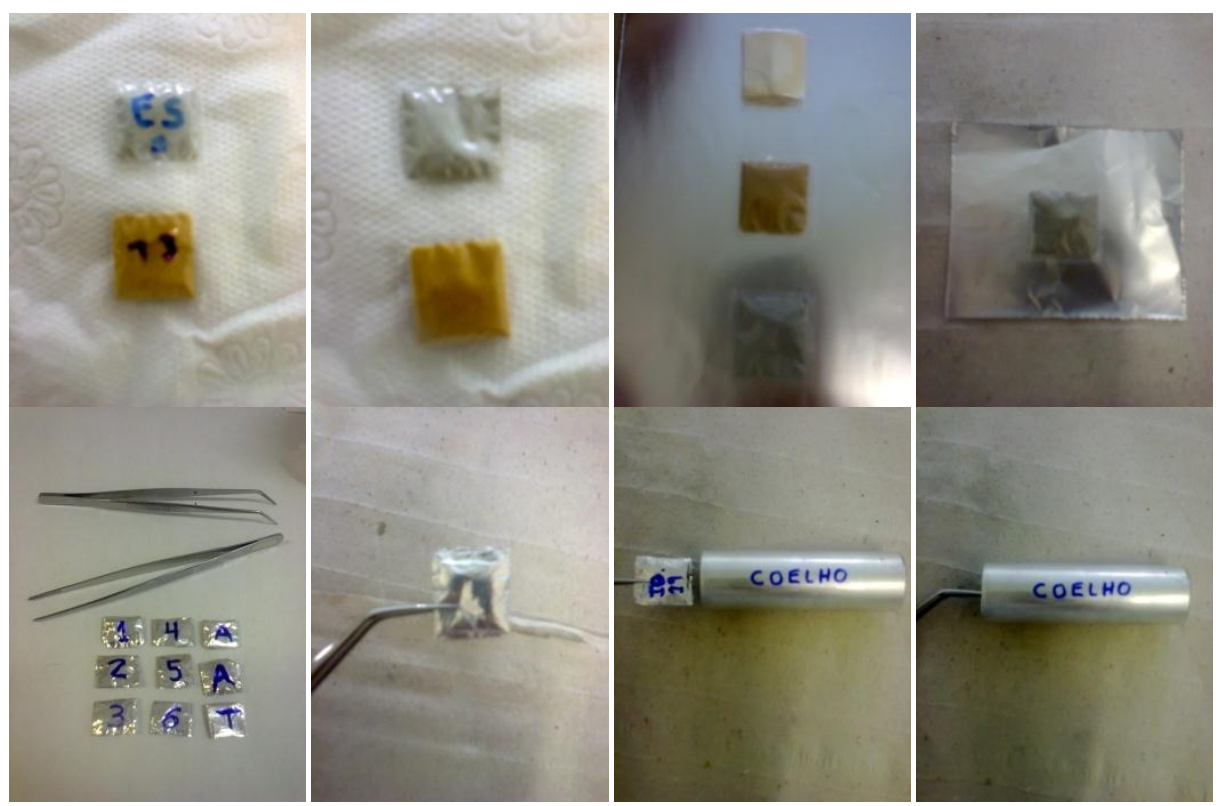

Figura 7.4. Representação da montagem de um experimento para o processo de irradiação

\subsection{Montagem das amostras após a irradiação}

Após o processo de irradiação, aguardou-se o tempo adequado de decaimento radioativo para amostras e padrões sintéticos. Decorrido o tempo adequado, com o auxílio de duas pinças retirou-se o sanduíche do coelho, desembrulhou-se a folha 
de alumínio característico do sanduíche. Separou-se amostras e padrões e removeu-se o invólucro externo de cada um deles.

A seguir, amostras e padrões foram colocados em estruturas chamadas panelinhas. Cada panelinha é um compartimento redondo feito de aço inoxidável com tamanho característico, o qual se encaixa perfeitamente na estrutura do espectrômetro de raios gama, garantindo que todas as amostras e padrões estejam em uma mesma posição no momento da detecção.

Após posicionada na panelinha cada amostra e/ou padrão sintético foi preso com auxílio de uma fita adesiva, usada para imobilização da amostra e/ou padrão sintético numa posição adequada na panelinha. Finalizado o processo, as panelinhas foram dispostas no interior de estruturas de chumbo denominadas castelos, onde permaneceram até o momento do processo de medição dos raios gama. A Figura 7.5 apresenta as etapas no processo de montagem das amostras e/ou padrões sintéticos para o processo de detecção.

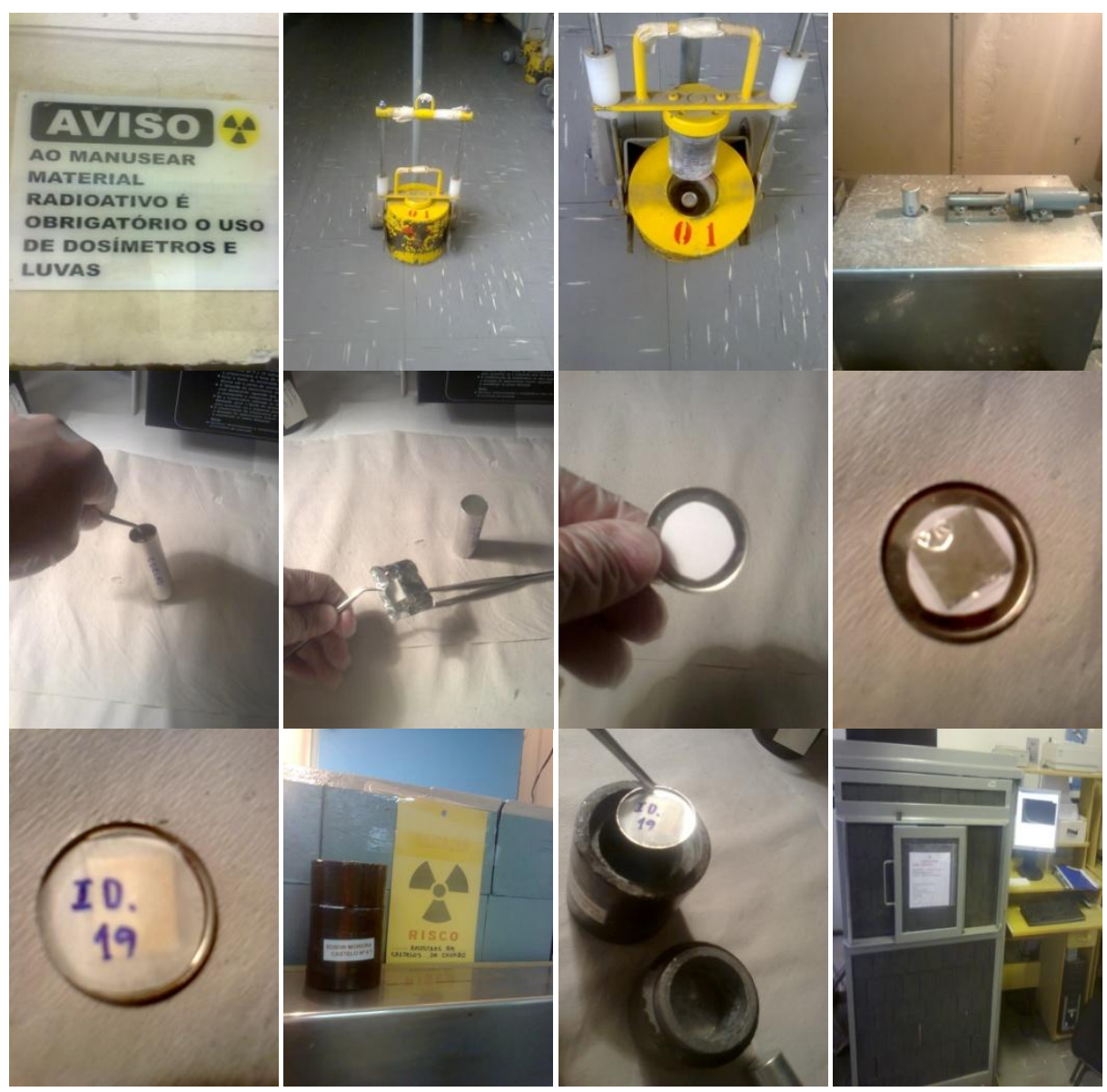

Figura 7.5. Representação da montagem das amostras e/ou padrões sintéticos para o processo de detecção 


\subsection{Otimização dos métodos de medição}

A otimização dos métodos de medição foi realizada em duas etapas. A primeira consistiu na investigação dos padrões sintéticos (composição e tempo de medição) e a segunda na investigação sobre a influência de alguns fatores do processo de medição, com ênfase no comportamento das amostras (tempo de medição da amostra, distância entre amostra e detector e tempo de decaimento antes da medição para amostra).

\subsubsection{Otimização univariada na medição dos padrões sintéticos}

Como ponto de partida para a otimização dos procedimentos analíticos, direcionou-se o estudo para a confecção dos padrões sintéticos, analisando-se a viabilidade (vantagens e desvantagens) do preparo de um único padrão que contivesse todos os mensurandos de interesse. O principal objetivo foi avaliar a influência causada pelo uso de um único padrão sintético que contivesse todos os mensurandos de interesse frente aos resultados obtidos com o uso de diversos padrões monoelementares.

Em um segundo momento alterou-se o tempo de medição dispensado ao processo de medição da atividade induzida pelos mensurandos nestes padrões, visando à avaliação da influência dessa variável no resultado final. Para isso, foram definidas três diferentes configurações de tempo de medição para o estudo: 60 min (condição mais utilizada pelos pesquisadores do LAN), 40 min (condição intermediária) e 20 min (condição almejada neste trabalho).

Nestes estudos, a concentração dos mensurandos e geometria foram idênticas para cada um dos padrões preparados. Além disso, todos os padrões foram irradiados em um único procedimento, visando-se minimizar interferências ocasionadas pela incidência de diferentes fluxos de nêutrons. 


\subsubsection{Otimização multivariada para os parâmetros de detecção (Planejamento Fatorial, DOE)}

A otimização das condições para o delineamento mais favorável para alguns fatores do processo de detecção foi estudada por meio de um Planejamento Fatorial $2^{3}$ completo, para cada um dos quatro métodos.

Neste estudo, foram avaliadas as influências associadas a três importantes fatores do processo de medição: tempo de decaimento da amostra antes do início da medição $(A)$, distância entre amostra e detector no momento da medição $(B)$ e tempo de medição da amostra $(C)$. As Tabelas 7.4, 7.5, 7.6 e 7.7 apresentam a configuração dos níveis atribuídos à cada um dos diferentes métodos.

Tabela 7.4. Delineamento experimental para o método-BIO-1

\begin{tabular}{ccc}
\hline Fator & Nível -1 & Nível +1 \\
\hline Tempo de decaimento da amostra (A) & 5 dias & 9 dias \\
Distância entre amostra e detector (B) & $98 \mathrm{~mm}$ & $3 \mathrm{~mm}$ \\
Tempo de medição da amostra (C) & 1 hora & 3 horas \\
\hline
\end{tabular}

Tabela 7.5. Delineamento experimental para o método-BIO-2

\begin{tabular}{ccc}
\hline Fator & Nível -1 & Nível +1 \\
\hline Tempo de decaimento da amostra (A) & 10 dias & 22 dias \\
Distância entre amostra e detector (B) & $98 \mathrm{~mm}$ & $3 \mathrm{~mm}$ \\
Tempo de medição da amostra (C) & 6 horas & 10 horas \\
\hline
\end{tabular}

Tabela 7.6. Delineamento experimental para o método-GEO-1

\begin{tabular}{ccc}
\hline Fator & Nível -1 & Nível +1 \\
\hline Tempo de decaimento da amostra (A) & 5 dias & 9 dias \\
Distância entre amostra e detector (B) & $98 \mathrm{~mm}$ & $3 \mathrm{~mm}$ \\
Tempo de medição da amostra (C) & 1 hora & 3 horas \\
\hline
\end{tabular}


Tabela 7.7. Delineamento experimental para o método-GEO-2

\begin{tabular}{ccc}
\hline Fator & Nível -1 & Nível +1 \\
\hline Tempo de decaimento da amostra (A) & 10 dias & 22 dias \\
Distância entre amostra e detector (B) & $98 \mathrm{~mm}$ & $3 \mathrm{~mm}$ \\
Tempo de medição da amostra (C) & 2 horas & 6 horas \\
\hline
\end{tabular}

As condições otimizadas foram obtidas por meio dos cálculos de efeito principal e interação das variáveis, obtidos com o erro relativo do resultado da média de três medições para cada mensurando. Para avaliar-se o grau de significância estatística dos resultados, realizou-se um teste- $t$ (t-Student) com 95\% de confiança. A hipótese nula $\left(\mathrm{H}_{0}\right)$ foi aceita quando o valor das médias para os diferentes experimentos não apresentou diferença estatisticamente significativa. Por outro lado, havendo diferença estatisticamente significativa da média dos resultados obtidos para um mesmo experimento a hipótese alternativa $\left(\mathrm{H}_{1}\right)$ foi aceita e $\mathrm{H}_{0}$ rejeitada. Assim sendo, para valores de $p \geq 0,05$ (5\% de nível de significância) $\mathrm{H}_{0}$ foi aceita e para $p<0,05$ aceitou-se $\mathrm{H}_{1}$.

Optou-se pelo uso de diferentes valores para os níveis atribuídos a cada uma das configurações analíticas para amostras geológicas e biológicas, visto que as concentrações dos mensurandos nestas matrizes não são similares (para a maioria das vezes).

Com esse tratamento, valores de $p<0,05$ para os efeitos principais e interações entre os fatores indicam as interações e/ou fatores mais importantes para o processo de otimização dos procedimentos analíticos em INAA conforme o delineamento experimental proposto.

Possíveis fatores perturbadores, como massa de amostra $(150 \pm 10 \mathrm{mg})$, geometria da amostra e padrão (10 mm x $8 \mathrm{~mm}$ x $1 \mathrm{~mm})$, tempo de irradiação ( 8 horas) e fluxo de nêutrons térmicos (entre 0,5 e $1,010^{15} \mathrm{~m}^{-2} \mathrm{~s}^{-1}$ ) foram controlados e mantidos constantes para todos os experimentos requeridos para a realização do estudo de DOE. 


\subsection{Validação dos métodos de medição}

Os parâmetros de desempenho estudados durante a validação dos métodos foram: precisão (repetitividade, precisão intermediária e reprodutibilidade), veracidade, seletividade, limite de detecção, limite de quantificação, robustez, linearidade, faixa de trabalho e incerteza de medição.

Ainda, como parte do escopo de validação, elaborou-se os respectivos procedimentos operacionais padrão (POP) para os métodos validados e o desenvolvimento de um guia prático para a validação de métodos de medição, o qual contém todos os procedimentos e cálculos necessários para o desenvolvimento de um processo formal para a validação dos métodos de INAA. Estes documentos da qualidade encontram-se disponíveis para consulta na Secção de Anexos.

\subsubsection{Delineamentos importantes para o processo de validação dos métodos de medição}

As amostras e padrões analisados nos diversos estudos foram irradiadas no reator de pesquisas IEA-R1 do CRPq sob potência de 4,5 MW. Para os estudos realizados, todas as amostras e padrões foram encapados com uma folha de (denominada de invólucro externo), acondicionados e dispostos de forma aleatória quanto à ordem de montagem no interior dos coelhos de alumínio e encaminhados para o setor responsável para o processo de irradiação.

É importante citar que todos os estudos relacionados ao processo de validação tiveram seus experimentos realizados em ordem aleatória e que os MRCs utilizados foram o Tecido de Mexilhão do IPEN / CNEN-SP para matriz biológica (MOREIRA, 2010) e o Sedimento Marinho SRM 2702 do NIST para matriz geológica (NIST, 2012).

A Tabela 7.8 apresenta a configuração experimental aplicada à todos os métodos de medição durante o processo de validação analítica. 
Tabela 7.8. Configuração experimental aplicada à todos os métodos de medição no processo de validação analítica

\begin{tabular}{cc}
\hline Fator & Valor atribuído \\
\hline Geometria (amostra e padrão) & $10 \mathrm{~mm} \times 8 \mathrm{~mm} \times 1 \mathrm{~mm}$ \\
Tempo de irradiação & 8 horas \\
Fluxo de nêutrons térmicos & 0,5 à $1,010^{15} \mathrm{~m}^{-2} \mathrm{~s}^{-1}$ \\
Montagem do experimento de irradiação & 2 padrões +6 amostras \\
Massa da amostra & $155 \pm 10 \mathrm{mg}$ \\
\hline
\end{tabular}

\subsubsection{Pico analítico de cada mensurando para a medição de raios gama}

A Tabela 7.9 apresenta os picos de energia utilizados para a medição da atividade induzida por cada mensurando, bem como o tempo de meia vida de cada radionuclídeo.

Tabela 7.9. Pico de energia e tempo de meia-vida de cada mensurando (CHU et al., 1999)

\begin{tabular}{ccc}
\hline Radionuclídeo & Tempo de meia-vida (dia) & Pico de energia $(\mathrm{keV})$ \\
\hline${ }^{76} \mathrm{As}$ & 1,078 & 559,10 \\
${ }^{51} \mathrm{Cr}$ & 27,70 & 320,08 \\
${ }^{60} \mathrm{Co}$ & 1925 & 1173,23 \\
${ }^{59} \mathrm{Fe}$ & 44,50 & 1099,25 \\
${ }^{86} \mathrm{Rb}$ & 18,63 & 1077,00 \\
${ }^{122} \mathrm{Sb}$ & 2,724 & 564,24 \\
${ }^{46} \mathrm{Sc}$ & 83,79 & 889,28 \\
${ }^{75} \mathrm{Se}$ & 119,8 & 264,66 \\
${ }^{65} \mathrm{Zn}$ & 244,3 & 1115,54 \\
\hline
\end{tabular}

\subsubsection{Precisão}

A precisão dos métodos de medição foi avaliada de acordo com os resultados obtidos para a estimativa do valor de $r, P I$ e $R$. 


\subsubsection{Veracidade}

A veracidade do método foi estimada por meio do cálculo de En (Eq.3) para a média dos resultados obtidos para os procedimentos do escopo de validação.

\subsubsection{Seletividade}

A seletividade dos métodos foi avaliada por meio da análise de cinco diferentes MRCs de matriz similar à utilizada no processo de validação dos métodos (ver Tabela 7.1). As análises foram realizadas em triplicata para cada MRC avaliado. Ao resultado obtido, calculou-se o valor do En.

\subsubsection{Limite de detecção e limite de quantificação}

O limite de detecção e o limite de quantificação foram estimados para uma amostra típica para cada mensurando, em cada método de medição, de acordo com as Equações 7 e 8.

\subsubsection{Robustez}

Para a avaliação da robustez foi realizado o delineamento experimental univariado em um nível de observação. Isto significa que cada variável estudada, teve sua influência determinada por meio da comparação do resultado obtido para a medição na condição padrão do método com o resultado obtido em uma condição modificada. As variáveis (fatores) estudadas foram o tempo de decaimento da amostra até o início do processo de medição, distância entre amostra e detector, fluxo de nêutrons térmicos, geometria da amostra e do padrão sintético, massa da amostra.

\subsubsection{Linearidade}

A linearidade para cada mensurando foi avaliada por meio da análise de cinco MRCs de matriz similar as do respectivo método de medição. Paralelamente a 
isso, cinco padrões sintéticos com concentração similar a encontrada nas amostras também foram analisados como se fossem amostras.

Os resultados obtidos foram dispostos em gráfico. Desta forma, a linearidade foi avaliada de acordo com os resultados obtidos para o coeficiente de correlação para todas as medições (amostras e padrões sintéticos) para cada mensurando, procedimento bastante parecido ao estabelecido e utilizado por BODE e BLAAUW (2012).

\subsubsection{Faixa de trabalho}

A faixa de trabalho foi estimada de acordo com a concentração dos mensurandos em amostras típicas, paralelamente ao estudo de linearidade do método de medição.

\subsubsection{Incerteza de medição}

A estimativa das componentes da incerteza de medição foi realizada de acordo com o método simulado para as componentes de entrada em INAA: massa da amostra, massa do mensurando no padrão sintético, atividade do radionuclídeo na amostra, atividade do radionuclídeo no padrão sintético e constante de decaimento do radionuclídeo. 


\section{RESULTADOS E DISCUSSÃO}

\subsection{Delineamento dos mensurandos e matrizes}

Este estudo foi embasado nas respostas dos pesquisadores do CRPq às perguntas desenvolvidas da carta-formulário (Anexo 1). Foram convidados para participação dez pesquisadores, sendo que destes, apenas um não retornou as respostas solicitadas no questionário.

Como resposta à pergunta sobre os mensurandos de maior importância para o desenvolvimento das pesquisas, verificou-se que para cinco pesquisadores $\mathrm{As}, \mathrm{Fe}$ e $\mathrm{Zn}$ são os mensurandos de maior importância, independentemente da matriz analisada. Para quatro deles, o Cr e para três deles $\mathrm{Co}, \mathrm{Sc}, \mathrm{Se}$ e U.

Quanto às matrizes rotineiramente analisadas, verificou-se que dois pesquisadores trabalham exclusivamente com matrizes biológicas, dois somente com matrizes geológicas e cinco deles com ambas as matrizes.

Verificou-se que dois pesquisadores não utilizam padrões sintéticos em seus procedimentos analíticos, realizando a comparação diretamente ao resultado obtido na análise de MRCs de matriz similar. Este tipo de procedimento pode vir a ser bem vantajoso quando o MRC e a amostra apresentarem matriz e concentração para mensurandos similares. Por outro lado, é possível que as incertezas associadas a este procedimento sejam mais elevadas do que as obtidas num procedimento com o emprego de padrões sintéticos. Outro ponto fundamental é que uma vez utilizado como padrão, o MRC não poderá ser utilizado como ferramenta para a validação do procedimento experimental. Vale ressaltar que os dois pesquisadores que acenaram à esta configuração experimental (não uso de padrões sintéticos) trabalham exclusivamente com amostras de matriz geológica.

Um dos pesquisadores consultados relatou que não utiliza padrão comparador multielementar (apenas padrões monoelementares), enquanto que para 
outros oito o uso de padrões multielementares - sejam padrões sintéticos ou MRCs de matriz similar a da amostra - é uma prática realizada rotineiramente.

Perguntou-se ainda sobre a configuração experimental rotineiramente utilizada nas pesquisas com matriz geológica e biológica. Neste contexto, o tempo de irradiação adotado varia entre 4 e 8 horas para a análise de matriz geológica e entre 6 e 16 horas para a análise de matriz biológica. Essa prática é muito comum visto que amostras de matriz biológica apresentam, em geral, menor teor dos mensurandos em sua composição. Visando-se contornar essa dificuldade, os pesquisadores solicitam um tempo de irradiação maior para amostras com esse perfil.

Assim como o tempo de irradiação, o tempo de mediçãodos padrões (sintéticos ou MRCs) e amostras varia grandemente. Para matriz geológica, o tempo de medição dos padrões varia entre 30 e 180 minutos e o tempo de medição para amostras entre 60 e 180 minutos. Para matriz biológica, pesquisadores submetem os mesmos padrões em medições que variam entre 30 e 240 minutos e as amostras entre 120 e 720 minutos.

O tempo médio relatado para o início da medição após o período de irradiação das amostras e padrões varia entre 5 e 8 dias para uma primeira medição e entre 10 e 20 dias para uma segunda medição, considerando-se ambas as matrizes.

Pesquisadores relataram que utilizam amostras com massa entre $40 \mathrm{mg}$ e $250 \mathrm{mg}$ independentemente da matriz, sendo que o valor para a moda foi $150 \mathrm{mg}$.

Sugeriu-se ainda que os pesquisadores indicassem aos parâmetros que poderiam ser otimizados para os procedimentos realizados em suas respectivas linhas de pesquisa. Para três pesquisadores, nenhum parâmetro necessita ser otimizado, para outros dois, a maior dificuldade encontra-se relacionada à forma de realização dos cálculos de concentração e incerteza para os resultados. Ainda, um pesquisador acenou à necessidade real da implementação do método comparativo- $k_{0}$ e outros dois a necessidade iminente da realização da validação dos procedimentos analíticos visandose o embasamento da qualidade analítica dos resultados obtidos. Um pesquisador não respondeu a esta pergunta.

Este estudo fez-se de grande importância para o delineamento dos métodos de medição que tiveram seus procedimentos validados neste trabalho, visando-se o atendimento às reais necessidades dos pesquisadores do LAN que trabalham 
rotineiramente com INAA. Com base nas respostas deste questionário, elaborou-se o plano de validação realizado neste trabalho.

\subsection{Ensaios preliminares}

\subsubsection{Verificação da calibração de balões volumétricos}

A Tabela 8.1 apresenta a média \pm desvio padrão para a verificação da calibração para os balões volumétricos.

Tabela 8.1. Média dos resultados e desvio padrão obtidos para a verificação da calibração de balões volumétricos $(n=10)$

\begin{tabular}{ccc}
\hline Balão Volumétrico & Volume Certificado & Volume de Verificação \\
\hline BV ALR 6830/10 & $10,00 \pm 0,01 \mathrm{~mL}$ & $10,00 \pm 0,01 \mathrm{~mL}$ \\
BV ALR 6831/10 & $10,00 \pm 0,01 \mathrm{~mL}$ & $10,02 \pm 0,02 \mathrm{~mL}$ \\
\hline
\end{tabular}

Quanto a estimativa da contribuição das componentes de incerteza, levou-se em consideração o desvio padrão obtido para $n=10$ medições, o valor do certificado de calibração do balão volumétrico e o coeficiente de expansão térmica da água. A Tabela 8.2 apresenta as componentes de incerteza para a estimativa da incerteza de medição em balões volumétricos.

Tabela 8.2. Componentes de incerteza para a estimativa da incerteza de medição em balões volumétricos

\begin{tabular}{cccc}
\hline Identificação & Fonte de incerteza & Tipo da distribuição & Fator de abrangência \\
\hline$u_{1}$ & Certificado de calibração & Triangular & $\sqrt{6}$ \\
$u_{2}$ & Desvio padrão $(n=10)$ & Normal & 1 \\
$u_{3}$ & Expansão térmica da água & Retangular & $\sqrt{ } 3$ \\
\hline
\end{tabular}

A componente expansão térmica da água foi calculada de acordo com a Equação 39 (ÁVILA et al., 2014). Esta fórmula é adaptada para o cálculo do coeficiente de expansão térmica para a água e em temperaturas maiores que $20^{\circ} \mathrm{C}$. 


$$
\alpha=0,00021 V(T-20)
$$

onde:

$\alpha$ é o valor atribuído ao coeficiente de expansão térmica $\left(\mathrm{mL}^{\circ} \mathrm{C}\right)$;

$V$ é o volume do recipiente $(\mathrm{mL})$;

$T$ é a temperatura no momento da verificação $\left({ }^{\circ} \mathrm{C}\right)$.

A Tabela 8.3 apresenta os resultados para a estimativa da incerteza de medição para cada balão volumétrico investigado e a Figura 8.1 a contribuição das fontes de incerteza na verificação dos balões volumétricos.

Tabela 8.3. Resultado para a estimativa da incerteza de medição para a verificação de balões volumétricos

\begin{tabular}{cccc}
\hline Balão & Fonte de incerteza & $u_{x}(\mathrm{~mL})$ & $u_{x}^{2}(\mathrm{~mL})$ \\
\hline & $u_{1}$ & 0,0041 & $1,7 \mathrm{E}-5$ \\
BV ALR 6830/10 & $u_{2}$ & 0,0056 & $3,1 \mathrm{E}-5$ \\
& $u_{3}$ & 0,0036 & $1,3 \mathrm{E}-5$ \\
& & $u_{c}$ & $0,0078 \mathrm{~mL}$ \\
BV ALR 6831/10 & $u_{1}$ & $0,(k=2 ; 95 \%)$ & $0,016 \mathrm{~mL}$ \\
\hline & $u_{2}$ & 0,0041 & $1,7 \mathrm{E}-5$ \\
& $u_{3}$ & 0,0024 & $3,2 \mathrm{E}-4$ \\
& & $u_{c}$ & $5,9 \mathrm{E}-6$ \\
& & $U(k=2 ; 95 \%)$ & $0,019 \mathrm{~mL}$ \\
\hline
\end{tabular}

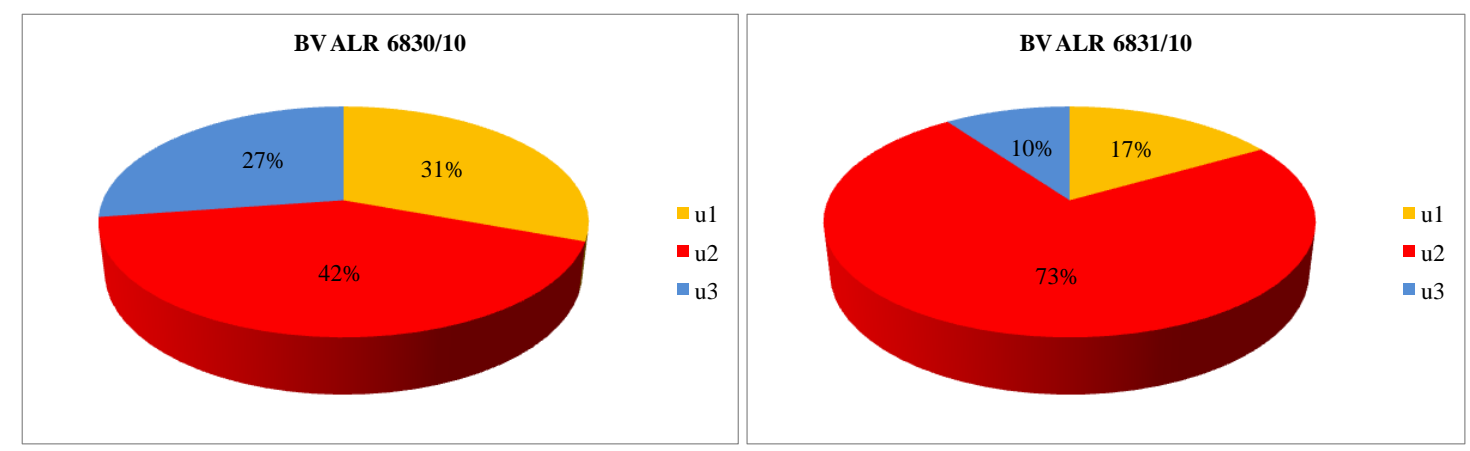

Figura 8.1. Contribuição das fontes de incerteza no processo de verificação de balões volumétricos 
De acordo com os resultados, pode-se verificar que a componente com maior contribuição à estimativa da incerteza padrão no processo de verificação de balões volumétricos é a do desvio padrão para $n=10$ repetições, cuja contribuição variou entre $42 \%$ e $72 \%$ em relação a somatória dos valores das componentes de incerteza. No mesmo contexto, a contribuição relacionada à componente valor do certificado de calibração variou entre $17 \%$ e $31 \%$ e entre $10 \%$ e $27 \%$ para à componente do coeficiente de expansão térmica da água.

Os resultados encontrados para ambos os balões foram considerados satisfatórios e equivalentes aos especificados pelo certificado de calibração do fabricante.

\subsubsection{Verificação da calibração de micropipetas}

As especificações do fabricante (Eppendorf) quanto aos valores para erros sistemáticos e aleatórios para cada micropipeta são apresentados na Tabela 8.4. A média dos resultados obtidos para cada um dos volumes verificados são apresentados na Tabela 8.5.

Tabela 8.4. Especificações da Eppendorf da máxima porcentagem para erro sistemático e aleatório para as micropipetas

\begin{tabular}{cccc}
\hline Identificação & Volume nominal & Erro sistemático (\%) & Erro aleatório (\%) \\
\hline \multirow{2}{*}{$20-200 \mu \mathrm{L}$} & $20 \mu \mathrm{L}$ & $\pm 2,5$ & $\pm 0,7$ \\
& $100 \mu \mathrm{L}$ & $\pm 1,0$ & $\pm 0,3$ \\
& $200 \mu \mathrm{L}$ & $\pm 0,6$ & $\pm 0,2$ \\
\hline $100-1000 \mu \mathrm{L}$ & $100 \mu \mathrm{L}$ & $\pm 3,0$ & $\pm 0,6$ \\
& $500 \mu \mathrm{L}$ & $\pm 1,0$ & $\pm 0,2$ \\
$1-10 \mathrm{~mL}$ & $1000 \mu \mathrm{L}$ & $\pm 0,6$ & $\pm 0,2$ \\
\hline & $1 \mathrm{~mL}$ & $\pm 3,0$ & $\pm 0,6$ \\
& $5 \mathrm{~mL}$ & $\pm 0,8$ & $\pm 0,2$ \\
& $10 \mathrm{~mL}$ & $\pm 0,6$ & $\pm 0,15$ \\
\hline
\end{tabular}


Tabela 8.5. Resultados do procedimento de verificação para as diferentes micropipetas (média \pm desvio padrão, $n=10$ )

\begin{tabular}{ccccc}
\hline Identificação & Volume nominal $(\mathrm{mL})$ & Volume verificado $(\mathrm{mL})$ & ER $(\%)$ & DPR (\%) \\
\hline \multirow{3}{*}{$1-10 \mathrm{~mL}$} & 2,00 & $1,0091 \pm 0,0073$ & 0,90 & 0,69 \\
& 3,00 & $2,010 \pm 0,010$ & 0,50 & 0,49 \\
& 4,00 & $2,995 \pm 0,013$ & 0,17 & 0,43 \\
& 5,00 & $3,989 \pm 0,012$ & 0,28 & 0,30 \\
$100-1000 \mu \mathrm{L}$ & 10,0 & $4,991 \pm 0,012$ & 0,18 & 0,24 \\
& 0,100 & $10,004 \pm 0,016$ & 0,040 & 0,16 \\
\hline \multirow{3}{*}{$20-200 \mu \mathrm{L}$} & 0,250 & $0,1010 \pm 0,0027$ & 1,0 & 0,27 \\
& 0,500 & $0,2482 \pm 0,0027$ & 1,1 & 0,11 \\
& 1,00 & $0,4980 \pm 0,0042$ & 0,99 & 0,084 \\
& 0,025 & $0,9965 \pm 0,0031$ & 0,75 & 0,31 \\
\hline & 0,050 & $0,024880 \pm 0,000062$ & 0,48 & 0,25 \\
& 0,100 & $0,05012 \pm 0,00032$ & 0,64 & 0,24 \\
& 0,200 & $0,10087 \pm 0,00031$ & 0,87 & 0,31 \\
& & $0,20073 \pm 0,00012$ & 0,36 & 0,060 \\
\hline
\end{tabular}

Os resultados obtidos para todas as medições variaram entre $0,040 \%$ e $1,1 \%$ para o valor de ER e entre $0,060 \%$ e $0,69 \%$ para o valor de DPR. Estes resultados foram comparados aos especificados no certificado de calibração para cada micropipeta. Desta forma, os resultados obtidos para ER foi comparado com os valores informados para erro sistemático enquanto que os resultados para DPR foram comparados com os valores informados para erro aleatório. A Figura 8.2 ilustra a metodologia de comparação dos resultados experimentais com os descritos nos certificados de calibração para cada micropipeta. 


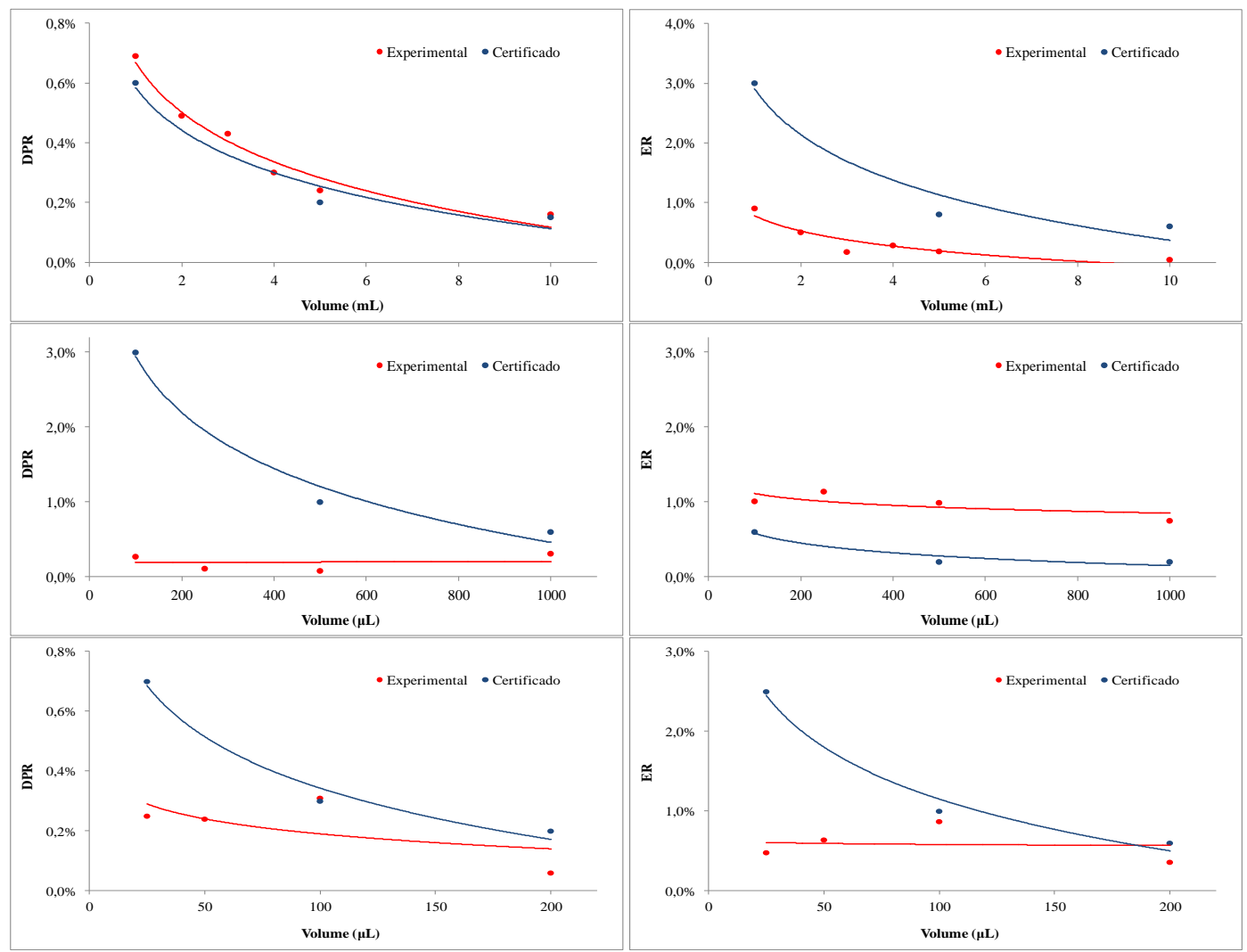

Figura 8.2. Comparação dos valores de ER (\%) e DPR (\%) com os valores informados nos certificados de calibração para cada micropipeta

Comparando-se os resultados obtidos para ER (\%) e DPR (\%) com os informados no certificado de calibração, é possível observar que, com exceção aos valores para DPR na micropipeta 1-10 mL (que indica que a variação nos resultados obtidos nos experimentos pode ser considerada superior à indicada pelo certificado de calibração quanto ao valor para erro aleatório) e de ER para a micropipeta 100-1000 $\mu \mathrm{L}$ (que indica que a variação nos resultados obtidos nos experimentos pode ser considerada superior à indicada pelo certificado de calibração quanto ao valor para erro sistemático) todos os demais resultados obtidos neste experimento de verificação estiveram em conformidade com os indicados nos certificados de calibração das micropipetas. Essa informação é facilmente visualizada nos gráficos onde a linha azul apresenta os valores do certificado e a linha vermelha os resultados experimentais.

A estimativa das incertezas foi realizada para os mesmos fatores considerados na estimativa das fontes de incerteza para balões volumétricos. Resultados são apresentados na Tabela 8.6. A importância relativa de cada um dos fatores para a estimativa da incerteza de medição são apresentados na Tabela 8.7. 
De acordo com os resultados pode-se verificar que o fator majoritário na estimativa da incerteza em medições com micropipetas está relacionado à incerteza de calibração do equipamento, conforme pode ser observado nos resultados obtidos para as micropipetas "1-10mL" e "20 - $200 \mu L "$. Contudo, para a micropipeta "100 - $1000 \mu \mathrm{L}$ " verificou-se que o fator majoritário foi o desvio padrão dos ensaios de repetitividade, atentando e corroborando com o fato apresentado na discussão da Figura 8.2 (fato esse que o erro relativo das medições apresentou valor superior ao do certificado do fabricante do equipamento.

Tabela 8.6. Resultado para a estimativa da incerteza de medição para a verificação de micropipetas $(\mu \mathrm{L})$

\begin{tabular}{ccccccc}
\hline Micropipeta & Volume $(\mu \mathrm{L})$ & $u_{1}$ & $u_{2}$ & $u_{3}$ & $u^{2}$ & $U ; k=2$ \\
\hline \multirow{3}{*}{$1-10 \mathrm{~mL}$} & 1000 & 12 & 7,3 & 0,12 & 14 & 29 \\
& 2000 & 20 & 10 & 0,24 & 23 & 45 \\
& 3000 & 22 & 13 & 0,36 & 26 & 51 \\
& 4000 & 20 & 12 & 0,48 & 23 & 46 \\
& 5000 & 16 & 12 & 0,61 & 20 & 41 \\
$100-1000$ & 10000 & 24 & 16 & 1,2 & 29 & 59 \\
\hline$\mu \mathrm{L}$ & 100 & 1,2 & 2,7 & 0,012 & 3,0 & 5,9 \\
& 250 & 2,0 & 2,7 & 0,030 & 3,4 & 6,8 \\
& 500 & 2,0 & 4,2 & 0,061 & 4,7 & 9,3 \\
$20-200 \mu \mathrm{L}$ & 1000 & 2,4 & 3,1 & 0,12 & 4,0 & 7,9 \\
\hline \multirow{3}{*}{100} & 25 & 0,26 & 0,062 & 0,003 & 0,26 & 0,53 \\
& 50 & 0,36 & 0,32 & 0,006 & 0,48 & 1,0 \\
& 100 & 0,41 & 0,31 & 0,012 & 0,51 & 1,0 \\
& 200 & 0,49 & 0,12 & 0,024 & 0,50 & 1,0 \\
\hline
\end{tabular}


Tabela 8.7. Importância relativa de cada um dos fatores para a estimativa da incerteza de medição

\begin{tabular}{cccccc}
\hline Micropipeta & Volume $(\mu \mathrm{L})$ & $u_{1}$ & $u_{2}$ & $u_{3}$ & Fator majoritário \\
\hline \multirow{3}{*}{$1-10 \mathrm{~mL}$} & 1000 & $62,3 \%$ & $37,1 \%$ & $0,56 \%$ & $u_{1}$ \\
& 2000 & $66,6 \%$ & $32,6 \%$ & $0,78 \%$ & $u_{1}$ \\
& 3000 & $62,3 \%$ & $36,7 \%$ & $1,0 \%$ & $u_{1}$ \\
& 4000 & $61,1 \%$ & $37,4 \%$ & $1,5 \%$ & $u_{1}$ \\
& 5000 & $56,4 \%$ & $41,5 \%$ & $2,1 \%$ & $u_{1}$ \\
$100-1000$ & 10000 & $58,7 \%$ & $38,4 \%$ & $2,9 \%$ & $u_{1}$ \\
\hline $\mathrm{L}$ & 100 & $31,1 \%$ & $68,6 \%$ & $0,29 \%$ & $u_{2}$ \\
& 250 & $42,8 \%$ & $56,6 \%$ & $0,59 \%$ & $u_{2}$ \\
& 500 & $32,4 \%$ & $66,6 \%$ & $1,0 \%$ & $u_{2}$ \\
$20-200 \mu \mathrm{L}$ & 1000 & $43,2 \%$ & $54,7 \%$ & $2,1 \%$ & $u_{2}$ \\
& 25 & $79,7 \%$ & $19,4 \%$ & $0,85 \%$ & $u_{1}$ \\
& 50 & $52,3 \%$ & $46,8 \%$ & $0,95 \%$ & $u_{1}$ \\
& 100 & $55,9 \%$ & $42,4 \%$ & $1,7 \%$ & $u_{1}$ \\
\hline \multirow{3}{*}{200} & $77,3 \%$ & $18,9 \%$ & $3,8 \%$ & $u_{1}$ \\
\hline
\end{tabular}

\subsection{Estudo dos picos analíticos em INAA}

Realizou-se a avaliação dos picos analíticos mais apropriados para os mensurandos de interesse em diferentes matrizes biológicas e geológicas sob as condições analíticas especificadas no Item 7.8. Neste estudo, foram considerados apenas os picos analíticos cujos resultados fossem quantificáveis de acordo com as condições analíticas pré estabelecidas. O MRC investigado neste estudo para matriz biológica foi o Tecido de Mexilhão, IPEN TM-1. A média dos resultados obtidos em três medições para cada pico analítico investigado em amostras de matriz biológica são apresentados na Tabela 8.8. Os mesmos resultados também são apresentados na Figura 8.3. 
Tabela 8.8. Resultados obtidos com o uso de diferentes picos analíticos Tecido de Mexilhão, IPEN TM-1, $n=3\left(\mathrm{mg} \mathrm{kg}^{-1}\right)$

\begin{tabular}{|c|c|c|c|c|c|}
\hline \multirow{2}{*}{ Mensurando } & \multirow{2}{*}{$\frac{\text { Pico analítico }(\mathrm{keV})}{559,1^{\mathrm{b}}}$} & \multicolumn{3}{|c|}{ Resultado $^{\text {a }}$} & \multirow[t]{2}{*}{ Valor Certificado $^{a}$} \\
\hline & & 13,1 & \pm & 1,0 & \\
\hline \multirow[t]{2}{*}{ As } & 657,05 & 15,5 & \pm & 2,9 & \multirow[t]{2}{*}{$13,6 \pm 1,7$} \\
\hline & 1216,08 & 14,7 & \pm & 1,6 & \\
\hline \multirow[b]{2}{*}{$\mathrm{Co}$} & $1173,23^{b}$ & 0,863 & \pm & 0,037 & \multirow[b]{2}{*}{$0,829 \pm 0,077$} \\
\hline & 1332,49 & 0,871 & \pm & 0,036 & \\
\hline $\mathrm{Cr}$ & $320,08^{b}$ & 1,19 & \pm & 0,13 & $1,24 \pm 0,28$ \\
\hline \multirow{3}{*}{$\mathrm{Fe}$} & 192,34 & 697 & \pm & 72 & \multirow{3}{*}{$593 \pm 53$} \\
\hline & $1099,25^{b}$ & 611 & \pm & 21 & \\
\hline & 1291,59 & 634 & \pm & 27 & \\
\hline $\mathrm{Rb}$ & $1077,00^{b}$ & 4,88 & \pm & 0,27 & $4,93 \pm 0,92$ \\
\hline \multirow{5}{*}{$\mathrm{Se}$} & 121,12 & 8,44 & \pm & 0,63 & \multirow{5}{*}{$4,42 \pm 0,45$} \\
\hline & 136,00 & 4,50 & \pm & 0,37 & \\
\hline & $264,66^{b}$ & 4,37 & \pm & 0,34 & \\
\hline & 279,54 & 5,06 & \pm & 0,42 & \\
\hline & 400,66 & 6,19 & \pm & 2,58 & \\
\hline \multirow[b]{2}{*}{ Sc } & $889,28^{b}$ & 0,201 & \pm & 0,010 & \multirow[b]{2}{*}{$0,199 \pm 0,023$} \\
\hline & 1120,55 & 0,202 & \pm & 0,016 & \\
\hline $\mathrm{Zn}$ & $1115,54^{b}$ & 118,3 & \pm & 5,2 & $118,5 \pm 9,5$ \\
\hline
\end{tabular}

$\overline{{ }^{a} \text { Incerteza corresponde à incerteza expandida, } U, k=2 ;{ }^{b} \text { Picos analíticos recomendados pela IAEA }}$ (IAEA, 1990)

Pode-se observar que para as amostras biológicas, com exceção ao pico analítico $121 \mathrm{keV}$ para $\mathrm{Se}$, todos demais apresentaram resultados equivalentes ao valor certificado do MRC. Ainda, é possível verificar que os picos analíticos recomendados pela IAEA (1990) apresentaram menores incertezas e de uma maneira geral, mais exatos quando comparado com os resultados para os demais picos analíticos. Desta forma, para amostras biológicas, decidiu-se adotar os picos analíticos recomendados pela IAEA visto que estes apresentaram resultados mais favoráveis à determinação da 
concentração total dos mensurandos investigados quando comparados com os resultados obtidos em outros picos analíticos.

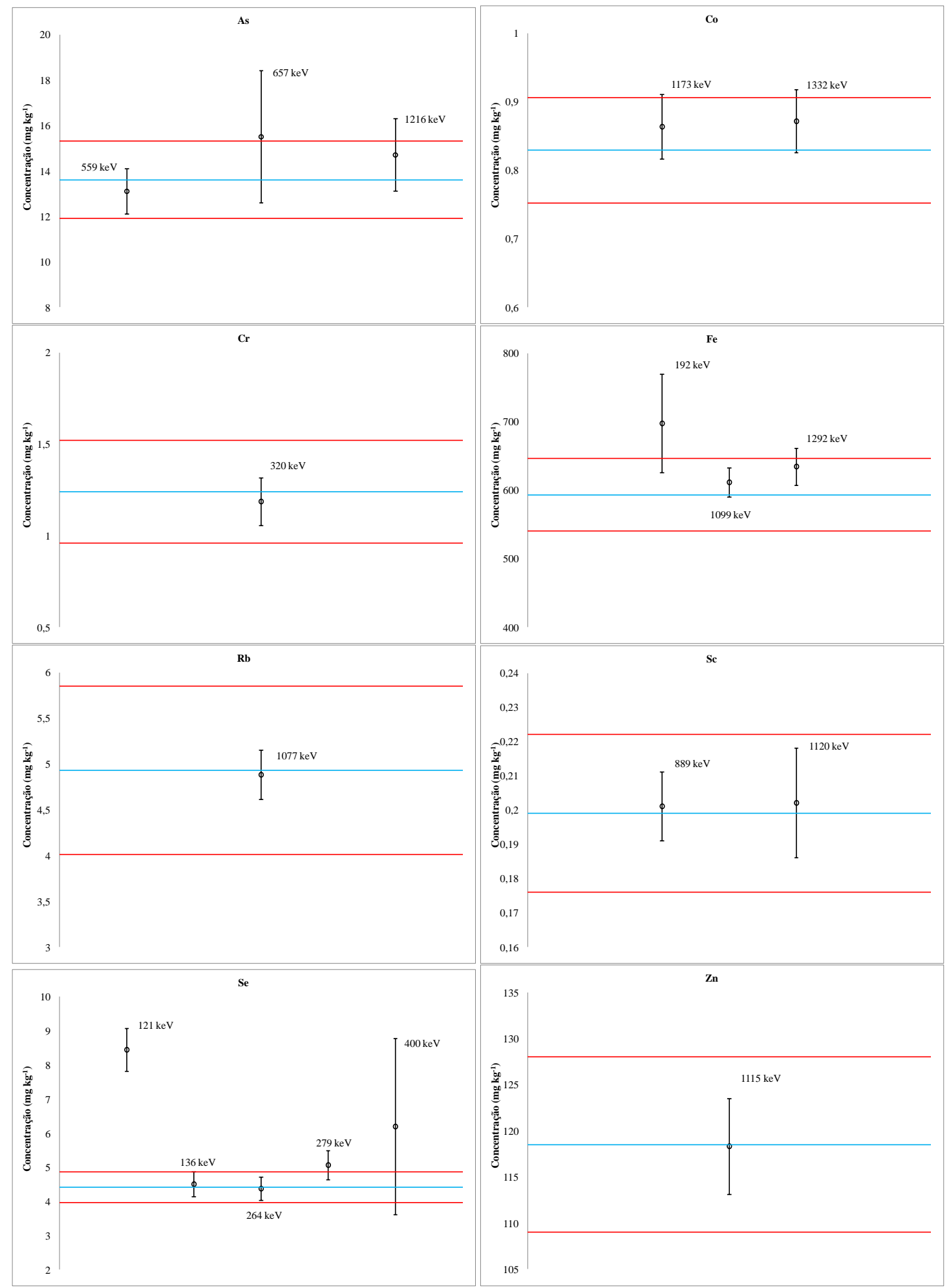

Figura 8.3. Resultados com incerteza expandida $(k=2)$ obtidos para o uso de diferentes picos analíticos em Tecido de Mexilhão, IPEN TM-1, $n=3\left(\mathrm{mg} \mathrm{kg}^{-1}\right)$ 
Para o procedimento em matriz geológica, utilizou-se o MRC Marine sediment NRCC MESS 3. A Tabela 8.9 e a Figura 8.4 apresentam os resultados obtidos para a análise de sedimento marinho.

Tabela 8.9. Resultados obtidos com o uso de diferentes picos analíticos para amostras de Sedimento Marinho NRCC MESS 3, $n=3\left(\mathrm{mg} \mathrm{kg}^{-1}\right)$

\begin{tabular}{|c|c|c|c|c|c|}
\hline Mensurando & Pico de Energia (keV) & \multicolumn{3}{|c|}{ Resultado $^{a}$} & Valor certificado $^{a}$ \\
\hline \multirow{3}{*}{ As } & $559,1^{b}$ & 21,5 & \pm & 1,1 & \multirow{3}{*}{$21,2 \pm 1,1$} \\
\hline & 657,05 & 22,1 & \pm & 1,3 & \\
\hline & 1216,08 & 19,4 & \pm & 4,1 & \\
\hline $\mathrm{Sb}$ & $564,24^{b}$ & 1,076 & \pm & 0,039 & $1,02 \pm 0,09$ \\
\hline \multirow{2}{*}{$\mathrm{Co}$} & $1173,23^{b}$ & 13,92 & \pm & 0,72 & \multirow{2}{*}{$14,4 \pm 2,0$} \\
\hline & 1332,49 & 13,80 & \pm & 0,85 & \\
\hline $\mathrm{Cr}$ & $320,08^{b}$ & 109,6 & \pm & 6,8 & $105 \pm 4$ \\
\hline \multirow{3}{*}{$\mathrm{Fe}$} & 192,34 & 43610 & \pm & 4133 & \multirow{3}{*}{$43400 \pm 1100$} \\
\hline & $1099,25^{b}$ & 43247 & \pm & 961 & \\
\hline & 1291,59 & 43726 & \pm & 1034 & \\
\hline \multirow[b]{2}{*}{ Sc } & $889,28^{b}$ & 16,02 & \pm & 0,84 & \multirow{2}{*}{$\mathrm{NI}^{\mathrm{c}}$} \\
\hline & 1120,55 & 16,10 & \pm & 0,89 & \\
\hline $\mathrm{Zn}$ & $1115,54^{b}$ & 171 & \pm & 13 & $159 \pm 8$ \\
\hline
\end{tabular}

\footnotetext{
${ }^{\mathrm{a}}$ Incerteza corresponde à incerteza expandida, $U, k=2 ;{ }^{\mathrm{b}}$ Picos analíticos recomendados pela IAEA
} (IAEA, 1990); 'Valor não certificado e não informado para o mensurando 


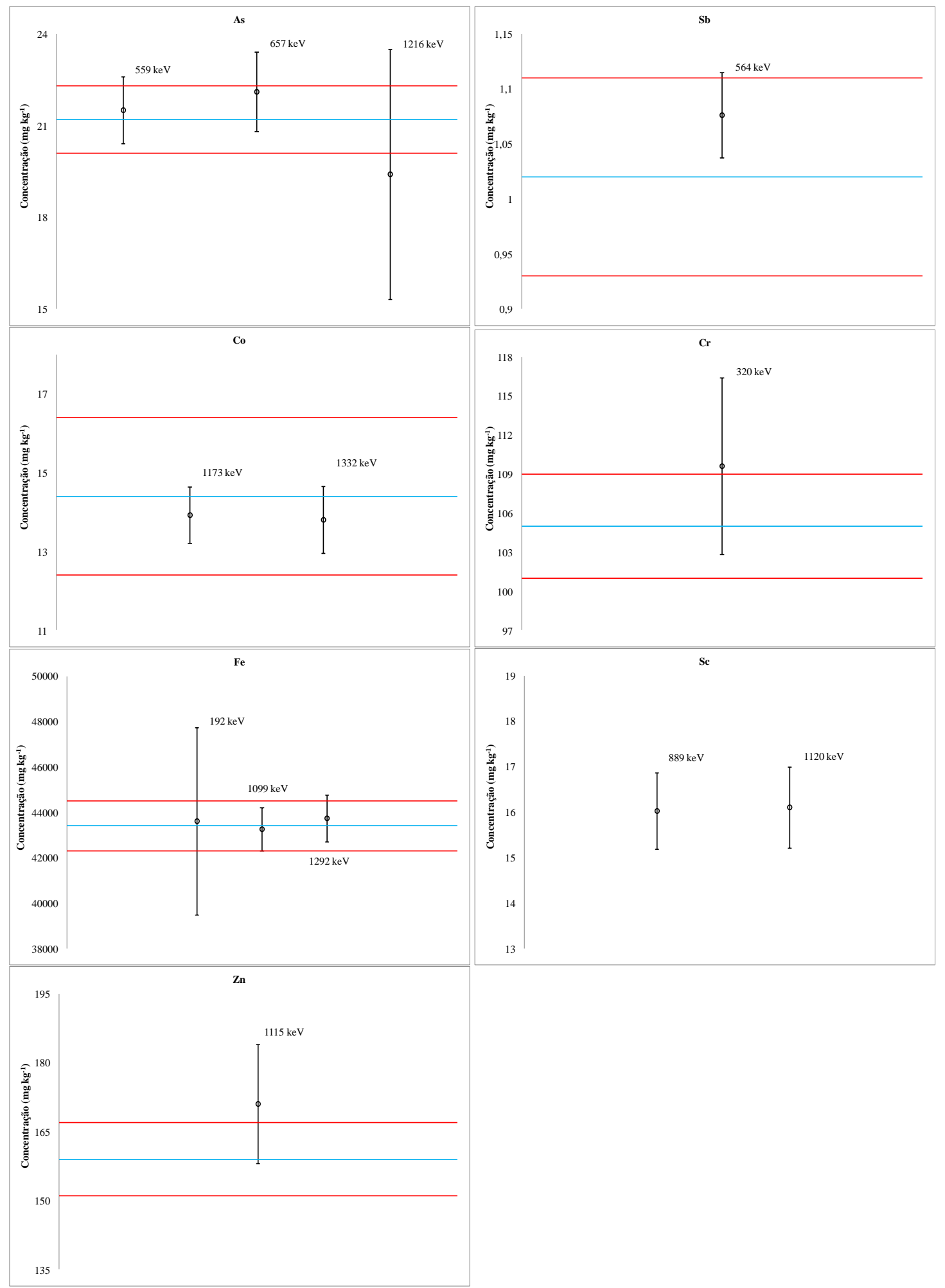

Figura 8.4. Resultados com incerteza expandida $(k=2)$ obtidos para o uso de diferentes picos analíticos em Sedimento Marinho NRCC MESS $3, n=3\left(\mathrm{mg} \mathrm{kg}^{-1}\right)$

Os resultados obtidos para a análise de Sedimento Marinho NRCC MESS 3 (matriz geológica) apresentaram comportamento similar ao observado para os 
resultados em matriz biológica. Os picos analíticos que apresentaram melhores resultados para exatidão e os menores índices de incerteza para As, Sb, Co, Cr, Fe e Zn foram os recomendados pela IAEA. Para Sc, os resultados apresentaram-se bastante similares para os picos analíticos avaliados, tanto para valor quanto para incerteza. Contudo, para este mensurando não havia a informação do produtor sobre o valor certificado.

Em geral, todos os picos analíticos recomendados pela IAEA apresentaram incertezas da mesma ordem de grandeza que as informadas nos certificados dos MRCs. Para matriz biológica, a incerteza relacionada às medições com os picos analíticos recomendados foram menores que as informadas no certificado do MRC para todos os mensurandos. Para análise em matriz geológica, Sb, Co e Fe também apresentaram valores de incerteza menor que as informadas no certificado do $\mathrm{MRC}, \mathrm{Cr}$ e $\mathrm{Zn}$ apresentaram incertezas maiores e As o mesmo valor. Para Sc, esse quesito não pode ser avaliado pela ausência desta informação no certificado do MRC.

A Tabela 8.10 apresenta informações sobre os radionuclídeos analisados, o tempo de meia vida para o decaimento radioativo eos picos analíticos selecionados para a realização do escopo da validação para os diferentes métodos de medição em INAA.

Tabela 8.10. Pico analítico e tempo de meia-vida de cada radionuclídeo (IAEA, 1990)

\begin{tabular}{ccc}
\hline Radionuclídeo & Tempo de meia-vida $(\mathrm{d}){ }^{\text {a }}$ & Pico de energia $(\mathrm{keV})$ \\
\hline${ }^{76} \mathrm{As}$ & $1,0778[20]$ & 559,10 \\
${ }^{60} \mathrm{Co}$ & $1924,06[18]$ & 1173,23 \\
${ }^{51} \mathrm{Cr}$ & $27,7025[24]$ & 320,08 \\
${ }^{59} \mathrm{Fe}$ & $44,502[6]$ & 1099,25 \\
${ }^{86} \mathrm{Rb}$ & $18,631[18]$ & 1077,00 \\
${ }^{122} \mathrm{Sb}$ & $2,7238[2]$ & 564,11 \\
${ }^{46} \mathrm{Sc}$ & $83,79[4]$ & 889,28 \\
${ }^{75} \mathrm{Se}$ & $119,779[4]$ & 264,66 \\
${ }^{65} \mathrm{Zn}$ & $244,26[26]$ & 1115,54 \\
\hline
\end{tabular}

${ }^{a}$ [Incerteza] corresponde à incerteza na (s) última (s) casa (s) decimal (is) (CHU et al., 1999) 


\subsection{Otimização dos métodos de medição}

\subsubsection{Otimização univariada na medição dos padrões sintéticos}

As diferentes configurações de confecção dos padrões sintéticos (monoelementar e multielementar) foram avaliadas por meio da comparação da média aritmética dos resultados obtidos para a análise em duplicata de amostras de Tecido de Mexilhão IPEN TM-1 e Sedimento Marinho NRCC MESS 3. Os resultados foram calculados para as amostras de MRC utilizando-se nove diferentes padrões sintéticos, sendo oito de natureza monoelementar e um multielementar, este último contendo todos os mensurandos.

Padrões sintéticos tiveram a atividade dos mensurandos medidos por 60 minutos. Amostras de Tecido de Mexilhão IPEN TM-1 tiveram a atividade dos mensurandos medidos por 120 (As) e 600 minutos (demais mensurandos). Amostras de Sedimento Marinho NRCC MESS 3 tiveram a atividade dos mensurandos medidos por 120 (AS e Sb) e 240 minutos (demais mensurandos). A média dos resultados obtidos para análise de Tecido de Mexilhão IPEN TM-1 em cada condição experimental é apresentada na Tabela 8.11.

Tabela 8.11. Média dos resultados $\left(\mathrm{mg} \mathrm{kg}^{-1}\right)$ com incerteza expandida, $k=2$, obtidos para o uso de padrões de configuração monoelementar e multielementar para a análise de Tecido de Mexilhão IPEN TM-1 $(n=2)$

\begin{tabular}{cccc}
\hline Mensurando & Padrão monoelementar & Padrão multielementar & $C E$ \\
\hline $\mathrm{As}$ & $15,0 \pm 1,2$ & $15,1 \pm 1,6$ & 0,99 \\
$\mathrm{Co}$ & $0,783 \pm 0,039$ & $0,779 \pm 0,042$ & 0,99 \\
$\mathrm{Cr}$ & $1,233 \pm 0,063$ & $1,225 \pm 0,067$ & 0,99 \\
$\mathrm{Fe}$ & $546 \pm 19$ & $548 \pm 25$ & 1,00 \\
$\mathrm{Rb}$ & $4,88 \pm 0,27$ & $4,79 \pm 0,23$ & 0,98 \\
$\mathrm{Sc}$ & $0,1965 \pm 0,0076$ & $0,1964 \pm 0,0075$ & 1,00 \\
$\mathrm{Se}$ & $4,93 \pm 0,35$ & $4,94 \pm 0,26$ & 1,00 \\
$\mathrm{Zn}$ & $122,9 \pm 5,4$ & $121,4 \pm 5,2$ & 1,00 \\
\hline
\end{tabular}


Visando a confirmação da equivalência entre as médias obtidas para a análise com padrão mono e multielementar foi calculado o coeficiente de equivalência das médias, de acordo com a Equação 40.

$$
C E=\left|\frac{x_{1}}{x_{2}}\right|
$$

onde:

$C E$ é o coeficiente de equivalência entre as médias aritméticas dos resultados;

$x_{1}$ é a média dos resultados obtidos com o padrão 1;

$x_{2}$ é a média dos resultados obtidos com o padrão 2 .

Conforme observado nos resultados, foi verificada a existência da equivalência entre a média dos resultados para o cálculo da concentração dos mensurandos utilizando os dois diferentes padrões: mono e multielementar. Neste critério, o índice 1,00 representa o mais alto grau de equivalência e 0,00 o menor.

Pode-se verificar que para os mensurandos Fe, Sc, Se e Zn o índice obtido foi igual a 1,00, ou seja, a equivalência para a média dos resultados foi de $100 \%$. Para As, Co e Cr obteve-se um índice de 0,99 e para $\mathrm{Rb} 0,98$. Isso evidencia o fato de que não existe diferença significativa entre os resultados obtidos para medições que utilizam padrões mono ou multielementares, ao menos para este grupo de mensurandos e para a matriz utilizada.

Quanto ao valor para incerteza obtido para a média dos resultados, pode-se verificar que estes são bastante comparáveis para os dois diferentes procedimentos (com padrões mono e multielementar), realizados em duplicata. Para $\mathrm{Rb}, \mathrm{Sc}$, Se e $\mathrm{Zn}$, a incerteza associada ao resultado utilizando-se padrão multielementar é menor que a incerteza associada ao procedimento com padrão monoelementar. Por outro lado, para As, $\mathrm{Co}, \mathrm{Cr}$ e $\mathrm{Fe}$ este comportamento não foi verificado, isto é, os menores valores para incerteza estão associados ao uso de padrão monoelementar.

Para amostras de matriz geológica, os mensurandos $\mathrm{Co}, \mathrm{Fe}, \mathrm{Sb}$ e $\mathrm{Sc}$ apresentaram como valor para o índice $C E 1,00$, ou seja, a equivalência para a média dos resultados foi de $100 \%$. Para As e Cr obteve-se um índice de 0,99 e para Zn 0,97. Assim como já verificado para amostras de matriz biológica, os resultados para amostras de matriz geológica indicam que não existe diferença significativa entre os resultados obtidos para medições que utilizam padrões mono ou multielementares em INAA para o grupo de mensurandos testados. Estes são argumentos válidos para se 
afirmar que a utilização de um padrão com configuração mono ou multielementar não influencia o resultado da medição para o grupo de mensurandos estudados.

Tabela 8.12. Média dos resultados $\left(\mathrm{mg} \mathrm{kg}^{-1}\right)$ com incerteza expandida, $k=2$, obtidos para o uso de padrões de configuração monoelementar e multielementar para a análise de Sedimento Marinho NRCC MESS $3(n=2)$

\begin{tabular}{cccc}
\hline Mensurando & Padrão monoelementar & Padrão multielementar & $C E$ \\
\hline As & $21,9 \pm 1,0$ & $22,1 \pm 1,1$ & 0,99 \\
$\mathrm{Co}$ & $14,60 \pm 0,79$ & $14,58 \pm 0,082$ & 1,00 \\
$\mathrm{Cr}$ & $101,3 \pm 6,3$ & $100,6 \pm 6,7$ & 0,99 \\
$\mathrm{Fe}$ & $43861 \pm 1499$ & $44012 \pm 2035$ & 1,00 \\
$\mathrm{Sb}$ & $1,069 \pm 0,042$ & $1,065 \pm 0,054$ & 1,00 \\
$\mathrm{Sc}$ & $15,88 \pm 0,65$ & $15,88 \pm 0,62$ & 1,00 \\
$\mathrm{Zn}$ & $160 \pm 10$ & $165 \pm 11$ & 0,97 \\
\hline
\end{tabular}

Verificou-se que houve o aumento ao valor da incerteza associada aos resultados para o uso de padrão multielementar para $\mathrm{As}, \mathrm{Co}, \mathrm{Cr}, \mathrm{Fe}, \mathrm{Sb}$ e $\mathrm{Zn}$ quando comparado ao procedimento com padrão monoelementar. Para a medição de Sc, foi observado o comportamento contrário. Contudo, este fato parece não afetar significativamente o resultado final das medições.

Tendo em vista o fato de que a utilização de um padrão multielementar reduz o tempo necessário para preparo e medição dos experimentos (uma vez que se utiliza apenas 1 e não 9 padrões analíticos) e de que com um menor número de padrões maior é o número de amostras que podem ser inseridas em um mesmo lote experimental, definiu-se para este trabalho de validação a utilização de um único padrão multielementar que contenha todos os mensurandos do escopo de validação.

A avaliação sobre a influência referente à variação no tempo de medição da atividade dos mensurandos no padrão analítico também foi realizada em duplicata para os mesmos MRCs. Calculou-se os resultados para três diferentes tempos de medição de um mesmo padrão analítico (20 min, $40 \mathrm{~min}$ e $60 \mathrm{~min}$ ) para cada uma das amostras.

Neste estudo, o principal objetivo foi a avaliação da influência associada à alteração do tempo de medição da atividade dos mensurandos do padrão sintético, cujo tempo padrão - para a maioria dos pesquisadores do LAN - é de 60 minutos. A hipótese 
foi que devido a natureza de confecção dos padrões (elevada concentração, ausência de interferentes, elevada atividade induzida e baixos valores para estatística de contagem (entre $0,1 \%$ e $4 \%$ ) o tempo de medição da atividade dos mensurandos do padrão analítico esteja superestimado e que a redução deste tempo não afetaria significativamente o resultado final. As Tabelas 8.13 e 8.14 apresentam os resultados obtidos para as diferentes matrizes estudadas (média e desvio padrão, $n=2$ ).

Tabela 8.13. Média dos resultados $\left(\mathrm{mg} \mathrm{kg}^{-1}\right)$ com incerteza expandida, $k=2$, obtidos para diferentes tempos de medição da atividade dos mensurandos do padrão sintético para amostras de Tecido de Mexilhão IPEN TM-1 $(n=2)$

\begin{tabular}{cccc}
\hline \multirow{2}{*}{ Mensurando } & \multicolumn{3}{c}{ Tempo de medição (min) } \\
\cline { 2 - 4 } & 20 & 40 & 60 \\
\hline As & $13,91 \pm 0,22$ & $13,77 \pm 0,19$ & $13,79 \pm 0,13$ \\
$\mathrm{Co}$ & $0,856 \pm 0,046$ & $0,854 \pm 0,041$ & $0,854 \pm 0,039$ \\
$\mathrm{Cr}$ & $1,17 \pm 0,18$ & $1,14 \pm 0,10$ & $1,16 \pm 0,10$ \\
$\mathrm{Fe}$ & $624 \pm 15$ & $615 \pm 13$ & $621 \pm 12$ \\
$\mathrm{Rb}$ & $4,97 \pm 0,21$ & $4,89 \pm 0,20$ & $4,85 \pm 0,18$ \\
$\mathrm{Sc}$ & $0,1999 \pm 0,0023$ & $0,1999 \pm 0,0022$ & $0,1999 \pm 0,0018$ \\
$\mathrm{Se}$ & $4,55 \pm 0,17$ & $4,55 \pm 0,12$ & $4,57 \pm 0,11$ \\
$\mathrm{Zn}$ & $118,3 \pm 1,1$ & $118,1 \pm 1,0$ & $118,2 \pm 1,0$ \\
\hline
\end{tabular}

Tabela 8.14. Média dos resultados $\left(\mathrm{mg} \mathrm{kg}^{-1}\right)$ com incerteza expandida, $k=2$, obtidos para diferentes tempos de medição da atividade dos mensurandos do padrão sintético para amostras de Sedimento Marinho NRCC MESS $3(n=2)$

\begin{tabular}{cccc}
\hline \multirow{2}{*}{ Mensurando } & \multicolumn{3}{c}{ Tempo de medição (min) } \\
\cline { 2 - 4 } & 20 & 40 & 60 \\
\hline As & $20,6 \pm 1,2$ & $21,0 \pm 1,0$ & $21,32 \pm 0,92$ \\
Co & $14,44 \pm 0,74$ & $14,21 \pm 0,72$ & $14,21 \pm 0,65$ \\
Cr & $102,8 \pm 6,5$ & $105,0 \pm 6,3$ & $103,5 \pm 6,2$ \\
Fe & $44123 \pm 1163$ & $43754 \pm 1007$ & $43670 \pm 984$ \\
$\mathrm{Sb}$ & $1,069 \pm 0,049$ & $1,063 \pm 0,032$ & $1,063 \pm 0,029$ \\
$\mathrm{Sc}$ & $16,02 \pm 0,59$ & $16,00 \pm 0,56$ & $16,01 \pm 0,56$ \\
$\mathrm{Zn}$ & $158 \pm 14$ & $156 \pm 10$ & $155,5 \pm 9,7$ \\
\hline
\end{tabular}


De acordo com os resultados apresentados nas Tabela 8.13 e 8.14, é possível observar a existência de uma tendência para a redução do valor da incerteza a medida em que se aumenta o tempo de medição do padrão sintético para ambas as matrizes. Isso se deve ao fato de que a incerteza na atividade do padrão sintético (estatística de contagem) é a maior fonte de incerteza para medições em INAA. A estatística de contagem está intimamente relacionada ao tempo de medição. Quanto maior o tempo de medição, uma menor estatística de contagem é esperada (ao menos para os mensurandos deste estudo). Resultados obtidos para diferentes tempos de medição da atividade do mensurando nos padrões sintéticos foram considerados equivalentes.

O fator tempo de medição da atividade dos mensurandos no padrão sintético não apresentou contribuição significativa para a otimização dos métodos de medição. Durante esseo estudo, todas as amostras utilizadas fizeram parte de um mesmo lote de análise e que o padrão sintético utilizado foi o mesmo para ambas as matrizes (biológica e geológica), e assim consequentemente ambas as amostras (Tecido de Mexilhão IPEN TM-1 e Sedimento Marinho NRCC MESS 3). Através deste estudo, decidiu-se definir o tempo de contagem da atividade dos mensurandos nos padrões sintéticos em 20 minutos para os métodos que fazem parte deste trabalho de validação.

Estudos específicos que venham requerer uma diminuição da incerteza relacionada à estatística de contagem deverão ter uma configuração analítica com maior tempo de medição para padrões sintéticos e amostras. Esta estratégia é bastante plausível para os mensurandos estudados neste trabalho, visto que isso favorece a diminuição da contribuição relacionada a esta fonte de incerteza. Para outros mensurandos, cujo tempo de meia vida para o decaimento radioativo do radionuclídeo seja menor, uma investigação de caso deve ser realizada visando definir uma estratégia adequada.

\subsubsection{Otimização multivariada para os parâmetros de detecção (Planejamento Fatorial, DOE)}

Procedimentos de otimização multivariada são amplamente utilizados para a otimização das diversas variáveis que influenciam o resultado final de um processo. Ao longo dos anos esse procedimento ganhou grande importância - especialmente no 
cenário industrial - na otimização monoelementar de procedimentos, isto é, de uma única variável resposta. Neste trabalho foi-se um passo adiante disso.

Em um primeiro momento realizou-se o procedimento tradicional do DOE, ou seja, visando a otimização de uma variável resposta por vez. Em um segundo momento, aplicou-se os mesmos procedimentos do DOE para a otimização de métodos multielementar visando-se identificar a importância dos fatores estudados não somente para um único, mas para um conjunto de mensurandos, um conjunto de variáveis respostas.

Deste trabalho dois artigos foram elaborados. Um primeiro artigo, com a primeira etapa do trabalho foi apresentado no 2013 International Nuclear Atlantic Conference (INAC 2013), estando disponível para consulta no Anexo 3. O artigo completo com a descrição da segunda etapa deste estudo inédito em INAA foi apresentado no 4th International Nuclear Chemistry Congress (4th INCC) e submetido para publicação no Journal of Radioanalytical and Nuclear Chemistry (JRNC) nos anais do 4th INCC (Anexo 4).

A Tabela 8.15 apresenta a média e o desvio padrão dos resultados obtidos em cada experimento (cujo desenho experimental foi apresentado no item 7.8.2) para amostras Tecido de Mexilhão IPEN TM-1 (MÉTODO BIO-2). A Tabela 8.17 apresenta os resultados e valores obtidos para cada efeito no DOE, também para matriz biológica.

De acordo com os resultados, foi possível verificar que o fator mais importante para a otimização dos procedimentos de INAA para matriz biológica é o tempo de decaimento da amostra (A) $(p<0,05)$. Ainda, a interação entre os fatores AB $(p<0,05)$ apresentou-se como o mais correto caminho para a otimização multivariada dos procedimentos. Por outro lado os fatores distância entre amostra e detector (B) e tempo de contagem da amostra (C) parecem não apresentar nenhuma influência significativa sobre o resultado final, corroborando com os resultados encontrados no Item 8.4.1. As interações entre os fatores $\mathrm{AC}, \mathrm{BC}$, e $\mathrm{ABC}$ também não apresentaram significância para o procedimento de otimização multivariada. 
Tabela 8.15. Resultados obtidos nos experimentos do Planejamento Fatorial $2^{3}$ para amostras de Tecido de Mexilhão IPEN TM-1

\begin{tabular}{|c|c|c|c|c|c|c|c|c|c|c|}
\hline \multirow[t]{2}{*}{ Experimento } & \multicolumn{3}{|c|}{ Fator e nível } & \multicolumn{7}{|c|}{ Resultado, $\mathrm{mg} \mathrm{kg}^{-1}$ (média \pm desvio padrão, $n=3$ ) } \\
\hline & A & $\mathrm{B}$ & $\mathrm{C}$ & Co & $\mathrm{Cr}$ & $\mathrm{Fe}$ & $\mathrm{Rb}$ & Sc & $\mathrm{Se}$ & $\mathrm{Zn}$ \\
\hline e1 & -1 & -1 & -1 & $1,229 \pm 0,091$ & $0,83 \pm 0,26$ & $774 \pm 110$ & $4,52 \pm 0,14$ & $0,2070 \pm 0,0049$ & $4,52 \pm 0,38$ & $144 \pm 13$ \\
\hline $\mathrm{e} 2$ & +1 & -1 & -1 & $0,854 \pm 0,071$ & $0,87 \pm 0,24$ & $633 \pm 54$ & $4,04 \pm 1,11$ & $0,2072 \pm 0,0041$ & $4,29 \pm 0,42$ & $121,9 \pm 8,0$ \\
\hline e3 & -1 & +1 & -1 & $1,014 \pm 0,084$ & $1,15 \pm 0,43$ & $670 \pm 84$ & $4,53 \pm 0,15$ & $0,2063 \pm 0,0057$ & $4,76 \pm 0,59$ & $122,2 \pm 9,3$ \\
\hline e4 & -1 & -1 & +1 & $1,200 \pm 0,087$ & $1,17 \pm 0,23$ & $682 \pm 102$ & $4,56 \pm 0,14$ & $0,2050 \pm 0,0042$ & $4,56 \pm 0,38$ & $142 \pm 11$ \\
\hline e5 & +1 & +1 & -1 & $0,839 \pm 0,071$ & $1,21 \pm 0,27$ & $632 \pm 33$ & $4,73 \pm 0,32$ & $0,1998 \pm 0,0033$ & $4,73 \pm 0,27$ & $118,2 \pm 6,7$ \\
\hline e6 & +1 & -1 & +1 & $0,853 \pm 0,067$ & $0,91 \pm 0,46$ & $627 \pm 44$ & $4,61 \pm 0,79$ & $0,2049 \pm 0,0019$ & $4,45 \pm 0,30$ & $123,3 \pm 6,5$ \\
\hline $\mathrm{e} 7$ & -1 & +1 & +1 & $1,001 \pm 0,080$ & $1,29 \pm 0,33$ & $667 \pm 93$ & $4,59 \pm 0,14$ & $0,2075 \pm 0,0044$ & $4,59 \pm 0,47$ & $118,8 \pm 8,9$ \\
\hline e8 & +1 & +1 & +1 & $0,836 \pm 0,045$ & $1,19 \pm 0,26$ & $631 \pm 36$ & $4,81 \pm 0,35$ & $0,2001 \pm 0,0020$ & $4,57 \pm 0,35$ & $118,1 \pm 6,9$ \\
\hline \multicolumn{4}{|c|}{ Valor Certificado $^{a}$} & $0,829 \pm 0,077$ & $1,24 \pm 0,28$ & $593 \pm 53$ & $4,93 \pm 0,92$ & $0,199 \pm 0,023$ & $4,42 \pm 0,45$ & $118,5 \pm 9,5$ \\
\hline
\end{tabular}

${ }^{\mathrm{a}}$ Valor certificado e incerteza expandida, $k=2$ (MOREIRA, 2010)

Tabela 8.16. Resultados obtidos nos experimentos do Planejamento Fatorial $2^{3}$ para amostras de Sedimento de Estuário NIST SRM 1646a

\begin{tabular}{|c|c|c|c|c|c|c|c|c|}
\hline \multirow[t]{2}{*}{ Experimento } & \multicolumn{3}{|c|}{ Fator e nível } & \multicolumn{5}{|c|}{ Resultado, $\mathrm{mg} \mathrm{kg}^{-1}$ (média \pm desvio padrão, $n=2$ ) } \\
\hline & $\mathrm{A}$ & $\mathrm{B}$ & $\mathrm{C}$ & Co & $\mathrm{Cr}$ & $\mathrm{Fe}$ & $\mathrm{Sc}$ & $\mathrm{Zn}$ \\
\hline e1 & -1 & -1 & -1 & $4,03 \pm 0,12$ & $42,10 \pm 0,57$ & $19332 \pm 648$ & $4,940 \pm 0,061$ & $42,79 \pm 0,42$ \\
\hline $\mathrm{e} 2$ & +1 & -1 & -1 & $4,75 \pm 0,17$ & $40,88 \pm 0,18$ & $20428 \pm 387$ & $4,929 \pm 0,066$ & $49,77 \pm 0,42$ \\
\hline e3 & -1 & +1 & -1 & $4,69 \pm 0,21$ & $39,22 \pm 0,13$ & $21289 \pm 401$ & $4,929 \pm 0,057$ & $45,21 \pm 0,13$ \\
\hline e4 & -1 & -1 & +1 & $4,08 \pm 0,20$ & $41,72 \pm 0,29$ & $20840 \pm 177$ & $4,931 \pm 0,061$ & $42,38 \pm 0,98$ \\
\hline e5 & +1 & +1 & -1 & $4,85 \pm 0,13$ & $40,81 \pm 0,10$ & $19982 \pm 170$ & $4,942 \pm 0,056$ & $49,00 \pm 0,11$ \\
\hline e6 & +1 & -1 & +1 & $4,73 \pm 0,13$ & $41,03 \pm 2,05$ & $20347 \pm 508$ & $4,925 \pm 0,064$ & $49,84 \pm 0,15$ \\
\hline e7 & -1 & +1 & +1 & $4,73 \pm 0,15$ & $39,85 \pm 0,14$ & $20219 \pm 950$ & $4,926 \pm 0,066$ & $44,92 \pm 0,16$ \\
\hline e8 & +1 & +1 & +1 & $4,93 \pm 0,10$ & $40,92 \pm 0,10$ & $20417 \pm 446$ & $4,948 \pm 0,057$ & $48,99 \pm 0,12$ \\
\hline \multicolumn{4}{|c|}{ Valor certificado ${ }^{a}$} & $5^{b}$ & $40,9 \pm 1,9$ & $20080 \pm 380$ & $5^{b}$ & $48,9 \pm 1,6$ \\
\hline
\end{tabular}

${ }^{\mathrm{a}}$ Valor certificado e incerteza expandida, $k=2 ;{ }^{b}$ Valor informativo (não certificado) (NIST, 2004) 
Tabela 8.17. Efeitos principais (A; B; C) e contrastes (A:B; A:C; B:C; A:B:C) em INAA para amostras de Tecido de Mexilhão IPEN TM-1

\begin{tabular}{ccccc}
\hline Interação & Efeito & Erro & $t$-valor & $p$-valor \\
\hline A & $-8,9$ E-02 & 2,6 E-02 & $-3,46$ & 7,0 E-04 \\
B & $-6,9$ E-05 & 2,6 E-02 & $-2,7$ E-03 & 0,99 \\
C & 8,7 E-03 & 2,6 E-02 & 0,34 & 0,74 \\
A:B & 4,7 E-02 & 2,6 E-02 & 1,84 & 6,7 E-02 \\
A:C & 1,4 E-03 & 2,6 E-02 & 5,4 E-02 & 0,96 \\
B:C & $-8,5$ E-03 & 2,6 E-02 & $-0,33$ & 0,74 \\
A:B:C & $-7,1$ E-03 & 2,6 E-02 & $-0,28$ & 0,78 \\
\hline
\end{tabular}

$n=160 ; t_{(\alpha=0.05)} \sim 1.98($ NIST/SEMANTECH, 2013$)$

Tabela 8.18. Efeitos principais $(A ; B ; C)$ e contrastes (A:B; A:C; B:C; A:B:C) em INAA para amostras de Sedimento de Estuário NIST SRM 1646a

\begin{tabular}{ccccc}
\hline Interação & Efeito & Erro & $t$-valor & $p$-valor \\
\hline A & $4,0 \mathrm{E}-02$ & $1,2 \mathrm{E}-02$ & 3,32 & $1,4 \mathrm{E}-03$ \\
B & $1,6 \mathrm{E}-02$ & $1,2 \mathrm{E}-02$ & 1,32 & 0,19 \\
C & $3,2 \mathrm{E}-03$ & $1,2 \mathrm{E}-02$ & 0,26 & 0,79 \\
A:B & $-1,5 \mathrm{E}-02$ & $1,2 \mathrm{E}-02$ & $-1,26$ & 0,21 \\
A:C & $4,7 \mathrm{E}-04$ & $1,2 \mathrm{E}-02$ & 0,04 & 0,97 \\
B:C & $-2,8 \mathrm{E}-03$ & $1,2 \mathrm{E}-02$ & $-0,23$ & 0,82 \\
A:B:C & $7,2 \mathrm{E}-03$ & $1,2 \mathrm{E}-02$ & 0,60 & 0,55 \\
\hline
\end{tabular}

$n=72 ; t_{(\alpha=0.05)} \sim 1.99($ NIST/SEMANTECH, 2013)

Resultados obtidos para Sedimento de Estuário NIST SRM $1646 a$ (MÉTODO GEO-2) são apresentados nas Tabelas 8.16 e 8.18. Estes resultados corroboram aos encontrados para Tecido de Mexilhão IPEN TM-1, sugerindo que a otimização de métodos de medição em INAA independe da natureza da amostra e está fortemente correlacionada ao fator $\mathrm{A}(p<0,05)$. A interação $\mathrm{AB}(p<0,05)$, especialmente para As, Co e Cr demonstrou ser bastante significativa. Os fatores B e C a as interações $\mathrm{AC}, \mathrm{BC}$ e $\mathrm{ABC}$ não apresentaram resultados significativos para nenhum dos mensurandos em amostras de Sedimento de Estuário NIST SRM 1646a. 
De acordo com os resultados observados para o estudo de otimização multivariada dos métodos de medição (Planejamento Fatorial, DOE), foi possível definir as melhores condições analítica quanto a exatidão dos resultados para o conjunto de variáveis estudadas. Este estudo, que é inédito, trouxe valiosas informações sobre as características do processo de detecção por espectrometria de raios gama para os métodos de INAA. Em função dos resultados obtidos, foi possível delinear-se as condições padrão para cada um dos métodos de medição, em que se obtiveram resultados mais exatos.

\subsection{Validação dos métodos de medição}

\subsubsection{Delineamento das condições específicas para os métodos de medição}

A Tabela 8.19 apresenta o delineamento para os diferentes métodos de medição, após realizadas todas asa etapas de otimização e do estudo de planejamento fatorial. Todo o processo de validação dos métodos foi realizado de acordo com as informações descritas nesta tabela.

Visando a comparação com estudos futuros, o tempo-morto - isto é, o tempo que o espectrômetro não consegue registrar o sinal referente aos raios gama advindos das amostras e padrões irradiados - das medições para as amostras foi entre 7 $\%$ e $18 \%$ para matriz geológica e entre $2 \%$ e $16 \%$ para matriz biológica. O tempomorto referente à medição dos padrões sintéticos ficou entre $1 \%$ e $3 \%$ para todos os experimentos. Valores muitos discrepantes a estes devem ter seus resultados avaliados com cautela, visto que a estimativa dos valores para os parâmetros de validação e para incerteza expandida associada à concentração dos mensurandos pode ser alterada, particularmente para os casos onde o valor para o tempo-morto seja muito superior aos característicos deste estudo de validação. 
Tabela 8.19. Delineamento das condições padrão para cada método de medição

\begin{tabular}{|c|c|c|c|c|}
\hline & Método- $B I O-1$ & Método-GEO-1 & Método-BIO-2 & Método-GEO-2 \\
\hline Matriz & Biológica & Geológica & Biológica & Geológica \\
\hline Mensurando(s) & As & As e $\mathrm{Sb}$ & $\begin{array}{c}\mathrm{Co}, \mathrm{Cr}, \mathrm{Fe}, \mathrm{Rb} \\
\mathrm{Sc}, \text { Se e } \mathrm{Zn}\end{array}$ & $\begin{array}{c}\mathrm{Co}, \mathrm{Cr}, \mathrm{Fe}, \mathrm{Sc} \mathrm{e} \\
\mathrm{Zn}\end{array}$ \\
\hline $\begin{array}{c}\text { Tempo de decaimento após a } \\
\text { irradiação }\end{array}$ & $7-8$ dias & 7-8 dias & 20-22 dias & $20-22$ dias \\
\hline $\begin{array}{c}\text { Tempo de medição para } \\
\text { amostras }\end{array}$ & 60 minutos & 60 minutos & 360 minutos & 120 minutos \\
\hline $\begin{array}{c}\text { Tempo de medição para } \\
\text { padrões sintéticos }\end{array}$ & 20 minutos & 20 minutos & 20 minutos & 20 minutos \\
\hline $\begin{array}{c}\text { Distância entre } \\
\text { amostra/padrão e detector }\end{array}$ & $33 \mathrm{~mm}$ & $33 \mathrm{~mm}$ & $3 \mathrm{~mm}$ & $3 \mathrm{~mm}$ \\
\hline Massa de amostra & \multicolumn{4}{|c|}{$150 \pm 10 \mathrm{mg}$} \\
\hline $\begin{array}{c}\text { Geometria das amostras e } \\
\text { padrões }\end{array}$ & \multicolumn{4}{|c|}{$10 \mathrm{~mm} \times 8 \mathrm{~mm} \times 1 \mathrm{~mm}$} \\
\hline Tempo de Irradiação & \multicolumn{4}{|c|}{8 horas } \\
\hline $\begin{array}{c}\text { Massa dos mensurandos nos } \\
\text { padrões sintéticos }\end{array}$ & \multicolumn{4}{|c|}{ Vide Tabela 7.3} \\
\hline Pico analítico do mensurando & \multicolumn{4}{|c|}{ Vide Tabela 8.8} \\
\hline Método de quantificação & \multicolumn{4}{|c|}{ Espectrometria de raios gama } \\
\hline Detector (modelo) & \multicolumn{4}{|c|}{ Detector HPGe - Canberra GC 2018} \\
\hline Analisador de multicanal & \multicolumn{4}{|c|}{ DSA 1000} \\
\hline Software do detector & \multicolumn{4}{|c|}{ Genie 2000 - Gamma Acquisition \& Analysis v. 3.1} \\
\hline Técnica & \multicolumn{4}{|c|}{ INAA } \\
\hline
\end{tabular}

A seguir, foram apresentados e discutidos os resultados para a validação de cada um dos quatro métodos de medição. Para cada método éapresentada uma tabela com todos os resultados resumidos e na sequência estes resultados foramdiscutidos. Para a apresentação dos resultados da estimativa da incerteza de medição e no estudo de robustez do método foi adotado o mesmo procedimento. Os estudos de seletividade e linearidade foram apresentados em um item a parte, visto que para estes parâmetros foi realizado um único estudo para todos os métodos.

Visando facilitar o entendimento dos resultados obtidos, estes foram sumariamente divididos em dois diferentes grupos de métodos, agrupados de acordo com os mensurandos de interesse. Desta forma, o grupo 1 é formado pelo método-BIO-1 (concentração total de As em matrizes biológicas) e método-GEO-1 (concentração total 
de $\mathrm{As}$ e $\mathrm{Sb}$ em matrizes geológicas). Por consequência, o método-BIO-2 (concentração total de $\mathrm{Co}, \mathrm{Cr}, \mathrm{Fe}, \mathrm{Rb}, \mathrm{Sc}, \mathrm{Se}$ e $\mathrm{Zn}$ em matrizes biológicas) e o método-GEO-2 (concentração total de $\mathrm{Co}, \mathrm{Cr}, \mathrm{Fe}, \mathrm{Sc}$ e $\mathrm{Zn}$ em matrizes geológicas) constituem o grupo 2 dos métodos.

\subsubsection{Linearidade, Seletividade e Faixa de Trabalho}

A verificação sobre a existência de linearidade para os resultados obtidos para mensurandos foi realizada através dos resultados encontrados para a análise de 5 diferentes MRCs de matriz biológica, 5 diferentes MRCs de matriz geológica e de 5 padrões sintéticos multielementares (exceto para o MÉTODO BIO-1, cujo padrão é monoelementar) contendo todos os mensurandos estudados em diferentes níveis de concentração. Via de regra, mensurandos característicos para os métodos em matriz biológica tiveram a linearidade dos resultados avaliada somente com os resultados obtidos para os MRCs de matriz biológica e para os padrões. O mesmo se aplica aos mensurandos específicos para os métodos em matriz geológica.

Na prática, o termo concentração não exemplifica o procedimento adotado na análise dos padrões, visto que uma única solução de trabalho foi utilizada. Para avaliar-se as "diferentes concentrações", pipetou-se diferentes volumes da solução de trabalho nos papéis filtro, obtendo-se diferentes 5 diferentes massas dos mensurando. Cada configuração resultou na preparação de um padrão sintético.

A linearidade para cada mensurando foi analisada e constatada através da análise da correlação entre os valores do experimentais e teóricos para os resultados dos MRCs e padrões. Os MRCs utilizados neste estudo foram os mesmos apresentados na Tabela 7.1. Os resultados foram dispostos de maneira gráfica em função da massa do mensurando na amostra. Para converter o valor da concentração dos mensurandos dos MRCs foi utilizada a Equação 41.

$$
m_{m e n}=\frac{m(1-W) x_{v}}{10^{6}}
$$

onde:

$m_{m e n}$ é a massa do mensurando na amostra em função da massa de MRC utilizada no experimento $(\mathrm{mg})$;

$m$ é a massa de MRC utilizada no experimento $(\mathrm{kg})$; 
$W$ é o teor de umidade da amostra de MRC;

e $x_{v}$ é o valor certificado do mensurando no $\operatorname{MRC}\left(\mathrm{mg} \mathrm{kg}^{-1}\right)$.

As Tabelas 8.20 (padrões sintéticos) e 8.21 (MRCs) apresentam os resultados obtidos nos experimentos para verificação da linearidade nos diferentes métodos de medição. A Figura 8.5 apresenta o gráfico para a linearidade dos resultados de cada mensurando.

De acordo com a Resolução-RE no 899/2003 da ANVISA, resultados para o estudo de linearidade são considerados adequados para o método quando obtidos valores maiores ou igual $0,99\left(\mathrm{r}^{2} \geq 0,99\right)$ para o coeficiente de linearidade (ANVISA, 2003). De acordo com esse critério, a linearidade em INAA para todos os mensurandos estudados foi considerada adequada, obtendo-se valores de $r^{2}$ maiores que 0,99 em todos os estudos.

A análise de regressão linear ainda apresenta outro importante dado para a interpretação dos resultados: o coeficiente de intersecção da reta. Alguns autores sugerem a linearidade em INAA pode ser avaliada levando-se em consideração somente o valor do coeficiente de intersecção, chamado de coeficiente não-linear (BODE \& BLAAUW, 2012). De acordo com os autores, é possível fazer o cálculo da regressão linear confrontando os valores e incertezas para os resultados com os de referência (no caso da amostra ser um MRC).Neste trabalho, os valores para o coeficiente de intersecção no estudo de linearidade pelo método de regressão linear ficaram entre 0,007 para Sc e 3,6 para Fe.

Visto que a linearidade foi estimada com os resultados de MRCs e padrões sintéticos multielementar gerando resultados adequados, podemos afirmar a os métodos de INAA possuem elevada seletividade, visto que do contrário não seria verificada uma linearidade adequada para a análise de diferentes MRCs, com diferentes composições. 
Tabela 8.20. Resultados obtidos para os experimentos de linearidade utilizando-se padrões multielementar preparados por diluição $(\mu \mathrm{g})$

\begin{tabular}{|c|c|c|c|c|c|c|c|c|c|}
\hline \multirow[t]{2}{*}{ Amostra } & \multicolumn{9}{|c|}{ Resultado (valor de referência) } \\
\hline & As & Co & $\mathrm{Cr}$ & $\mathrm{Fe}$ & $\mathrm{Rb}$ & $\mathrm{Sb}$ & Sc & $\mathrm{Se}$ & $\mathrm{Zn}$ \\
\hline \multirow{2}{*}{ Padrão1 } & $0,636 \pm 0,023$ & $0,606 \pm 0,019$ & $0,570 \pm 0,018$ & $132,67 \pm 2,84$ & $2,259 \pm 0,075$ & $0,337 \pm 0,011(0,3$ & $0,0588 \pm 0,0031$ & $0,610 \pm 0,026$ & $6,00 \pm 0,19$ \\
\hline & $(0,626 \pm 0,016)$ & $(0,626 \pm 0,015)$ & $(0,628 \pm 0,016)$ & $(125,1 \pm 2,7)$ & $(2,498 \pm 0,064)$ & $131 \pm 0,0081)$ & $(0,0625 \pm 0,0033)$ & $(0,625 \pm 0,035)$ & $(6,26 \pm 0,16)$ \\
\hline \multirow{2}{*}{ Padrão2 } & $1,249 \pm 0,042$ & $1,3236 \pm 0,036$ & $1,304 \pm 0,036$ & $262,3 \pm 5,4$ & $4,98 \pm 0,13$ & $0,642 \pm 0,019$ & $0,1280 \pm 0,0063$ & $1,260 \pm 0,091$ & $12,79 \pm 0,39$ \\
\hline & $(1,251 \pm 0,031)$ & $(1,252 \pm 0,030)$ & $(1,26 \pm 0,032)$ & $(250,2 \pm 5,4)$ & $(4,99 \pm 0,13)$ & $(0,626 \pm 0,016)$ & $(0,1250 \pm 0,0066)$ & $(1,250 \pm 0,070)$ & $(12,51 \pm 0,31)$ \\
\hline \multirow{2}{*}{ Padrão3 } & $2,502 \pm 0,081$ & $2,507 \pm 0,068$ & $2,528 \pm 0,062$ & $493 \pm 11$ & $10,2 \pm 0,27$ & $1,252 \pm 0,042$ & $0,2395 \pm 0,0013$ & $2,50 \pm 0,19$ & $26,13 \pm 0,92$ \\
\hline & $(2,505 \pm 0,063)$ & $(2,505 \pm 0,61)$ & $(2,512 \pm 0,065)$ & $(500 \pm 11)$ & $(9,99 \pm 0,26)$ & $(1,252 \pm 0,032)$ & $(0,2501 \pm 0,0129)$ & $(2,50 \pm 0,14)$ & $(25,03 \pm 0,63)$ \\
\hline \multirow{2}{*}{ Padrão4 } & $5,06 \pm 0,14$ & $4,97 \pm 0,26$ & $4,94 \pm 0,14$ & $751 \pm 27$ & $19,94 \pm 0,52$ & $2,524 \pm 0,084$ & $0,4919 \pm 0,0026$ & $4,88 \pm 0,36$ & $48,5 \pm 1,4$ \\
\hline & $(5,00 \pm 0,13)$ & $(5,01 \pm 0,12)$ & $(5,02 \pm 0,13)$ & $(750 \pm 16)$ & $(19,98 \pm 0,51)$ & $(2,505 \pm 0,65)$ & $(0,500 \pm 0,026)$ & $(5,00 \pm 0,28)$ & $(50,1 \pm 1,3)$ \\
\hline \multirow{2}{*}{ Padrão5 } & $10,01 \pm 0,27$ & $9,46 \pm 0,50$ & $10,034 \pm 0,29$ & $971 \pm 42$ & $37,16 \pm 1,16$ & $5,01 \pm 0,14$ & $1,098 \pm 0,0518$ & $9,91 \pm 0,75$ & $101,8 \pm 2,3$ \\
\hline & $(10,00 \pm 0,25)$ & $(10,02 \pm 0,24)$ & $(10,05 \pm 0,26)$ & $(1000 \pm 22)$ & $(39,96 \pm 1,02)$ & $(5,01 \pm 0,13)$ & $(1,000 \pm 0,052)$ & $(10,00 \pm 0,56)$ & $(100,1 \pm 2,6)$ \\
\hline
\end{tabular}


Tabela 8.21. Resultados obtidos para os experimentos de linearidade para a análise de diferentes MRCs $\left(\mathrm{mg} \mathrm{kg}^{-1}\right)$

\begin{tabular}{|c|c|c|c|c|c|c|c|c|c|}
\hline \multirow[t]{2}{*}{ Amostra } & \multicolumn{9}{|c|}{ Resultado (valor de referência) ${ }^{a, b}$} \\
\hline & As & Co & $\mathrm{Cr}$ & $\mathrm{Fe}$ & $\mathrm{Rb}$ & $\mathrm{Sb}$ & $\mathrm{Sc}$ & $\mathrm{Se}$ & $\mathrm{Zn}$ \\
\hline SRM 1646a & $\begin{array}{c}6,13 \pm 0,31 \\
(6,23 \pm 0,21)\end{array}$ & $\begin{array}{c}4,64 \pm 0,54 \\
(5)^{\mathrm{b}}\end{array}$ & $\begin{array}{c}41,0 \pm 1,9 \\
(40,9 \pm 1,9)\end{array}$ & $\begin{array}{c}20425 \pm 897 \\
(20080 \pm 390)\end{array}$ & $\mathrm{NR}^{\mathrm{c}}$ & $\begin{array}{c}0,355 \pm 0,033 \\
(0,3)^{\mathrm{b}}\end{array}$ & $\begin{array}{c}4,65 \pm 0,20 \\
(5)^{\mathrm{b}}\end{array}$ & $\mathrm{NR}^{\mathrm{c}}$ & $\begin{array}{c}47,2 \pm 4,9 \\
(48,9 \pm 1,6)\end{array}$ \\
\hline SRM 8704 & $\begin{array}{c}17,5 \pm 1,8 \\
(17)^{\mathrm{b}}\end{array}$ & $\begin{array}{c}13,82 \pm 0,97 \\
(13,57 \pm 0,43)\end{array}$ & $\begin{array}{c}125,6 \pm 6,7 \\
(121,9 \pm 3,8)\end{array}$ & $\begin{array}{c}41614 \pm 1265 \\
(39700 \pm 1000)\end{array}$ & $\mathrm{NR}^{\mathrm{c}}$ & $\begin{array}{c}3,039 \pm 0,094 \\
(3,07 \pm 0,32)\end{array}$ & $\begin{array}{c}11,35 \pm 0,26 \\
(11,26 \pm 0,19)\end{array}$ & $\mathrm{NR}^{\mathrm{c}}$ & $\begin{array}{c}403 \pm 19 \\
(408 \pm 15)\end{array}$ \\
\hline MESS 3 & $\begin{array}{c}22,4 \pm 1,4 \\
(21,2 \pm 1,1)\end{array}$ & $\begin{array}{c}14,25 \pm 0,84 \\
(14,4 \pm 2)\end{array}$ & $\begin{array}{c}102,2 \pm 6,1 \\
(105 \pm 4)\end{array}$ & $\begin{array}{c}41274 \pm 1308 \\
(43400 \pm 1100)\end{array}$ & $\mathrm{NR}^{\mathrm{c}}$ & $\begin{array}{c}1,059 \pm 0,084 \\
(1,02 \pm 0,09)\end{array}$ & $\mathrm{NR}^{\mathrm{c}}$ & $\mathrm{NR}^{\mathrm{c}}$ & $\begin{array}{l}151 \pm 10 \\
(159 \pm 8)\end{array}$ \\
\hline BCR 667 & $\mathrm{NR}^{\mathrm{c}}$ & $\begin{array}{l}22,4 \pm 1,3 \\
(23 \pm 1,3)\end{array}$ & $\begin{array}{c}171 \pm 12 \\
(178 \pm 16)\end{array}$ & $\begin{array}{c}44325 \pm 1376 \\
(44800 \pm 1000)\end{array}$ & $\mathrm{NR}^{\mathrm{c}}$ & $\begin{array}{c}0,982 \pm 0,062 \\
(0,96 \pm 0,05)\end{array}$ & $\begin{array}{c}13,81 \pm 0,31 \\
(13,7 \pm 0,7)\end{array}$ & $\mathrm{NR}^{\mathrm{c}}$ & $\begin{array}{c}185 \pm 11 \\
(175 \pm 13)\end{array}$ \\
\hline SRM 2702 & $\begin{array}{c}44,2 \pm 1,6 \\
(45,3 \pm 1,8)\end{array}$ & $\begin{array}{c}27,3 \pm 1,2 \\
(27,76 \pm 0,58)\end{array}$ & $\begin{array}{c}368 \pm 13 \\
(352 \pm 22)\end{array}$ & $\begin{array}{c}77870 \pm 1870 \\
(79100 \pm 2400)\end{array}$ & $\mathrm{NR}^{\mathrm{c}}$ & $\begin{array}{l}5,53 \pm 0,33 \\
(5,6 \pm 0,24)\end{array}$ & $\begin{array}{c}25,78 \pm 0,64 \\
(25,9 \pm 1,1)\end{array}$ & $\mathrm{NR}^{\mathrm{c}}$ & $\begin{array}{c}479 \pm 11 \\
(485,3 \pm 4,2)\end{array}$ \\
\hline SRM 2976 & $\begin{array}{c}11,9 \pm 1,4 \\
(13,3 \pm 1,8)\end{array}$ & $\begin{array}{c}0,6595 \pm 0,052 \\
(0,61 \pm 0,02)\end{array}$ & $\begin{array}{c}0,480 \pm 0,024 \\
(0,5 \pm 0,16)\end{array}$ & $\begin{array}{c}188 \pm 16 \\
(171 \pm 4,9)\end{array}$ & $\begin{array}{c}4,12 \pm 0,12 \\
(4,14 \pm 0,09)\end{array}$ & $\mathrm{NR}^{\mathrm{c}}$ & $\mathrm{NR}^{\mathrm{c}}$ & $\begin{array}{l}1,81 \pm 0,16 \\
(1,8 \pm 0,15)\end{array}$ & $\begin{array}{c}125 \pm 14 \\
(137 \pm 13)\end{array}$ \\
\hline SRM 1566b & $\begin{array}{c}7,32 \pm 0,43 \\
(7,65 \pm 0,65)\end{array}$ & $\begin{array}{c}0,366 \pm 0,018 \\
(0,371 \pm 0,009)\end{array}$ & $\mathrm{NR}^{\mathrm{c}}$ & $\begin{array}{c}206 \pm 10 \\
(205,8 \pm 6,8)\end{array}$ & $\begin{array}{c}3,51 \pm 0,17 \\
(3,26 \pm 0,14)\end{array}$ & $\mathrm{NR}^{\mathrm{c}}$ & $\mathrm{NR}^{\mathrm{c}}$ & $\begin{array}{c}1,94 \pm 0,11 \\
(2,06 \pm 0,15)\end{array}$ & $\begin{array}{l}1477 \pm 106 \\
(1424 \pm 46)\end{array}$ \\
\hline DORM 2 & $\begin{array}{c}16,55 \pm 0,71 \\
(18 \pm 1,1)\end{array}$ & $\begin{array}{c}0,189 \pm 0,010 \\
(0,182 \pm 0,031)\end{array}$ & $\begin{array}{c}40,8 \pm 3,6 \\
(34,7 \pm 5,5)\end{array}$ & $\begin{array}{c}160 \pm 15 \\
(142 \pm 10)\end{array}$ & $\mathrm{NR}^{\mathrm{c}}$ & $\mathrm{NR}^{\mathrm{c}}$ & $\mathrm{NR}^{\mathrm{c}}$ & $\begin{array}{c}1,388 \pm 0,081 \\
(1,4 \pm 0,09)\end{array}$ & $\begin{array}{c}22,9 \pm 1,7 \\
(25,6 \pm 2,3)\end{array}$ \\
\hline IAEA 407 & $\begin{array}{c}12,22 \pm 0,66 \\
(12,6 \pm 0,3)\end{array}$ & $\begin{array}{c}0,096 \pm 0,0022 \\
(0,1 \pm 0,01)\end{array}$ & $\begin{array}{l}0,81 \pm 0,052 \\
(0,73 \pm 0,06)\end{array}$ & $\begin{array}{c}158,3 \pm 9,3 \\
(146 \pm 3)\end{array}$ & $\begin{array}{c}3,15 \pm 0,13 \\
(2,86 \pm 0,41)\end{array}$ & $\mathrm{NR}^{\mathrm{c}}$ & $\mathrm{NR}^{\mathrm{c}}$ & $\begin{array}{c}2,88 \pm 0,11 \\
(2,83 \pm 0,13)\end{array}$ & $\begin{array}{c}64,2 \pm 2,1 \\
(67,1 \pm 0,8)\end{array}$ \\
\hline IPEN TM 1 & $\begin{array}{c}12,64 \pm 0,84 \\
(13,6 \pm 1,7)\end{array}$ & $\begin{array}{c}0,832 \pm 0,032 \\
(0,829 \pm 0,077)\end{array}$ & $\begin{array}{c}1,26 \pm 0,19 \\
(1,24 \pm 0,28)\end{array}$ & $\begin{array}{c}576 \pm 23 \\
(593 \pm 53)\end{array}$ & $\begin{array}{c}4,88 \pm 0,23 \\
(4,93 \pm 0,92)\end{array}$ & $\mathrm{NR}^{\mathrm{c}}$ & $\mathrm{NR}^{\mathrm{c}}$ & $\begin{array}{c}4,54 \pm 0,34 \\
(4,42 \pm 0,45)\end{array}$ & $\begin{array}{r}110,2 \pm 8,3 \\
(118,5 \pm 9,5)\end{array}$ \\
\hline
\end{tabular}

a) incerteza corresponde a incerteza expandida, $k=2$; b) valor informativo, não certificado; c) NR representa que a análise não foi realizada 


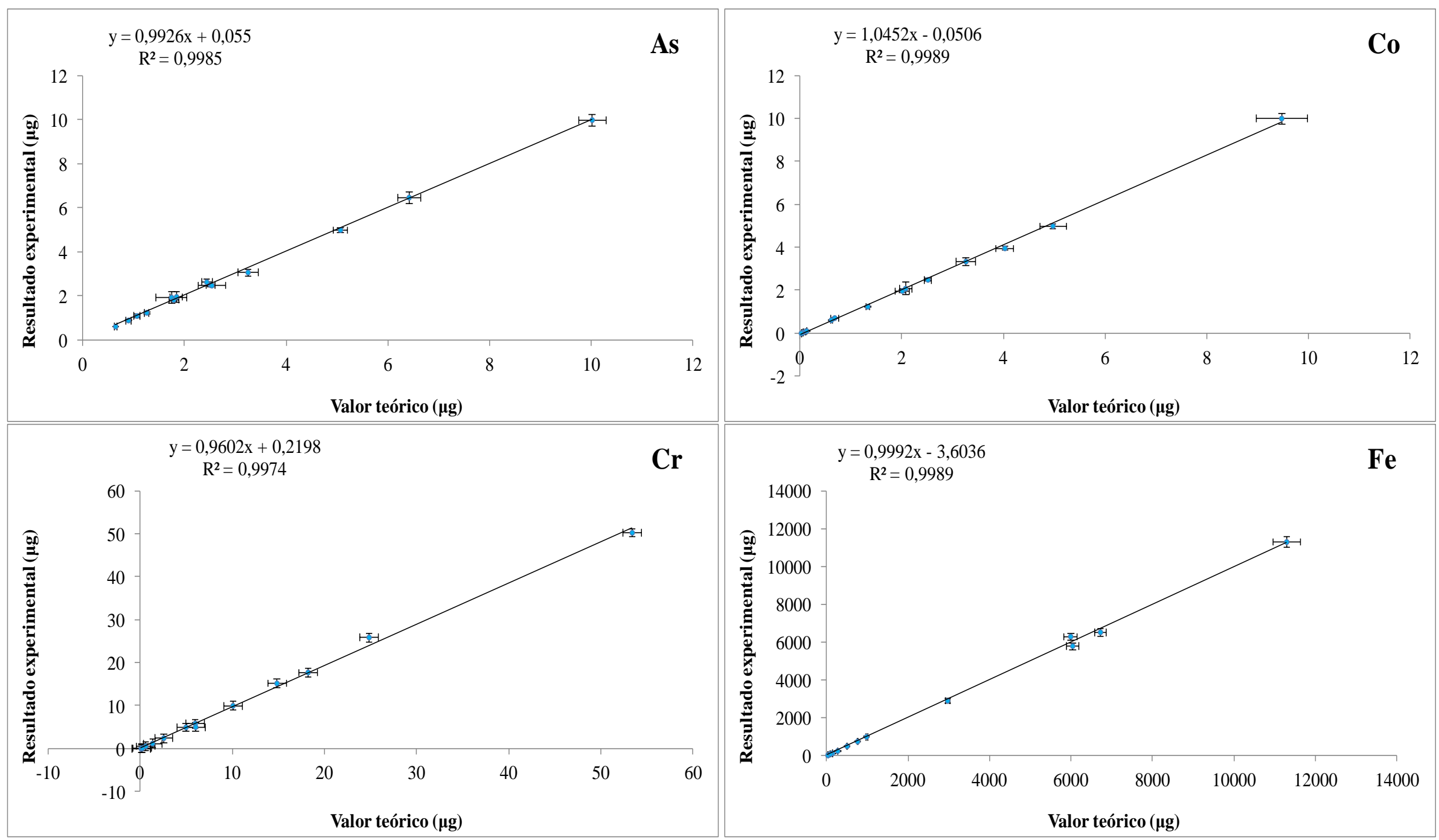

Figura 8.5. Resultados de linearidade para cada mensurando 


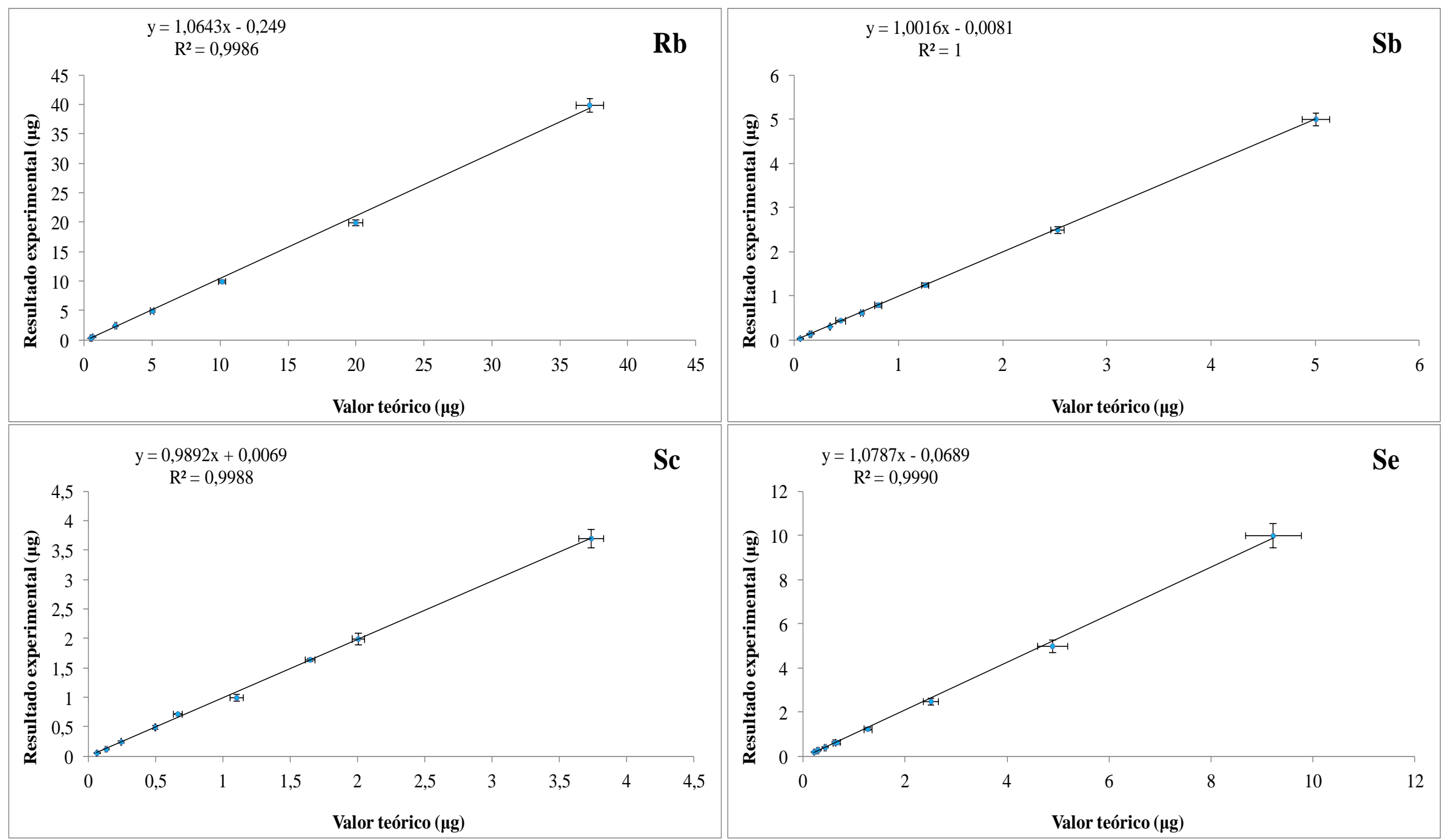

Figura 8.5. Resultados de linearidade para cada mensurando (continuação) 


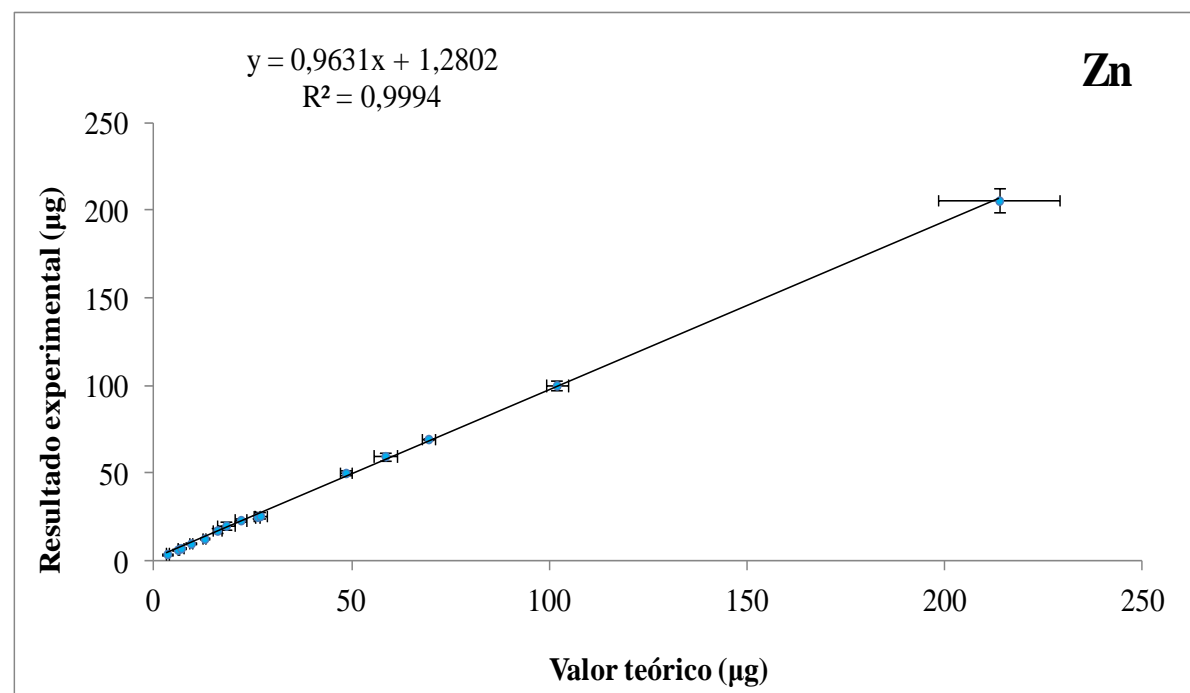

Figura 8.5. Resultados de linearidade para cada mensurando (continuação)

A Tabela 8.22 apresenta a faixa de trabalho cuja linearidade e seletividade foram estudadas. Esta tem como limite inferior ao valor do LQ do mensurando no respectivo método e como limite superior o maior valor de concentração verificada para uma amostra nos estudos de linearidade e seletividade.

Tabela 8.22. Faixa de trabalho para cada mensurando em INAA

\begin{tabular}{ccc}
\hline Método & Mensurando & Faixa de trabalho $\left(\mathrm{mg} \mathrm{kg}^{-1}\right)$ \\
\hline Método BIO-1 & $\mathrm{As}$ & $2,1-69$ \\
\hline Método GEO-1 & $\mathrm{As}$ & $1,8-69$ \\
& $\mathrm{Sb}$ & $0,27-35$ \\
\hline Método BIO-2 & $\mathrm{Co}$ & $0,025-65$ \\
& $\mathrm{Cr}$ & $0,48-69$ \\
& $\mathrm{Fe}$ & $13-79100$ \\
& $\mathrm{Rb}$ & $0,93-256$ \\
& $\mathrm{Sc}$ & $0,028-26$ \\
& $\mathrm{Se}$ & $0,54-64$ \\
& $\mathrm{Zn}$ & $1,1-1424$ \\
Método GEO-2 & $\mathrm{Co}$ & $0,51-65$ \\
& $\mathrm{Cr}$ & $4,2-69$ \\
& $\mathrm{Fe}$ & $411-79100$ \\
& $\mathrm{Sc}$ & $0,069-26$ \\
& $\mathrm{Zn}$ & $16-1424$
\end{tabular}




\subsubsection{Método-BIO-1 e método-GEO-1}

A Tabela 8.23 apresenta os resultados de validação para o método-BIO-1 (Tecido de Mexilhão IPEN TM-1) e a Tabela 8.24 apresenta os resultados de validação para o método-GEO-1 (Sedimento Marinho NIST SRM 2702).

Tabela 8.23. Resultados de validação para o método-BIO-1

\begin{tabular}{cccc}
\hline Parâmetro de Validação & $n$ & $E n$ & Resultado \\
\cline { 2 - 4 } & 7 & 0,24 & $0,53 \mathrm{mg} \mathrm{kg}^{-1}$ \\
\hline Limite de repetitividade & 26 & 0,52 & $0,81 \mathrm{mg} \mathrm{kg}^{-1}$ \\
Precisão Intermediária & 26 & 0,52 & $2,3 \mathrm{mg} \mathrm{kg}^{-1}$ \\
Limite de reprodutibilidade & 5 & $-0,15$ & $0,79 \mathrm{mg} \mathrm{kg}^{-1}$ \\
Limite de detecção & 5 & $-0,15$ & $2,1 \mathrm{mg} \mathrm{kg}^{-1}$ \\
Limite de quantificação & 5 & $-0,15$ & $3,6-5,5 \%$ \\
Incerteza expandida relativa, $k=2$ & & Adequada $(-1,0<E n<1,0)$ \\
Veracidade & \multicolumn{2}{c}{}
\end{tabular}

Tabela 8.24. Resultados de validação para o método-GEO-1

\begin{tabular}{cccc}
\hline Parâmetro de Validação & \multicolumn{3}{c}{ As } \\
\cline { 2 - 4 } & $n$ & $0 n$ & Resultado \\
\hline Limite de repetitividade & 7 & 0,50 & $0,72 \mathrm{mg} \mathrm{kg}^{-1}$ \\
Precisão Intermediária & 28 & 0,05 & $1,3 \mathrm{mg} \mathrm{kg}^{-1}$ \\
Limite de reprodutibilidade & 28 & 0,05 & $3,6 \mathrm{mg} \mathrm{kg}^{-1}$ \\
Limite de detecção & 5 & $-0,32$ & $0,59 \mathrm{mg} \mathrm{kg}^{-1}$ \\
Limite de quantificação & 5 & $-0,32$ & $1,8 \mathrm{mg} \mathrm{kg}^{-1}$ \\
Incerteza expandida relativa, $k=2$ & 5 & $-0,32$ & $3,7-4,2 \%$ \\
Veracidade & & Adequada $(-1,0<E n<1,0)$ \\
\cline { 2 - 4 } & \multicolumn{2}{c}{$\mathrm{Sb}$} \\
Limite de repetitividade & $n$ & $E n$ & $\mathrm{Resultado}^{-}$ \\
Precisão Intermediária & 7 & $-0,24$ & $0,16 \mathrm{mg} \mathrm{kg}^{-1}$ \\
Limite de reprodutibilidade & 28 & 0,01 & $0,34 \mathrm{mg} \mathrm{kg}^{-1}$ \\
Limite de detecção & 28 & 0,01 & $0,96 \mathrm{mg} \mathrm{kg}^{-1}$ \\
Limite de quantificação & 5 & 0,06 & $0,089 \mathrm{mg} \mathrm{kg}^{-1}$ \\
Incerteza expandida relativa, $k=2$ & 5 & 0,06 & $0,27 \mathrm{mg} \mathrm{kg}^{-1}$ \\
Veracidade & 5 & 0,06 & $3,3-4,6 \%$ \\
\hline & & Adequada $(-1,0<E n<1,0)$ \\
\hline
\end{tabular}


De acordo com os resultados, a mínima variação natural esperada para dois ou mais resultados (repetitividade) obtidos para a medição da concentração total de As em amostras biológicas é de $0,53 \mathrm{mg} / \mathrm{kg}$ (método-BIO-1). Para amostras geológicas (método-GEO-1), o limite de repetitividade para As foi 0,72 mg/kg, resultado bastante similar ao encontrado para o método-BIO-1.

Esse fato de certa forma é esperado para INAA, visto que a técnica independe da matriz de estudo e que os métodos do grupo 1 apresentam exatamente os mesmos valores para as variáveis estudadas. Ainda para o método-GEO-1, o limite de repetitividade para $\mathrm{Sb}$ foi $0,16 \mathrm{mg} / \mathrm{kg}$. Os resultados foram obtidos para o nível de significância de $5 \%(\alpha=0,05)$ de acordo com a distribuição $t$-Student.

A veracidade dos resultados foi avaliada de acordo com o En obtido para cada ensaio e para a média aritmética dos resultados. A Figura 8.6 apresenta os resultados para $E n$ obtidos em cada ensaio do procedimento de estimativa do limite de repetitividade para As (método-BIO-1). Os valores obtidos para o En variaram entre 0,20 no ensaio 7 e 0,26 no ensaio 1 . Para a média dos resultados, o valor foi 0,24. Desta forma, o grau de veracidade para os resultados foi considerado satisfatório $(-1,0<E n<1,0)$.

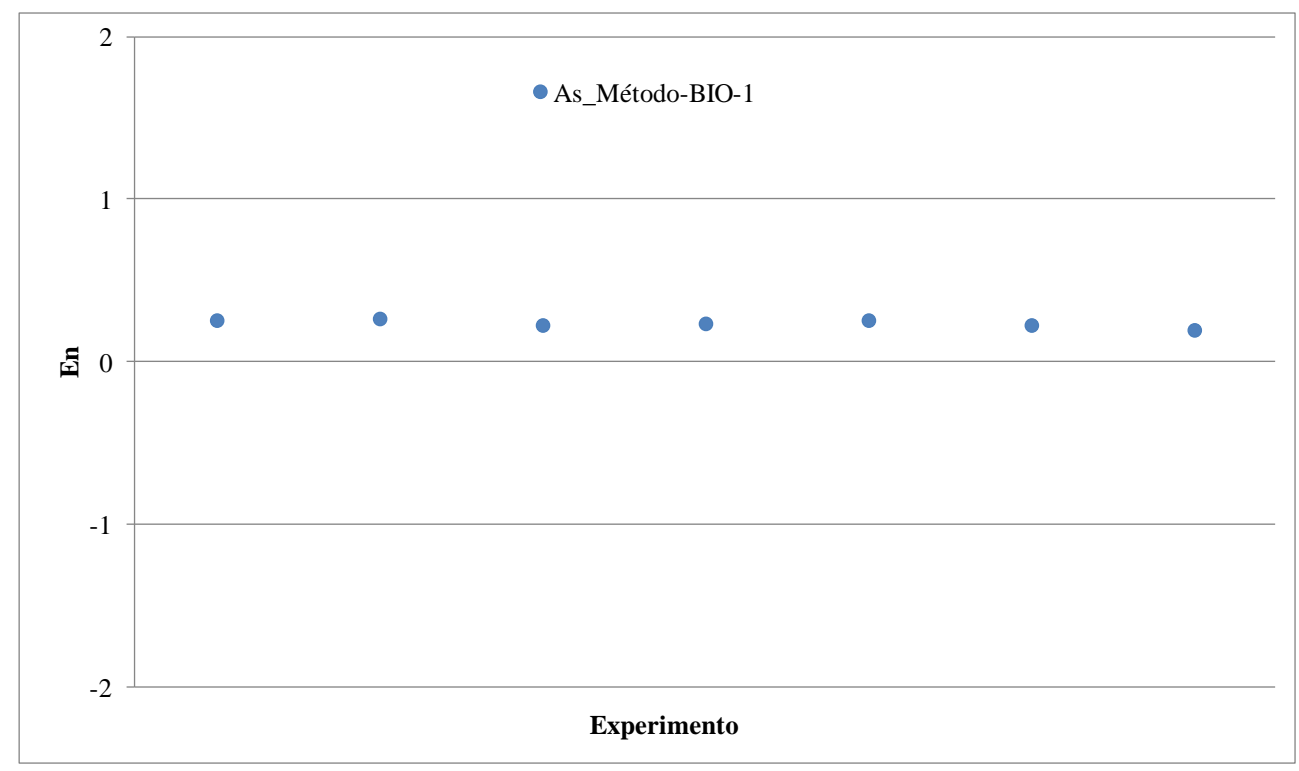

Figura 8.6. En obtido para cada ensaio (método-BIO-1)

A Figura 8.7 apresenta o En obtidos em cada ensaio do procedimento de estimativa do limite de repetitividade para As e Sb (método-GEO-1). Os valores do 
En obtidos para os resultados de As variaram entre 0,26 e 0,74, sendo 0,50 o valor médio obtido. Resultados para Sb tiveram uma variação nos valores para o En entre -0,81 no ensaio 7 e 0,05 no ensaio 5. Para média aritmética dos resultados, o En obtido foi - 0,24 . Os resultados foram obtidos para o nível de significância de $5 \%$ ( $\alpha$ $=0,05)$ para a distribuição $t$-Student. Ainda, de acordo com o critério de avaliação em todos os ensaios foram encontrados valores satisfatórios para veracidade dos resultados $(-1,0<E n<1,0)$.

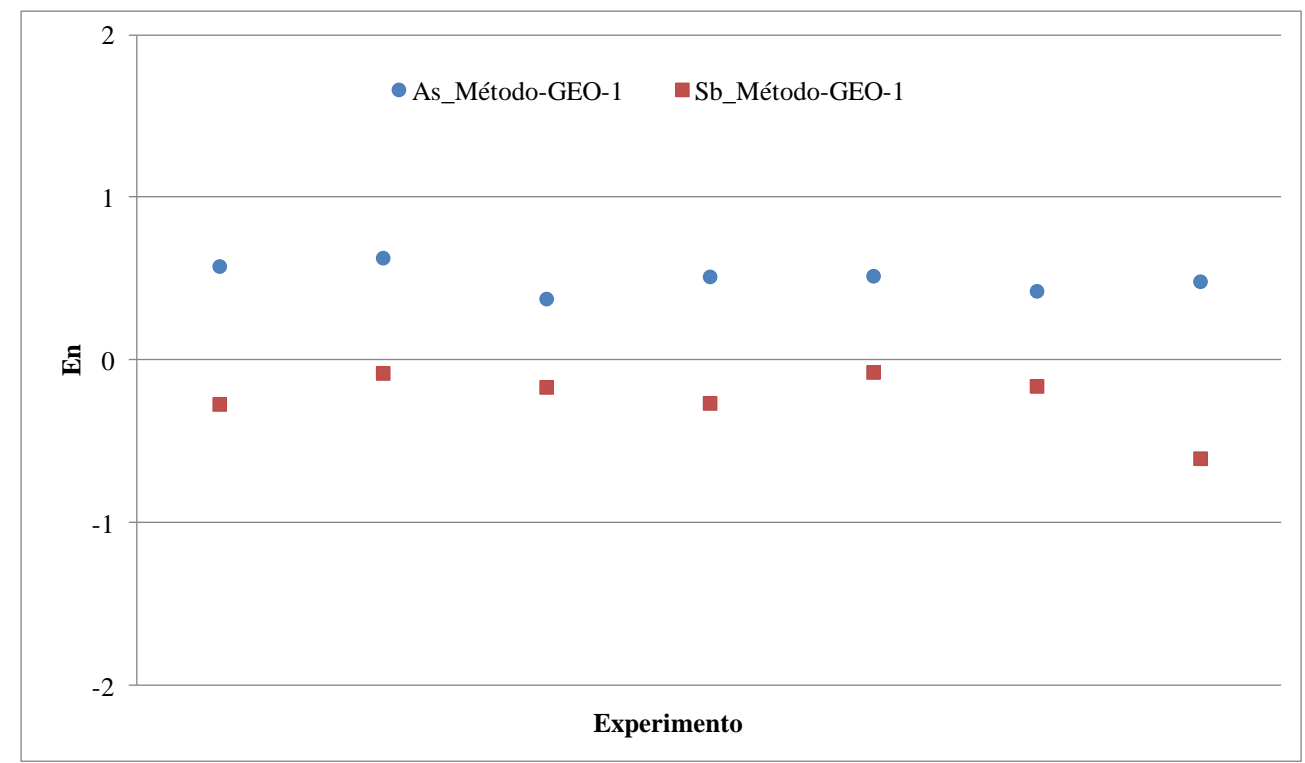

Figura 8.7. En obtido para cada ensaio (método-GEO-1)

Os resultados obtidos em cada ensaio para os dois diferentes métodos parecem apresentar-se de forma tendenciosa quando observada a distribuição destes nos gráficos de En. Para o método-BIO-1, foram observados somente valores maiores que zero para todos os ensaios e a mesma situação aparece quando analisamos os resultados obtidos para cada um dos ensaios de As (método-GEO-1). Por outro lado, o En observado para $\mathrm{Sb}$ no método-GEO-1 apresentou-se tendenciosamente para a obtenção de valores menor que zero.

Contudo, esses valores não indicam a existência de tendências, não para os resultados de um estudo de repetitividade. Uma vez que os ensaios foram realizados em um único dia, por um mesmo analista, com os mesmos reagentes, em um mesmo equipamento e no menor intervalo de tempo possível, uma mínima variação dos resultados obtidos em ensaios independentes deve ser esperada, afinal, este é o 
objetivo da estimativa para o limite de repetitividade de um método. Este comportamento não deve ser esperado para um procedimento de precisão intermediária e reprodutibilidade, por exemplo, uma vez que estes medem a maior variação natural esperada para dois ou mais resultados obtidos para um método específico.

A avaliação da precisão intermediária, isto é, da variabilidade natural dos resultados dentro do laboratório de Laboratório de Ativação Neutrônica (LAN) do Centro do Reator de Pesquisa (CRPq), foi feita considerando-se quatro principais fatores: diferentes processos de irradiação, diferentes espectrômetros para a medição da atividade dos mensurandos nas amostras e padrões, diferentes dias de operação e diferentes analistas para o preparo das amostras.

Precisão intermediária $(P I)$ quer dizer "o máximo valor esperado para variabilidade natural de duas ou mais medições em amostras idênticas realizadas sob as condições especificadas por um respectivo método" (INMETRO, 2010), neste caso, em estudos realizados dentro do LAN. Este difere do limite de reprodutibilidade $(\mathrm{R})$, uma vez que o $\mathrm{R}$ representa o máximo valor esperado para variabilidade natural de duas ou mais medições em amostras idênticas, realizadas sob as condições especificadas por um respectivo método em laboratórios diferentes.

Primeiramente, realizou-se o teste Shappiro-Wilk para normalidade dos conjuntos de dadospara 95\% confiança. Eventuais outliers identificados pelo teste de Grubbs foram excluídos ${ }^{3}$. Esse processo se faz particularmente importante visando à confiabilidade dos resultados e a uma posterior análise devariância ANOVA com testet para identificação da significância sobre a contribuição dos fatores estudados (LOPES \& SANTOS, 2008).

De acordo com teste de Shappiro-Wilk pode-se afirmar que os resultados obtidos nos ensaios do estudo de precisão intermediária para As (método-BIO-1) seguem uma distribuição normal. Isso é evidenciado pelo valor obtido para $p>0,05(p=0,43)$. Como $p>0,05$ aceita-se $\mathrm{H}_{0}$ e rejeita-se $\mathrm{H}_{1}$ para o

\footnotetext{
${ }^{3}$ De acordo com o teste de Grubbs, 2 outliers foram verificados dentro do conjunto de dados do mensurando As para o método-BIO-1. Estes resultados foram excluídos do conjunto de dados usado para análises posteriores.
} 
grau de $5 \%$ de significância, ou seja, assume-se que os valores seguem uma distribuição normal com $95 \%$ de confiança estatística.

Mesmo comportamento para normalidade também foi verificado para os resultados dos ensaios referentes ao mensurando As no método-GEO-1, para o qual o valor de $p$ obtido (Figura 8.9) para o teste de Shappiro-Wilk foi $p=0,33$. Para Sb, obteve-se um valor para $p=0,09$. Desta forma, admite-se com $95 \%$ de confiança estatística que os respectivos conjuntos de dados apresentam uma distribuição normal.

Realizou-se o teste de Levene para a verificação da homogeneidade da variância dos resultados obtidos para cada método. Para a medição de As em matriz biológica (método-BIO-1) obteve-se $p=0,48$. Os resultados de As e $\mathrm{Sb}$ em matriz geológica (método-GEO-1) os valores de pobtidos para teste de Levene foram respectivamente $p=0,38$ e $p=0,094$. Assim como para o teste de Shappiro-Wilk, valores obtidos para $p>0,05$ implicam na aceitação de $\mathrm{H}_{0}$ e na rejeição de $\mathrm{H}_{1}$ para 5 \% de significância (HAIR et al., 2009). Desta forma, pode-se afirmar que a variância dos resultados é homogênea.

Uma maneira simples e eficiente para verificarse o comportamento sobre problemas de assimetria e curtose é comparando-se a média com a mediana obtida para o mesmo conjunto de dados. Não havendo problemas relacionados a estes fatores, média e mediana deverão ser numericamente muito parecidos (LOPES \& SANTOS, 2008). A Tabela 8.25 apresenta o conjunto de resultados utilizados para a verificação da normalidade dos resultados obtidos para As (método-BIO-1) e As e Sb (método-GEO-1).

Tabela 8.25. Conjunto de resultados utilizados para verificação sobre a normalidade dos resultados obtidos para As (método-BIO-1) e As e $\mathrm{Sb}$ (método-GEO-1)

\begin{tabular}{ccccccc}
\hline \multicolumn{2}{c}{$\begin{array}{c}\text { Mensurando e } \\
\text { Método }\end{array}$} & $\begin{array}{c}\text { Shappiro-Wilk } \\
(\text { estatística } p)\end{array}$ & $\begin{array}{c}\text { Levene } \\
(\text { estatística } p)\end{array}$ & Média $(\mathrm{mg} / \mathrm{kg})$ & $\begin{array}{c}\text { Mediana } \\
(\mathrm{mg} / \mathrm{kg})\end{array}$ & $\mathrm{n}$ \\
\hline \multirow{2}{*}{$B I O-1$} & As & $p=0,43$ & $p=0,48$ & 12,9 & 12,9 & 26 \\
\hline \multirow{2}{*}{$G E O-1$} & As & $p=0,33$ & $p=0,38$ & 45,5 & 45,6 & 28 \\
& Sb & $p=0,090$ & $p=0,094$ & 5,59 & 5,63 & 28 \\
\hline
\end{tabular}


Pode-se verificar que para As no método-BIO-1, o valor encontrado para média é igual ao obtido para mediana $(12,9 \mathrm{mg} / \mathrm{kg})$. Esse é um exemplo de uma situação de simetria perfeita para o conjunto de dados. As e Sb no método-GEO-1 também apresentaram valores semelhantes para média e mediana. Esses resultados são bons indicadores de que as distribuições apresentam formato simétrico e de que não existem problemas de curtose. Desta forma, os respectivos conjuntos de dados são considerados adequados do ponto de vista estatístico para o cálculo da contribuição dos fatores estudados por meio de ANOVA e teste $t$.

A estimativa de $P I$ para As no método-BIO-1 foi $0,81 \mathrm{mg} / \mathrm{kg}$. Para o métodoGEO-1, os valores observados da estimativa de $P I$ foram $1,3 \mathrm{mg} / \mathrm{kg}$ para As e 0,34 para Sb. É possível verificar que a concentração de As é maior no MRC utilizado nos experimentos do método-GEO-1 do que para o utilizado no método-BIO-1. Neste caso, o valor numérico da estimativa de $P I$ também é maior para o métodoGEO-1 (1,3 mg/kg > 0,81 mg/kg). Contudo, quando o valor da estimativa de $P I$ é divido pelo valor da concentração certificada de As nos MRCs, verifica-se para o método-BIO-1 este corresponde a aproximadamente $6 \%$ do valor da concentração certificada, enquanto que para o método-GEO-1 este representa aproximadamente $3 \%$. Essa comparação indica que não existe uma correlação entre o valor da estimativa de $P I$ e o valor da concentração do MRC utilizado. Contudo, um menor valor para a estimativa de PI pode ser encontrado utilizando-se um MRC com menor valor para a incerteza associada ao resultado certificado (não numericamente, mas proporcionalmente).

Pode-se verificar que para As (em ambos os métodos) a estimativa do valor para $P I$ foi menor que o da respectiva incerteza expendida $(k=2)$ associada à concentração certificada dos MRCs. Para Sb (método-GEO-1) a estimativa de PI foi maior que a incerteza padrão expandida declarada pelo produtor do MRC.

A veracidade dos resultados foi avaliada para cada método de acordo com o En obtido para o resultado de cada medição. A Figura 8.8 apresenta a distribuição dos resultados quanto ao En obtido em cada medição para o método-BIO-1 e a Figura 8.9 apresenta a distribuição dos resultados quanto ao En obtido em cada medição para o método-GEO-1. 


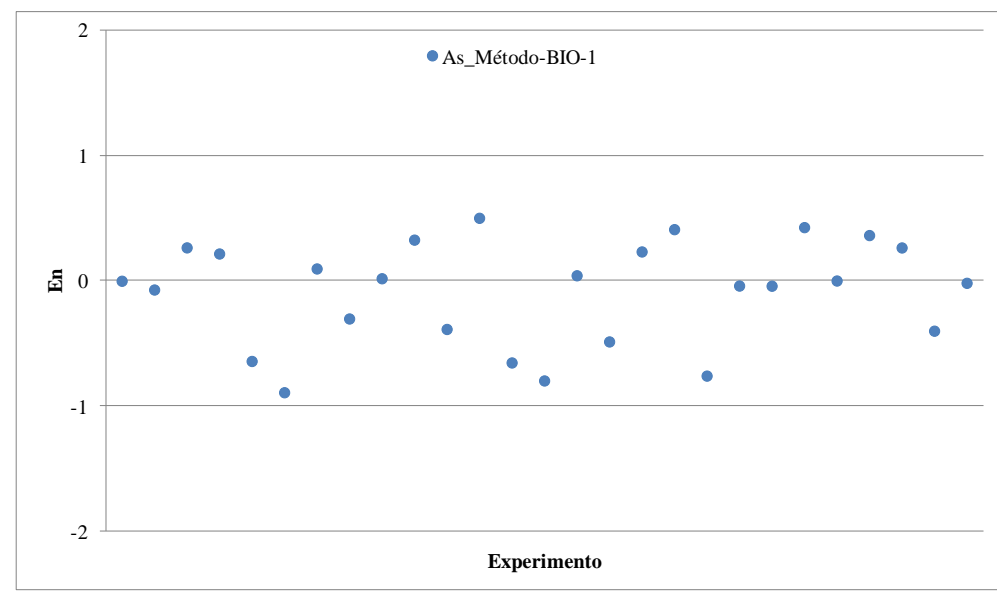

Figura 8.8. Gráfico da distribuição dos resultados obtidos para En (método-BIO-1)

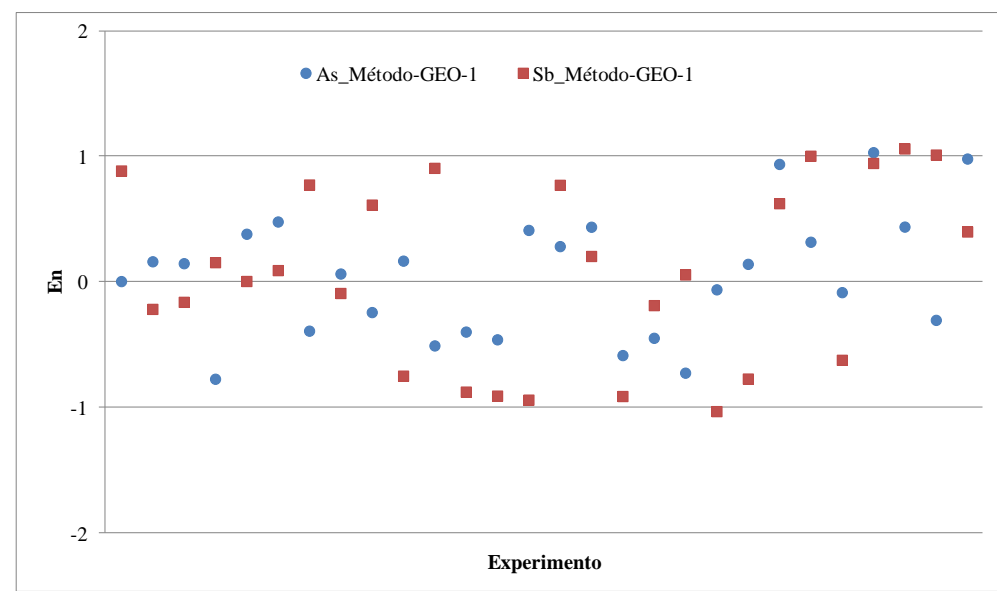

Figura 8.9. Gráfico da distribuição dos resultados obtidos para En (método-GEO-1)

Neste trabalho propôs-se uma nova maneira de interpretar os resultados obtidos para $r$ e $P I$. Muitas vezes estes resultados são menosprezados e agregam pouca importância ao escopo de validação frente à parcela atribuída ao cálculo de estimativa da incerteza de medição. Contudo, na visão do autor deste trabalho é possível obter importante informação para a comparação do desempenho de $n$ diferentes métodos de medição por meio da razão $r$ / PI.

Ocálculo da razão percentual $r$ / PI pode ser uma indicação sobre a robustez do método de medição. Neste contexto, a interpretação é que quanto maior o valor encontrado para a razão $r$ / PI, maior a robustez para os resultados das medições. Resumidamente, isso quer dizer que quanto maior o valor encontrado para a $r / P I$, menor é a probabilidade para que pequenas alterações nas condições 
de operação padrão do método tenham uma influência significativa e/ou tendenciosa no resultado final da medição.

Comparando o valor de PI com o valor de $r$ é possível fazer uma interpretação sobre a porcentagem referente à variação natural dos resultados para um mensurando em um método. A Tabela 8.26 apresenta o valor obtido para a razão percentual $r$ / PI, ou seja, o valor da porcentagem da variância dos resultados de $P I$ que pode ser explicado em função da variação natural dos resultados. Pode-se verificar que os valores percentuais obtidos para As $(66,7 \%$ no método-BIO-1 e $55,4 \%$ no método-GEO-1) para ambos os métodos foram superiores aos valor encontrado para $\mathrm{Sb}(47,1 \%$ no método-GEO-1).

A interpretação destes resultados é a de que 64,8 \% (método-BIO-1) e 55,4 \% (método-GEO-1) da variabilidade dos resultados obtidos na medição de As no LAN corresponde a variação natural esperada aos resultados. Dentro do mesmo raciocínio, 47,1 \% da variabilidade obtida para a medição de Sb (método-GEO-1) no LAN corresponde a variação natural esperada aos resultados. Propõe-se que este parâmetro seja calculado para os demais estudos de validação subsequentes a trabalho visando à comparação dos resultados obtidos em diferentes configurações experimentais.

Tabela 8.26. Resultados para a razão $r$ / PI (método-BIO-1 e método-GEO-1)

\begin{tabular}{ccc}
\hline Mensurando & método-BIO-1 & método-GEO-1 \\
\hline $\mathrm{As}$ & $66,7 \%$ & $55,4 \%$ \\
$\mathrm{Sb}$ & $* \mathrm{ND}$ & $47,1 \%$
\end{tabular}

* ND representa que o mensurando não faz parte do respectivo método.

Realizou-se ANOVA com teste $t$ para a investigação da existência de fatores significativos dentro do conjunto de dados para reprodutibilidade, contudo, nenhum dos fatores estudados (diferentes analistas, diferentes equipamentos, diferentes reagentes e diferentes dias) apresentou-se significativo para os mensurandos avaliados.

O limite de reprodutibilidade $(R)$ foi estimado utilizando-se o desvio padrão da precisão interna, uma vez da impossibilidade da avaliação do desempenho do método em outros laboratórios.

Quando bem estimados e interpretados, os valores de $r, P I$ e $R$ podem ser excelentes indicativos de que algo está interferindo na variabilidade natural dos 
resultados. Um equipamento pode estar descalibrado, um reagente vencido, pode haver um problema amostral, ou seja, sugerindo a existência de erros (aleatórios e/ou sistemáticos).

Em INAA, os valores de $L D$ e $L Q$ são muito dependentes da natureza da amostra (matriz, granulometria, composição química, entre outros) e da região do espectro em que o pico analítico característico para o mensurando está localizado. Para um mesmo mensurando, diferentes picos certamente resultarão em diferentes $L D s$ e LQs. Desta forma, os valores citados têm caráter informativo para as condições estabelecidas aos métodos e para as amostras utilizadas neste estudo, devendo ser analisado com cautela ao se utilizar diferentes amostras, visto que estes podem ter seus valores alterados.

De acordo com os resultados, o $L D$ encontrado para As no métodoGEO-1 foi numericamente inferior ao do método-BIO-1 $\left(0,59 \mathrm{mg} \mathrm{kg}^{-1} \mathrm{e}\right.$ $0,79 \mathrm{mg} \mathrm{kg}^{-1}$ respectivamente). Em INAA, esta informação está diretamente relacionada com o valor da radiação de fundo encontrada sob o pico analítico no espectro de raios gama. Apesar disso, os valores obtidos são da mesma ordem de grandeza. Para $\mathrm{Sb}$, o valor de $L D$ foi $0,089 \mathrm{mg} \mathrm{kg}^{-1}$.

A comparação de resultados para $L D$ e $L Q$ são bastante complicados quando se trata de métodos com configurações analíticas diferentes. Mesmo dentro do LAN, diferentes pesquisadores utilizam diferentes métodos para o cálculo da concentração dos mesmos mensurandos. Uma comparação plausível dos resultados pode ser realizada com os valores obtidos por MOREIRA (2010) durante sua tese de doutoramento. Este, obteve $L D$ de $0,83 \mathrm{mg} \mathrm{kg}^{-1}$ para a medição do mensurando As em condições bastante similares e para amostras idênticas as deste estudo (método-BIO-1). Apesar de terem se passado mais de 4 anos do término de seu trabalho, o resultado obtido para a medição de As em amostras de matriz biológica continua o mesmo, assumindo-se equivalência entre os mesmos.

A estimativa das contribuições de cada fonte de incerteza foi realizada em função dos resultados para 5experimentos, sendo estas, as mesmas amostras utilizadas para a estimativa do $L D$ e $L Q$ de cada mensurando. As fontes de incerteza estudadas foram: massa do mensurando na amostra, massa do mensurando no padrão sintético, incerteza da medição na atividade do radionuclídeo para na amostra, incerteza da 
medição na atividade do radionuclídeo para o padrão sintético, diferenças na geometria de irradiação e a incerteza relacionada à constante de decaimento do radionuclídeo.

No método BIO-1, a incerteza percentual para o resultado de medição das 5 amostras analisadas estiveram entre $3,6 \%$ e 5,5\%. No método GEO-1 estes valores variaram entre $3,7 \%$ e 4,2 \% para As e 3,3\% e 4,6\% para Sb. Ao valor final correspondente a incerteza, calculou-se o valor relativo para cada uma das diferentes fontes. A Figura 8.10 apresenta os resultados obtidos quanto à contribuição relativa para as principais fontes de incerteza para As no método BIO-1 e a Figura 8.11 os resultados obtidos para As e Sb no método GEO-1.

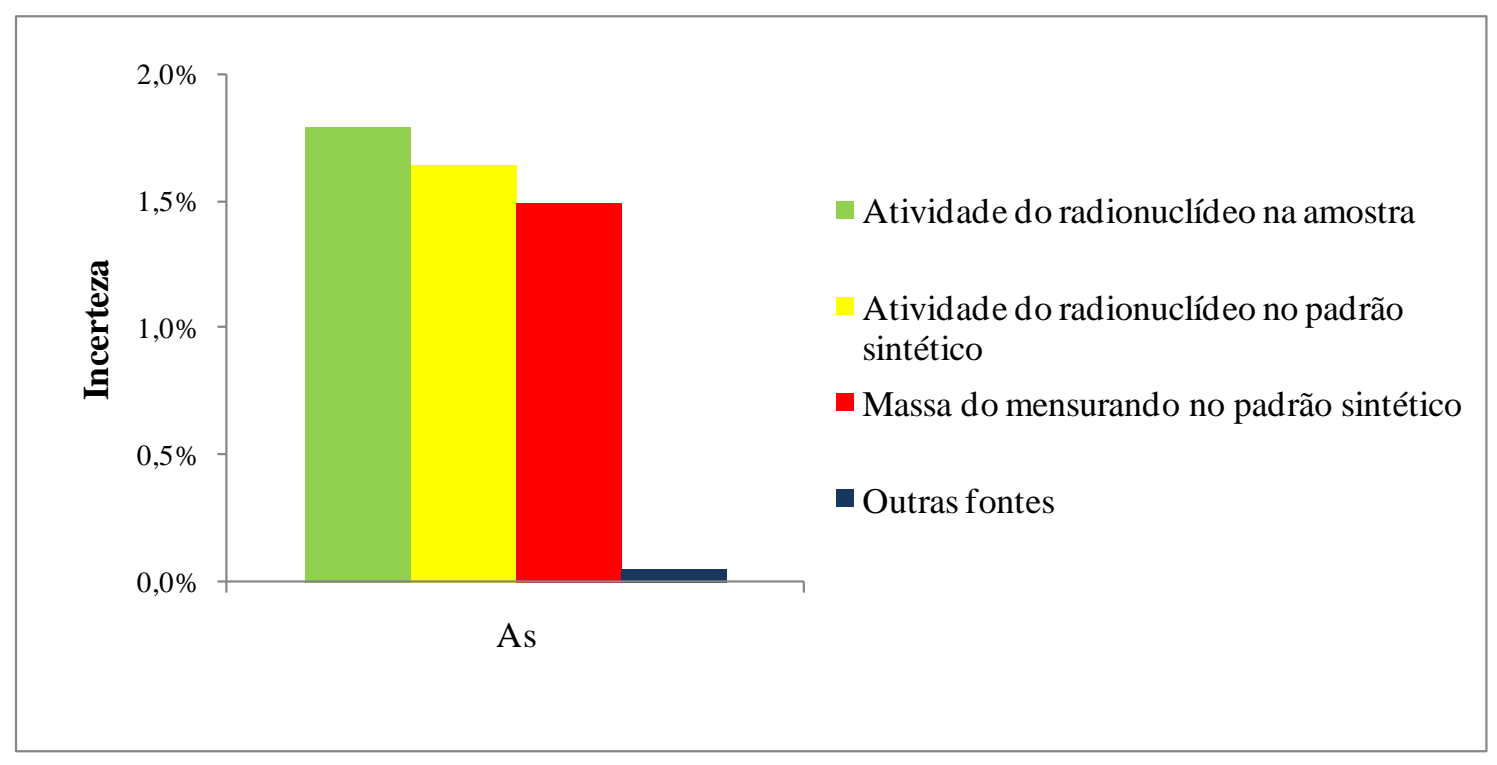

Figura 8.10. Contribuição relativa das principais fontes de incerteza para As (método BIO-1)

De acordo com os resultados, pode-se verificar que a principal fonte de incerteza para a medição de As é a incerteza relacionada a atividade do radionuclídeo no padrão sintético, tanto para o método-BIO-1 quanto para o método-GEO-1.

Contudo, para este mensurando três fatores apresentaram contribuições quase que idênticas. para a estimativa da incerteza dos resultados. Atividade do radionuclídeo no padrão sintético, atividade do radionuclídeo na amostra e massa do mensurando no padrão sintético demonstraram ser fontes majoriotárias para a estimativa da incerteza para As. Outras fontes de incerteza representaram cerca de $0,1 \%$ do valor total. Para a medição de Sb em matriz geológica, a principal fonte de incerteza foi a massa do mensurando no padrão sintético, seguido pela atividade do radionuclídeo no padrão sintético. 


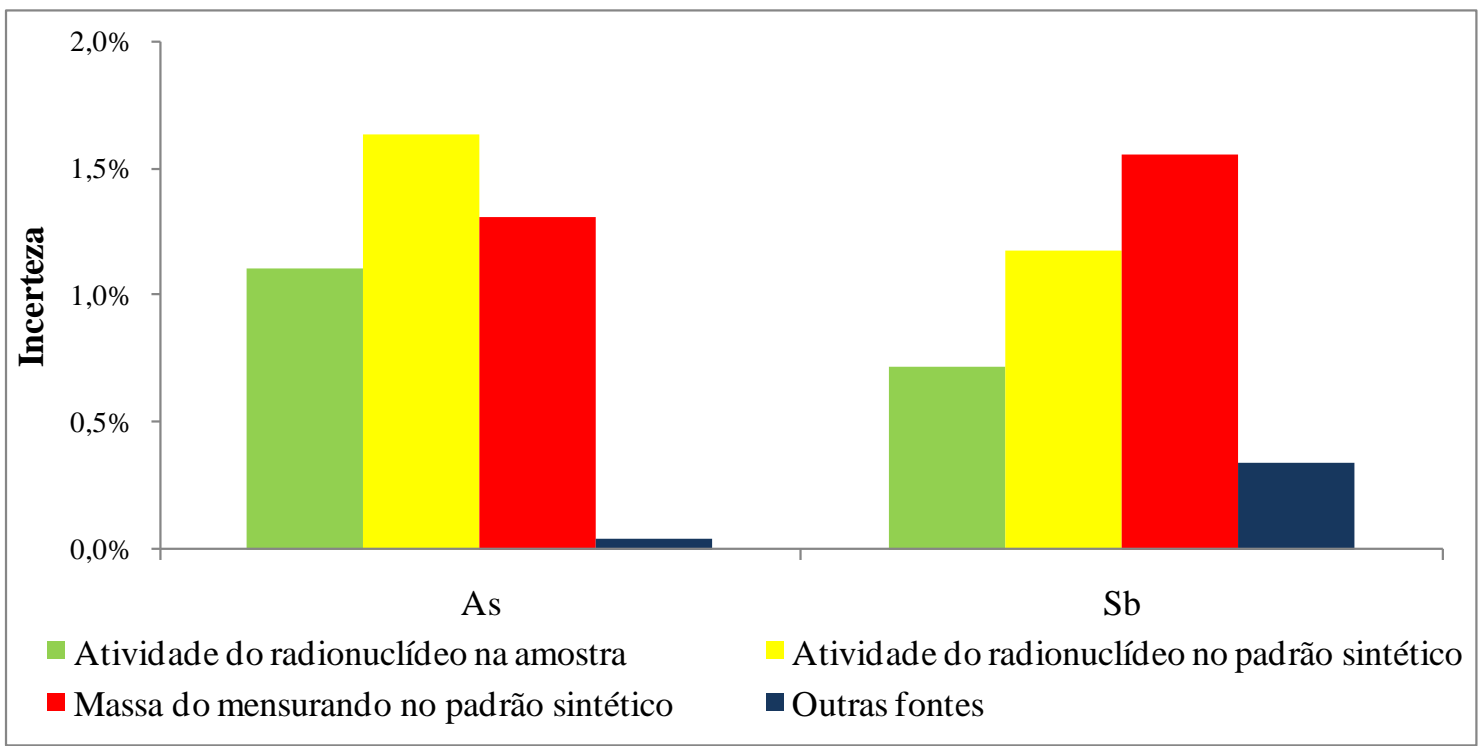

Figura 8.11. Contribuição relativa das principais fontes de incerteza para $\mathrm{As}$ e $\mathrm{Sb}$ (método GEO-1)

Estes resultados acenam para possíveis estratégias quando se desejar diminuir o valor da incerteza nas medições de As em INAA. Uma vez que as principais fontes de incerteza estão relacionadas à configuração do padrão sintético, pode-se aumentar a massa do mensurando no padrão sintético e junto a isso, pode-se aumentar o tempo de medição para o mesmo. Com isso, deve-se verificar a redução na incerteza relacionada à estatística de contagem do padrão sintético. Para minimizar as fontes de incerteza na amostra, seria necessária uma mudança no método de medição, possivelmente aumentando-se o tempo de contagem para amostra. Contudo, os resultados apresentaram-se como bastante satisfatórios neste escopo de validação.

\subsubsection{Método-BIO-2 e método GEO-2}

A Tabela 8.27 apresenta os resultados de validação para o método-BIO-2 (Tecido de Mexilhão IPEN TM-1) e a Tabela 8.28 os resultados referentes ao método GEO-2 (Sedimento Marinho NIST SRM 2702).

Por meio da análise do limite de repetitividade faz-se possível estimar a variação natural mínima para dois resultados obtidos. Este fato apresenta elevada importância quando se desejafazer uma explicação de algumas fontes de incerteza relacionadas ao processo de caracterização de um material de referência e da participação de estudos interlaboratoriais. Além disso, pode ajudar no entendimento dos valores referentes à precisão intermediária $(P I)$ e ao limite de reprodutibilidade $(R)$. 
Pode-se verificar que os valores obtidos para o $r, P I$ e $R$ para o método BIO-2 apresentaram valores bastante inferior aos obtidos para os mesmos mensurandos no método GEO-2. Esse fato pode ser explicado uma vez que amostras ambientais de matriz geológica (neste caso, um sedimento marinho) apresentam concentração bastante elevadas para os mensurandos analisados quando comparados com amostras de matriz biológica (tecido de mexilhão).

Tabela 8.27. Resultados de validação para o método-BIO-2

\begin{tabular}{|c|c|c|c|}
\hline \multirow{2}{*}{ Parâmetro de Validação } & \multicolumn{3}{|c|}{ Co } \\
\hline & $n$ & En & Resultado \\
\hline Limite de repetitividade & 7 & $-0,13$ & $0,037 \mathrm{mg} \mathrm{kg}^{-1}$ \\
\hline Precisão Intermediária & 28 & 0,12 & $0,045 \mathrm{mg} \mathrm{kg}^{-1}$ \\
\hline Limite de reprodutibilidade & 28 & 0,12 & $0,13 \mathrm{mg} \mathrm{kg}^{-1}$ \\
\hline Limite de detecção & 5 & 0,17 & $0,0083 \mathrm{mg} \mathrm{kg}^{-1}$ \\
\hline Limite de quantificação & 5 & 0,17 & $0,025 \mathrm{mg} \mathrm{kg}^{-1}$ \\
\hline Incerteza expandida relativa, $k=2$ & 5 & 0,17 & $6,1-6,2 \%$ \\
\hline \multirow[t]{3}{*}{ Veracidade } & \multicolumn{3}{|c|}{ Adequada $(-1,0<E n<1,0)$} \\
\hline & \multicolumn{3}{|c|}{$\mathrm{Cr}$} \\
\hline & $n$ & $E n$ & Resultado \\
\hline Limite de repetitividade & 7 & $-0,07$ & $0,066 \mathrm{mg} \mathrm{kg}^{-1}$ \\
\hline Precisão Intermediária & 28 & $-0,01$ & $0,14 \mathrm{mg} \mathrm{kg}^{-1}$ \\
\hline Limite de reprodutibilidade & 28 & $-0,01$ & $0,40 \mathrm{mg} \mathrm{kg}^{-1}$ \\
\hline Limite de detecção & 5 & 0,19 & $0,16 \mathrm{mg} \mathrm{kg}^{-1}$ \\
\hline Limite de quantificação & 5 & 0,19 & $0,48 \mathrm{mg} \mathrm{kg}^{-1}$ \\
\hline Incerteza expandida relativa, $k=2$ & 5 & 0,19 & $7,9-8,0 \%$ \\
\hline \multirow[t]{3}{*}{ Veracidade } & \multicolumn{3}{|c|}{ Adequada $(-1,0<E n<1,0)$} \\
\hline & \multicolumn{3}{|c|}{$\mathrm{Fe}$} \\
\hline & $n$ & $E n$ & Resultado \\
\hline Limite de repetitividade & 7 & 0,22 & $22 \mathrm{mg} \mathrm{kg}^{-1}$ \\
\hline Precisão Intermediária & 28 & 0,42 & $28 \mathrm{mg} \mathrm{kg}^{-1}$ \\
\hline Limite de reprodutibilidade & 28 & 0,42 & $78 \mathrm{mg} \mathrm{kg}^{-1}$ \\
\hline Limite de detecção & 5 & $-0,14$ & $4,3 \mathrm{mg} \mathrm{kg}^{-1}$ \\
\hline Limite de quantificação & 5 & $-0,14$ & $20 \mathrm{mg} \mathrm{kg}^{-1}$ \\
\hline Incerteza expandida relativa, $k=2$ & 5 & $-0,14$ & $6,8-7,1 \%$ \\
\hline Veracidade & \multicolumn{3}{|c|}{ Adequada $(-1,0<E n<1,0)$} \\
\hline
\end{tabular}


Tabela 8.27. Resultados de validação para o método-BIO-2 (continuação)

\begin{tabular}{|c|c|c|c|}
\hline \multirow{2}{*}{ Parâmetro de Validação } & \multicolumn{3}{|c|}{$\mathrm{Rb}$} \\
\hline & $n$ & $E n$ & Resultado \\
\hline Limite de repetitividade & 7 & 0,29 & $0,16 \mathrm{mg} \mathrm{kg}^{-1}$ \\
\hline Precisão Intermediária & 27 & $-0,37$ & $0,39 \mathrm{mg} \mathrm{kg}^{-1}$ \\
\hline Limite de reprodutibilidade & 27 & $-0,37$ & $1,1 \mathrm{mg} \mathrm{kg}^{-1}$ \\
\hline Limite de detecção & 5 & $-0,26$ & $0,31 \mathrm{mg} \mathrm{kg}^{-1}$ \\
\hline Limite de quantificação & 5 & $-0,26$ & $0,95 \mathrm{mg} \mathrm{kg}^{-1}$ \\
\hline Incerteza expandida relativa, $k=2$ & 5 & $-0,26$ & $7,1-7,4 \%$ \\
\hline \multirow[t]{3}{*}{ Veracidade } & \multicolumn{3}{|c|}{ Adequada $(-1,0<E n<1,0)$} \\
\hline & \multicolumn{3}{|c|}{ Sc } \\
\hline & $n$ & $E n$ & Resultado \\
\hline Limite de repetitividade & 7 & $-0,09$ & $0,0061 \mathrm{mg} \mathrm{kg}^{-1}$ \\
\hline Precisão Intermediária & 28 & $-0,11$ & $0,0078 \mathrm{mg} \mathrm{kg}^{-1}$ \\
\hline Limite de reprodutibilidade & 28 & $-0,11$ & $0,022 \mathrm{mg} \mathrm{kg}^{-1}$ \\
\hline Limite de detecção & 5 & 0,06 & $0,0092 \mathrm{mg} \mathrm{kg}^{-1}$ \\
\hline Limite de quantificação & 5 & 0,06 & $0,028 \mathrm{mg} \mathrm{kg}^{-1}$ \\
\hline Incerteza expandida relativa, $k=2$ & 5 & 0,06 & $5,3-5,9 \%$ \\
\hline \multirow[t]{3}{*}{ Veracidade } & \multicolumn{3}{|c|}{ Adequada $(-1,0<E n<1,0)$} \\
\hline & \multicolumn{3}{|c|}{$\mathrm{Se}$} \\
\hline & $n$ & En & Resultado \\
\hline Limite de repetitividade & 7 & $-0,09$ & $0,12 \mathrm{mg} \mathrm{kg}^{-1}$ \\
\hline Precisão Intermediária & 28 & 0,05 & $0,26 \mathrm{mg} \mathrm{kg}^{-1}$ \\
\hline Limite de reprodutibilidade & 28 & 0,05 & $0,73 \mathrm{mg} \mathrm{kg}^{-1}$ \\
\hline Limite de detecção & 5 & $-0,13$ & $0,18 \mathrm{mg} \mathrm{kg}^{-1}$ \\
\hline Limite de quantificação & 5 & $-0,13$ & $0,56 \mathrm{mg} \mathrm{kg}^{-1}$ \\
\hline Incerteza expandida relativa, $k=2$ & 5 & $-0,13$ & $8,5-9,0 \%$ \\
\hline \multirow[t]{3}{*}{ Veracidade } & \multicolumn{3}{|c|}{ Adequada $(-1,0<E n<1,0)$} \\
\hline & \multicolumn{3}{|c|}{$\mathrm{Zn}$} \\
\hline & $n$ & $E n$ & Resultado \\
\hline Limite de repetitividade & 7 & $-0,03$ & $4,0 \mathrm{mg} \mathrm{kg}^{-1}$ \\
\hline Precisão Intermediária & 27 & $-0,03$ & $5,4 \mathrm{mg} \mathrm{kg}^{-1}$ \\
\hline Limite de reprodutibilidade & 27 & $-0,03$ & $15 \mathrm{mg} \mathrm{kg}^{-1}$ \\
\hline Limite de detecção & 5 & 0,18 & $0,36 \mathrm{mg} \mathrm{kg}^{-1}$ \\
\hline Limite de quantificação & 5 & 0,18 & $1,1 \mathrm{mg} \mathrm{kg}^{-1}$ \\
\hline Incerteza expandida relativa, $k=2$ & 5 & 0,18 & $7,9-8,5 \%$ \\
\hline Veracidade & \multicolumn{3}{|c|}{ Adequada $(-1,0<E n<1,0)$} \\
\hline
\end{tabular}


Tabela 8.28. Resultados de validação para o método-GEO-2

\begin{tabular}{|c|c|c|c|}
\hline \multirow{2}{*}{ Parâmetro de Validação } & \multicolumn{3}{|c|}{ Co } \\
\hline & $n$ & En & Resultado \\
\hline Limite de repetitividade & 7 & $-0,19$ & $0,87 \mathrm{mg} \mathrm{kg}^{-1}$ \\
\hline Precisão Intermediária & 28 & $-0,17$ & $1,1 \mathrm{mg} \mathrm{kg}^{-1}$ \\
\hline Limite de reprodutibilidade & 28 & $-0,17$ & $3,2 \mathrm{mg} \mathrm{kg}^{-1}$ \\
\hline Limite de detecção & 5 & $-0,03$ & $0,17 \mathrm{mg} \mathrm{kg}^{-1}$ \\
\hline Limite de quantificação & 5 & $-0,03$ & $0,51 \mathrm{mg} \mathrm{kg}^{-1}$ \\
\hline Incerteza expandida relativa, $k=2$ & 5 & $-0,03$ & $6,9-7,0 \%$ \\
\hline \multirow[t]{3}{*}{ Veracidade } & \multicolumn{3}{|c|}{ Adequada $(-1,0<E n<1,0)$} \\
\hline & \multicolumn{3}{|c|}{$\mathrm{Cr}$} \\
\hline & $n$ & $E n$ & Resultado \\
\hline Limite de repetitividade & 7 & $-0,55$ & $9,8 \mathrm{mg} \mathrm{kg}^{-1}$ \\
\hline Precisão Intermediária & 27 & $-0,01$ & $16 \mathrm{mg} \mathrm{kg}^{-1}$ \\
\hline Limite de reprodutibilidade & 27 & $-0,01$ & $44 \mathrm{mg} \mathrm{kg}^{-1}$ \\
\hline Limite de detecção & 5 & 0,26 & $1,4 \mathrm{mg} \mathrm{kg}^{-1}$ \\
\hline Limite de quantificação & 5 & 0,26 & $4,3 \mathrm{mg} \mathrm{kg}^{-1}$ \\
\hline Incerteza expandida relativa, $k=2$ & 5 & 0,26 & $8,7-9,3 \%$ \\
\hline \multirow[t]{3}{*}{ Veracidade } & \multicolumn{3}{|c|}{ Adequada $(-1,0<E n<1,0)$} \\
\hline & \multicolumn{3}{|c|}{$\mathrm{Fe}$} \\
\hline & $n$ & $E n$ & Resultado \\
\hline Limite de repetitividade & 7 & $-0,07$ & $1239 \mathrm{mg} \mathrm{kg}^{-1}$ \\
\hline Precisão Intermediária & 28 & 0,28 & $3196 \mathrm{mg} \mathrm{kg}^{-1}$ \\
\hline Limite de reprodutibilidade & 28 & 0,28 & $8948 \mathrm{mg} \mathrm{kg}^{-1}$ \\
\hline Limite de detecção & 5 & $-0,10$ & $137 \mathrm{mg} \mathrm{kg}^{-1}$ \\
\hline Limite de quantificação & 5 & $-0,10$ & $418 \mathrm{mg} \mathrm{kg}^{-1}$ \\
\hline Incerteza expandida relativa, $k=2$ & 5 & $-0,10$ & $7,3-7,9 \%$ \\
\hline Veracidade & \multicolumn{3}{|c|}{ Adequada $(-1,0<E n<1,0)$} \\
\hline
\end{tabular}


Tabela 8.28. Resultados de validação para o método-GEO-2 (continuação)

\begin{tabular}{|c|c|c|c|}
\hline \multirow{2}{*}{ Parâmetro de Validação } & \multicolumn{3}{|c|}{$\mathrm{Sc}$} \\
\hline & $n$ & $E n$ & Resultado \\
\hline Limite de repetitividade & 7 & $-0,16$ & $0,37 \mathrm{mg} \mathrm{kg}^{-1}$ \\
\hline Precisão Intermediária & 28 & $-0,69$ & $1,1 \mathrm{mg} \mathrm{kg}^{-1}$ \\
\hline Limite de reprodutibilidade & 28 & $-0,69$ & $3,1 \mathrm{mg} \mathrm{kg}^{-1}$ \\
\hline Limite de detecção & 5 & 0,14 & $0,023 \mathrm{mg} \mathrm{kg}^{-1}$ \\
\hline Limite de quantificação & 5 & 0,14 & $0,070 \mathrm{mg} \mathrm{kg}^{-1}$ \\
\hline Incerteza expandida relativa, $k=2$ & 5 & 0,14 & $5,0-5,2 \%$ \\
\hline \multirow[t]{3}{*}{ Veracidade } & \multicolumn{3}{|c|}{ Adequada $(-1,0<E n<1,0)$} \\
\hline & \multicolumn{3}{|c|}{$\mathrm{Zn}$} \\
\hline & $n$ & $E n$ & Resultado \\
\hline Limite de repetitividade & 7 & $-0,03$ & $14 \mathrm{mg} \mathrm{kg}^{-1}$ \\
\hline Precisão Intermediária & 28 & 0,37 & $62 \mathrm{mg} \mathrm{kg}^{-1}$ \\
\hline Limite de reprodutibilidade & 28 & 0,37 & $174 \mathrm{mg} \mathrm{kg}^{-1}$ \\
\hline Limite de detecção & 5 & $-0,06$ & $5,3 \mathrm{mg} \mathrm{kg}^{-1}$ \\
\hline Limite de quantificação & 5 & $-0,06$ & $16 \mathrm{mg} \mathrm{kg}^{-1}$ \\
\hline Incerteza expandida relativa, $k=2$ & 5 & $-0,06$ & $9,7-11,4 \%$ \\
\hline Veracidade & \multicolumn{3}{|c|}{ Adequada $(-1,0<E n<1,0)$} \\
\hline
\end{tabular}

Os valores encontrados para $r$ variaram entre $0,0061 \mathrm{mg} \mathrm{kg}^{-1}$ para Sc e 4,0 $\mathrm{mg} \mathrm{kg}^{-1}$ para Zn (método BIO-2) e entre $0,37 \mathrm{mg} \mathrm{kg}^{-1}$ para Sc e $1239 \mathrm{mg} \mathrm{kg}^{-1}$ para Fe (método GEO-2). Visto que $r, P I$ e $R$ estão intimamente relacionados, os valores extremos para $P I$ e $R$ em ambos os métodos pertencem aos mesmos mensurandos Sc e $\mathrm{Zn}$ (método BIO-2) e Sc e Fe (método GEO-2), mas esses dados pouco representam quando analisados isoladamente, fato que dificulta sua discussão.

No escopo de validação dos métodos $B I O-2$ e GEO-2, a veracidade dos resultados foi considerada adequada para todos os mensurandos, isto é, obteve-se valores para $-1,0<$ $E n<$ 1,0 para todos os ensaios realizados, conforme apresentado nas Figuras 8.12 (método BIO-2) e 8.13 (método GEO-2). Isso corrobora o elevado grau analítico característico para os resultados gerados em um método primário de medição, o qual é a INAA. 


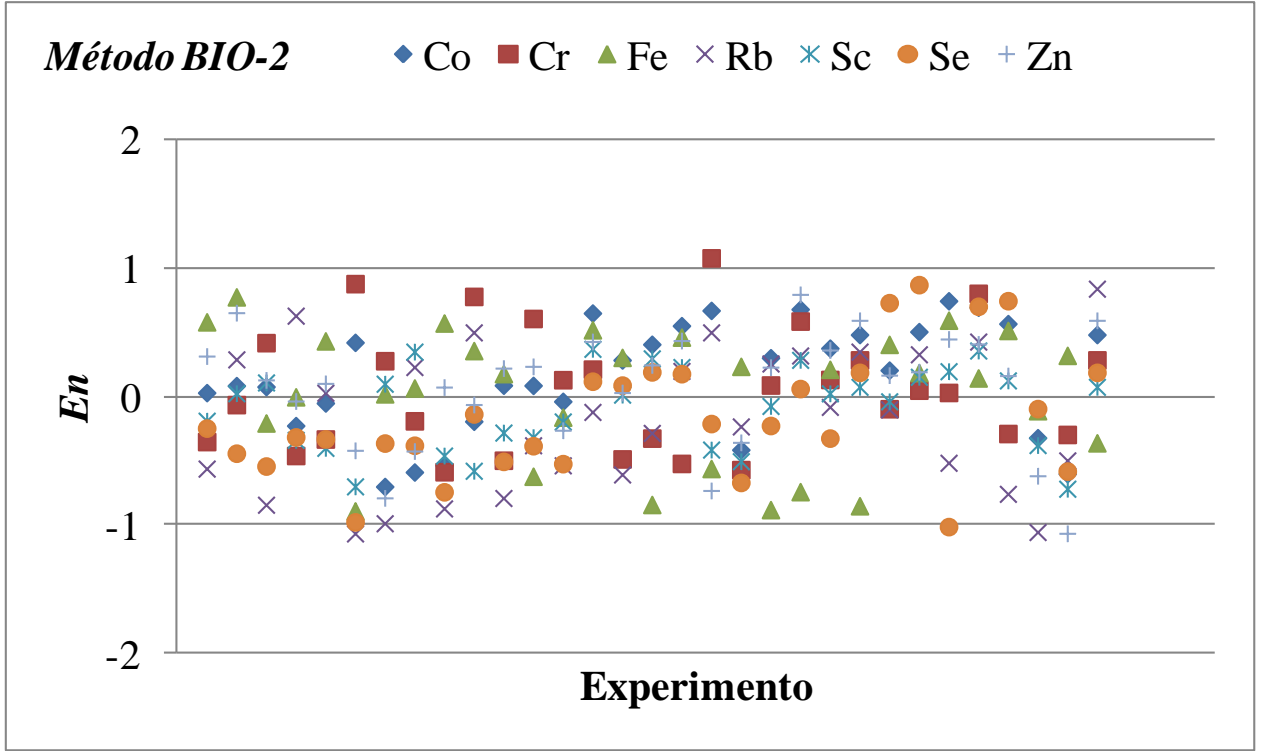

Figura 8.12. En obtido para cada ensaio (método-BIO-2)

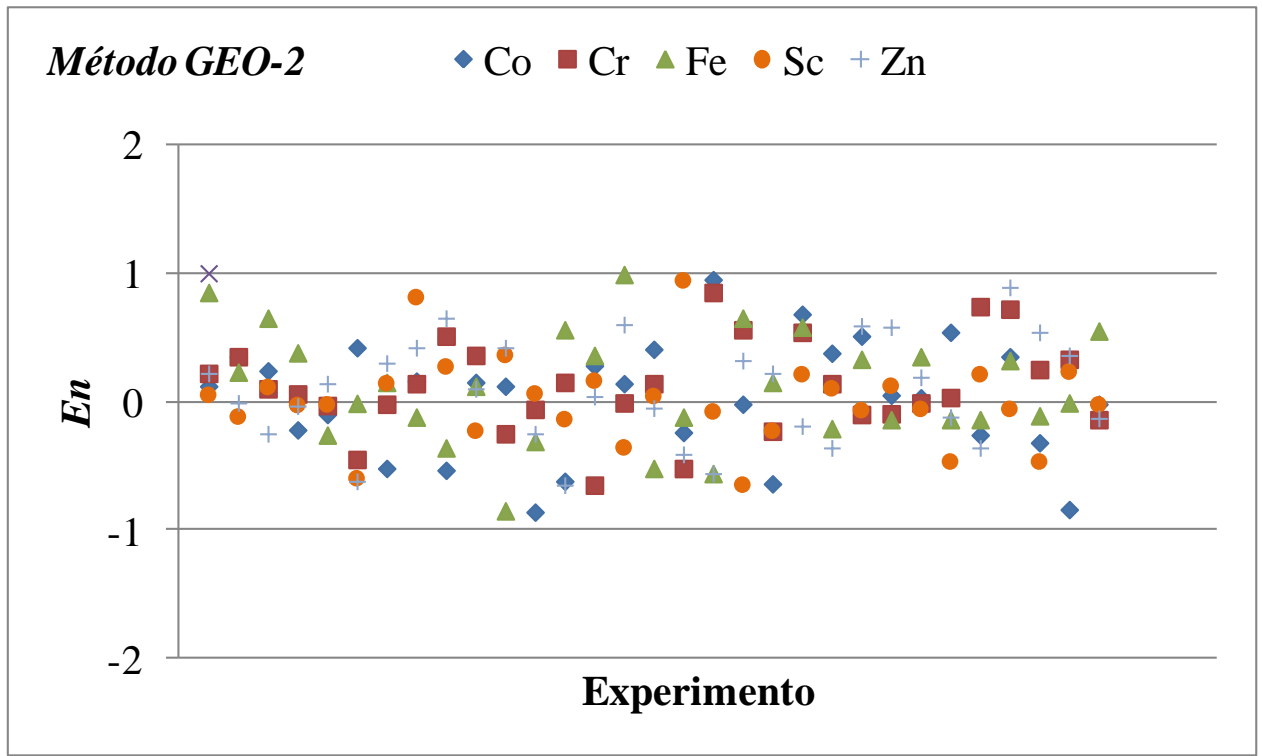

Figura 8.13. En obtido para cada ensaio (método-GEO-2)

Calculou-se os valores para a razão $r$ / PI para os mensurandos dos métodos BIO-2 e GEO-2. Os resultados são apresentados na Tabela 8.29. 
Tabela 8.29.Resultados para a razão $r$ / PI(método BIO-2 e método GEO-2)

\begin{tabular}{ccc}
\hline Mensurando & Método $B I O-2$ & Método GEO-2 \\
\hline $\mathrm{Co}$ & $82,2 \%$ & $79,1 \%$ \\
$\mathrm{Cr}$ & $47,1 \%$ & $61,3 \%$ \\
$\mathrm{Fe}$ & $78,6 \%$ & $38,8 \%$ \\
$\mathrm{Rb}$ & $41,0 \%$ & $* \mathrm{ND}$ \\
$\mathrm{Sc}$ & $78,2 \%$ & $33,6 \%$ \\
$\mathrm{Se}$ & $46,2 \%$ & $* \mathrm{ND}$ \\
$\mathrm{Zn}$ & $74,1 \%$ & $22,6 \%$ \\
\hline
\end{tabular}

* ND representa que o mensurando não faz parte do respectivo método.

Por meio da razão $r$ / PI faz-se possível a interpretação sobre a o quanto da máxima variação esperada para dois resultados (amostras idênticas) pode ser explicado em função da variação natural dos resultados.

De acordo com os resultados, é possível verificar-se que para o método BIO-2 foram obtidos resultados entre $41,0 \%$ para $\mathrm{Rb}$ e $82,2 \%$ para Co. Já para o método GEO-2, os resultados variaram entre $22,6 \%$ para $\mathrm{Zn}$ e $79,1 \%$ para Co.

Através da análise dos resultados da Tabela 8.29 é possível verificar-se que uma porcentagem maior para a variação dos resultados do método BIO-2 pode ser explicado em função da variação natural dos mesmos (exceção ao $\mathrm{Cr}$, cuja variação dos resultados é melhor explicada no método GEO-2). Este fato indica que as variáveis principais do método $\mathrm{BIO}-2$ foram otimizadas de uma maneira mais adequada que as do método GEO-2 (uma vez que ambos tiveram seus procedimentos realizados em um mesmo período de tempo, usando os mesmos reagentes e equipamentos), visto que o primeiro apresenta resultados mais satisfatórios para a maioria dos mensurandos.

Para avaliação da significância dos fatores de robustez para cada um dos mensurandos, realizou-se o mesmo procedimento descrito no item anterior, ou seja, verificou-se sobre a presença de outliers (Grubbs $)^{4}$, a normalidade para o conjunto de

\footnotetext{
${ }^{4}$ De acordo com o teste de Grubbs, foi encontrado 1 outlier dentro do conjunto de dados dos mensurandosCr e Zn (método-GEO-2). No método BIO-2 observou-se a existência de 1 outlier dentro do conjunto de dados do mensurando $\mathrm{Rb}$. Estes resultados foram excluídos do conjunto de dados usado para análises posteriores.
} 
dados (Shappiro-Wilk), a homogeneidade da variância (Levene) e a homocedasticidade (média-mediana). Os resultados são apresentados na Tabela 8.30.

De acordo com os resultados obtidos, foi possível verificar que todos os conjuntos de dados apresentaram-se adequados para o tratamento estatístico para a investigação sobre a significância dos fatores através da realização da ANOVA.

Analisando-se os fatores referentes à robustez (diferentes analistas, equipamentos reagentes, dias), foi verificado que nenhum dos fatores apresentou-se como significante para o método BIO-2 e método GEO-2. Em todos os casos foram observados valor de $p>0,05$ para todos os mensurandos. Mudanças no fluxo de nêutrons térmicos e pequenas anomalias na geometria das amostras também apresentaram valor de $p>0,05$.

Tabela 8.30. Conjunto de resultados utilizados para verificação sobre a normalidade dos resultados obtidos para o método-BIO-2 e método-GEO-2

\begin{tabular}{ccccccc}
\hline $\begin{array}{c}\text { Mensurando e } \\
\text { Método }\end{array}$ & $\begin{array}{c}\text { Shappiro-Wilk } \\
\text { (estatística } p)\end{array}$ & $\begin{array}{c}\text { Levene } \\
\text { (estatística } p \text { ) }\end{array}$ & Média $(\mathrm{mg} / \mathrm{kg})$ & $\begin{array}{c}\text { Mediana } \\
(\mathrm{mg} / \mathrm{kg})\end{array}$ & $\mathrm{n}$ \\
\hline $\mathrm{Co}$ & $p=0,26$ & $p=0,21$ & 0,85 & 0,86 & 28 \\
& $\mathrm{Cr}$ & $p=0,37$ & $p=0,43$ & 1,2 & 1,2 & 28 \\
& $\mathrm{Fe}$ & $p=0,11$ & $p=0,092$ & 648 & 644 & 28 \\
& $\mathrm{Rb}$ & $p=0,15$ & $p=0,18$ & 4,5 & 4,5 & 27 \\
& $\mathrm{Sc}$ & $p=0,094$ & $p=0,11$ & 0,19 & 0,20 & 28 \\
& $\mathrm{Se}$ & $p=0,72$ & $p=0,81$ & 4,4 & 4,4 & 28 \\
& $\mathrm{Zn}$ & $p=0,41$ & $p=0,43$ & 118 & 118 & 28 \\
\hline \multirow{3}{*}{ GEO-2 } & $\mathrm{Co}$ & $p=0,15$ & $p=0,18$ & 28 & 29 & 28 \\
& $\mathrm{Cr}$ & $p=0,068$ & $p=0,075$ & 349 & 349 & 27 \\
& $\mathrm{Fe}$ & $p=0,088$ & $p=0,10$ & 81265 & 81263 & 28 \\
& $\mathrm{Sc}$ & $p=0,22$ & $p=0,23$ & 24 & 24 & 28 \\
& $\mathrm{Zn}$ & $p=0,10$ & $p=0,095$ & 490 & 490 & 27 \\
\hline
\end{tabular}

A estimativa das contribuições de cada fonte de incerteza foi realizada em função dos resultados para 5 experimentos, sendo estas, as mesmas amostras utilizadas para a estimativa do $L D$ e $L Q$ de cada mensurando. As fontes de incerteza estudadas foram: massa do mensurando na amostra, massa do mensurando no padrão sintético, incerteza da medição na atividade do radionuclídeo para na amostra, incerteza da 
medição na atividade do radionuclídeo para o padrão sintético, diferenças na geometria de irradiação e a incerteza relacionada a constante de decaimento do radionuclídeo. Os resultados foram avaliados em função do valor relativo obtido para a incerteza expandida $(k=2)$ frente ao resultado da medição. Os resultados já foram apresentados na Tabelas 8.27 (método BIO-2) e 8.28 (método GEO-2).

De acordo com os resultados, pode-se verificar que para todos os mensurandos o valor da incerteza relativa foi menor que $12 \%$. No método BIO-2, os menores valores percentuais foram obtidos na medição de Sc (entre 5,3 \% e 5,9 \%; $n=5$ ) e os maiores para Se (entre $8,5 \%$ e $9,0 \% ; n=5$ ). Para o método GEO-2, os menores valores percentuais também foram encontrados para Sc $(5,0 \%$ e $5,2 \% ; n=5)$ e os maiores para $\mathrm{Zn}(9,7 \%$ e $11,4 \% ; n=5$ ). A Figura 8.14 (método BIO-2) e Figura 8.15 (método GEO-2) apresentam a importância relativa dos fatores estudados para a composição numérica do valor da incerteza para cada mensurando.

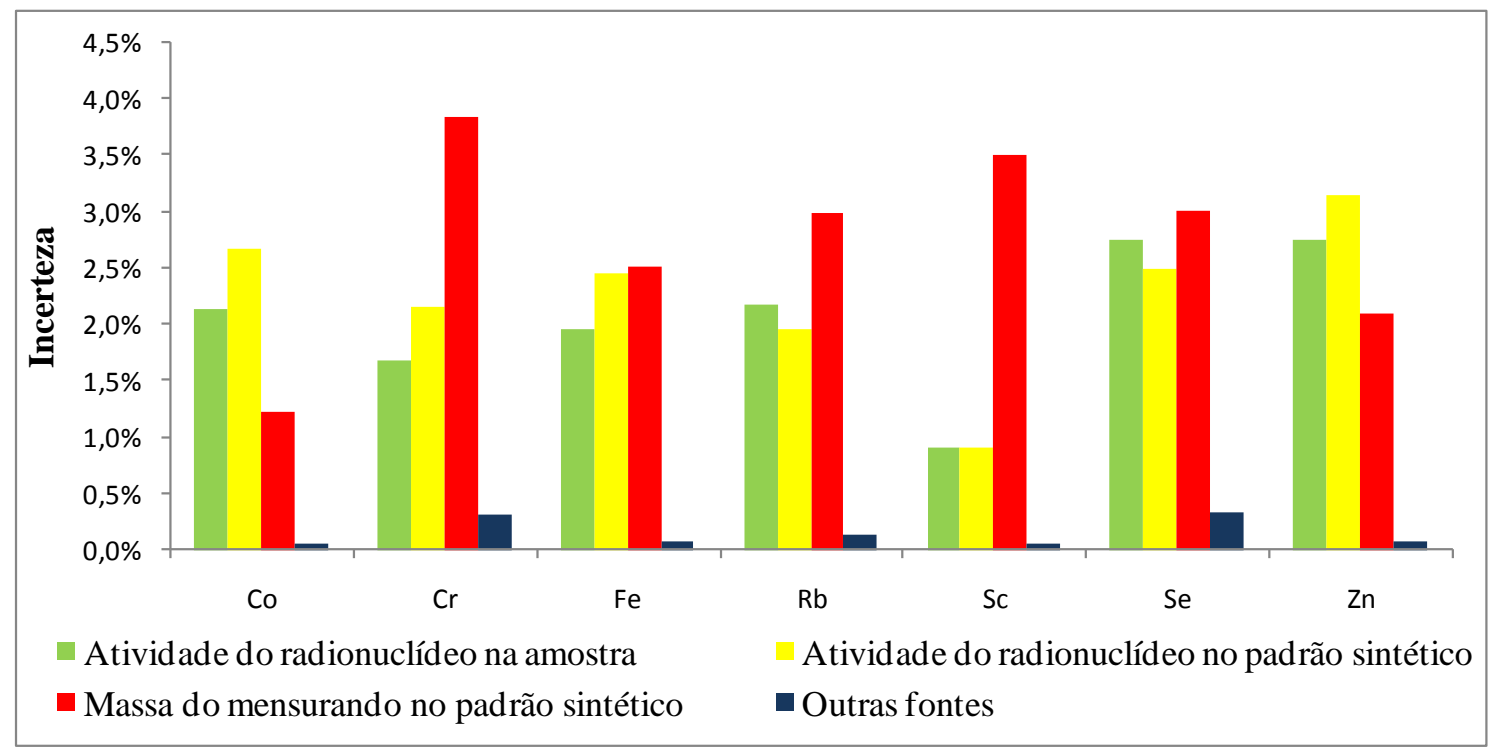

Figura 8.14. Contribuição relativa das principais fontes de incerteza para $\mathrm{Co}, \mathrm{Cr}, \mathrm{Fe}$, $\mathrm{Rb}, \mathrm{Sc}$, Se e Zn (método-BIO-2) 


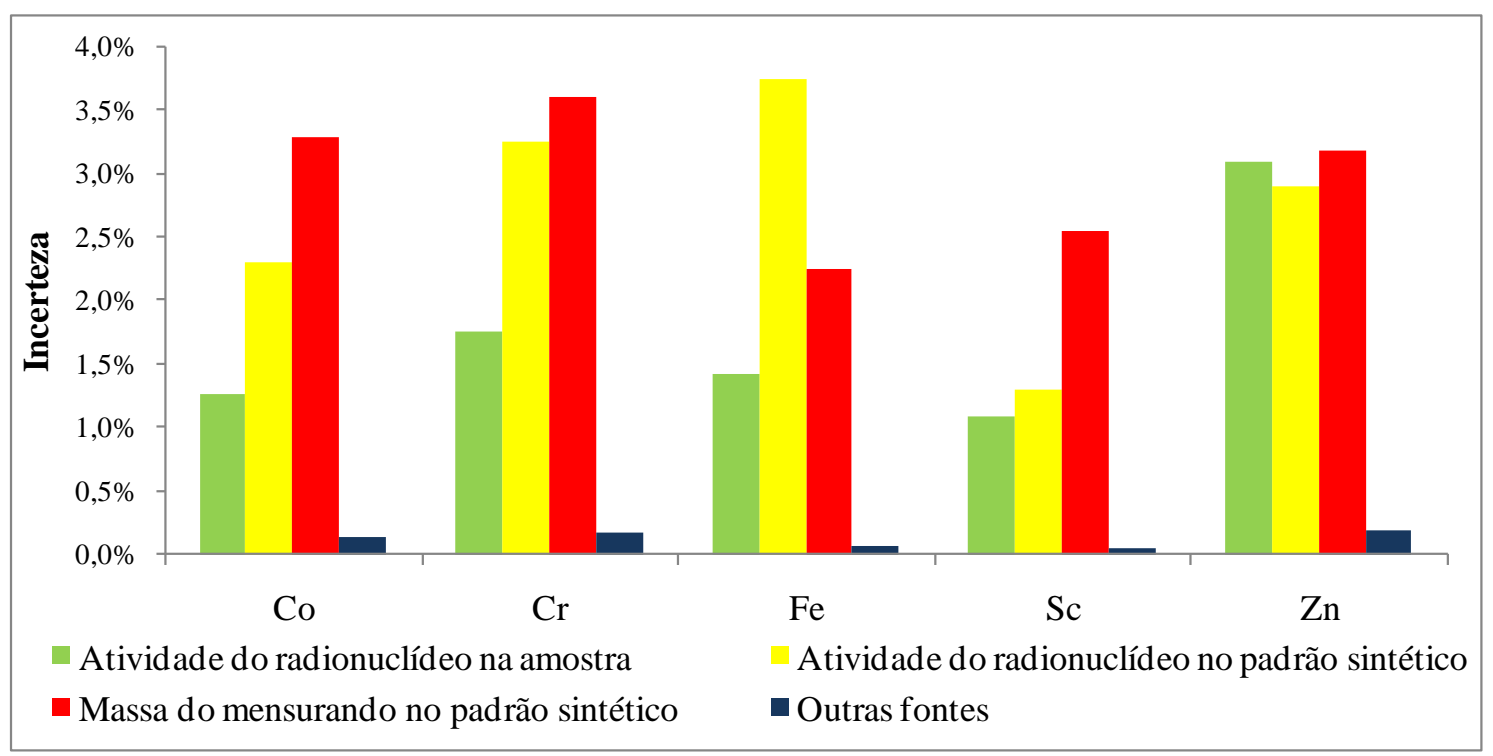

Figura 8.15. Contribuição relativa das principais fontes de incerteza para $\mathrm{Co}, \mathrm{Cr}, \mathrm{Fe}, \mathrm{Sc}$ e $\mathrm{Zn}$ (método-GEO-2)

Por meio dos resultados os resultados é possível observar a existência de três as fontes de incerteza majoritárias para os mensurandos pertencentes ao método BIO-2. Atividade do radionuclídeo na amostra, atividade do radionuclídeo no padrão sintético e massa do mensurando no padrão sintético englobam entre $96 \%$ e $99 \%$ das contribuições para a estimativa das incertezas para os mensurandos. Destas, a massa do mensurando no padrão sintético apresentou ser fator majoritário para $\mathrm{Cr}$, $\mathrm{Fe}, \mathrm{Rb}, \mathrm{Sc}$ e Se, enquanto que a atividade do radionuclídeo no padrão sintético foi fator majoritário para Co e Zn.

Pode-se afirmar que fontes relacionadas ao padrão sintético são majoritárias para a estimativa da incerteza do resultado para os mensurandos do método BIO-2. Uma forma de reduzir esta contribuição é aumentar a massa do mensurando no padrão sintético, juntamente com o aumento do tempo de contagem do mesmo (redução da estatística de contagem). Contudo, resultados foram considerados adequados para o uso pretendido.

Assim como verificado para o método $B I O-2$, três são as fontes de incerteza mais importantes para os mensurandos pertencentes ao método GEO-2: atividade do radionuclídeo na amostra, atividade do radionuclídeo no padrão sintético e massa do mensurando no padrão sintético. Destas, massa do mensurando no padrão sintético apresentou ser o fator majoritário na estimativa da incerteza para $\mathrm{Co}, \mathrm{Cr}$, Sc e Zn. Para $\mathrm{Fe}$, atividade do radionuclídeo no padrão sintético foi o fator majoritário. 
As mesmas afirmações feitas para o método $B I O-2$ sugerindo uma via de diminuição da incerteza associada ao resultado, podem ser igualmente favoráveis para a diminuição do valor da incerteza para os mensurandos do método GEO-2, visto que a configuração do padrão sintético demonstra ser a principal fonte de incerteza para os métodos validados. As estratégias adotadas, cálculos e resultados foram considerados adequados para a técnica e igualmente satisfatórios. 


\section{CONCLUSÕES}

Neste trabalho de mestrado foi realizada a validação formal dos métodos de INAA utilizados para a determinação da concentração total de As, Co, Cr, Fe, Rb, Sc, Se e Zn em matriz biológica e As, Co, Cr, Fe, Sb, Sc e Zn em matriz geológica, com a utilização de materiais de referência certificados. Todo o processo foi realizado de acordo com as recomendações do Guia para a validação do INMETRO DOQ-CGCRE-008, o qual atende em plenitude às diretrizes da norma NBR ISO/IEC 17025.

Realizou-se a otimização de cada método de medição por meio do emprego de desenhos experimentais de Planejamento Fatorial, algo inédito até então em INAA. E foi-se além disso. Uma nova aplicação para o uso de Planejamento Fatorial foi proposto neste trabalho, o qual compreende em uma otimização multielementar para métodos de medição.

A estimativa das fontes de incertezas foi realizada de acordo com as recomendações do Guia para a expressão da incerteza de medição (ISO GUM) com o uso do método simulado. Além disso, fez-se um minucioso estudo sobre as fontes majoritárias de incerteza de medição para cada mensurando. Resultados indicaram que três são as principais fontes de incerteza majoritárias: atividade do radionuclídeo no padrão sintético, atividade do radionuclídeo na amostra e massa do mensurando no padrão sintético.

Documentos da Qualidade registrando todas as etapas do processo de validação foram confeccionados de acordo com as recomendaçãoes da norma NBR ISO/IEC 17025 e estão disponíveis para os usuários do LAN. Além destes, esta dissertação de mestrado trouxe uma descrição detalhada de todos os experimentos realizados, podendo ser utilizada como fonte de consulta para trabalhos futuros.

Outra contribuição atribuída a este trabalho é a continuação do processo de reestruturação do sistema de gestão da qualidade para o LAN, que nos últimos anos tem desenvolvido uma linha de pesquisa relacionada à produção diversos materiais de referência certificado em matrizes biológicas. Com este estudo, a gerência do LAN tem 
em mãos mais uma ferramenta auxiliar para pleitear a certificação das atividades desenvolvidas no laboratório segundo exigências da norma NBR ISO/IEC 17025.

Perspectivas para próximos trabalhos são referentes à continuação do processo de reestruturação do sistema de gestão da qualidade para o LAN e à melhorias relacionadas a implementação das metodologias 5S, Lean Six sigma e Just in time. Sugere-se um trabalho visando a melhoria dos processos de confecção de amostras e padrões sintéticos, buscando-se com isso melhorar os valores de repetitividade e precisão intermediária. Além disso, o LAN possui uma grande quantidade de métodos de medição à serem validados e a validação destes métodos é uma exigência para um maior embasamento da qualidade analítica dos resultados gerados pelo Laboratório. 


\section{SECÇÃO DE ANEXOS}

\section{ANEXO 1.}

Carta formulário 
Caro(a) pesquisador(a) e usuário(a) do CRPq,

O questionário em anexo faz parte do plano de trabalho de mestrado intitulado "Validação dos métodos de Análise por Ativação do Laboratório de Analise por Ativação Neutrônica do IPEN-CNEN/SP, visando à produção de materiais de referência certificados", um projeto ambicioso e de grande importância que beneficiará toda a comunidade acadêmica. $O$ referido projeto, visa promover a adequação do sistema da qualidade já implementado às normas atuais, conforme normas e recomendações ISO ABNT NBR/IEC 17025. Contudo, este não é um processo simples.

Para que seja realizada a validação dos métodos do laboratório de Análise por Ativação Neutrônica, especialmente para INAA comparativo, é necessária a realização da padronização das diversas etapas que envolvem o procedimento analítico, otimizandoos, quando possível. Para isso, todas as variáveis devem ser identificadas e os "valores ideais" para estas, definidos.

Visando-se a democratização deste processo de validação, de forma que este atenda todos os usuários do laboratório em excelência, solicito a Vossa Senhoria o preenchimento do formulário em anexo com os dados analíticos rotineiramente utilizados nas pesquisas. Estes dados servirão como ponto de partida para a interpretação estatística dos procedimentos experimentais, para que com isso, sejam estabelecidas as condições mais apropriadas para a análise, favorecendo a todos os usuários do laboratório. Para tanto, sua participação é indispensável.

Atenciosamente,

Robson Petroni

Bacharel e Licenciado em Química (2012);

Aluno de Mestrado em Tecnologia Nuclear - Aplicações, sob orientação do Prof Dr Edson Gonçalves Moreira 
Por favor, responda o questionário a seguir.

Nome (opcional):

e-mail (opcional):

ramal (opcional):

data:

Principais Linhas de Pesquisa:

Matriz(es) rotineiramente analisada(s):

Complete o formulário a seguir conforme o grau de importância dos seguintes elementos em sua(s) linha(s) de pesquisa que são quantificados com INAA método comparativo:
(1) - Muito Importante
(3) - Pouco Importante
(2) - Importante
(4) - Nenhuma Importância

\begin{tabular}{|c|c|c|}
\hline \multicolumn{3}{|c|}{ MATERIAL BIOLÓGICO: } \\
\hline As $(\quad)$ & Co ( ) & $\operatorname{Cr}(\quad)$ \\
\hline $\mathrm{Fe}(\quad)$ & Se $(\quad)$ & $\mathrm{Zn}(\quad)$ \\
\hline
\end{tabular}

\begin{tabular}{|c|c|c|}
\hline \multicolumn{3}{|c|}{ MATERIAL GEOLÓGICO: } \\
\hline As $(\quad)$ & Co $(\quad)$ & $\operatorname{Cr}(\quad)$ \\
\hline $\mathrm{Fe}(\quad)$ & $\operatorname{Se}(\quad)$ & $\mathrm{Zn}(\quad)$ \\
\hline
\end{tabular}


Cite os cinco elementos de maior importância em sua(s) pesquisa(s) cuja quantificação é feita através de INAA método comparativo:

Utiliza materiais de referência como comparador? SIM（ ） NÃO ( )

Caso a resposta seja sim, quais? Para quais elementos e matrizes?

Utiliza padrões pipetados? SIM( ) NÃO( )

Caso a resposta seja sim, descreva a massa em $\mu \mathrm{g}$ dos cinco elementos de maior importância nos padrões pipetados.

Utiliza padrão multielementar em sua rotina experimental?

$\operatorname{SIM}(\quad) \quad N A ̃ O(\quad)$

Caso a resposta seja sim, descreva-o(s).

Preencha o(s) quadro(s) a seguir com os dados analíticos usualmente utilizados para análise(s) de material biológico(1) e material geológico(2), onde “* * refere-se aos elementos com $t_{1 / 2}$ mais curtos $e$ " $* *$ " refere-se aos elementos com $\mathrm{t}_{1 / 2}$ mais longos. 
1 - MATERIAL BIOLÓGICO - Dados analíticos

Tempo de Irradiação (h) -

* Tempo de Decaimento (dias) -

* Tempo de Contagem para os padrões (h) -

* Tempo de Contagem para as amostras (h) -

** Tempo de Decaimento (dias) -

** Tempo de Contagem para os padrões (h) -

** Tempo de Contagem para as amostras (h) -

Massa da amostra (mg) -

Prateleira para análise $\left(\mathrm{n}^{\circ}\right)$ -

\section{2- MATERIAL GEOLÓGICO-Dados analíticos}

Tempo de Irradiação (h) -

* Tempo de Decaimento (dias) -

* Tempo de Contagem para os padrões (h) -

* Tempo de Contagem para as amostras (h) -

** Tempo de Decaimento (dias) -

** Tempo de Contagem para os padrões (h) -

** Tempo de Contagem para as amostras (h) -

Massa da amostra (mg) -

Prateleira para análise $\left(\mathrm{n}^{\circ}{ }^{\circ}\right)$ -

Em sua opinião, onde o método pode ser otimizado (apontar o(s) parâmetro(s) e sugira o sentido da otimização): 
$\operatorname{SIM}(\quad) \quad N A ̃ O(\quad)$

Gostaria de participar de novos questionários deste trabalho?

SIM（ ) NÃO( )

Sua colaboração foi muito importante para este trabalho de mestrado.

Muito Obrigado!

Qualquer dúvida ou sugestão estamos à disposição.

Robson Petroni (mailto:robsonpetroni@usp.br)

Prof Dr Edson Gonçalves Moreira (mailto:emoreira@ipen.br 


\title{
SECÇÃO DE ANEXOS
}

\author{
ANEXO 2.
}

OPTIMIZATION OF INSTRUMENTAL NEUTRON ACTIVATION

ANALYSIS METHOD BY MEANS OF $2^{\mathrm{k}}$ EXPERIMENTAL DESIGN

TECHNIQUE AIMING THE VALIDATION OF ANALYTICAL

PROCEDURES

(Trabalho apresentado no 2013-International Nuclear Atlantic Conference, INAC) 


\title{
OPTIMIZATION OF INSTRUMENTAL NEUTRON ACTIVATION ANALYSIS METHOD BY MEANS OF $2^{\mathrm{k}}$ EXPERIMENTAL DESIGN TECHNIQUE AIMING THE VALIDATION OF ANALYTICAL PROCEDURES
}

\author{
Robson Petroni and Edson G. Moreira \\ Instituto de Pesquisas Energéticas e Nucleares (IPEN / CNEN - SP) \\ Av. Professor Lineu Prestes 2242 \\ 05508-000 São Paulo, SP \\ rpetroni@ipen.br \\ emoreira@ipen.br
}

\begin{abstract}
In this study optimization of procedures and standardization of Instrumental Neutron Activation Analysis (INAA) methods were carried out for the determination of the elements arsenic, chromium, cobalt, iron, rubidium, scandium, selenium and zinc in biological materials. The aim is to validate the analytical methods for future accreditation at the National Institute of Metrology, Quality and Technology (INMETRO). The $2^{\mathrm{k}}$ experimental design was applied for evaluation of the individual contribution of selected variables of the analytical procedure in the final mass fraction result. Samples of Mussel Tissue Certified Reference Material and multi-element standards were analyzed considering the following variables: sample decay time, counting time and sample distance to detector. The standard multi-element concentration (comparator standard), mass of the sample and irradiation time were maintained constant in this procedure. By means of the statistical analysis and theoretical and experimental considerations it was determined the optimized experimental conditions for the analytical methods that will be adopted for the validation procedure of INAA methods in the Neutron Activation Analysis Laboratory (LAN) of the Research Reactor Center (CRPq) at the Nuclear and Energy Research Institute (IPEN - CNEN/SP). Optimized conditions were estimated based on the results of z-score tests, main effect and interaction effects. The results obtained with the different experimental configurations were evaluated for accuracy (precision and trueness) for each measurand.
\end{abstract}

\section{INTRODUCTION}

Currently, the implementation of a quality management system is absolutely essential to a measurement laboratory. By means of the processes of certification and/or accreditation, the laboratory can demonstrate that it has facilities, equipment and suitable analytical measurement methods to the quality assurance of generated results [1]. These processes can be formalized by adapting to a wide series of standards and protocols, depending on the activities performed in the laboratory. In Brazil, for measurements in 
chemistry, the ABNT NBR ISO/IEC 17025 [2] stands out as the most important regulation standard. In this context, validation of measurement procedures is a prerequisite for the implementation and suitability of the quality system in a laboratory.

A first strategy adopted in the validation process must be the optimization of analytical conditions. Thereby, it is possible to identify the importance of each factor to the measurement process, as well as the uncertainty associated with it. Experimental design is a very useful tool for the optimization of analytical procedures [3-6]. By means of main effect and interaction contrasts, it is possible a correct understanding of the influence caused by each factor to the end result of analysis [7].

Depending on the purpose of the use, experimental conditions and number of variables to be investigated, different models of experimental designs can be used, among then, $2^{\mathrm{k}}(2$ levels for $\mathrm{k}$ variables), $3^{\mathrm{k}}$ (3 levels for $\mathrm{k}$ variables) and generically $\mathrm{x}^{\mathrm{k}}$ ( $\mathrm{x}$ levels for $\mathrm{k}$ variables), from that $\mathrm{x} \geq 2$ and $\mathrm{k} \geq 2$. In the context, $2^{\mathrm{k}}$ experimental design is very useful method for the investigation of preliminary studies with two different levels for each variable $\mathrm{k}$. By means of this strategy, it is possible to evaluate and understand the influence that each variable "carries" to the final result. Nevertheless, the major advantage of the experimental design methods is the conduction of a multivariate optimization, explaining how the different variables are correlated and the importance of this correlation for the optimization of analytical method ${ }^{[8]}$.

For a better understanding of the $2 \mathrm{k}$ experimental design carried in this work, it is necessary a knowledge of some terms and definitions, such as factor, level, main effect, interaction contrast and standard error [8]. These concepts are presented below.

Factor: each variable of study. In this work, sample decay time, sample distance to detector and sample counting time are the investigated factors;

Level: experimental condition assigned to each factor investigated. Usually, in a traditional experimental design, two different levels are assigned for each factor. These levels are denominated level - (assigned to less favorable condition) and level + (assigned to more favorable condition). Furthermore, a standard condition (current configuration 
procedure) is also required for a correct analysis of results. This condition is denominated level 0;

Main Effect: result obtained with the variation of different levels (- to + ) assigned to a factor. It can be calculated according to Equation 1.

$$
\mathrm{ME}=2(\Sigma \mathrm{x}+-\Sigma \mathrm{x}-) / \mathrm{n}
$$

where:

ME is the main effect result;

$\mathrm{x}+$ is the experimental result of level + ;

$\mathrm{x}$ - is the experimental result of level -;

and $\mathrm{n}$ is the number of experiments.

Interaction Contrasts: is the comparison of results on one or more levels of a factor, iterating the results obtained with those found for other factors. Briefly, it can be defined as the change in the level of a factor affecting the result obtained for another factor [9].

Standard Error: measurement error in the result of an effect. It is the same value for the main effect and interaction contrast (Equation 2).

$$
\mathrm{E}=\mathrm{s} /(2 \mathrm{k}-1) 1 / 2
$$

where:

$\mathrm{E}$ is the standard error of main effect and interaction contrasts;

$\mathrm{s}$ is the standard deviation of the results;

and $\mathrm{k}$ is the number of factors.

In the study, a $2^{3}$ experimental design (two levels for three variables) was used to identify the importance of selected factors to the accurate final result, aiming the optimization and validation of analytical procedure for the determination of arsenic, chromium, cobalt, iron, rubidium, scandium, selenium and zinc in biological matrix materials, performing Instrumental Neutron Activation Analysis (INAA).

Samples of a Mussel Tissue Reference Material (CRM) [10] were analyzed by INAA comparative method [11]. The determination of the main effect and interaction contrasts 
for each experiment, were developed considering the relative error of mean results obtained for three replicate analyses. The equations and results for quantification of measurands were calculated in Microsoft Office Excel spreadsheet [12] and results are presented as mean values and one standard deviation.

\section{EXPERIMENTAL}

\subsection{Sample, Elemental and Multi-elemental Standard Preparation}

Mussel Tissue CRM samples of approximately $150 \mathrm{mg}$ were weighed in polyethylene bags using a Shimadzu AEM-5200 analytical balance. Elemental (for As) and multielemental standards (for $\mathrm{Cr}, \mathrm{Co}, \mathrm{Fe}, \mathrm{Rb}, \mathrm{Sc}, \mathrm{Se}$ and $\mathrm{Zn}$ ) were prepared by pipetting solutions with predetermined mass onto Whatman paper filters using Eppendorf pipettes with variable volume $(20 \mu \mathrm{L}$ to $100 \mu \mathrm{L})$. Elemental and multielemental stock solutions were prepared in volumetric flasks using different Spex standard element solution. After drying, paper filters were folded and stored in polyethylene bags with the same geometry of the samples. Polyethylene bags containing samples and standards were sealed and stored until the analysis was performed. Three replicate analyses for each sample were randomly performed, using the same irradiation time and thermal neutron flux, but on different days.

\subsection{Irradiation and Element Determination}

Samples of Mussel Tissue CRM, element and multi-element standards (comparator standard), were simultaneously irradiated during $8 \mathrm{~h}$ under a thermal neutron flux of $10^{13}$ $\mathrm{n} \mathrm{cm}{ }^{-2} \mathrm{~s}^{-1}$ at IEA-R1 Nuclear Research Reactor. ${ }^{76} \mathrm{As},{ }^{51} \mathrm{Cr},{ }^{60} \mathrm{Co},{ }^{59} \mathrm{Fe},{ }^{86} \mathrm{Rb},{ }^{46} \mathrm{Sc},{ }^{75} \mathrm{Se}$ and ${ }^{65} \mathrm{Zn}$ radionuclides were quantified by gamma-ray spectrometry, using a Canberra GC2018 hyperpure Ge detector coupled a DSA 1000 multichannel analyzer. Genie 2000 - Gamma Acquisition \& Analysis 3.1 software was used to perform the processing of the gamma-ray spectrum. The concentration of the measurands was obtained by comparing the photopeak area of the interest element in the spectrum of the sample with that of the multi-element standard by means of Equation 3 [13]. 


$$
C=\left(A_{s} w_{s t} C_{s t}\right) e^{-\lambda\left(t_{s}-t_{s t}\right)} /\left(A_{s t} W_{s}\right)
$$

where:

$\mathrm{C}$ is the sample element concentration (in $\mathrm{mg} \mathrm{kg}^{-1}$ );

$\mathrm{C}_{\mathrm{st}}$ is the standard element concentration (in $\mathrm{mg} \mathrm{kg}^{-1}$ );

As is the activity of the element in the sample (in cps);

Ast is the activity of the element in the standard (in cps);

Ws and Wst are the weights of the sample and standard (in g), respectively;

$\lambda$ is the element decay constant;

and $\left(t_{s}-t_{s t}\right)$ is the difference of the counting time between the sample and standard.

\subsection{Experimental Design}

Mussel tissue CRM samples were analyzed considering the following factors: sample decay time (A), distance of sample to detector (B) and counting time (C). Measurands were arranged in two groups according to half-life of the daughter radionuclide. Group 1 was composed by As and Group 2 by $\mathrm{Co}, \mathrm{Cr}, \mathrm{Fe}, \mathrm{Rb}, \mathrm{Se}, \mathrm{Sc}$ and $\mathrm{Zn}$. Table 1 presents the analytical peak and half-life of measurands [14].

Table 1: Radionuclides, half-life and analytical peak

\begin{tabular}{|c|c|c|}
\hline Radionuclide & Half-life (days) & Analytical peak (keV) \\
\hline${ }^{76} \mathrm{As}$ & 1.078 & 559.10 \\
\hline${ }^{51} \mathrm{Cr}$ & 27.70 & 1173.23 \\
\hline${ }^{60} \mathrm{Co}$ & 1925 & 1099.25 \\
\hline${ }^{59} \mathrm{Fe}$ & 44.50 & 1077.00 \\
\hline${ }^{86} \mathrm{Rb}$ & 18.63 & 889.28 \\
\hline${ }^{46} \mathrm{Sc}$ & 83.79 & 264.66 \\
\hline${ }^{75} \mathrm{Se}$ & 119.8 & 1115.54 \\
\hline${ }^{65} \mathrm{Zn}$ & 244.3 & \\
\hline
\end{tabular}


Different levels for each factor are shown in Table 2 (for As) and Table 3 (for Cr, Co, Fe, $\mathrm{Rb}$, Sc, Se and $\mathrm{Zn}$ ). The variables standard multi-element concentration, mass of the sample and irradiation time were maintained constant for this procedure.

Table 2: Arsenic experimental design: levels and conditions.

\begin{tabular}{|c|c|c|c|}
\hline Factor & Level - & Level 0 & Level + \\
\hline Sample decay time (A) & 5 days & 7 days & 9 days \\
\hline Distance of sample to detector (B) & Shelf 3 & Shelf 1 & Shelf 0 \\
\hline Counting time (C) & 1 hour & 2 hours & 3 hours \\
\hline
\end{tabular}

Table 3: Chromium, cobalt, iron, rubidium, scandium, selenium and zinc experimental design: levels and conditions.

\begin{tabular}{|c|c|c|c|}
\hline Factor & Level - & Level 0 & Level + \\
\hline Sample decay time (A) & 10 days & 15 days & 20 days \\
\hline Distance of sample to detector (B) & Shelf 3 & Shelf 1 & Shelf 0 \\
\hline Counting time (C) & 6 hours & 8 hours & 10 hours \\
\hline
\end{tabular}

Variables arising from the preparation of standards and samples, detection system and irradiation process, were assumed to be constant terms in this study. The matrix of experimental design and configuration of each different experiment is shown in Table 4. 
Table 4: Matrix of $2^{\mathrm{k}}$ experimental design

\begin{tabular}{|c|c|c|c|c|c|c|c|c|}
\hline Experiment & *Contributions & $\mathbf{A}$ & $\mathbf{B}$ & $\mathbf{C}$ & $\mathbf{A B}$ & $\mathbf{A C}$ & $\mathbf{B C}$ & $\mathbf{A B C}$ \\
\hline $\mathrm{y}_{1}$ & $\mathrm{a}_{0} \mathrm{~b}_{0} \mathrm{c}_{0}$ & - & - & - & + & + & + & - \\
\hline $\mathrm{y}_{2}$ & $\mathrm{a}_{1} \mathrm{~b}_{0} \mathrm{c}_{0}$ & + & - & - & - & - & + & + \\
\hline $\mathrm{y}_{3}$ & $\mathrm{a}_{0} \mathrm{~b}_{1} \mathrm{c}_{0}$ & - & + & - & - & + & - & + \\
\hline $\mathrm{y}_{4}$ & $\mathrm{a}_{1} \mathrm{~b}_{1} \mathrm{c}_{0}$ & + & + & - & + & - & - & - \\
\hline $\mathrm{y}_{5}$ & $\mathrm{a}_{0} \mathrm{~b}_{0} \mathrm{c}_{1}$ & - & - & + & + & - & - & + \\
\hline $\mathrm{y}_{6}$ & $\mathrm{a}_{1} \mathrm{~b}_{0} \mathrm{c}_{1}$ & + & - & + & - & + & - & - \\
\hline $\mathrm{y}_{7}$ & $\mathrm{a}_{0} \mathrm{~b}_{1} \mathrm{c}_{1}$ & - & + & + & - & - & + & - \\
\hline $\mathrm{y}_{8}$ & $\mathrm{a}_{1} \mathrm{~b}_{1} \mathrm{c}_{1}$ & + & + & + & + & + & + & + \\
\hline
\end{tabular}

* where 0 and 1 match to different levels (- and + respectively)

The results obtained with different experimental configurations were evaluated for accuracy (precision and trueness) for the different measurands. Optimized conditions were estimated based on the results of z-score tests (Equation 4), relative error (Equation 5) [15], main effect and interaction contrasts.

$$
\mathrm{Z}=\left(\mathrm{C}_{\mathrm{s}}-\mathrm{C}_{\mathrm{CRM}}\right) / \mathrm{u}_{\mathrm{CRM}}
$$

where:

$\mathrm{Z}$ is a $\mathrm{z}$-score value for experiment;

$\mathrm{C}_{\mathrm{s}}$ the mean result for three replicates;

$\mathrm{C}_{\mathrm{CRM}}$ the measurand certified concentration in the CRM;

and $\mathrm{u}_{\mathrm{CRM}}$ the combined uncertainty in the CRM.

$$
\mathrm{RE}=100 \times\left(\mathrm{C}_{\mathrm{s}}-\mathrm{C}_{\mathrm{CRM}}\right) / \mathrm{C}_{\mathrm{CRM}}
$$

where:

$\mathrm{RE}$ is a relative error to mean result of measurement;

$\mathrm{C}_{\mathrm{s}}$ the mean result for three replicates;

and $\mathrm{C}_{\mathrm{CRM}}$ the measurand certified concentration in the CRM. 
For each experiment, three replicates analysis were conducted, totalizing twenty four experiments at this $2^{3}$ experimental design for INAA.

\section{RESULTS AND DISCUSSION}

\subsection{Levels and Factors}

Initially, aiming to check whether the values assigned to the different levels had been properly delineated, the samples were analyzed in -, 0 e + conditions (see Table 4). Figure 1 shows the z-score values of the results obtained in different conditions $(-, 0,+)$ for each measurand. Results of experiments are presented in Table 5 as mean \pm standard deviation, Z-score values and relative standard deviation (RSD).

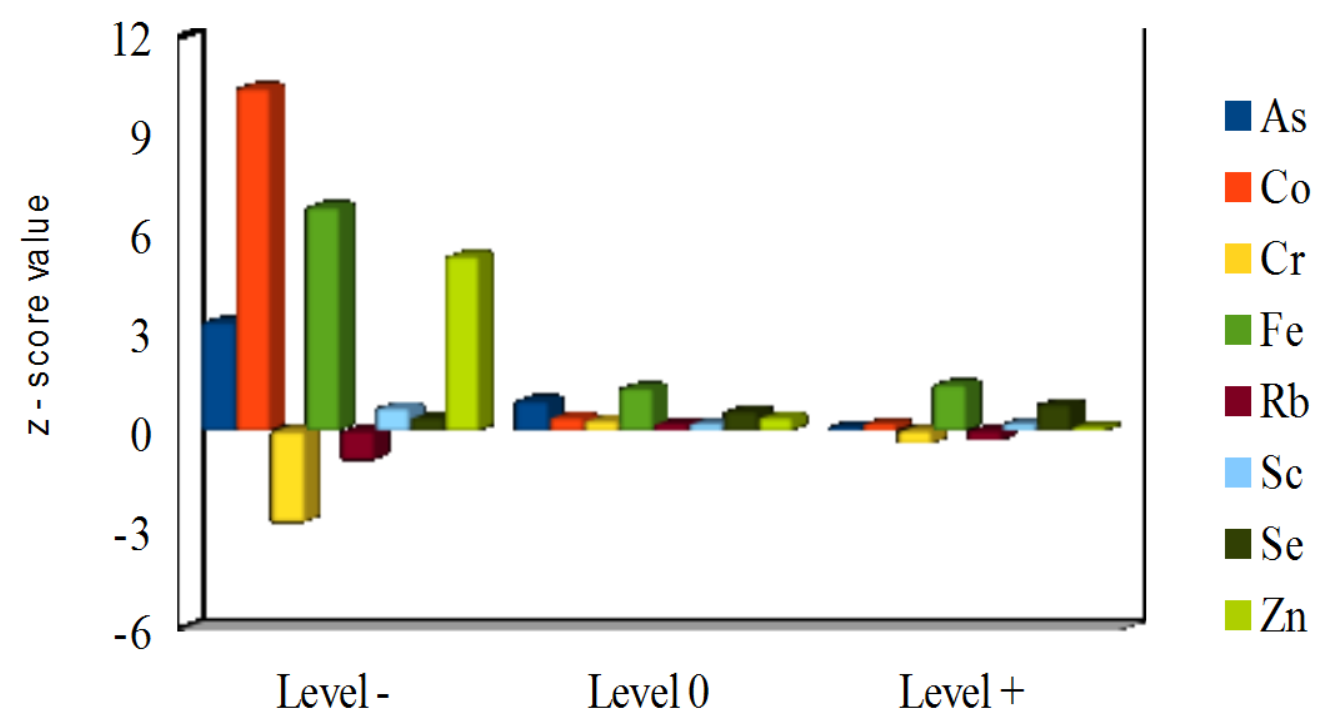

Figure 1: Z-Score values obtained for the different levels 
Table 5: Mean results, $z$-score values and relative standard deviations (RSD) obtained at conditions -, 0 and + for each measurand.

\begin{tabular}{|c|c|c|c|c|c|}
\hline Measurand & Level & $\begin{array}{c}\text { * Mean Result } \\
\left(\mathrm{mg} \mathrm{kg}^{-1}\right)\end{array}$ & $\begin{array}{c}\text { Certified Concentration } \\
\qquad\left(\mathrm{mg} \mathrm{kg}^{-1}\right)\end{array}$ & $\begin{array}{l}\text { z-score } \\
\text { value }\end{array}$ & RSD \\
\hline \multirow{3}{*}{ Arsenic } & - & $16.4 \pm 2.0$ & \multirow{3}{*}{$13.6 \pm 1.7$} & 3.3 & $12 \%$ \\
\hline & 0 & $12.8 \pm 0.59$ & & 0.9 & $4.7 \%$ \\
\hline & + & $13.6 \pm 0.88$ & & 0.0 & $6.6 \%$ \\
\hline \multirow{3}{*}{ Cobalt } & - & $1.229 \pm 0.091$ & \multirow{3}{*}{$0.829 \pm 0.077$} & 10 & $7.4 \%$ \\
\hline & 0 & $0.842 \pm 0.077$ & & 0.4 & $9.1 \%$ \\
\hline & + & $0.836 \pm 0.045$ & & 0.2 & $5.4 \%$ \\
\hline \multirow{3}{*}{ Chromium } & - & $0.85 \pm 0.16$ & \multirow{3}{*}{$1.24 \pm 0.28$} & -2.8 & $19 \%$ \\
\hline & 0 & $1.28 \pm 0.24$ & & 0.3 & $19 \%$ \\
\hline & + & $1.19 \pm 0.26$ & & -0.4 & $22 \%$ \\
\hline \multirow{3}{*}{ Iron } & - & $774 \pm 110$ & \multirow{3}{*}{$593 \pm 53$} & 6.8 & $14 \%$ \\
\hline & 0 & $628 \pm 71$ & & 1.3 & $11 \%$ \\
\hline & + & $631 \pm 36$ & & 1.4 & $5.7 \%$ \\
\hline \multirow{3}{*}{ Rubidium } & - & $4.52 \pm 0.14$ & \multirow{3}{*}{$4.93 \pm 0.92$} & -0.9 & $3.1 \%$ \\
\hline & 0 & $5.03 \pm 0.21$ & & 0.2 & $4.2 \%$ \\
\hline & + & $4.81 \pm 0.35$ & & -0.3 & $7.3 \%$ \\
\hline \multirow{3}{*}{ Scandium } & - & $0.208 \pm 0.005$ & \multirow{3}{*}{$0.199 \pm 0.023$} & 0.7 & $2.4 \%$ \\
\hline & 0 & $0.201 \pm 0.003$ & & 0.2 & $1.5 \%$ \\
\hline & + & $0.201 \pm 0.002$ & & 0.2 & $1.0 \%$ \\
\hline \multirow{3}{*}{ Selenium } & - & $4.52 \pm 0.38$ & \multirow{3}{*}{$4.42 \pm 0.45$} & 0.4 & $8.4 \%$ \\
\hline & 0 & $4.55 \pm 0.39$ & & 0.6 & $8.6 \%$ \\
\hline & + & $4.59 \pm 0.35$ & & 0.8 & $7.6 \%$ \\
\hline \multirow{3}{*}{ Zinc } & - & $143.6 \pm 12.6$ & \multirow{3}{*}{$118.5 \pm 9.5$} & 5.3 & $8.8 \%$ \\
\hline & 0 & $120.4 \pm 5.6$ & & 0.4 & $4.7 \%$ \\
\hline & + & $118.1 \pm 6.9$ & & 0.1 & $5.8 \%$ \\
\hline
\end{tabular}

\footnotetext{
* mean results \pm standard deviation $(\mathrm{n}=3)$
} 
Analyzing the results by overlapping the experimental result (mean and standard deviation) with the CRM certified value, it was observed that, with exception of the results for $\mathrm{Co}$ and $\mathrm{Zn}$ in the condition - $\left(1.229 \pm 0.0091 \mathrm{mg} \mathrm{kg}^{-1}\right.$ and $143.6 \pm 12.6 \mathrm{mg} \mathrm{kg}^{-1}$ respectively), all other results are inside these rough acceptance criteria. By means of the z-score analysis, it can be seen that the results for condition + presented a greater degree of trueness than of condition -, with exception of Se, where the condition - was most favorable condition.

By means of relative standard deviation, it was carried out an estimation of precision to the mean results in different conditions $(-$ and + ). It was verified that for measurands As, $\mathrm{Co}, \mathrm{Fe}, \mathrm{Sc}, \mathrm{Se}$ and $\mathrm{Zn}$, more precise results were obtained in the condition + , with values between $1.0 \%(\mathrm{Sc})$ and $7.6 \%(\mathrm{Se}) . \mathrm{Cr}$ and $\mathrm{Rb}$ presented the least relative standard deviation in the condition - (18.6\% and $3.1 \%$ respectively). Table 6 presents the most favorable condition for accuracy (trueness and precision) of the results for each measurand.

Table 6: Trueness and precision (most favorable condition)

\begin{tabular}{|c|c|c|c|c|}
\hline & \multicolumn{2}{|c|}{ Precision } & \multicolumn{2}{c|}{ Trueness } \\
\hline Measurand & Level - & Level + & Level - & Level + \\
\hline Arsenic & & $\sqrt{ }$ & $\sqrt{ }$ \\
\hline Cobalt & & $\sqrt{ }$ & & $\sqrt{ }$ \\
\hline Chromium & $\sqrt{ }$ & $\sqrt{ }$ & $\sqrt{ }$ \\
\hline Iron & & $\sqrt{ }$ & & $\sqrt{ }$ \\
\hline Rubidium & $\sqrt{ }$ & $\sqrt{ }$ & $\sqrt{ }$ \\
\hline Scandium & & $\sqrt{ }$ & & \\
\hline Selenium & & $\sqrt{ }$ & & \\
\hline Zinc & & & & \\
\hline
\end{tabular}


Taking into account the discussed results, the level + showed best results for trueness and precision for As, $\mathrm{Co}, \mathrm{Fe}, \mathrm{Se}$ and $\mathrm{Zn}$ measurands. $\mathrm{Cr}$ and $\mathrm{Rb}$ presented the more precise results to level -, but not more exact. Selenium presented more exact results to level -, but not more precise. However, the mean of results presented to rubidium, scandium and selenium measurands are statistically equivalent on the different levels. Hence, it can be inferred that INAA is a very robust method for the quantification of rubidium, scandium and selenium in biological matrix materials.

\subsection{Experimental Design}

Eight experiments were simultaneously performed aiming to evaluate the influence caused by changing of the different levels into each factor (Table 4). Z-score values are presented in Table 7 and relative error to the results are shown in Table 8. Table 9 presents mean results of experiments for different measurands.

Analysis for main effect and interaction contrasts for each measurand were performed considering the relative error of mean results obtained for three replicate analyses. For assessing the statistical significance of the result, a t-test (t-Student) was carried to the 95\% confidence level.

In this work, $\mathrm{H}_{0}$ (null hypothesis) was accepted when there is no statistically significant difference for the means with $95 \%$ confidence, in other words, when the means are statistically equivalent. $\mathrm{H}_{1}$ (alternative hypothesis) was accepted when there is a statistically significant difference for the means with $95 \%$ confidence, to the means that are not statistically equivalent.

For $\mathrm{p} \geq 0.05$ (to $5 \%$ significance level) $\mathrm{H}_{0}$ was accepted. Otherwise, $\mathrm{H}_{0}$ was rejected and $\mathrm{H}_{1}$ accepted. Results were performed in experimental design spreadsheet [16]. Main effects and interaction contrasts results are presented in the Table 10. 
Table 7: Experimental Design z-score values

\begin{tabular}{|c|c|c|c|c|c|c|c|c|}
\hline Design & As & $\mathbf{C o}$ & $\mathbf{C r}$ & $\mathbf{F e}$ & $\mathbf{R b}$ & $\mathbf{S c}$ & $\mathbf{S e}$ & $\mathbf{Z n}$ \\
\hline $\mathrm{y}_{1}$ & 3.3 & 10 & -2.9 & 6.8 & -0.9 & 0.7 & 0.4 & 5.3 \\
\hline $\mathrm{y}_{2}$ & -4.2 & 0.7 & -2.7 & 1.5 & -1.9 & 0.7 & -0.6 & 0.7 \\
\hline $\mathrm{y}_{3}$ & 2.3 & 4.8 & -0.7 & 2.9 & -0.9 & 0.6 & 1.6 & 0.8 \\
\hline $\mathrm{y}_{4}$ & -1.5 & 0.3 & -0.3 & 1.6 & -0.4 & 0.1 & 1.5 & -0.1 \\
\hline $\mathrm{y}_{5}$ & 2.8 & 9.6 & -0.5 & 3.4 & -0.8 & 0.6 & 0.7 & 4.9 \\
\hline $\mathrm{y}_{6}$ & -3.5 & 0.7 & -2.3 & 1.3 & -0.7 & 0.5 & 0.1 & 1.0 \\
\hline $\mathrm{y}_{7}$ & 1.3 & 4.5 & 0.4 & 2.8 & -0.7 & 0.7 & 0.8 & 0.2 \\
\hline $\mathrm{y}_{8}$ & 0.0 & 0.2 & -0.4 & 1.4 & -0.3 & 0.2 & 0.7 & 0.1 \\
\hline
\end{tabular}

Table 8: Experimental Design Relative Error of Mean Results

\begin{tabular}{|c|c|c|c|c|c|c|c|c|}
\hline Design & As & Co & Cr & Fe & Rb & Sc & Se & Zn \\
\hline $\mathrm{y}_{1}$ & $21 \%$ & $48 \%$ & $-33 \%$ & $30 \%$ & $-8.3 \%$ & $4.5 \%$ & $2.3 \%$ & $21 \%$ \\
\hline $\mathrm{y}_{2}$ & $-26 \%$ & $3.0 \%$ & $-30 \%$ & $6.7 \%$ & $-18 \%$ & $4.0 \%$ & $-2.9 \%$ & $2.9 \%$ \\
\hline $\mathrm{y}_{3}$ & $14 \%$ & $22 \%$ & $-7.3 \%$ & $13 \%$ & $-8.1 \%$ & $3.5 \%$ & $7.7 \%$ & $3.1 \%$ \\
\hline $\mathrm{y}_{4}$ & $-9.6 \%$ & $1.2 \%$ & $-2.4 \%$ & $6.6 \%$ & $-4.1 \%$ & $0.5 \%$ & $7.7 \%$ & $-0.3 \%$ \\
\hline $\mathrm{y}_{5}$ & $17 \%$ & $45 \%$ & $-5.6 \%$ & $15 \%$ & $-7.5 \%$ & $3.0 \%$ & $3.2 \%$ & $20 \%$ \\
\hline $\mathrm{y}_{6}$ & $-22 \%$ & $2.9 \%$ & $-27 \%$ & $5.7 \%$ & $-6.5 \%$ & $3.0 \%$ & $0.7 \%$ & $4.1 \%$ \\
\hline $\mathrm{y}_{7}$ & $8.1 \%$ & $21 \%$ & $4.0 \%$ & $12 \%$ & $-6.9 \%$ & $4.0 \%$ & $3.8 \%$ & $0.3 \%$ \\
\hline $\mathrm{y}_{8}$ & $0.0 \%$ & $0.8 \%$ & $-4.0 \%$ & $6.4 \%$ & $-2.4 \%$ & $1.0 \%$ & $3.4 \%$ & $-0.3 \%$ \\
\hline
\end{tabular}


Table 9: Experimental Design Results (in $\mathrm{mg} \mathrm{kg}^{-1}$ ) (mean results \pm standard deviation, $\mathrm{n}=3$ )

\begin{tabular}{|c|c|c|c|c|c|c|c|c|}
\hline \multirow{2}{*}{ Experiment } & As & Co & Cr & Fe & Rb & Sc & Se \\
\cline { 2 - 8 } & $13.6 \pm 1.7^{*}$ & $0.829 \pm 0.077^{*}$ & $1.24 \pm 0.28^{*}$ & $593 \pm 53^{*}$ & $4.93 \pm 0.92^{*}$ & $0.199 \pm 0.023^{*}$ & $4.42 \pm 0.45^{*}$ & $118.5 \pm 9.5^{*}$ \\
\hline $\mathrm{y}_{1}$ & $16.4 \pm 2.0$ & $1.229 \pm 0.091$ & $0.83 \pm 0.26$ & $774 \pm 110$ & $4.52 \pm 0.14$ & $0.208 \pm 0.005$ & $4.52 \pm 0.38$ & $143.6 \pm 12.6$ \\
\hline $\mathrm{y}_{2}$ & $10.0 \pm 2.6$ & $0.854 \pm 0.071$ & $0.87 \pm 0.24$ & $633 \pm 54$ & $4.04 \pm 1.11$ & $0.207 \pm 0.004$ & $4.29 \pm 0.42$ & $121.9 \pm 8.0$ \\
\hline $\mathrm{y}_{3}$ & $15.5 \pm 1.0$ & $1.014 \pm 0.084$ & $1.15 \pm 0.43$ & $670 \pm 84$ & $4.53 \pm 0.15$ & $0.206 \pm 0.006$ & $4.76 \pm 0.59$ & $122.2 \pm 9.3$ \\
\hline $\mathrm{y}_{4}$ & $12.3 \pm 0.8$ & $0.839 \pm 0.071$ & $1.21 \pm 0.27$ & $632 \pm 33$ & $4.73 \pm 0.32$ & $0.200 \pm 0.003$ & $4.73 \pm 0.27$ & $118.2 \pm 6.7$ \\
\hline $\mathrm{y}_{5}$ & $15.9 \pm 1.4$ & $1.200 \pm 0.087$ & $1.17 \pm 0.23$ & $682 \pm 102$ & $4.56 \pm 0.14$ & $0.205 \pm 0.004$ & $4.56 \pm 0.38$ & $141.7 \pm 11.4$ \\
\hline $\mathrm{y}_{6}$ & $10.6 \pm 2.0$ & $0.853 \pm 0.067$ & $0.91 \pm 0.46$ & $627 \pm 44$ & $4.61 \pm 0.79$ & $0.205 \pm 0.002$ & $4.45 \pm 0.30$ & $123.3 \pm 6.5$ \\
\hline $\mathrm{y}_{7}$ & $14.7 \pm 0.9$ & $1.001 \pm 0.080$ & $1.29 \pm 0.33$ & $667 \pm 93$ & $4.59 \pm 0.14$ & $0.207 \pm 0.004$ & $4.59 \pm 0.47$ & $118.8 \pm 8.9$ \\
\hline $\mathrm{y}_{8}$ & $13.6 \pm 0.9$ & $0.836 \pm 0.045$ & $1.19 \pm 0.26$ & $631 \pm 36$ & $4.81 \pm 0.35$ & $0.201 \pm 0.002$ & $4.57 \pm 0.35$ & $118.1 \pm 6.9$ \\
\hline
\end{tabular}

* CRM certified values, uncertainties are expanded uncertainties, $\mathrm{k}=2$. 
Table 10: Main Effects (A, B, C) and Interaction Contrasts (AB, AC, BC, ABC)

\begin{tabular}{|c|c|c|c|c|c|c|c|c|c|c|c|}
\hline \multicolumn{6}{|c|}{ Arsenic } & \multicolumn{6}{|c|}{ Cobalt } \\
\hline Effect & Result & & Error & $t$-value & $p$-value & Effect & Result & & Error & $t$-value & $p$-value \\
\hline Mean & 0,24 & \pm & 1,98 & 0,12 & 0,90567 & Mean & 18.0 & \pm & 1.87 & 9.64 & $<0.00001$ \\
\hline A & $-29,3$ & \pm & 3,96 & 7,41 & $<0.00001$ & A & -32.0 & \pm & 3.73 & 8.58 & $<0.00001$ \\
\hline B & 5,99 & \pm & 3,96 & 1,51 & 0,14939 & B & -13.5 & \pm & 3.73 & 3.61 & 0.00233 \\
\hline $\mathrm{C}$ & 1,21 & \pm & 3,96 & 0,31 & 0,76334 & $\mathrm{C}$ & -1.42 & \pm & 3.73 & 0.38 & 0.70897 \\
\hline $\mathrm{AB}$ & 13,7 & \pm & 3,96 & 3,47 & 0,00318 & $\mathrm{AB}$ & 11.6 & \pm & 3.73 & 3.10 & 0.00693 \\
\hline $\mathrm{AC}$ & 5,99 & \pm & 3,96 & 1,51 & 0,14939 & $\mathrm{AC}$ & 1.18 & \pm & 3.73 & 0.32 & 0.75662 \\
\hline $\mathrm{BC}$ & 0,84 & \pm & 3,96 & 0,21 & 0,83376 & $\mathrm{BC}$ & 0.39 & \pm & 3.73 & 0.11 & 0.91761 \\
\hline $\mathrm{ABC}$ & 1,95 & \pm & 3,96 & 0,49 & 0,62928 & $\mathrm{ABC}$ & -0.51 & \pm & 3.73 & 0.14 & 0.89240 \\
\hline \multicolumn{6}{|c|}{ Chromium } & \multicolumn{6}{|c|}{ Iron } \\
\hline Effect & Result & & Error & $t$-value & $p$-value & Effect & Result & & Error & $t$-value & $p$-value \\
\hline Mean & -13.0 & \pm & 4.58 & 2.85 & 0.01169 & Mean & 12.1 & \pm & 2.59 & 4.65 & 0.00027 \\
\hline A & -5.66 & \pm & 9.16 & 0.62 & 0.54486 & A & -11.4 & \pm & 5.19 & 2.19 & 0.04337 \\
\hline B & 21.2 & \pm & 9.16 & 2.32 & 0.03402 & B & -4.89 & \pm & 5.19 & 0.94 & 0.35996 \\
\hline $\mathrm{C}$ & 9.98 & \pm & 9.16 & 1.09 & 0.29190 & $\mathrm{C}$ & -4.30 & \pm & 5.19 & 0.83 & 0.41945 \\
\hline $\mathrm{AB}$ & 4.06 & \pm & 9.16 & 0.44 & 0.66336 & $\mathrm{AB}$ & 5.14 & \pm & 5.19 & 0.99 & 0.33633 \\
\hline $\mathrm{AC}$ & -8.91 & \pm & 9.16 & 0.97 & 0.34502 & $\mathrm{AC}$ & 3.71 & \pm & 5.19 & 0.71 & 0.48492 \\
\hline $\mathrm{BC}$ & -5.15 & \pm & 9.16 & 0.56 & 0.58165 & $\mathrm{BC}$ & 3.96 & \pm & 5.19 & 0.76 & 0.45614 \\
\hline $\mathrm{ABC}$ & 2.45 & \pm & 9.16 & 0.27 & 0.79269 & $\mathrm{ABC}$ & -3.54 & \pm & 5.19 & 0.68 & 0.50470 \\
\hline \multicolumn{6}{|c|}{ Rubidium } & \multicolumn{6}{|c|}{ Scandium } \\
\hline Effect & Result & & Error & $t$-value & $p$-value & Effect & Result & & Error & $t$-value & $p$-value \\
\hline Mean & -7.73 & \pm & 2.15 & 3.59 & 0.00244 & Mean & 2.95 & \pm & 0.41 & 7.26 & $<0.00001$ \\
\hline A & -0.05 & \pm & 4.30 & 0.01 & 0.99075 & A & -1.63 & \pm & 0.81 & 2.00 & 0.06220 \\
\hline B & 4.72 & \pm & 4.30 & 1.10 & 0.28955 & B & -1.36 & \pm & 0.81 & 1.70 & 0.10921 \\
\hline $\mathrm{C}$ & 3.80 & \pm & 4.30 & 0.88 & 0.39010 & $\mathrm{C}$ & -0.38 & \pm & 0.81 & 0.46 & 0.65066 \\
\hline $\mathrm{AB}$ & 4.31 & \pm & 4.30 & 1.00 & 0.33164 & $\mathrm{AB}$ & -1.38 & \pm & 0.81 & 1.70 & 0.10921 \\
\hline $\mathrm{AC}$ & 2.79 & \pm & 4.30 & 0.65 & 0.52629 & $\mathrm{AC}$ & 0.13 & \pm & 0.81 & 0.16 & 0.87808 \\
\hline $\mathrm{BC}$ & -2.38 & \pm & 4.30 & 0.55 & 0.58751 & $\mathrm{BC}$ & 0.88 & \pm & 0.81 & 1.08 & 0.29533 \\
\hline $\mathrm{ABC}$ & -2.59 & \pm & 4.30 & 0.60 & 0.55645 & $\mathrm{ABC}$ & -0.12 & \pm & 0.81 & 0.15 & 0.88046 \\
\hline \multicolumn{6}{|c|}{ Selenium } & \multicolumn{6}{|c|}{ Zinc } \\
\hline Effect & Result & & Error & $t$-value & $p$-value & Effect & Result & & Error & $t$-value & $p$-value \\
\hline Mean & 3.28 & \pm & 1.66 & 1.97 & 0.06633 & Mean & 6.31 & \pm & 1.57 & 4.01 & 0.00100 \\
\hline A & -1.92 & \pm & 3.33 & 0.58 & 0.57159 & A & -9.44 & \pm & 3.15 & 3.00 & 0.00847 \\
\hline B & 4.98 & \pm & 3.33 & 1.49 & 0.15440 & B & -11.2 & \pm & 3.15 & 3.56 & 0.00259 \\
\hline $\mathrm{C}$ & -0.79 & \pm & 3.33 & 0.24 & 0.81504 & $\mathrm{C}$ & -0.83 & \pm & 3.15 & 0.26 & 0.79452 \\
\hline $\mathrm{AB}$ & 1.92 & \pm & 3.33 & 0.58 & 0.57159 & $\mathrm{AB}$ & 7.48 & \pm & 3.15 & 2.38 & 0.03028 \\
\hline $\mathrm{AC}$ & 0.68 & \pm & 3.33 & 0.20 & 0.84104 & $\mathrm{AC}$ & 1.40 & \pm & 3.15 & 0.45 & 0.66167 \\
\hline $\mathrm{BC}$ & -3.05 & \pm & 3.33 & 0.92 & 0.37260 & $\mathrm{BC}$ & -0.62 & \pm & 3.15 & 0.20 & 0.84570 \\
\hline $\mathrm{ABC}$ & -0.68 & \pm & 3.33 & 0.20 & 0.84104 & $\mathrm{ABC}$ & 0.01 & \pm & 3.15 & 0.00 & 0.99737 \\
\hline
\end{tabular}




\subsubsection{Experimental design considerations for arsenic}

Results for arsenic were considered satisfactory to all experiments by interpolation of the experimental results with the certified value (see Table 6). Nevertheless, it was observed a great difference for variance of results in the different experiments. Z-score values were between -4.2 ( $\left.\mathrm{y}_{2}\right)$ and $2.8\left(\mathrm{y}_{5}\right)$ and relative error between -26\% and $17 \%$. Best results for trueness were observed to experiments $\mathrm{y}_{8}$ and $\mathrm{y}_{7}$ respectively. Experiments $\mathrm{y}_{4}, \mathrm{y}_{7}$ and $\mathrm{y}_{8}$ presented the most precise results.

Main effect and interaction contrast analysis presented the factor A as the most important factor for optimization of this analytical procedure and that best results are closely related to levels attributed to B (Main effect: $p<0.00001$; Contrast AB: $\mathrm{p}=0.00318)$.

In this case, a multivariate optimization procedure proved to be of value. If this method was not implemented, $\mathrm{y}_{8}$ experiment would be considered the best analytical condition. However, it is noticed that factor $\mathrm{C}$ has no significant influence on the results. In other words, measuring for 1 or 3 hours does not cause significant differences to the result.

Thus, according to the results and based on the $\mathrm{AB}$ contrasts, it was decided to keep the standard condition for the A and B factors (level 0) as the best condition, once the measurement for 9 days (level + of factor A) generated results with a increased uncertainty associated to analytical measurement (in countings per second). As factor $\mathrm{C}$ was not directly related to results, level - was considered as the optimal level.

Optimized condition for arsenic measurand in biological matrix samples by INAA adopted in this study was: 7 days to sample decay time, shelf 1 to sample distance to detector and 1 hour to counting time of sample.

\subsubsection{Experimental design considerations for cobalt, chromium, iron, rubidium, scandium, selenium and zinc}


According to the results, it was inferred that experiments $\mathrm{y}_{8}$ and $\mathrm{y}_{4}$ presented the best results for all measurands. Experiments $\mathrm{y}_{1}$ and $\mathrm{y}_{5}$ presented the worst results. Analyzing the configuration of the experiments $\mathrm{y}_{8}$ and $\mathrm{y}_{4}$, it is a possible to verify that the factor $\mathrm{C}$ (counting time) was changed from the level + to - . Nevertheless, there was no significant change of the results because A and B were maintained in level + . In the context, counting time showed the lowest influence to the detection process for $\mathrm{Co}, \mathrm{Cr}, \mathrm{Fe}, \mathrm{Rb}, \mathrm{Sc}, \mathrm{Se}$ and $\mathrm{Zn}$ measurands by INAA comparative method. This fact is even more evidenced in the analyses of results obtained to main effect and interaction contrasts.

By means of p-values for main effects and assuming a normal distribution of the results, it was verified that for factor $\mathrm{C}, \mathrm{H}_{0}$ was accepted for all measurands. Therefore, the level change did not affect the final result. In other words, there is no evidence that change of the counting time for sample from 6 to 10 hours gives rise to a positive or negative effect on the final result.

Nonetheless, in this investigative step, it was obtained two distinct behaviors for measurands. The first was observed for $\mathrm{Rb}, \mathrm{Sc}$ and $\mathrm{Se}$, where main effect and interaction contrast results did not present statistically significant differences. For this group of measurands, different levels settings for the factors did not influence the final result of analysis. This fact can be easily seen in the results shown in Tables 7 (mean results) and 8 (z-score value).

$\mathrm{Co}, \mathrm{Cr}, \mathrm{Fe}$ and $\mathrm{Zn}$ presented a distinct result. By means of p-values results of main effect and interaction contrast it is possible to observe an important influence assigned to the factor A for Fe $(\mathrm{p}=0.04337)$, Co $(\mathrm{p}<0.00001)$ and $\mathrm{Zn}(\mathrm{p}=$ $0.00847)$, factor $\mathrm{B}$ for $\mathrm{Cr}(\mathrm{p}=0.03402), \mathrm{Co}(\mathrm{p}=0.00233)$ and $\mathrm{Zn}(\mathrm{p}=0.00259)$ and $\mathrm{AB}$ interaction for $\mathrm{Co} \quad(\mathrm{p}=0.00643)$ and $\mathrm{Zn}$ $(\mathrm{p}=0.03028)$. For Co, the small $\mathrm{p}$-value obtained for factor $\mathrm{A}(\mathrm{p}<0.00001)$ can be attributed to the presence of spectral interferences for analytical photopeak utilized (factor A, level-). 
In this case, the optimization of analytical procedure should be directed to the interactions between such variables. Thus, interaction contrast analysis arises as a lighthouse to guide the path to be followed.

The $2^{\mathrm{k}}$ experimental design showed to be an important tool for optimization of the analytical procedure for this group of measurands. If a univariate optimization procedure was used, conditions of the experiment $\mathrm{y} 8$ (level + to $\mathrm{A}, \mathrm{B}$ and $\mathrm{C}$ factors) would be chosen as the optimized condition. However, a multivariate procedure was able to show that factor $\mathrm{C}$ does not present significant influence to the results. Thus, it was observed that $\mathrm{A}$ and $\mathrm{B}$ are the most important factors to the detection step in INAA. Furthermore, it was verified that the relationship between these variables is of great importance for best results, particularly to zinc and cobalt measurands.

$\mathrm{AC}, \mathrm{BC}$ and $\mathrm{ABC}$ interactions did not present important interactions for the optimization of analytical procedures for the levels attributed to the different factors in this study.

Thus, optimal condition for the measurement of cobalt, chromium, iron, rubidium, selenium, scandium and zinc in biological matrix samples by INAA was: 20 days to sample decay time, shelf 0 to sample distance to detector and 6 hours to counting time of sample. Subsequent tests will indicate on the precision and trueness of analytical results for this configuration.

\section{CONCLUSION}

In this study, $2^{\mathrm{k}}$ experimental design was an important tool for the optimization of element determination by INAA. By means of the statistical analysis and theoretical and experimental considerations it was determined the optimized experimental conditions for the analytical methods that will be adopted for the future steps of the validation procedure of INAA methods in the Neutron Activation Analysis Laboratory (LAN) of the Research Reactor Center (CRPq) at the Nuclear and Energy Research Institute (IPEN - CNEN/SP). For As, optimal analytical condition was: 7 days to sample decay time, shelf 1 to sample distance to detector and 1 hour 
to counting time of sample. For others measurands ( $\mathrm{Co}, \mathrm{Cr}, \mathrm{Fe}, \mathrm{Rb}, \mathrm{Sc}, \mathrm{Se}$ and $\mathrm{Zn}$ ), the analytical optimized condition was: 20 days to sample decay time, shelf 0 to sample distance to detector and 6 hours to counting time of sample.

\section{ACKNOWLEDGMENTS}

Authors are indebted to the financial support received from IPEN - CNEN/SP and the Brazilian National Council for Scientific and Technological Development $(\mathrm{CNPq})$.

\section{REFERENCES}

1. Agência Nacional de Vigilância Sanitária, Seleção, uso e interpretação de programas de ensaios de proficiência por laboratórios, Agência Nacional de Vigilância Sanitária, Brasília (2005).

2. Associação Brasileira de Normas Técnicas, ABNT NBR ISO/IEC 17025: Requisitos gerais para a competência de laboratórios de ensaio e calibração, Associação Brasileira de Normas Técnicas, Rio de Janeiro, pp. 1-31 (2005).

3. N. Reynier, J. F. Blais, G. Mercier, "Optimization of arsenic and pentachlorophenol removal from soil using an experimental design methodology", Journal of soils and sediments, 13, pp. 1189-1200 (2013).

4. S. Izadyar, S. Fatemi, T. Mousavand, "Synthesis and modification of nano-sized $\mathrm{TiO} 2$ for photo-degradation process under visible light irradiation; a Placket-Burman experimental design”, Materials Research Bulletin, 48, pp. 3196-3203 (2013).

5. E. V. C. Galdámez, Aplicação das técnicas de planejamento e análises de experimentos na melhoria da qualidade de um processo de fabricação de produtos plásticos, Dissertação de Mestrado - Escola de Engenharia de São Carlos, São Carlos, Brazil (2002).

6. E. R. Pereira-Filho, R. J. Poppi, M. A. Z. Arruda, "Employment of factorial design for optimization of pirolisys and atomization temperatures for $\mathrm{Al}, \mathrm{Cd}, \mathrm{Ni}$ and $\mathrm{Pb}$ determination by ET AAS" Quim. Nova, 25. 2, pp. 246-253 (2002).

7. B. Barros Neto, I. S. Scarminio, R. E. Bruns, Planejamento e Otimização de Experimentos, Campinas, Brazil (1996). 
8. W. G. Cochran, G. M. Cox, "Experimental designs”, John Wiley \& Sons, Inc., pp. 148-157 (1966).

9. H. D. R. Martínez, “Analyzing interactions of fitted models", http://cran.rproject.org/web/packages/phia/vignettes/phia.pdf (2013)

10. E. G. Moreira, Preparo e caracterização de um material de referência de mexilhão Perna perna (Linnaeus, 1758), Tese de Doutoramento - Instituto de Pesquisas Energética e Nucleares, São Paulo, Brazil (2010).

11. R. R. Greenberg, P. Bode, E. A. De Nadai Fernandes, "Neutron activation analysis: A primary method of measurement", Spectrochimic Acta. Part B, pp. 193$241(2011)$

12. Microsoft, "Microsoft Office Excel", http://office.microsoft.com/pt-br/excel/ (2013)

13. W. D. Ehmann, D. E. Vance, Radiochemistry and Nuclear Methods of Analysis, John Wiley \& Sons, Inc., New York, USA (1991).

14. S. Y. F. Chu, L. P. Elkstrõm, R. B. Firestone, "The Lund/LBNL Nuclear Data Search: Version 2.0, February 1999”, http://nucleardata.nuclear.lu.se/toi/ (2013)

15. E. Prichard, V. Barwick, Quality assurance in Analytical chemistry, John Wiley \& Sons, Inc., Chicester, United Kingdon (2008)

16. R. F. Teófilo, M. M. C. Ferreira, "Chemometrics II: Spreadsheets for experimental design calculations, a tutorial”, Quim. Nova, 29. 2, pp. 338-350 (2006). 


\title{
SECÇÃO DE ANEXOS
}

\author{
ANEXO 3. \\ EXPERIMENTAL DESIGN APPLIED FOR THE OPTIMIZATION \\ OF INAA METHODS \\ (Trabalho apresentado no 4th International Nuclear Chemistry Congress, INCC)
}




\title{
Experimental Design applied for the optimization of INAA methods
}

\author{
Robson Petroni and Edson G. Moreira \\ Instituto de Pesquisas Energéticas e Nucleares (IPEN - CNEN/SP) \\ Av. Professor Lineu Prestes 2242 \\ 05508-000 São Paulo, SP, BRAZIL
}

\begin{abstract}
In this work a $2^{3}$ Experimental Design was carried out aiming the multivariate optimization of Instrumental Neutron Activation Analysis (INAA) for mass fraction determination of Co, $\mathrm{Cr}, \mathrm{Fe}, \mathrm{Rb}, \mathrm{Sc}, \mathrm{Se}$ and $\mathrm{Zn}$ in biological samples and $\mathrm{Co}, \mathrm{Cr}, \mathrm{Fe}, \mathrm{Sc}$ and $\mathrm{Zn}$ in geological samples. The factors investigated were sample decay time, sample distance to detector and sample measurement time. The optimized condition for each method was outlined according to the results of main effect and interaction contrasts for each measurand (monoelemental optimization) and for all measurands considered simultaneously (multielemental optimization).
\end{abstract}

Keywords: experimental design; full factorial design; method optimization; INAA

\section{Introduction}

The implementation of a quality management system is essential to a measurement laboratory to demonstrate that it has facilities, equipment and suitable analytical measurement methods to the quality assurance of analytical results. By means of the certification and/or accreditation processes, the laboratory can demonstrate that its results are fit for the intended use. 
These processes can be formalized by complying with a wide series of standards and protocols, depending on the activities performed by the laboratory. In Brazil, for measurements in chemistry, the ISO/IEC 17025 Standard is the most important regulation standard. In this context, the validation of measurement methods is a prerequisite for the implementation and suitability of the quality system in a laboratory $[1]$.

Before starting the experiments required by the scope of method validation (detection limit, quantification limit, selectivity, specificity, linearity, repeatability, intermediate precision, reproducibility and trueness) it is usually appropriate to conduct an in-depth study on the characteristics of the technique, analytical interferences, uncertainties, reagents, among others, aiming to identify possible factors that may jeopardize the quality of results. In other words, a measurement method optimization should be carried out.

In this study, a $2^{3}$ experimental design was applied to identify the importance of selected factors to the accurate end result, aiming the optimization to a subsequent validation of two INAA methods.

\section{Theory}

A classical method optimization consists of varying each investigated variable while holding all others as constant terms. This method is widely used but usually requires a large number of experiments to be performed and the optimization procedure does not consider the results of the main effect and interaction contrasts among variables [2].

Often, these studies are virtually impossible to be carried out or simply do not generate significant results for the method optimization. As alternative, some authors have reported the use of the Experimental Design (DOE) as an important tool for the 
optimization of methods and processes in several areas of research and manufacture, particularly for monoelemental methods [2-8].

For a better understanding of the $2^{3}$ experimental design carried in this study, it is necessary to define some terms, such as factor, level, main effect, interaction contrast and standard error. These concepts are presented below [9]:

Factor: each variable investigated for the method optimization. In this study, three factors were considered: sample decay time (A), sample distance to detector (B) and sample measurement time $(\mathrm{C})$.

Level: experimental condition assigned to each factor investigated. In a 23 experimental design, two different levels are assigned for each factor. These levels are denominated level -1 (assigned to less favorable condition) and level +1 (assigned to more favorable condition). The assignment of +1 or -1 levels is given arbitrarily and does not interfere with the experiments or the interpretation of results.

Main Effect: result obtained with the variation of different levels assigned to a factor. Mathematically, it is calculated according to (1).

$$
M E=2 \frac{\sum\left(y^{+1}\right)-\sum\left(y^{-1}\right)}{n}
$$

where:

$M E$ is the main effect value of a factor;

$\sum(y+1)$ and $\sum(y-1)$ are summation of the results obtained for all experiments in level +1 and -1 respectively (including replicates); $n$ is the number of experiments (including replicates). 
Interaction Contrast: the half of the difference between the main effect of a factor in the level of another factor. Briefly, it can be defined as the change in the level of a factor affecting the result for another factor [10];

Standard Error: measurement error in the result of an effect and/or interaction. It is calculated according to (2).

$$
E=\frac{s}{\sqrt{2^{(k-1)}}}
$$

where:

$E$ is the measurement error in the result of an effect;

$s$ is the standard deviation of the results obtained for all experiments;

$k$ is the number of factors investigated.

Depending on the experimental conditions and number of factors to be investigated, different models of DOE can be used. Among then we have the $x^{k}$ ( $x$ levels for $k$ factors), whereas $x \geq 2$ and $k \geq 2$ and the $x^{k-p}$ when the number of factors investigated is greater than 4.

According to the model chosen and the number of replicas of the experiments, we can perform different methods for obtain the results. The full factorial design is the most widely used for studies with three or fewer factors and levels. For studies with larger number of factors, the model of randomized blocks is the most appropriate [11].

The major advantage of the DOE is the conduction of a multivariate optimization which needs a smaller number of experiments when compared to classical optimization methods (univariate procedure). By means of main effect and interaction contrasts it is possible to explain how the different factors are correlated and just how important these correlations 
are for the method optimization. Thus, it is possible to evaluate and understand the contribution of each factor to the end result $[11,12]$.

Nevertheless, the main assumptions required by DOE are the complete randomization of experiments, independent results for each measurement and a normal distribution for the obtained results $[11,12]$.

\section{Experimental}

\section{Instrumental Neutron Activation Analysis}

Subsamples of Mussel Tissue Reference Material (RM) [13] and Estuarine Sediment Certified Reference Material (CRM) [14] of $150 \pm 10 \mathrm{mg}$ were weighed in polyethylene packaging previously cleaned, using a Shimadzu AEM-5200 analytical balance. The standard working solution was prepared by dilution of Spex CRM element solutions in volumetric flask. Multielemental standards were prepared by pipetting of the solution containing all measurands onto Whatman paper filters using Eppendorf micropipette. After drying, the paper filters were folded, placed and sealed in polyethylene packaging with the same sample geometry $(10 \mathrm{~mm} \times 8 \mathrm{~mm} \times 1 \mathrm{~mm})$.

The INAA comparative method was performed for the mass fraction determination of $\mathrm{Co}, \mathrm{Cr}, \mathrm{Fe}, \mathrm{Rb}, \mathrm{Sc}, \mathrm{Se}$ and $\mathrm{Zn}$ in biological samples and $\mathrm{Co}, \mathrm{Cr}, \mathrm{Fe}, \mathrm{Sc}$ and $\mathrm{Zn}$ in geological samples. Samples and multielemental standards were simultaneously irradiated for $8 \mathrm{~h}$ under 0.5 to $1.0 \times 10^{13} \mathrm{~cm}^{-2} \mathrm{~s}^{-1}$ thermal neutron flux at IEA-R1 Nuclear Research Reactor. ${ }^{60} \mathrm{Co},{ }^{51} \mathrm{Cr},{ }^{59} \mathrm{Fe},{ }^{86} \mathrm{Rb},{ }^{46} \mathrm{Sc},{ }^{75} \mathrm{Se}$ and ${ }^{65} \mathrm{Zn}$ radionuclides were quantified by gamma-ray spectrometry, using a GC2018 Canberra HPGe detector coupled to a DSA 1000 multichannel analyzer.

Genie 2000 - Gamma Acquisition \& Analysis 3.1 software was used to obtain gamma ray spectra. Mass fraction calculations were carried out using a Microsoft Excel 
spreadsheet for suitable radionuclide photopeak energies. Three replicate analyses for biological samples and two replicate analyses for geological samples were randomly performed.

\section{Experimental Design}

In this study, a $2^{3}$ experimental design $\left(2^{3}\right.$ full factorial design $)$ was applied for optimization of two multielemental methods of INAA at the Neutron Activation Analysis Laboratory (LAN, IPEN - CNEN/SP). Three factors of the detection step were investigated: sample decay time (A), sample distance to detector (B) and sample measurement time (C). Table 1 presents the values assigned to the different levels for each factor.

Table 1 Values assigned to different levels of each factor

\begin{tabular}{ccccc}
\hline Factor & \multicolumn{2}{c}{ Biological matrix samples } & \multicolumn{2}{c}{ Geological matrix samples } \\
\hline \multirow{2}{*}{ Sample decay time (A) } & Level -1 & Level +1 & Level -1 & Level +1 \\
\cline { 2 - 5 } & 10 days & 22 days & 10 days & 22 days \\
Sample distance to detector (B) & Shelf 3 & Shelf 0 & Shelf 3 & Shelf 0 \\
Sample measurement time (C) & $(98 \mathrm{~mm})$ & $(3 \mathrm{~mm})$ & $(98 \mathrm{~mm})$ & $(3 \mathrm{~mm})$ \\
& 6 hours & 10 hours & 2 hours & 6 hours \\
\hline
\end{tabular}

Different levels were designed according to the standard configuration of the methods. Originally, biological samples are measured 14-15 days after irradiation for a period of 10 hours in shelf $1(33 \mathrm{~mm})$ and geological samples are measured 14-15 days after irradiation for 3 hours in shelf 0 ( $3 \mathrm{~mm})$. The main objective of this work was to perform a decrease in sample measurement time without impairing the accuracy of the results, aiming an increase in the analytical output of the laboratory. 
Results obtained for each measurand in different levels $(-1$ and +1$)$ were evaluated for accuracy (precision and trueness) by means of $z$-score and relative standard deviation (RSD) calculations. Main effect and interaction contrasts analyses were outlined considering the relative error of the results and the calculations were carried in $\mathrm{R}$ 2.5.1 software $[12,15]$.

For assessing the statistical significance of the results, a $t$-test was carried at the $95 \%$ confidence level. $\mathrm{H}_{0}$ hypothesis (null hypothesis) was accepted when there was no statistically significant difference between the means, i.e., when the means are statistically equivalent. On the other hand, $\mathrm{H}_{1}$ hypothesis (alternative hypothesis) was accepted for means not statistically equivalent. In short, for $p \geq 0.05 \mathrm{H}_{0}$ was accepted. Otherwise, $\mathrm{H}_{0}$ was rejected and $\mathrm{H}_{1}$ accepted [16].

\section{Results and Discussion}

\section{Levels and Factors}

In order to check whether the values assigned to the different levels were properly delineated, the samples were analyzed in the -1 and +1 conditions (according to Table 1 ). Figure 1 shows $z$-scores according to Thompson's criteria $[17,18]$ and RSD results for the mean results obtained in different levels for the biological matrix sample while Figure 2 shows the results for the geological matrix sample.

According to $z$-score analysis, level +1 results for biological and geological matrix samples presented best results for trueness when compared to level -1 , with exception of Se where the level -1 was the most favorable condition. Results for biological samples varied from 0.17 to 3.98 (level -1) and 0.04 to $0.99($ level +1) and for geological samples from 0.10 to 2.14 (level -1) and 0.01 to $0.92($ level +1$)$. 


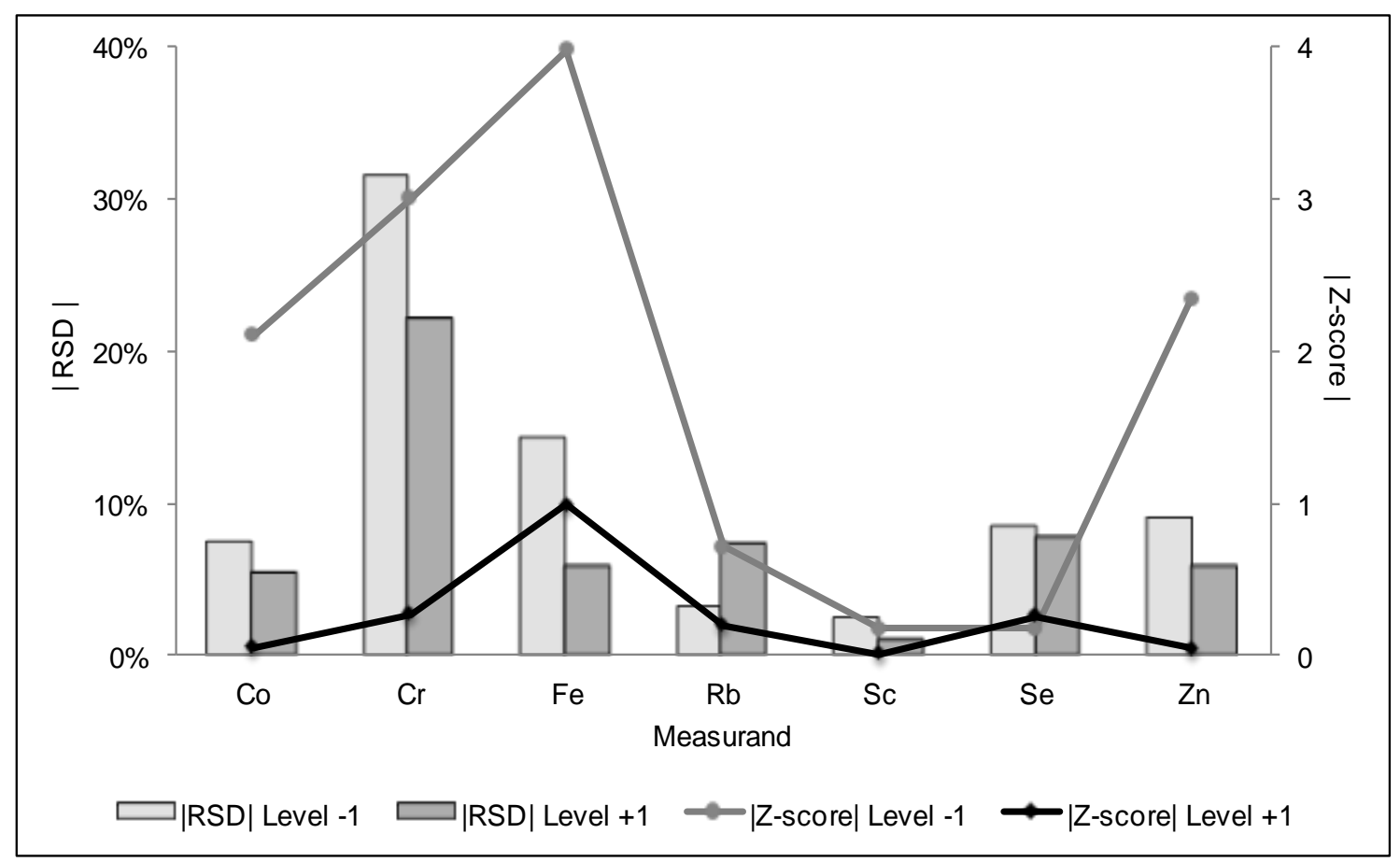

Fig. $1 Z$ score and RSD results for the different levels assigned to the factors (biological matrix sample)

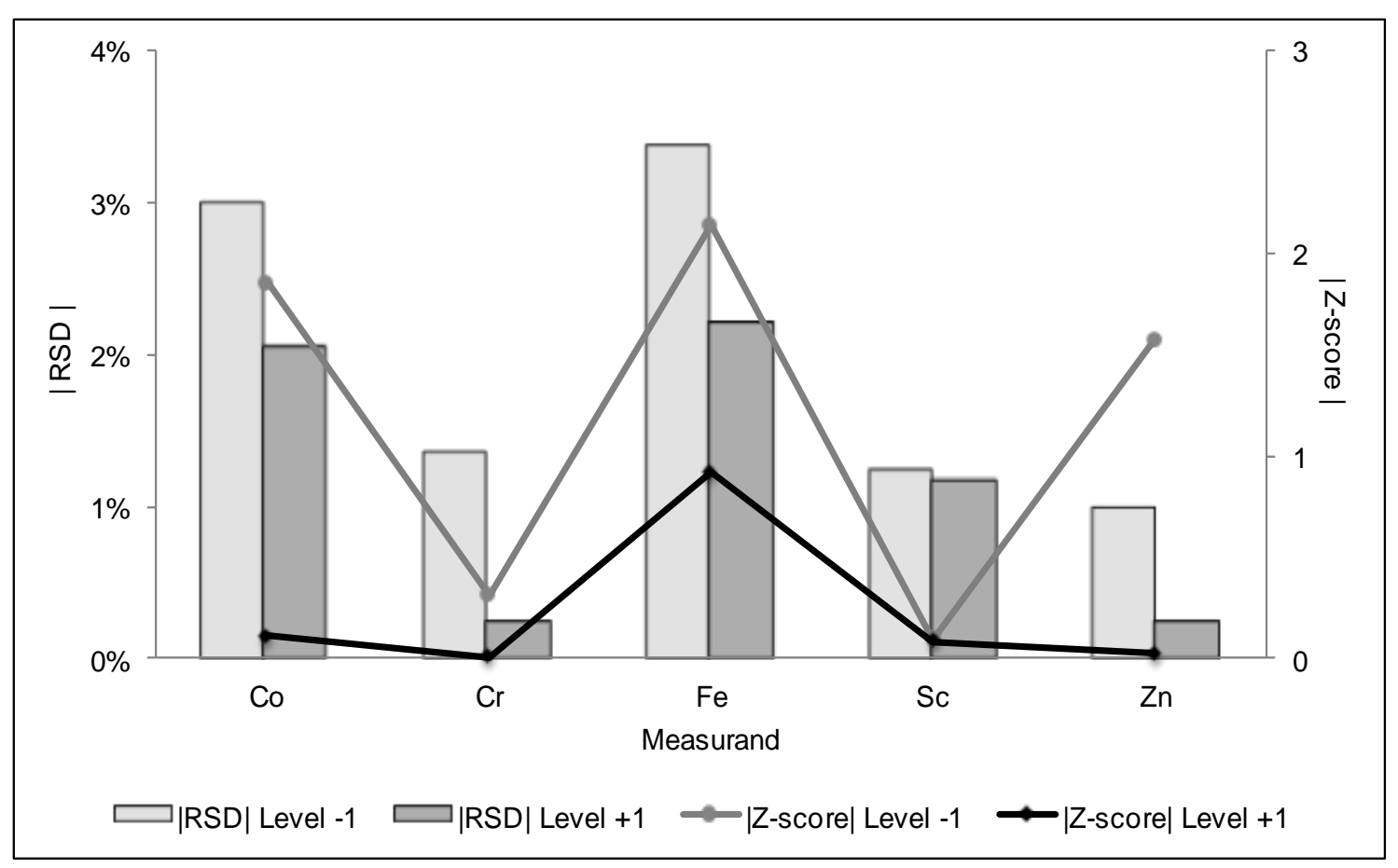

Fig. $2 Z$ score and RSD results for the different levels assigned to the factors (geological matrix sample) 
An estimate of the precision was obtained according to the RSD results. For biological matrix sample it was verified that more precise results were obtained for $\mathrm{Co}, \mathrm{Fe}, \mathrm{Sc}, \mathrm{Se}$ and $\mathrm{Zn}$ in the level +1 , with values between $1.0 \%$ for $\mathrm{Sc}$ and $21 \%$ for $\mathrm{Cr}$. $\mathrm{Rb}$ presented the least RSD for the condition $-1(3.1 \%)$. On the other hand, results for the geological matrix sample were more precise for all measurands in the level $+1(2.0 \%, 0.24 \%, 2.2$ $\%, 1.2 \%$ and $0.25 \%$ for $\mathrm{Co}, \mathrm{Cr}, \mathrm{Fe}, \mathrm{Sc}$ and $\mathrm{Zn}$, respectively).

Best results for trueness and precision were obtained for geological matrix sample when compared to the biological matrix sample results in similar analytical conditions. This fact can be attributed to differences in the matrix characteristics as well as element composition, mass fraction content, granulometry and particle size distribution.

\section{Experimental design (DOE)}

\section{Biological matrix samples}

The matrix of the $2^{3}$ experimental design was compounded of 168 results, as three replicate analyses were performed for the 7 measurands. For each result it was calculated the relative error to the reference value aiming to a data standardization. With the relative error for all measurands were outlined the main effect and interaction contrasts to the method. Mean results and standard deviation obtained for the DOE experiments are presented in Table 2. Table 3 present main effect and interaction contrasts results.

Experiments $\mathrm{e}_{8}$ and $\mathrm{e}_{4}$ presented the best results for all measurands and experiments $\mathrm{e}_{1}$ and $e_{5}$ presented the worst results (trueness and precision). Analyzing the configuration of the experiments $e_{8}$ and $e_{4}$, it is possible to verify that $C$ was changed from the level+1 to level -1 , namely, there were not evidences that the change from 6 to 10 hours gave rise to a positive or negative influence on the end result. Nevertheless, there was no significant change of the results because $\mathrm{A}$ and $\mathrm{B}$ were maintained in level +1 . 
Table 2 Mass fraction results obtained by INAA at a $2^{3}$ experimental design in biological matrix sample (mean value \pm standard deviation, $n=3$ )

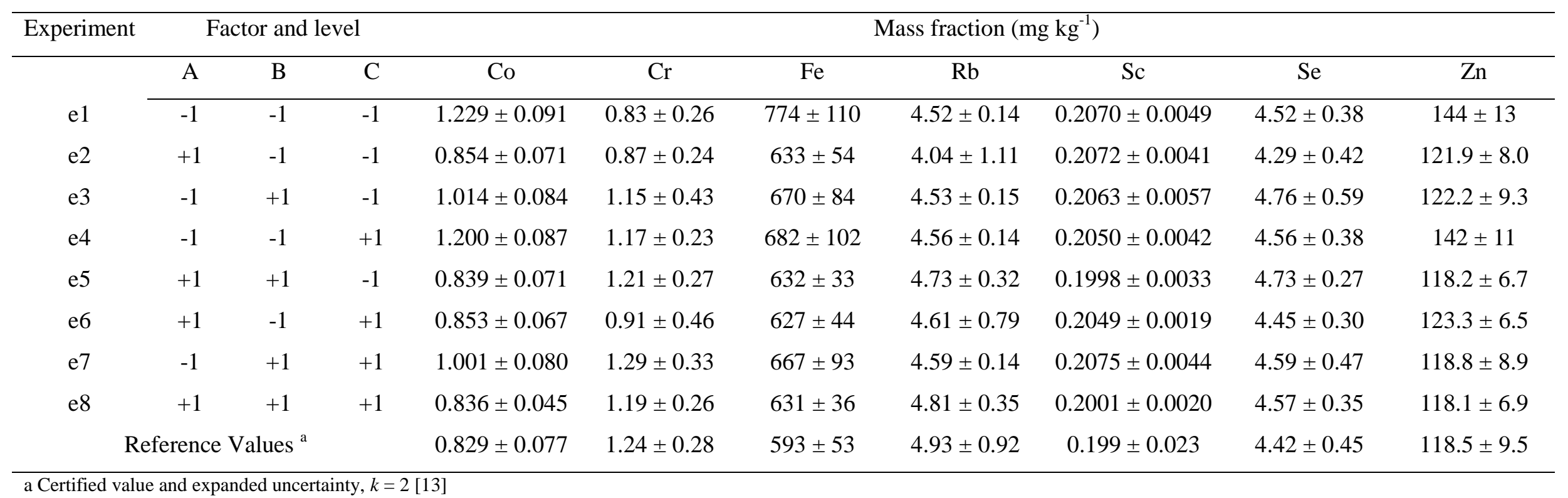


Table 3 Main effects (A; B; C) and interaction contrasts (A:B; A:C; B:C; A:B:C) for the INAA method of biological matrix samples

\begin{tabular}{ccccc}
\hline Interaction & Effect & Error & $t$-value & $p$-value \\
\hline A & $-8.9 \mathrm{E}-02$ & $2.6 \mathrm{E}-02$ & -3.46 & $7.0 \mathrm{E}-04$ \\
B & $-6.9 \mathrm{E}-05$ & $2.6 \mathrm{E}-02$ & $-2.7 \mathrm{E}-03$ & 0.99 \\
C & $8.7 \mathrm{E}-03$ & $2.6 \mathrm{E}-02$ & 0.34 & 0.74 \\
A:B & $4.7 \mathrm{E}-02$ & $2.6 \mathrm{E}-02$ & 1.84 & $6.7 \mathrm{E}-02$ \\
A:C & $1.4 \mathrm{E}-03$ & $2.6 \mathrm{E}-02$ & $5.4 \mathrm{E}-02$ & 0.96 \\
B:C & $-8.5 \mathrm{E}-03$ & $2.6 \mathrm{E}-02$ & -0.33 & 0.74 \\
A:B:C & $-7.1 \mathrm{E}-03$ & $2.6 \mathrm{E}-02$ & -0.28 & 0.78 \\
\hline
\end{tabular}

$n=160 ; t_{(\alpha=0.05)} \sim 1.98[19]$

Factor A was the main factor for the multielemental optimization in biological matrix sample $(p=0.00070)$. Factor $\mathrm{B}$ and interactions $\mathrm{A}: \mathrm{B}, \mathrm{A}: \mathrm{C}, \mathrm{B}: \mathrm{C}$ and $\mathrm{A}: \mathrm{B}: \mathrm{C}$ were not statistically significant for the optimization of multielemental method.

The second step of this work was the evaluation of each effect for one-to-one-measurand, aiming to investigate which factors are statistically significant for a monoelemental optimization. In this investigative step, it was obtained two distinct behaviors for the group of measurands. It was observed that for $\mathrm{Rb}, \mathrm{Sc}$ and $\mathrm{Se}$ the results obtained of main effect and interaction contrast did not present statistically significant differences for any factors.

On the other hand, $\mathrm{Co}, \mathrm{Cr}, \mathrm{Fe}$ and $\mathrm{Zn}$ presented distinct results. According to the results of main effect and interaction contrasts it was possible to observe an important influence assigned to the factor A for Fe $(p=0.04337)$, Co $(p<0.00001)$ and $\mathrm{Zn}(p=0.00847)$, factor $\mathrm{B}$ for $\mathrm{Cr}(p=0.03402)$, Co $(p=0.00233)$ and $\mathrm{Zn}(p=0.00259)$ and $\mathrm{A}: \mathrm{B}$ interaction for $\mathrm{Co}(p=0.00643)$ and $\mathrm{Zn}(p=0.03028)$. 
If a univariate optimization procedure was used, conditions of the experiment $\mathrm{e}_{8}(\mathrm{level}+1$ to $\mathrm{A}, \mathrm{B}$ and $\mathrm{C}$ ) would be chosen as the optimized condition. However, with the multivariate procedure it was possible to show that $\mathrm{A}$ and $\mathrm{B}$ are the most important factors to the detection step in INAA and that the interaction between these variables is of great importance for best results (trueness and precision), particularly to $\mathrm{Zn}$ and Co. $\mathrm{AC}, \mathrm{BC}$ and $\mathrm{ABC}$ interactions did not present as important interactions for the monoelemental method optimization for the levels attributed to the different factors in this study. In this study, the optimal condition for measurement of $\mathrm{Co}, \mathrm{Cr}, \mathrm{Fe}, \mathrm{Rb}, \mathrm{Sc}, \mathrm{Se}$ and $\mathrm{Zn}$ in biological matrix sample was: 22 days to sample decay time $(\mathrm{A} ;+1)$, shelf 0 to sample distance to detector $(B ;+1)$ and 6 hours to counting time of sample $(\mathrm{C} ;-1)$.

\section{Geological matrix samples}

The matrix of geological $2^{3}$ experimental design was compounded of 80 results (two replicate analyses for five measurands). The same data treatment performed to the biological matrix sample was also carried out. Table 4 present the mean results for each experiment of the DOE and Table 5 present the main effects and interaction contrasts for this method of measurement.

Over again, if a univariate optimization procedure was used, conditions of the experiment $\mathrm{e}_{8}($ level +1 to $\mathrm{A}, \mathrm{B}$ and $\mathrm{C})$ would be chosen as the optimized condition. With exception of Sc, the best results were obtained in this condition. Analyzing the significance of the effects it was verified that factor A was the most important factor for the method optimization in geological matrix samples $(p=0.0014)$. On the other hand, $\mathrm{B}$ and $\mathrm{C}$ 
Table 4 Mass fraction results obtained by INAA at a $2^{3}$ experimental design in geological matrix sample (mean value \pm standard deviation, $n=2$ )

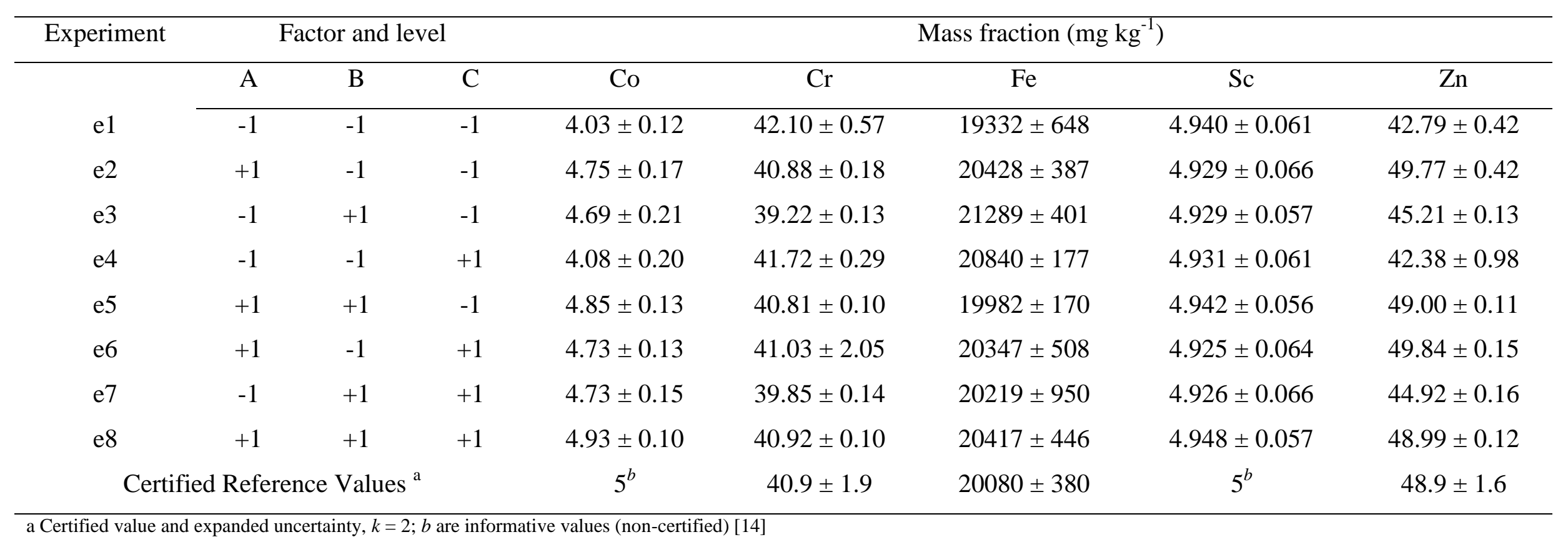


factors, $\mathrm{A}: \mathrm{B}, \mathrm{A}: \mathrm{C}, \mathrm{B}: \mathrm{C}$ and $\mathrm{A}: \mathrm{B}: \mathrm{C}$ interactions did not present statistically significant for this group of measurands.

Table 5 Main effects (A; B; C) and interaction contrasts (A:B; A:C; B:C; A:B:C) for the INAA method of geological matrix samples

\begin{tabular}{ccccc}
\hline Interaction & Effect & Error & $t$-value & $p$-value \\
\hline A & $4.0 \mathrm{E}-02$ & $1.2 \mathrm{E}-02$ & 3.32 & $1.4 \mathrm{E}-03$ \\
B & $1.6 \mathrm{E}-02$ & $1.2 \mathrm{E}-02$ & 1.32 & 0.19 \\
C & $3.2 \mathrm{E}-03$ & $1.2 \mathrm{E}-02$ & 0.26 & 0.79 \\
A:B & $-1.5 \mathrm{E}-02$ & $1.2 \mathrm{E}-02$ & -1.26 & 0.21 \\
A:C & $4.7 \mathrm{E}-04$ & $1.2 \mathrm{E}-02$ & 0.04 & 0.97 \\
B:C & $-2.8 \mathrm{E}-03$ & $1.2 \mathrm{E}-02$ & -0.23 & 0.82 \\
A:B:C & $7.2 \mathrm{E}-03$ & $1.2 \mathrm{E}-02$ & 0.60 & 0.55 \\
\hline
\end{tabular}

$n=72 ; t_{(\alpha=0.05)} \sim 1.99[19]$

By means of the evaluating one-to-one measurand, it was observed a significant influence assigned to the factor $\mathrm{A}$ for $\mathrm{Co}(p=0.0001)$ and $\mathrm{Zn}(p<0.00001)$, factor B for $\mathrm{Co}(p=0.00016) \mathrm{Cr}(p=0.012)$, and $\mathrm{Zn}(p=0.0057)$ and $\mathrm{A}: \mathrm{B}$ interaction for Co $(p=0.0029), \operatorname{Cr}(p=0.018)$ and $\mathrm{Zn}(p<0.00001)$. Results for Fe and Sc did not present statistically significant differences for any factor and/or interaction.

According to the results, $\mathrm{A}$ and $\mathrm{B}$ factors and $\mathrm{A}: \mathrm{B}$ interaction presented the most significant contribution for the optimization of INAA methods for most measurands (Co, $\mathrm{Cr}$ and $\mathrm{Zn}$ ). On the other hand, factor $\mathrm{C}$ does not present significant influence on the final results. 
In this work, the optimal condition for the measurement of $\mathrm{Co}, \mathrm{Cr}, \mathrm{Fe}, \mathrm{Sc}$, and $\mathrm{Zn}$ in geological matrix samples was: 22 days to sample decay time $(\mathrm{A} ;+1)$, shelf 0 to sample distance to detector $(\mathrm{B} ;+1)$ and 6 hours to counting time of sample $(\mathrm{C} ;-1)$.

\section{Conclusion}

In this study a new strategy was proposed for the optimization of multielemental methods using a full factorial design. Coherent results were found for optimization of two different matrix samples (biological and geological). According to the results, factor A (sample decay time) was the main factor for the optimization of the INAA methods. Factor B (sample distance to detector) and A:B interaction presented important contribution for the optimization of one-to-one measurand for $\mathrm{Co}, \mathrm{Cr}, \mathrm{Fe}$ and $\mathrm{Zn}$ in biological matrix samples and $\mathrm{Co}, \mathrm{Cr}$ and $\mathrm{Zn}$ in geological matrix samples. Hence it is concluded that the $2^{3}$ experimental design technique may present suitable results when employed for the optimization of multielemental methods.

\section{Acknowledgments}

Authors are indebted to the financial support received from Nuclear and Energy Research Institute (IPEN - CNEN/SP) and the grant from Brazilian National Council for Scientific and Technological Development $(\mathrm{CNPq})$, process number 130022/2013-6.

\section{References}

1. ISO, International Organization for Standardization (2005) ISO/IEC 17025:

General requirements for the competence of testing and calibration laboratories. International Organization for Standardization, Geneva 
2. Zhag WL, Zhang ZB, Cao XH, Liu YH (2014) Uranium adsorption studies on hydrothermal carbon produced by chitosan using statistical design method. J Radioanal Nucl Chem. 301:197-205

3. Reynier N, Blais JF, Mercier G (2013) Optimization of arsenic and pentachlorophenol removal from soil using an experimental design methodology. J Soils Sediments. 13:1189-1200

4. Izadyar S, Fatemi S, Mousavand T (2013) Synthesis and modification of nanosized $\mathrm{TiO}_{2}$ for photo-degradation process under visible light irradiation; a PlacketBurman experimental design. Mater Res Bull. 48:3196-3203

5. Sanaa NT, Didi MA, Villemin D (2012) Uranium micelle-mediated extraction in acetate medium: factorial design optimization. J Radioanal Nucl Chem. 293:789795

6. Outola I, Inn K, Ford R, Markham S, Outola P (2009) Optimizing standard sequential extraction protocol with lake and ocean sediments. J Radioanal Nucl Chem. 282:321-327

7. Kurosaky H, Radford R, Filliben J, Inn KGW (2008) An orthogonal design of experiment exploratory data analysis for plutonium contamination. J Radioanal Nucl Chem. 276:323-328

8. Pereira-Filho ER, Poppi RJ, Arruda MAZ (2002) Employment of factorial design for optimization of pyrolysis and atomization temperatures for $\mathrm{Al}, \mathrm{Cd}, \mathrm{Ni}$ and $\mathrm{Pb}$ determination by ET AAS. Quim Nova, 25: 246-253

9. Teófilo RF, Ferreira MMC (2006) Chemometrics II: Spreadsheets for experimental design calculations, a tutorial. Quim Nova. 29:338-350

10. Martínez HDR (2013) Analyzing interactions of fitted models. http://cran.rproject.org/web/packages/phia/vignettes/phia.pdf. Accessed 29 Sep 2014 
11. Eriksson L, Johasson E, Kettaneh-Wold N, Wiktrom C, Wold S (2008) Design of Experiments: Principles and Applications. MKS Umetrics, Umea

12. Clewer A G, Scanisbrick DH (2011) Practical Statistics and Experimental Design for Plant and Crop Science. John Wiley \& Sons, Chichester

13. Moreira EG (2010) Preparo e caracterização de um material de referência de mexilhão Perna perna (Linnaeus, 1758). Doctoral Thesis, São Paulo University, São Paulo. http://www.teses.usp.br/teses/disponiveis/85/85131/tde-21062011093245/en.php. Accessed 29 Sep 2014

14. NIST Certificate of Analysis: Standard Reference Material 1646a Estuarine Sediment. https://www-s.nist.gov/srmors/view_cert.cfm?srm=1646A. Accessed 29 Sep 2014

15. Rasch D, Pilz J, Verdooren R, Gebhardt A (2011) Optimal Experimental Design with R. Chapman \& Hall/CRC, Boca Raton

16 Sheskin DJ (2004) Parametric and non parametric statistical procedures. Chapman \& Hall/CRC, Boca Raton

17. Thompson M (2000) Recent trends in inter-laboratory precision at ppb and sub-ppb concentrations in relation to fitness for purpose criteria in proficiency testing. Analyst, 125:385-386

18. Prichard E, Barwick V (2008) Quality assurance in analytical chemistry. Wiley-LGC, Teddington

19. NIST/SEMANTECH (2013) e-Handbook of Statistical Methods. http://www.itl.nist.gov/div898/handbook/. Acessed 30 Sep 2014 


\title{
SECÇÃO DE ANEXOS
}

\author{
ANEXO 4. \\ MASS FRACTION DETERMINATION OF TOTAL As IN \\ GEOLOGICAL MATRIX SAMPLE BY INSTRUMENTAL \\ NEUTRON ACTIVATION ANALYSIS: A STUDY OF METHOD \\ VALIDATION \\ (Trabalho Trabalho apresentado no $14^{\circ}$ Congresso RESAG_ENQUALAB2014)
}




\title{
MASS FRACTION DETERMINATION OF TOTAL AS IN GEOLOGICAL MATRIX SAMPLE BY INSTRUMENTAL NEUTRON ACTIVATION ANALYSIS: A STUDY OF METHOD VALIDATION
}

\author{
Robson Petroni ${ }^{1}$, Edson G. Moreira ${ }^{2}$ \\ ${ }^{1}$ Instituto de Pesquisas Energéticas e Nucleares (IPEN - CNEN/SP), São Paulo, Brazil, robsonpetroni@usp.br \\ ${ }^{2}$ Instituto de Pesquisas Energéticas e Nucleares (IPEN - CNEN/SP), São Paulo, Brazil, emoreira@ipen.br
}

\begin{abstract}
In this study the method validation of total As mass fraction in geological matrix samples by Instrumental Neutron Activation Analysis was carried out, according to ISO/IEC 17025:2005 and recommendations of INMETRO DOQ-CGCRE-008. Accuracy, robustness, selectivity, linearity, detection limit, quantification limit and uncertainties were outlined in a marine sediment certified reference material.
\end{abstract}

Keywords: method validation, As, sediment, INAA

\section{INTRODUCTION}

The Neutron Activation Analysis Laboratory (LAN) is a subdivision of the Research Reactor Centre (CRPq) at IPEN - CNEN/SP. Since 2010's, a new Quality policy has been implemented aiming to obtain full compliance with the requirements of NBR ISO/IEC 17025:2005. The implementation of this new quality management system is absolutely essential to LAN, aiming to produce reference materials for environmental studies. In the context, the validation of measurement methods is essential for suitability of the laboratory in this quality system.

ISO/IEC 17025:2005 specifies the general requirements for the competence to carry out tests and/or calibrations, including sampling. It covers testing and calibration performed using standard methods, non-standard methods, and laboratorydeveloped methods [1]. The method validation is defined as "the confirmation by examination and the provision of objective evidence that the particular requirements for a specific intended use are fulfilled". The validation process shall be as extensive as is necessary to meet the needs of the given application or field of application. The laboratory shall record the results obtained, the procedure used for the validation, and a statement as to whether the method is fit for the intended use.

The most important activity in LAN is Neutron Activation Analysis, especially the Instrumental Neutron Activation Analysis technique (INAA). INAA is a multielemental technique relatively free from the matrix effects, which has a non destructive character and do not require digestion procedures [2, 3]. This makes the technique attractive for several applications in geochemistry, environmental monitoring, biomonitoring, reference material characterization and related sciences [4-7].

INAA is employed for determination of several elements, based on the conversion of a non radioactive nuclide, in a radioactive nuclide (radionuclide). This process occur through neutron bombardment in the material to be analyzed resulting in nuclear reactions characteristics of each element. In INAA, the reaction product to 
be measured is the gamma radiation arising from the radionuclide obtained by the neutron bombardment process. Gamma-ray decay presents best characteristics for identification (selectivity) and simultaneous detection of different radionuclides [2].

In the procedure, sample and standard (containing know concentration of measurand) with the same geometry are simultaneously irradiated in a nuclear reactor. The determination of measurand content in the sample is obtained comparing the photopeak area of the radionuclide at gamma-ray spectrum of the sample with that of the standard (comparator method). According to the Comite Consultatif pour la Quantité de Matière (CCQM) INAA comparator method has potential to be considered a primary method of measurement [2].

Accuracy (trueness and precision), robustness, linearity, detection limit, quantification limit and uncertainties budget were outlined in marine sediment certified reference material. This study is one among many others developed aiming the suitability of LAN according to NBR ISO/IEC 17025:2005.

\section{OBJECTIVE}

The main objective of this study was to carry out the method validation of INAA for mass fraction determination of total-As in geological matrix sample, according to ISO/IEC 17025:2005 Standard and recommendations of INMETRO DOQCGCRE-008.

\section{METHODS AND MATERIALS}

\subsection{Instrumental Neutron Activation Analysis}

The INAA comparative method was performed for the mass fraction determination of total-As in geological matrix samples. Samples and multielemental standards were simultaneously irradiated for $8 \mathrm{~h}$ under 0.5 to $1.0 \times 10^{13} \mathrm{~cm}^{-2} \mathrm{~s}^{-1}$ thermal neutron flux at IEA-R1 Nuclear Research Reactor. ${ }^{76}$ As radionuclide was quantified by gamma-ray spectrometry, using a GC2018 Canberra HPGe detector coupled to a DSA 1000 multichannel analyzer. Genie 2000 - Gamma Acquisition \& Analysis 3.1 software was used to perform the processing of the gamma-ray spectrum. The analytical photopeak used to mass fraction determination of total-As was 559.10 $\mathrm{keV}$. Mass fraction calculations were carried out using a Microsoft Excel spreadsheet, according to Equation 1 [8].

$$
C=\frac{A * w s t * C s t * e^{(t-t s t)}}{A s t * w}
$$

where:

$C$ is the sample element concentration $\left(\mathrm{mg} \mathrm{kg}^{-1}\right)$;

Cst is the standard element concentration $\left(\mathrm{mg} \mathrm{kg}^{-1}\right)$;

$A$ is the activity of the element in the sample (cps);

Ast is the activity of the element in the standard (cps);

$w$ is the sample mass $(\mathrm{mg})$; 
wst is the mass of As in element standard (mg);

$\lambda$ is the radionuclide decay constant $\left(\lambda=\ln (2) / \mathrm{t}_{1 / 2}\right)\left(\mathrm{s}^{-1}\right)$;

and $(t-t s t)$ is the time difference between sample and element standard measurements.

\subsection{Samples and Elemental Standard Preparation}

Subsamples of Marine Sediment CRM [9] of $150 \pm 10 \mathrm{mg}$ were weighed in polyethylene packaging previously cleaned, using a Shimadzu AEM-5200 analytical balance. The standard working solution was prepared by dilution of As Spex CRM element solution in volumetric flask. Elemental standards were prepared by pipetting of the As working solution onto Whatman paper filters using Eppendorf micropipette. After drying, the paper filters were folded, placed and sealed in polyethylene packaging with the same sample geometry $(10 \mathrm{~mm} \times 8 \mathrm{~mm} \times$ $1 \mathrm{~mm})$.

\subsection{Measurement method}

Depending on the characteristics of the measurement method, different configurations may generate more or less favorable results. Thus, in a validation process is necessary to make the definition of the measurement method characteristics, taking into account prior knowledge about the technical and measurands. Table 1 present the configurations of measurement method for determination of total-As mass fraction in geological matrix samples by INAA on the comparative method.

\begin{tabular}{|l|l|}
\hline Method name & Geo-Total-As \\
\hline Technique & INAA \\
\hline Detection & Gamma-ray spectrometry \\
\hline Measurand & Total-As \\
\hline Matrix sample & Geological \\
\hline Measurement linear range & $3.0 \mathrm{mg} \mathrm{kg}$ to $50 \mathrm{mg} \mathrm{kg}^{-1}$ \\
\hline Sample mass & $150 \pm 10 \mathrm{mg}$ \\
\hline As-standard mass & $2.475 \pm 0.027 \mu \mathrm{g}$ \\
\hline As-peak energy & $559.10 \mathrm{keV}$ \\
\hline Sample/As-standard geometry & $10 \mathrm{~mm} \times 8 \mathrm{~mm} \mathrm{x} 1 \mathrm{~mm}$ \\
\hline Irradiation time & 8 hours \\
\hline Thermal neutron flux & 0.5 to $1.0 \times 10^{13} \mathrm{~cm}^{-2} \mathrm{~s}^{-1}$ \\
\hline $\begin{array}{l}\text { Sample/As-standard decay time } \\
\text { to measurement }\end{array}$ & 7 days \\
\hline Sample measurement time & $60 \mathrm{minutes}$ \\
\hline As-standard measurement time & $20 \mathrm{minutes}$ \\
\hline $\begin{array}{l}\text { Sample/As-standard distance to } \\
\text { detector }\end{array}$ & $33 \mathrm{~mm}$ \\
\hline
\end{tabular}

Table 1. Geo-Total-As measurement method characteristics 


\section{RESULTS AND DISCUSSION}

\subsection{Method performance characteristics}

Geo-Total-As method performance characteristics were outlined according to INMETRO DOQ-CGCRE-008 recommendations. The performance parameters investigated during the method validation procedure were: accuracy (trueness and precision), detection limit, quantification limit, robustness and measurement uncertainty.

Table 2 present the results obtained for repeatability limit (r), intermediate precision condition (IPC), reproducibility limit (R), trueness, detection limit (LOD) and quantification limit (LOQ) for the analysis of Marine sediment CRM by INAA on the comparative method.

\begin{tabular}{|c|c|c|c|c|c|c|}
\hline Method & $\mathrm{r}^{\mathrm{a}}$ & $\mathrm{IPC}^{\mathrm{a}}$ & $\mathrm{R}^{\mathrm{a}}$ & z-score & LOD $^{\mathrm{a}}$ & $\mathrm{LOQ}^{\mathrm{a}}$ \\
\hline Geo-Total-As & 0.72 & 1.3 & 3.6 & $\begin{array}{c}-1.1 \text { to } 1.5 \\
(0.08)\end{array}$ & 0.59 & 1.8 \\
\hline
\end{tabular}

a Results in $\mathrm{mg} \mathrm{kg}^{-1}$;

$\mathrm{b}$ Z-score range for all analyses; in parenthesis (z-score average)

Table 2. Method performance characteristics for the measurement of total-As in geological matrix samples by INAA on the comparative method

According to the results, the minimum natural deviation expected for two or more independent results for the measurement of total-As in geological matrix samples is $0.72 \mathrm{mg} \mathrm{kg}^{-1}$ (r) and the maximum variation expected for two or more independent results obtained at LAN (IPEN - CNEN/SP) is $1.3 \mathrm{mg} \mathrm{kg}^{-1}$ (IPC).

The evaluation of the IPC, i.e., the natural variability of the results within LAN, was performed considering four main factors: irradiation processes, the use of different gamma-ray spectrometers, different operating days and different analysts. Aiming to evaluate the significance of the factors, a $t$-test was performed for mean results obtained to each condition at the $5 \%$ significance. Results did not present any significant factors for $t$-test analyses.

$\mathrm{R}$ was estimated by means of the results obtained for IPC, as it was not possible to perform interlaboratory studies for evaluation of method performance in another measurement laboratories. Thus, the IPC result was multiplied by 2.8 , resulting in the $\mathrm{R}$ value estimation $\left(3.6 \mathrm{mg} \mathrm{kg}^{-1}\right)$.

By means of the r/IPC ratio is possible to make an interpretation about the percentage corresponding to the natural variation of the results for the method, that is, how much of the IPC value can be explained by the natural variability of the results (r). According to r/IPC ratio $56 \%$ of the variability of the results for IPC can be explained by the natural variability of the results. In this context, the interpretation is how the higher value found for r/IPC ratio, greater robustness of the measurement method. 
Trueness results ranged from -1.1 and 1.5 according to $\mathrm{z}$-score calculations and were considered suitable results. For all measurements, the z-score average was 0.08 .

The evaluation of the robustness status of the method as well as the measurement uncertainty estimation are still in progress. Anyway, from preliminary results, relative expanded uncertainties below $5 \%$ are feasible for this kind of matrix.

\section{CONCLUSION}

The sizing of the method performance characteristics and subsequent validation of methods in INAA, certainly contribute to support of the analytical quality of results at LAN. Another contribution of this work is attributed to the restructuring of the quality management system, according to NBR ISO/IEC 17025:2005 Standard.

\section{ACKNOWLEDGMENTS}

Authors are indebted to the financial support received from Nuclear and Energy Research Institute (IPEN - CNEN/SP) and the grant from Brazilian National Council for Scientific and Technological Development (CNPq), process number 130022/2013-6.

\section{REFERENCES}

[1] ISO - International Organization for Standardization, "ISO/IEC 17025:2005. General requirements for the competence of testing and calibration laboratories". International Organization for Standardization, Geneva (2005)

[2] R.R. Greenberg, P. Bode, E.A. De Nadai Fernandes, "Neutron activation analysis: A primary method of measurement". Spectrochim Acta B (2011) 66:193241

[3] P. Bode, E.A.N. Fernandes, R.R. Greenberg, "Metrology for chemical measurements and the position of INAA". J Radioanal Nucl Chem (2000) 245:109114

[4] R.L. Franklin, F.J. Ferreira, J.E. Bevilacqua, D.I.T. Fávaro, "Assessment of metals and trace elements in sediments from Rio Grande Reservoir, Brazil, by neutron activation analysis". J. Radioanal Nucl Chem (2012) 291:147-153

[5] L. Ma, L. Feng, A. Hioki, K.H. Cho, J. Vogl, A. Berger, G. Turk, S. Macleod, G. Labarraque, W.F. Tong, D. Schiel, C. Yafa, L. Valiente, L.A. Konopelko, C. Quetel, P. Vermaercke, J.V.L. Manzano, M. Linsky, E. Corte's, S. Tangpitayakul, L. Plangsangmas, L. Bergamaschi, R. Hearn, " International comparison of the determination of the mass fraction of cadmium, chromium, mercury and lead in polypropylene: the Comité Consultatif pour la Quantité de Matière pilot study CCQM-P106". Accred Qual Assur (2010) 15:39-44

[6] D. Seo, M.B.A. Vasconcellos, M.G.M. Catharino, E.G. Moreira, F.C.P.M. de Sousa, M. Saiki. "Vanadium determination in Perna perna mussels (Linnaeus, 1758: Mollusca Bivalvia) by instrumental neutron activation analysis using the passive 
biomonitoring in the Santos coast, Brazil". J Radioanal Nucl Chem (2013) 296:459463

[7] Moreira E.G. " Preparo e caracterização de um material de referência de mexilhão Perna perna (Linnaeus, 1758)". Doctoral Tesis - Instituto de Pesquisas Energética e Nucleares, São Paulo, Brazil (2010)

[8] W.D. Ehmann, D.E. Vance, "Radiochemistry and Nuclear Methods of Analysis". John Wiley \& Sons, New York (1991)

[9] NIST - National Institute of Standards and Technology, "Certificate of Analysis: Standard Reference Material 2702 Inorganics in Marine Sediment". (2012) https://www-s.nist.gov/srmors/view_detail.cfm?srm=2702. Accessed 12 Oct 2014 


\title{
SECÇÃO DE ANEXOS
}

\author{
ANEXO 5. \\ DOCUMENTOS DA QUALIDADE
}




\begin{tabular}{|c|c|c|}
\hline Centro do Reator de & MÉTODO BIO 1: Determinação da & Página 1 de 11 \\
Pesquisa - CRPq, & concentração de As em amostras de matriz & POP - CRPq/001 \\
IPEN - CNEN/SP & biológica (POP - CRPq/001) & Revisão: 00 \\
\hline
\end{tabular}

\title{
MÉTODO BIO 1: Determinação da concentração de As em amostras de matriz biológica
}

\begin{abstract}
1. INTRODUÇÃO
O método de Análise por Ativação com Nêutrons (NAA) se baseia na produção e posterior identificação de radionuclídeos artificiais a partir de elementos naturalmente estáveis. Esse processo ocorre por meio do bombardeamento com nêutrons no material a ser analisado (amostra), resultando em reações nucleares características para cada elemento. Em NAA, o produto da reação nuclear que é medido é a emissão de raios gama provenientes do decaimento radioativo dos radionuclídeos formados durante o processo de bombardeamento com nêutrons (BODE et al., 2000).
\end{abstract}

Em NAA, amostras e padrões são irradiados sob um fluxo de nêutrons térmicos provenientes de um reator nuclear. A sequência de eventos que ocorrem numa reação nuclear típica se inicia quando um nêutron interage com um núcleo alvo por meio de uma colisão inelástica, formando um núcleo composto num estado excitado. A energia de excitação do núcleo composto é devida à energia de ligação do nêutron com o núcleo. O núcleo composto formado quase que instantaneamente adquire uma configuração mais estável por meio da emissão de raios gama prontos, do inglês, prompt gamma rays. Em muitos casos, esta nova configuração do núcleo no estado passa por outras vias de decaimento por emissão de raios gama retardados, do inglês, delayed gamma rays (ALFASSI, 1990).

O sistema de deteç̧ão de raios gama é constituido basicamente por um detector semicondutor de germânio hiperpuro (HPGe) associado ao analisador de multi canal (MCA) e a um computador responsável pela análise dos dados obtidos durante o processo de medição, integração da área dos picos analíticos e geração do espectro com os resultados da medição dos raios gama. Esse sistema qualifica a técnica como bastante seletiva devido as característicvas do processo de detecção de raios gama.

NAA é uma técnica multielementar capaz de detectar e quantificar dezenas de elementos em uma única rodada de experimentos é independente de efeitos de matriz e é considerada uma técnica não destrutiva, uma vez que não requer processos de digestão das amostras, fato que contribui para a diminuição do risco de contaminação. Apresenta-se ainda uma técnica muito competitiva para a determinação do teor de elementos traço em matrizes ambientais, apresentando elevado nível de exatidão para a medição de muitos elementos (GREENBERG et al., 2011).

Outra grande vantagem da técnica está no fato da não obrigatoriedade de se analisar o branco analítico, pois não há utilização de reagentes para digestão da amostra, processos de extração ou separação de elementos. Por esse motivo, faz-se seguro afirmar que não há possibilidade de introdução de contaminantes após a irradiação nas amostras, exceto por contaminação de outro material radioativo (HAMIDATOU et al., 2013).

\section{APLICAÇÄO DO MÉTODO}

Este documento descreve o método para determinação da concentração total de As em amostras de matriz biológica por meio da técnica de Análise por Ativação com Nêutrons.

\section{REFERÊNCIAS NORMATIVAS}

ABNT, ASSOCIAÇÃO BRASILEIRA DE NORMAS TÉCNICAS. Sistemas de Gestão da Qualidade Fundamentos e vocabulário. Rio de Janeiro: ABNT, 2005 (ABNT NBR ISO 9000)

ABNT, ASSOCIAÇÃO BRASILEIRA DE NORMAS TÉCNICAS. Requisitos gerais para a competêncis de laboratórios de ensaio e calibração. 2 ed. corrigida, Rio de Janeiro: ABNT, 2006 (ABNT NBR ISO/IEC 17025:2005) 


\begin{tabular}{|c|c|c|}
\hline Centro do Reator de & MÉTODO BIO 1: Determinação da & Página 2 de 11 \\
Pesquisa - CRPq, & concentração de As em amostras de matriz & POP - CRPq/001 \\
IPEN - CNEN/SP & biológica (POP - CRPq/001) & Revisão: 00 \\
\hline
\end{tabular}

ABNT, ASSOCIAÇÃO BRASILEIRA DE NORMAS TÉCNICAS. Sistemas de Gestão da Qualidade Requisitos. 2 ed. corrigida, Rio de Janeiro: ABNT, 2009 (ABNT NBR ISO 9001)

ABNT, ASSOCIAÇÃO BRASILEIRA DE NORMAS TÉCNICAS. Gestão para o sucesso sustentado de uma organização - Uma abordagem da gestão da qualidade. 2 ed. corrigida Rio de Janeiro: ABNT, 2010 (ABNT NBR ISO 9004)

ANVISA, AGÊNCIA NACIONAL DE VIGILÂNCIA SANITÁRIA. Guia Para Qualidade em Química Analítica - Uma Assistência de Acreditação. $1^{\mathrm{a}} \mathrm{ed}$. Brasília, 2004

BRASIL. Resolução RE $n^{\circ} 899$, de 29 de maio de 2003. ANVISA, AGÊNCIA NACIONAL DE VIGILÂNCIA SANITÁRIA, 2003. Disponivel em:

<http://portal.anvisa.gov.br/wps/wcm/connect/4983b0004745975da005f43fbc4c6735/RE_899_2003_Det ermina+a+publica\%C3\%A7\%C3\%A30+do+Guia+para+valida\%C3\%A7\%C3\%A3o+de+m\%C3\%A9todos +anal\%C3\%ADticos+e+bioanal\%C3\%ADticos.pdf?MOD=AJPERES> Acesso em 18 junho, 2015

CURRIE, L. A. Nomenclature in evaluation of analytical methods including detection and quantification capabilities (IUPAC Recommendations 1995). Analytical Chimic Acta, 391:105-126, 1999

EURACHEM. The fitness for purpose of analytical methods. A laboratory guide to method validation and related topics, 1998. Disponivel em:

$<$ http://www.eurachem.org/images/stories/Guides/pdf/valid.pdf> Acesso em: 18 junho, 2015

EURACHEM/CITAC. Quantifying uncertainty in analytical measurement. EURACHEM/CITAC Guide CG 4, 2012. Disponivel em: <http://www.citac.cc/QUAM2012_P1.pdf> Acesso em: 18 junho, 2015 (QUAM:2012)

IAEA. International atomic Energy Agency. Use of research reactors for neutron activation analysis. Vienna, 2001 Disponivel em : <http://www-pub.iaea.org/MTCD/publications/PDF/te_1215_prn.pdf> Acesso em 18 junho, 2015 (IAEA-TECDOC 1215)

IAEA. International atomic Energy Agency. Uncertainty evaluation in instrumental and radiochemical neutron activation analysis. Vienna, 2004 Disponivel em : <http://www-pub.iaea.org/MTCD/publications/PDF/te_1401_web.pdf> Acesso em 18 junho, 2015 (IAEA-TECDOC1401)

INMETRO, INSTITUTO NACIONAL DE METROLOGIA, QUALIDADE E TECNOLOGIA. Orientação sobre validação de métodos analíticos. Rio de Janeiro, Fev. 2010. Disponível em: <http://www.inmetro.gov.br/Sidoq/Arquivos/CGCRE/DOQ/DOQ-CGCRE-8_03.pdf>, Acesso em: 18 junho, 2015 (DOQ-CGCRE-008)

INMETRO, INSTITUTO NACIONAL DE METROLOGIA, QUALIDADE E TECNOLOGIA. Vocabulário Internacional de Metrologia: conceitos fundamentais e gerais e termos associados. 1ed Lusobrasileira, Rio de Janeiro: INMETRO, 2012. Disponivel em:

<http://www.inmetro.gov.br/inovacao/publicacoes/vim_2012.pdf>, Acesso em: 18 junho, 2015 (VIM)

INMETRO, INSTITUTO NACIONAL DE METROLOGIA, QUALIDADE E TECNOLOGIA. Guia para a expressâo da incerteza de medição. 1ed Luso-brasileira. Rio de Janeiro: INMETRO, 2012. (ISO GUM)

ISO, INTERNATIONAL ORGANIZATION OF STANDADIZATION. Accuracy (trueness and precision) of measurement methods and results-- Part 1: General principles and definitions. Geneva, 2012 


\begin{tabular}{|c|c|c|}
\hline Centro do Reator de & MÉTODO BIO 1: Determinação da & Página 3 de 11 \\
Pesquisa - CRPq, & concentração de As em amostras de matriz & POP - CRPq/001 \\
IPEN - CNEN/SP & biológica (POP - CRPq/001) & Revisão: 00 \\
\hline
\end{tabular}

ISO, INTERNATIONAL ORGANIZATION OF STANDADIZATION. Accuracy (trueness and precision) of measurement methods and results- Part 3: Intermediate measures of the precision of a standard measurement method. Geneva, 2013

ISO, INTERNATIONAL ORGANIZATION OF STANDADIZATION. Accuracy (trueness and precision) of measurement methods and results - Practical guidance for the use of ISO 5725:1994 in designing, implementing and statistically analysing interlaboratory repeatability and reproducibility results. Geneva, 2005

\section{SIMBOLOS, SIGLAS E ABREVIAÇÕES}

ABNT : Associação Brasileira de Normas Técnicas ANVISA : Agência Nacional de Vigilância Sanitária

$A_{a}:$ atividade do radionuclídeo na amostra (cps)

$c$ : comprimento do padrão sintético

$A_{p}$ : atividade do radionuclídeo no padrão sintético para tempo de decaimento tp (cps)

$b$ : número de contagens da radiação de fundo sob o pico analítico (cps)

$C$ : concentração do mensurando na amostra $\left(\mathrm{mg} \mathrm{kg}^{-1}\right)$

$C R P q$ : Centro do Reator de Pesquisa

$D P$ : desvio padrão para a média de $n$ medições $\left(\mathrm{mg} \mathrm{kg}^{-1}\right)$

En : erro normalizado

GUM : Guia para expressão da incerteza de medição

$h$ : altura do padrão sintético

$H P G e$ : Espectrômetro de raios gama com detector de germânio hiperpuro (HPGe)

IAEA : Agência Internacional de Energia Atômica

INMETRO : Instituto Nacional de Metrologia: Qualidade e Tecnologia

IPEN - CNEN/SP : Instituto de Pesquisas Energéticas e Nucleares

ISO : Organização Internacional para a Padronização

$k$ : fator de abrangência da incerteza de medição; $k=2 ; a=0,05$

$L D$ : limite de detecção $\left(\mathrm{mg} \mathrm{kg}^{-1}\right)$

$L Q$ : limite de quantificação $\left(\mathrm{mg} \mathrm{kg}^{-1}\right)$

$m$ : número do ensaio da amostra, $m=1, n$

$M_{a}$ : massa da amostra $(\mathrm{kg})$

$m_{p}$ : massa do mensurando no padrão sintético $(\mathrm{mg})$

$M R$ : material de referência

$M R C$ : material de referência certificado

$n$ : número de medições

NAA : Análise por Ativação com Nêutrons Instrumental

NIST : National Institute of Standards and Technology; Intituto Nacional de Padrões e Tecnologia (EUA)

NRCC : National Research Council Canada; Conselho Nacional de Pesquisa do Canadá

$P l$ : precisão intermediária $\left(\mathrm{mg} \mathrm{kg}^{-1}\right)$

QUAM : Guia para a Quantificação da Incerteza nas medições analíticas

$r$ : limite de repetitividade $\left(\mathrm{mg} \mathrm{kg}^{-1}\right)$

$R$ : limite de reprodutibilidade $\left(\mathrm{mg} \mathrm{kg}^{-1}\right)$

$t:$ tempo real de medição da amostra (s)

$t_{\sigma a}$ : tempo de decaimento do radionuclídeo para medição da amostra (s)

$t_{\text {ap }}$ : tempo de decaimento do radionuclídeo para medição do padrão (s)

$t_{1 / 2}$ : tempo de meia vida para a atividade do radionuclídeo

$U$ : incerteza expandida do resultado, $k=2\left(\mathrm{mg} \mathrm{kg}^{-1}\right)$

$U_{v}$ : incerteza expandida do valor de referência, $k=2\left(\mathrm{mg} \mathrm{kg}^{-1}\right)$

VIM : Vocabulário Internacional de Metrologia

$x$ : resultado da medição $\left(\mathrm{mg} \mathrm{kg}^{-1}\right)$

$\bar{x}$ : média dos resultados para $n$ medições

$x_{m}$ : resultado obtido para o ensaio $\mathrm{m}$

$x_{\mathrm{v}}$ : valor de referência do MR ou MRC $\left(\mathrm{mg} \mathrm{kg}^{-1}\right)$

$\alpha$ : nível de significância estatística; $\alpha=0,05 ; 95 \%$ de confiança estatística

$\lambda$ : constante de decaimento do radionuclídeo $\left(\mathrm{s}^{-1}\right)$ 


\begin{tabular}{|c|c|c|}
\hline $\begin{array}{c}\text { Centro do Reator de } \\
\text { Pesquisa - CRPq, }\end{array}$ & MÉTODO BIO 1: Determinação da & Página 4 de 11 \\
IPEN - CNEN/SP & concentração de As em amostras de matriz & POP - CRPq/001 \\
biológica (POP - CRPq/001) & Revisão: 00 \\
\hline
\end{tabular}

\section{RESPONSABILIDADES}

É de responsabilidade do analista seguir o procedimento e estabelecer práticas que garantam a segurança e saúde. É obrigação da gerência do $\mathrm{CRPq}$ fornecer o uso de equipamentos de monitoramento para o controle da radioatividade ao que o analista estará exposto, bem como qualquer outro equipamento de proteção individual que se faça necessário para o cumprimento das leis e acordos para a manutenção da segurança quanto a contaminação química, biológica e radioativa. É responsabilidade do analista solicitar à gerência do $\mathrm{CRPq}$ a compra dos equipamentos de proteção individual que eventualmente não encontram-se disponiveis e utilizá-los de forma correta e segura. Qualquer acidente que envolva material radioativo deverá ser imediatamente informado ao Serviço de Proteção Radiológica. Ainda, é de responsabilidade do analista fazer a verificação de todos os equipamentos utilizados bem como o registro de uso dos mesmos.

\section{PRINCÍPIO DO MÉTODO}

O método NAA consiste na irradiação da amostra e do padrão sintético (no qual a concentração do mensurando é conhecida) de maneira simultânea, em um mesmo período de tempo, geometria de espaço e de fluxo de nêutrons. Após o período de decaimento apropriado, realiza-se a medição do espectro de raios gama na amostra e no padrão sintético numa mesma configuração de deteç̧ão e em um mesmo aparelho detector. A determinação da concentração do mensurando na amostra é calculada por meio da comparação da área dos picos (atividade) obtidos para amostra e padrão sintético. A equação fundamental para o cálculo da concentração de um mensurando em NAA é apresentada a seguir (1).

$$
C_{a}=\frac{m_{p} A_{a} e^{-\lambda(t a-t p)}}{A_{p} M_{a}}
$$

onde:

$C$ é a concentração do mensurando na amostra ( $\left.\mathrm{mg} \mathrm{kg}^{-1}\right)$;

$m_{\rho}$ é a massa do mensurando no padrão $(\mathrm{mg})$;

$A_{s}$ é a atividade do radionuclídeo na amostra (cps);

$\lambda$ é a constante de decaimento do radionuclídeo $\left(\mathrm{s}^{-1}\right)$.

$t_{\sigma a}$ é o tempo de decaimento do radionuclídeo até o momento início da medição da amostra (s);

$t_{a p}$ é o tempo de decaimento do radionuclídeo até o início da medição do padrão (s);

$M_{a}$ é a massa da amostra $(\mathrm{kg})$;

$A_{p}$ é a atividade do radionuclídeo no padrão sintético para tempo de decaimento tp (cps).

\section{EQUIPAMENTOS, VIDRARIA E REAGENTES}

\subsection{Equipamentos e vidrarias}

Estufa

Reator nuclear

Espectrômetro de raios gama com detector de germânio hiperpuro (HPGe)

Balança analítica

Máquina seladorado Sela-Pak

Aparelho deionizador de água (Mili - Q, Millipore; $18,2 \mathrm{~m} \Omega$ )

Micropipeta $(20-100 \mu \mathrm{L})$

Micropipeta (100 - $1000 \mu \mathrm{L})$

Micropipeta $(1000-5000 \mu \mathrm{L})$

Ponteira para micropipetas

Balão volumétrico calibrado de $10 \mathrm{~mL}$ Béquer de $10 \mathrm{~mL}$ 


\begin{tabular}{|c|c|c|}
\hline Centro do Reator de & MÉTODO BIO 1: Determinação da & Página 5 de 11 \\
Pesquisa - CRPq, & concentração de As em amostras de matriz & POP - CRPq/001 \\
IPEN - CNEN/SP & biológica (POP - CRPq/001) & Revisão: 00 \\
\hline
\end{tabular}

Folha de polietileno

Folha de papel filtro quantitativo

Folha de papel alumínio

Folha de papel absorvente

Baguetas de vidro

Recipiente de alumínio (coelho)

Recipiente de alumínio (panelinha)

Pinças de cabo longo

Castelo de chumbo

\subsection{Reagentes}

Ácido nítrico (10\%)

Solução padrão de As $1000 \mathrm{mg} \mathrm{L}^{-1}$

\section{PROCEDIMENTO}

\subsection{Lavagem e descontaminação das vidrarias}

- Com o auxílio de um sepilho, lavar a vidraria com sabão neutro comercial (Extran $3 \%$ );

- Enxaguar três vezes com água destilada;

- Preparar uma solução de $\mathrm{HNO}_{3}(10 \%)$;

- Acondicionar a solução em um recipiente de plástico com tampa dentro de uma capela;

- Dispor a vidraria previamente lavada no recipiente plástico com a solução de $\mathrm{HNO}_{3}(10 \%)$. Essa etapa é conhecida com banho ácido;

- Aguardar por 24 horas;

- Retirar a vidraria do banho ácido, enxaguar três vezes com água destilada e três vezes com água deionizada (Mili $-Q$, Millipore; $18,2 \mathrm{~m} \Omega$ );

- Aguardar a secagem da vidraria sob temperatura ambiente;

- Guardar a vidraria em local adequado.

\subsection{Solução de $\mathrm{HNO} 3(10 \%)$ ** Procedimento dentro de capela **}

- Adicionar cerca de 1 litro de água destilada em um balão volumétrico de 2 litros;

- Dispor $200 \mathrm{~mL}$ de $\mathrm{HNO}_{3}$ concentrado em um béquer de $500 \mathrm{~mL}$ ( $\mathrm{HNO}_{3}$ concentrado é corrosivo e nocivo à saúde. Nunca realize o procedimento fora da capela);

- Com o auxílio de uma bagueta, transferir de maneira lenta e cuidadosa os $200 \mathrm{~mL}$ de $\mathrm{HNO}_{3}$ concentrado para o balão volumétrico de 2 litros (Faça de maneira devagar. Reação exotérmica);

- Completar o volume do balão volumétrico com aguá destilada até o menisco;

- Tampar o balão volumétrico e homogeneizar a solução preparada;

- Transferir a solução para um frasco âmbar, identificar a solução e armazenar em local seguro, ventilado e ao abrigo da luz solar.

\subsection{Lavagem e confecção dos invólucros de polietileno}

- As folhas de polietileno utilizadas para o preparo dos invólucros para amostras e padrões sintéticos devem ser previamente lavadas em solução de $\mathrm{HNO}_{3} 10 \%$ (v/v) por um período de 48 horas, enxaguadas com $\mathrm{H}_{2} \mathrm{O}$ destilada e deionizada (Milli-Q, Millipore; $18,2 \mathrm{~m} \Omega$ ) e secas em temperatura ambiente em capela de fluxo laminar;

- Os invólucros devem ser confeccionados em geometria retangular de $1,0 \mathrm{~cm}$ de largura por $1,5 \mathrm{~cm}$ de comprimento selado em todas as extremidades com o auxílio de uma máquina seladora. Os invólucros foram armazenados em frasco devidamente identificado e mantidos ao abrigo da luz solar $e$ emtemperatura ambiente até o momento de sua utilização. 


\begin{tabular}{|c|c|c|}
\hline Centro do Reator de & MÉTODO BIO 1: Determinação da & Página 6 de 11 \\
$\begin{array}{c}\text { Pesquisa - CRPq, } \\
\text { IPEN - CNEN/SP }\end{array}$ & concentração de As em amostras de matriz & POP - CRPq/001 \\
bevisão: 00
\end{tabular}

\subsection{Confecção das estantes e papéis filtro}

- Para a confeç̧ão das estantes se deve-se fixar duas baguetas de vidro com o auxílio de dois pedaços de fita adesiva (um pedaço em cada extremidade), de modo que permaneçam fixas $e$ encostadas uma na outra.

- Para a confecção dos papéis filtro à serem utilizados no preparo dos padrões sintéticos, deve-se pegar uma ou mais folhas de papel filtro quantitativo e recortar de acordo com a seguinte dimensão: 2 $\mathrm{cm} \times 2,5 \mathrm{~cm}(\mathrm{~h} \times \mathrm{c}$ ). Ao lado cujo comprimento é $2,5 \mathrm{~cm}$ deve-se fazer um pequeno recorte com a tesoura que servirá como marcação, medindo-se a partir da ponta em $0,5 \mathrm{~cm}$. Posteriormente, esta marcação irá indicar a parte que deverá ser descartada após o processo de pipetagem da solução de trabalho.

\subsection{Preparo dos padrões sintéticos}

- Ao balão volumétrico de $10 \mathrm{~mL}$ (calibrado) adicionar aproximadamente $5 \mathrm{~mL}$ de água deionizada (Milli - Q, Millipore; $18,2 \mathrm{~m} \Omega$ );

- Pipetar exatamente $1000 \mu \mathrm{L}$ de solução padrão de As $\left(1000 \mathrm{mg} \mathrm{L}^{-1}\right)$ dentro do balão volumétrico de $10 \mathrm{~mL}$.

OBS: Deve-se manter a micropipeta na posição vertical durante todo o processo de pipetagem da solução padrão. No momento do despejo da solução pipetada dentro do balão volumétrico é importante que a ponteira da micropipeta esteja encostada na parede no balão volumétrico em uma posição abaixo da linha do menisco. Para isso, o balão volumétrico deve ser posicionado em uma posição ligeiramente inclinada, de modo que se faça um ângulo diferente de $90^{\circ}$ entre a ponteira da micropipeta e a parede do balão volumétrico. O êmbolo da micropipeta nunca deve ser pressionado até o fim durante o processo de pipetagem, mas somente até a posição correspondente a trava (a solução padrão deve estar em temperatura ambiente).

- Completar o volume do balão volumétrico com água deionizada (Milli $-\mathrm{Q}$, Millipore; $18,2 \mathrm{~m} \Omega$ ) até o menisco;

- Com um pedaço de papel absorvente, secar cuidadosamente a parte acima do menisco do balão volumétrico de modo à remover gotículas de água que estejam ali adsorvidas. Em hipótese alguma o papel adsorvente pode tocar na solução que está no limite do menisco. Se isso ocorrer, descarte apropriadamente a solução e reinicie novamente o procedimento;

- Tampar o balão volumétrico e homogeneizar a solução preparada (solução de trabalho);

- Aguardar cerca de 30 minutos antes de continuar o procedimento;

- Dispor os papéis filtro recortados em geometria adequada na estante preparada com as baguetas, de modo que estes não fiquem encostados uns aos outros. A extremidade do papel filtro que conter a marcação de $0,5 \mathrm{~cm}$ deverá ser inserido no espaço que existe entre as duas baguetas. Os papéis filtro devem permanecer em posição vertical durante todo o processo de pipetagem e secagem (os processos a seguir devem ser realizados no interior de uma capela);

- Transferir uma alíquota da solução preparada para um béquer de $10 \mathrm{~mL}$ previamente limpo e seco;

- Pipetar exatamente $25 \mu \mathrm{L}$ da solução de trabalho sobre cada um dos papéis filtro dispostos nas estantes de bagueta. Deve-se tomar cuidado para que o líquido pipetado não encoste na superfície da estante de bagueta e não ultrapasse a marca do recorte de $0,5 \mathrm{~cm}$. Se isso acontecer, descarte adequadamente a folha de papel filtro;

- Aguardar até que a alíquota da solução de trabalho pipetada nos papéis filtro sequem em temperatura ambiente (esse processo demora entre $6 \mathrm{~h}$ e $12 \mathrm{~h}$ );

- Com o auxílio de uma pinça, retire o papél filtro - cujo padrão de trabalho foi pipetado e já esta seco - das estantes de bagueta e com uma tesoura recorte a parte inferior do mesmo na distância de $0,5 \mathrm{~cm}$. Este $0,5 \mathrm{~cm}$ corresponde a parte do papel filtro de ficou em contato com a estante de bagueta. Esta parte deve ser descartada;

- Com a auxílio de outra pinça, dobre a folha de papel filtro (cujas dimensões devem ser $2 \mathrm{~cm} \times 2 \mathrm{~cm}$ ) ao meio tanto na largura quanto no comprimento, resultado em um padrão de geometria de $1 \mathrm{~cm} \times 1 \mathrm{~cm}$ (h X c); 


\begin{tabular}{|c|c|c|}
\hline Centro do Reator de & MÉTODO BIO 1: Determinação da & Página 7 de 11 \\
Pesquisa - CRPq, & concentração de As em amostras de matriz & POP - CRPq/001 \\
IPEN - CNEN/SP & biológica (POP - CRPq/001) & Revisão: 00 \\
\hline
\end{tabular}

- Colocar o padrão de geometria $1 \mathrm{~cm} \times 1 \mathrm{~cm}(\mathrm{~h} \times \mathrm{c}$ ) dentro de um invólucro de polietileno previamente preparado;

- Com o auxílio de uma seladora Sela-Pak, selar a extremidade aberta do invólucro bem rente ao padrão:

- Recortar a rebarba do invólucro acima do local que foi cuja extremidade foi selada;

- Identificar o padrão e acondicionar em local seco e ao abrigo da luz solar até o momento da análise.

\subsection{Preparo das amostras}

- Em uma balança analítica deve-se colocar um invólucro de polietileno em geometria adequada vazio (o invólucro de ter três lados selados e um lado aberto);

- Realizar a tara da massa do invólucro;

- Retirar o invólucro da balança analítica com o auxílio de uma pinça;

- Pesar em balança analítica $150 \pm 10 \mathrm{mg}$ de amostra em pó dentro do invólucro de polietileno;

- Registrar o uso da balança analítica no caderno de Registro de Uso da respectiva balança analítica;

- Anotar a massa da amostra na folha do formulário de pesagem de amostras;

- Com o auxílio de uma seladora Sela-Pak, selar a extremidade aberta do invólucro de modo que a geometria final seja idêntica à do padrão sintético $(1 \mathrm{~cm} \times 1 \mathrm{~cm})$.

- Recortar a rebarba do invólucro acima do local que foi cuja extremidade foi selada;

- Identificar a amostra e acondicionar em local seco e ao abrigo da luz solar até o momento da análise.

\subsection{Irradiação}

- Limpar a parte externa de amostras e padrões sintéticos (amostras e padrões devem ter geometria espacial idênticas: $1 \mathrm{~cm} \times 1 \mathrm{~cm}$ ) com um papel embebido em álcool etílico grau P.A. e, em seguida, com outro papel embebido em água deionizada (Milli $-\mathrm{Q}$, Millipore; $18,2 \mathrm{~m} \Omega$ );

- Secar a parte externa do invólucro com papel absorvente;

- Envolver uma capa de folha de papel alumínio em cada amostra e/ou padrão sintético, de modo que esta fique semelhante a um invólucro de papel alumínio. Deve-se usar uma mínima quantidade de papel alumínio nesta etapa;

- Identificar cada amostra e/ou padrão sintético, anotando-se o código sobre o invólucro de papel alumínio;

- Dispor amostras e padrão sintético uns sobre os outros, de maneira aleatória e de modo a formar um agrupamento;

- Envolver o agrupamento formado por amostras e padrão sintético com uma nova camada de folha de papel alumínio, de modo que estes mantenham-se fixos em uma mesma posição. A esta etapa se dá o nome de preparo do sanduíche;

- Inserir o sanduíche de amostras e padrão sintético dentro do recipiente de alumínio chamado coelho;

- Identificar o coelho com o código do experimento;

- Preencher a ficha de Solicitação para Irradiação de amostras;

- Encaminhar o coelho juntamente com a ficha de Solicitação de Irradiação de amostras corretamente preenchida e assinada para o departamento de irradiação de amostras do reator nuclear.

\subsection{Abertura do coe/ho}

- Ligar para o departamento de Proteção Radiológica solicitando o acompanhamento de um técnico de Radioproteção para o monitoramento das atividades de abertura do coelho;

- Com o auxílio de uma pinça de cabo longo deve-se acondicionar o coelho no aparelho de abertura de coelhos;

- Realizar a abertura do coelho acionando o aparelho de abertura de coelhos:

- Com o auxílio de uma pinça de cabo longo retirar o sanduiche do interior do coelho e acondicionar no dentro de um castelo de chumbo;

- Registrar a abertura do coelho no caderno de abertura de coelhos. 


\begin{tabular}{|c|c|c|}
\hline Centro do Reator de & MÉTODO BIO 1: Determinação da & Página 8 de 11 \\
Pesquisa - CRPq, & concentração de As em amostras de matriz & POP - CRPq/001 \\
IPEN - CNEN/SP & biológica (POP - CRPq/001) & Revisão: 00 \\
\hline
\end{tabular}

\subsection{Deteç̧ão de raios gama}

- Ir até uma capela que contenha uma barreira de proteção de chumbo;

- Colocar o castelo de chumbo contendo o sanduiche no interior da capela;

- Com o auxílio de uma pinça de cabo longo, retirar o sanduíche do castelo de chumbo;

- Desmontar o sanduíche, refazendo o processo inverso ao de montagem;

- Com o auxílio de duas pinças, retirar o invólucro de alumínio de cada uma das amostras e do padrão sintético. Deve-se ter bastante atenção nesta etapa visto que o invólucro de polietileno jamais deve ser rompido, sob o risco da ocorrência de contaminação radiológica. Apenas o invólucro de alumínio deve ser removido;

- As folhas de papel alumínio equivalentes ao sanduíche e aos invólucros de papel alumínio devem ser descartadas em lixo de residuo radioativo;

- Colocar cada uma das amostras e do padrão sintético (de maneira individual) no centro de um recipiente de alumínio chamado panelinha;

- Fixar amostras e/ou padrão sintético exatamente no centro da panelinha com a auxílio de um pedaço de fita adesiva. Esta etapa chama-se selagem das panelinha;

- Identificar as amostra e padrão sintético;

- Colocar cada panelinha devidamente selada e identificada no interior de um castelo de chumbo e transportar até a sala de contagens;

OBS: A medição da atividade do mensurando na amostra e padrão sintético deve ser realizada 7 dias após a data de irradiação e em um mesmo espectrômetro de raios gama. Amostras cuja irradiação tenha sido realizada em um período menor que 7 dias ou maior que 9 dias não devem ser analisadas.

- Dispor a panelinha dentro do detector de raios gama sob configuração de contagem adequada (Prateleira 1);

- Realizar a medição da atividade do mensurando no padrão sintético por um período de 1200 segundos;

- Realizar a medição da atividade do mensurando na amostra por um período de 3600 segundos;

- Imprimir o resultado com os valores de medição para cada amostra e padrão;

- Calcular a concentração do mensurando na amostra de acordo com a equação 1.

\subsection{Descarte de amostras e padrões sintéticos}

Após o processo de medição, amostras e padrão sintético devem ser descartados em lixo de resíduo radioativo.

\section{CONTROLE DE QUALIDADE}

O controle da qualidadedo procedimento é realizado por meio da análise do material de referência interno (MR) Tecido de Mexilhão TM-1 produzido pelo IPEN - CNEN/SP. A cada nova irradiação, uma alíquota de Tecido de Mexilhão TM-1 deve ser enviada como amostra e o resultado obtido para a concentração de As deve ser comparada com o valor de referência do mensurando no MR que é [As] $13,6 \pm 1,7 \mathrm{mg} \mathrm{kg}^{-1}$. Os resultados das amostras controle de Tecido de Mexilhão TM-1 devem ser avaliados em função do valor de En. O critério de aceitação para os resultados é $|E n| \leq 1$. Todos os resultados obtidos nas análises de amostras controle devem ser transcritos para a Planilha "Carta Controle MÉTODO BIO-1: Determinação da concentração de As em amostras de matriz biológica".

Antes de cada utilização, balanças analíticas e espectrômetros de raios gama devem ter seu funcionamento verificado em função do uso de padrões específicos. Todos os resultados das verificações devem ser registrados e arquivados em formulários específicos da qualidade.

\subsection{Validação do método}

O método de medição foi validado de acordo com as exigências da norma ABNT NBR ISO/IEC 17025, seguindo-se as orientações do Guia de validação de métodos INMETRO DOQ-CGCRE-008 e da Resolução RE n 899 da ANVISA que dispõe sobre a validação de métodos de medição. 


\begin{tabular}{|c|c|c|}
\hline Centro do Reator de & MÉTODO BIO 1: Determinação da & Página 9 de 11 \\
Pesquisa - CRPq, & concentração de As em amostras de matriz & POP - CRPq/001 \\
IPEN - CNEN/SP & biológica (POP - CRPq/001) & Revisão: 00 \\
\hline
\end{tabular}

\subsection{Seletividade do método, possíveis interferentes}

A elevada seletividade do método é referente à elevada seletividade da espectrometria de raios gama. Apesar disso, possiveis interferentes não podem ser excluídos. Ir e $\mathrm{Hg}$ podem ser considerados possiveis interferentes analíticos na determinação de As.

\subsection{Linearidade e faixa de trabalho}

A espectrometria de raios gama possui ampla faixa linear ( 0 à $1 \mathrm{~kg} \mathrm{~kg}^{-1}$ ). Contudo, anomalias na geometria entre amostras e padrão sintético, configuração da resolução do detector e tempo morto obtido durante a medição podem gerar eventos de não-linearidade às medições. Amostras típicas analisadas (MR Tecido de mexilhäo TM-1, MRC Mussel tissue-NIST SRM 2976, MRC Oyster tissueNIST SRM 1566b, MRC Fish tissue-IAEA 407 e MRC Dogfish Muscle-NRCC DORM 2) apresentaram valores de tempo morto durante a medição menores que $15 \%$. Nesta condição não foram observados efeitos de não-linearidade.

A faixa de trabalho recomendada varia entre o valor de $L Q$ até o valor de maior concentração observado no estudo de linearidade. Amostras analisadas devem atender a este requisito.

\subsection{Veracidade}

A veracidade deve ser avaliada em função do resultado obtido para a amostra controle Tecido de Mexilhão TM-1 por meio do cálculo de En (2).

$$
E n=\frac{x-x_{v}}{\sqrt{U^{2}+U_{v}^{2}}}
$$

onde:

En é o valor para erro normalizado;

$x$ é o resultado da medição $\left(\mathrm{mg} \mathrm{kg}^{-1}\right)$;

$x_{\mathrm{v}}$ é o valor de referência $\left(\mathrm{mg} \mathrm{kg}^{-1}\right)$;

$U$ é a incerteza expandida do resultado, $k=2\left(\mathrm{mg} \mathrm{kg}^{-1}\right)$;

$U_{v}$ é a incerteza expandida do valor de referência, $k=2\left(\mathrm{mg} \mathrm{kg}^{-1}\right)$.

\subsection{Critério de aceitação}

O critério de aceitação para os resultados é $|E n| \leq 1$

\subsection{Precisão}

A repetitividade do método foi determinada em função da análise de 7 amostras controle de Tecido de Mexilhão TM-1. O cálculo do resultado foi realizado de acordo com (3).

$$
r=2,8 s
$$

onde:

$r$ é o valor do limite de repetitividade $\left(\mathrm{mg} \mathrm{kg}^{-1}\right)$;

$s$ é o desvio padrão obtido para $n$ medições, $n \geq 7\left(\mathrm{mg} \mathrm{kg}^{-1}\right)$.

A precisão intermediária foi determinada em função da análise de 26 amostras controle de Tecido de Mexilhão TM-1. O cálculo do resultado foi realizado de acordo com (4).

$$
P I=\sqrt{\frac{1}{(n-1)} \sum_{m=1}^{n}\left(x_{m}-\bar{x}\right)^{2}}
$$




\begin{tabular}{|c|c|c|}
\hline Centro do Reator de & MÉTODO BIO 1: Determinação da & Página 10 de 11 \\
Pesquisa - CRPq, & concentração de As em amostras de matriz & POP - CRPq/001 \\
IPEN - CNEN/SP & biológica (POP - CRPq/001) & Revisão: 00 \\
\hline
\end{tabular}

onde:

Pl é o valor de precisão intermediária $\left(\mathrm{mg} \mathrm{kg}^{-1}\right)$;

$n$ é o número de amostras (alíquotas);

$m$ é o número do ensaio da amostra, $m=1, n$;

$x_{m}$ é o resultado obtido para o ensaio $k$;

$\bar{x}$ é a média dos resultados para $n$ medições.

A reprodutibilidade do método foi determinada de acordo com (5).

onde:

$$
R=2,8 P I
$$

$R$ é o valor do limite de reprodutibilidade $\left(\mathrm{mg} \mathrm{kg}^{-1}\right)$;

Pl é o valor de precisão intermediária $\left(\mathrm{mg} \mathrm{kg}^{-1}\right)$.

\subsection{Limite de detecção}

O limite de deteç̧ão (LD) foi calculado para a análise de uma amostra controle Tecido de Mexilhão TM-1 de acordo com (6).

$$
L D=3,29 \frac{\sqrt{b}}{t}
$$

onde:

$L_{D}$ é a taxa de contagem correspondente ao limite de deteç̧ão do método (cps);

$b$ é o número de contagens da radiação de fundo sob o pico analítico (cps);

$t$ é o tempo real de medição da amostra (s).

O resultado obtidos para $L D$ é convertido para $\mathrm{mg} \mathrm{kg}^{-1}$ utilizando a equação geral da ativação neutrônica (1).

\subsection{Limite de quantificação}

O limite de quantificação (LQ) foi calculado para a análise de uma amostra controle Tecido de Mexilhão TM-1 de acordo com (7).

$$
L Q=10 \frac{\sqrt{b}}{t}
$$

onde:

$L_{Q}$ é a taxa de contagem correspondente ao limite de quantificação do método (cps); $b$ é o número de contagens da radiação de fundo sob o pico analítico (cps); $t$ é o tempo real de medição da amostra (s).

O resultado obtidos para $L Q$ é convertido para $\mathrm{mg} \mathrm{kg}^{-1}$ utilizando a equação geral da ativação neutrônica (1).

\subsection{Incerteza de medição}

A estimativa da incerteza de medição foi realizada em função do método simulado, procedimento recomendado pelo Guia para a quantificação de incertezas de medição (EURACHEM/CITAC, 2012) e descrito passo a passo por Petroni (PETRONI, 2015). Levou-se em consideração as seguintes componentes de entrada em INAA: massa da amostra, massa do padrão sintético, atividade do radionuclídeo na amostra, atividade do radionuclídeo no padrão sintético e constante de decaimento do radionuclídeo. 


\begin{tabular}{|c|c|c|}
\hline Centro do Reator de & MÉTODO BIO 1: Determinação da & Página 11 de 11 \\
Pesquisa - CRPq, & concentração de As em amostras de matriz & POP - CRPq/001 \\
IPEN - CNEN/SP & biológica (POP - CRPq/001) & Revisão: 00 \\
\hline
\end{tabular}

\subsection{Pico analítico}

O cálculo da concentração de As na amostra deve ser realizado para a atividade verificada no pico analítico de $559,1 \mathrm{keV}$.

\section{CARACTERÍSTICAS DO MÉTODO DE MEDIÇÄO}

A seguir são apresentados as características correspondentes ao método de medição.

\begin{tabular}{cccc}
\hline Parâmetro de Validação & \multicolumn{2}{c}{ As } \\
\cline { 2 - 4 } & $n$ & 0,24 & Resultado \\
\hline Limite de repetitividade & 7 & $0,54 \mathrm{mg} \mathrm{kg}^{-1}$ \\
Precisão Intermediária & 26 & 0,52 & $0,81 \mathrm{mg} \mathrm{kg}^{-1}$ \\
Limite de reprodutibilidade & 26 & 0,52 & $2,3 \mathrm{mg} \mathrm{kg}^{-1}$ \\
Limite de deteç̧ão & 1 & 0,17 & $0,79 \mathrm{mg} \mathrm{kg}^{-1}$ \\
Limite de quantificação & 1 & 0,17 & $2,1 \mathrm{mg} \mathrm{kg}^{-1}$ \\
Incerteza expandida relativa, $k=2$ & 5 & $-0,15$ & $3,6-5,5 \%$ \\
Faixa de trabalho & & $2,1-69 \mathrm{mg} \mathrm{kg}^{-1}$ & Adequada $(-1,0<E n<1,0)$ \\
Veracidade & & \multicolumn{2}{c}{}
\end{tabular}

\section{REFERÊNCIAS}

ALFASSI, Z. B. Activation Analysis. CRC Press. Florida, 1990

BODE, P.; FERNANDES, E.A.N.; GREENBERG, R.R. Metrology for chemical measurements and the position of INAA. Journal of Radioanalytical and Nuclear Chemistry. 245:109-114, 2000

GREENBERG, R. R.; BODE, P.; FERNANDES, E. A. N. Neutron activation analysis: A primary method of measurement. Spectrochimica Acta Part B. 66:193-241, 2011

HAMIDATOU, L.; SLAMENE, H.; AKHAL, T.; ZOURANEN, B. Concepts, instrumentation and techniques of Neutron Activation Analysis. In: KHARFY, F. Imaging and Radioanalytical Techniques in Interdisciplinary Research - Fundamentals and Cutting Edge Applications. InTech, p. 141-177, 2013 Disponivel em: $\quad$ http://www.intechopen.com/books/imaging-and-radioanalytical-techniques-ininterdisciplinary-research-fundamentals-and-cutting-edge-applications> Acesso em 18 novembro, 2014

PETRONI, R. Validação dos métodos de Análise por Ativação do Laboratório de Análise por Ativação do IPEN - CNEN/SP visando a produção de materiais de referência certificados. Dissertação de Mestrado. Universidade de São Paulo, 2015

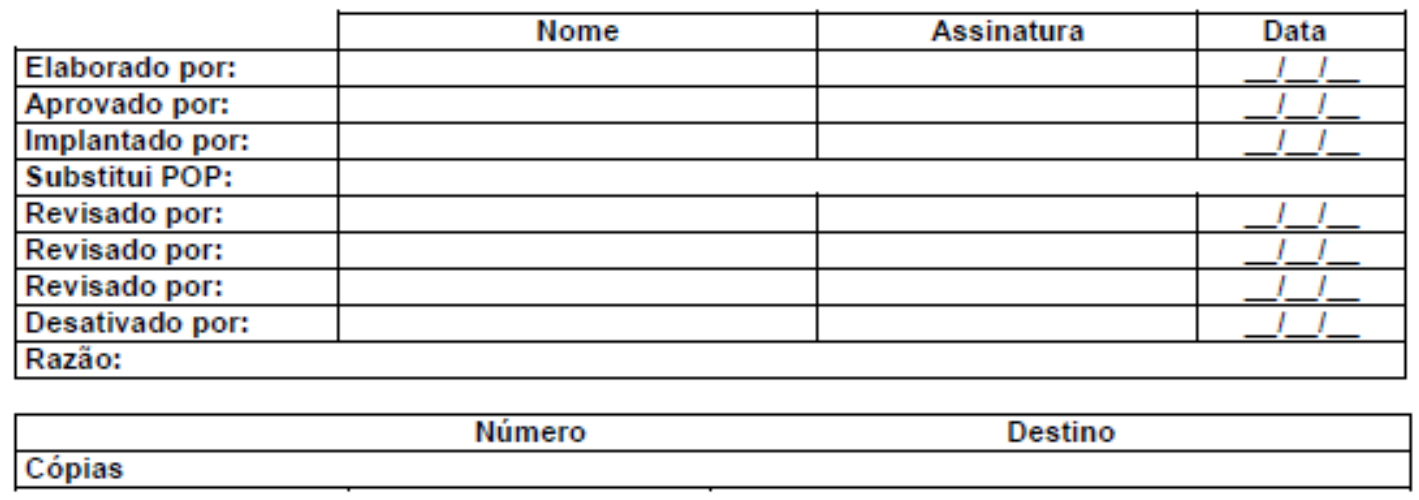




\begin{tabular}{|c|c|c|}
\hline $\begin{array}{c}\text { Centro do Reator de } \\
\text { Pesquisa - CRPq, }\end{array}$ & $\begin{array}{c}\text { MÉTODO BIO 2: Determinação da concentração } \\
\text { de Co, Cr, Fe, Rb, Sc, Se e Zn em amostras de }\end{array}$ & $\begin{array}{c}\text { Página } 1 \text { de 13 } \\
\text { POP - CRPq/002 } \\
\text { Revisão: } 00\end{array}$ \\
\hline
\end{tabular}

\title{
MÉTODO BIO 2: Determinação da concentração de $\mathrm{Co}, \mathrm{Cr}, \mathrm{Fe}, \mathrm{Rb}, \mathrm{Sc}$, $\mathrm{Se}$ e $\mathrm{Zn}$ em amostras de matriz biológica
}

\begin{abstract}
1. INTRODUÇÃO
O método de Análise por Ativação com Nêutrons (NAA) se baseia na produção e posterior identificação de radionuclídeos artificiais a partir de elementos naturalmente estáveis. Esse processo ocorre por meio do bombardeamento com nêutrons no material a ser analisado (amostra), resultando em reações nucleares características para cada elemento. Em NAA, o produto da reação nuclear que é medido é a emissão de raios gama provenientes do decaimento radioativo dos radionuclídeos formados durante o processo de bombardeamento com nêutrons (BODE et al., 2000).
\end{abstract}

Em NAA, amostras e padrões são irradiados sob um fluxo de nêutrons térmicos provenientes de um reator nuclear. A sequência de eventos que ocorrem numa reação nuclear típica se inicia quando um nêutron interage com um núcleo alvo por meio de uma colisão inelástica, formando um núcleo composto num estado excitado. A energia de excitação do núcleo composto é devida à energia de ligação do nêutron com o núcleo. $O$ núcleo composto formado quase que instantaneamente adquire uma configuração mais estável por meio da emissão de raios gama prontos, do inglês, prompt gamma rays. Em muitos casos, esta nova configuração do núcleo no estado passa por outras vias de decaimento por emissão de raios gama retardados, do inglês, delayed gamma rays (ALFASSI, 1990).

O sistema de detecção de raios gama é constituído basicamente por um detector semicondutor de germânio hiperpuro ( $\mathrm{HPGe}$ ) associado ao analisador de multi canal (MCA) e a um computador responsável pela análise dos dados obtidos durante o processo de medição, integração da área dos picos analíticos e geração do espectro com os resultados da medição dos raios gama. Esse sistema qualifica a técnica como bastante seletiva devido as característicvas do processo de deteç̧ão de raios gama.

NAA é uma técnica multielementar capaz de detectar e quantificar dezenas de elementos em uma única rodada de experimentos é independente de efeitos de matriz e é considerada uma técnica não destrutiva, uma vez que não requer processos de digestão das amostras, fato que contribui para a diminuição do risco de contaminação. Apresenta-se ainda uma técnica muito competitiva para a determinação do teor de elementos traço em matrizes ambientais, apresentando elevado nivel de exatidão para a medição de muitos elementos (GREENBERG et al., 2011).

Outra grande vantagem da técnica está no fato da não obrigatoriedade de se analisar o branco analítico, pois não há utilização de reagentes para digestão da amostra, processos de extração ou separação de elementos. Por esse motivo, faz-se seguro afirmar que não há possibilidade de introdução de contaminantes após a irradiação nas amostras, exceto por contaminação de outro material radioativo (HAMIDATOU et al., 2013).

\section{APLICAÇÄO DO MÉTODO}

Este documento descreve o método para determinação da concentração total de As em amostras de matriz biológica por meio da técnica de Análise por Ativação com Nêutrons.

\section{REFERÊNCIAS NORMATIVAS}

ABNT, ASSOCIAÇÃO BRASILEIRA DE NORMAS TÉCNICAS. Sistemas de Gestão da Qualidade Fundamentos e vocabulário. Rio de Janeiro: ABNT, 2005 (ABNT NBR ISO 9000)

ABNT, ASSOCIAÇÃO BRASILEIRA DE NORMAS TÉCNICAS. Requisitos gerais para a competência de laboratórios de ensaio e calibração. 2 ed. corrigida, Rio de Janeiro: ABNT, 2006 (ABNT NBR ISO/IEC 17025:2005) 


\begin{tabular}{|c|c|c|}
\hline Centro do Reator de & MÉTODO BIO 2: Determinação da concentração & Página 2 de 13 \\
Pesquisa - CRPq, & de Co, $\mathrm{Cr}, \mathrm{Fe}, \mathrm{Rb}, \mathrm{Sc}, \mathrm{Se}$ e Zn em amostras de & POP - CRPq/002 \\
IPEN - CNEN/SP & matriz biológica (POP - CRPq/002) & Revisão: 00 \\
\hline
\end{tabular}

ABNT, ASSOCIAÇÃO BRASILEIRA DE NORMAS TÉCNICAS. Sistemas de Gestão da Qualidade Requisitos. 2 ed. corrigida, Rio de Janeiro: ABNT, 2009 (ABNT NBR ISO 9001)

ABNT, ASSOCIAÇÃO BRASILEIRA DE NORMAS TÉCNICAS. Gestão para o sucesso sustentado de uma organização - Uma abordagem da gestão da qualidade. 2 ed. corrigida Rio de Janeiro: ABNT, 2010 (ABNT NBR ISO 9004)

ANVISA, AGÊNCIA NACIONAL DE VIGILÂNCIA SANITÁRIA. Guia Para Qualidade em Química

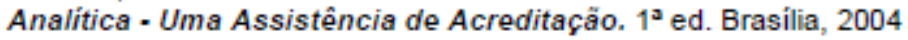

BRASIL. Resolução RE $n^{\circ} 899$, de 29 de maio de 2003. ANVISA, AGÊNCIA NACIONAL DE VIGILÂNCIA SANITÁRIA, 2003. Disponivel em:

<http://portal.anvisa.gov.br/wps/wcm/connect/4983b0004745975da005f43fbc4c6735/RE_899_2003_Det ermina+a+publica \%C3\%A7\%C3\%A3o+do+Guia+para+valida\%C3\%A7\%C3\%A3o+de+m\%C3\%A9todos + anal\%C3\%ADticos+e+bioanal\%C3\%ADticos.pdf?MOD=AJPERES> Acesso em 18 junho, 2015

CURRIE, L. A. Nomenclature in evaluation of analytical methods including detection and quantification capabilities (IUPAC Recommendations 1995). Analytical Chimic Acta, 391:105-126, 1999

EURACHEM. The fitness for purpose of analytical methods. A laboratory guide to method validation and related topics, 1998. Disponivel em:

<http://www.eurachem.org/images/stories/Guides/pdf/valid.pdf> Acesso em: 18 junho, 2015

EURACHEM/CITAC. Quantifying uncertainty in analytical measurement. EURACHEM/CITAC Guide CG 4, 2012. Disponivel em: <http://www.citac.cc/QUAM2012_P1.pdf> Acesso em: 18 junho, 2015 (QUAM:2012)

IAEA. International atomic Energy Agency. Use of research reactors for neutron activation analysis. Vienna, 2001 Disponivel em : <http://www-pub.iaea.org/MTCD/publications/PDF/te_1215_prn.pdf> Acesso em 18 junho, 2015 (IAEA-TECDOC 1215)

IAEA. International atomic Energy Agency. Uncertainty evaluation in instrumental and radio. chemical neutron activation analysis. Vienna, 2004 Disponível em $<$ http://www-pub.iaea.org/MTCD/publications/PDF/te_1401_web.pdfs Acesso em 18 junho, 2015 (IAEA-TECDOC1401)

INMETRO, INSTITUTO NACIONAL DE METROLOGIA, QUALIDADE E TECNOLOGIA. Orientação sobre validação de métodos analíticos. Rio de Janeiro, Fev. 2010. Disponível em: <http://www.inmetro.gov.br/Sidoq/Arquivos/CGCRE/DOQ/DOQ-CGCRE-8_03.pdf>, Acesso em: 18 junho, 2015 (DOQ-CGCRE-008)

INMETRO, INSTITUTO NACIONAL DE METROLOGIA, QUALIDADE E TECNOLOGIA. Vocabulário Internacional de Metrologia: conceitos fundamentais e gerais e termos associados. 1ed Lusobrasileira, Rio de Janeiro: INMETRO, 2012. Disponivel em:

<http://www.inmetro.gov.br/inovacao/publicacoes/vim_2012.pdf>, Acesso em: 18 junho, 2015 (VIM)

INMETRO, INSTITUTO NACIONAL DE METROLOGIA, QUALIDADE E TECNOLOGIA. Guia para a expressão da incerteza de medição. 1ed Luso-brasileira. Rio de Janeiro: INMETRO, 2012. (ISO GUM)

ISO, INTERNATIONAL ORGANIZATION OF STANDADIZATION. Accuracy (trueness and precision) of measurement methods and results-- Part 1: General principles and definitions. Geneva, 2012 


\begin{tabular}{|c|c|c|}
\hline Centro do Reator de & MÉTODO BIO 2: Determinação da concentração & Página 3 de 13 \\
Pesquisa - CRPq, & de Co, Cr, Fe, Rb, Sc, Se e Zn em amostras de & POP - CRPq/002 \\
IPEN - CNEN/SP & matriz biológica (POP - CRPq/002) & Revisão: 00 \\
\hline
\end{tabular}

ISO, INTERNATIONAL ORGANIZATION OF STANDADIZATION. Accuracy (trueness and precision) of measurement methods and results- Part 3: Intermediate measures of the precision of a standard measurement method. Geneva, 2013

ISO, INTERNATIONAL ORGANIZATION OF STANDADIZATION. Accuracy (trueness and precision) of measurement methods and resuits - Practical guidance for the use of ISO 5725:1994 in designing, implementing and statistically analysing interlaboratory repeatability and reproducibility results. Geneva, 2005

\section{SIMBOLOS, SIGLAS E ABREVIAÇÕES}

ABNT : Associação Brasileira de Normas Técnicas ANVISA : Agência Nacional de Vigilância Sanitária $A_{a}:$ atividade do radionuclídeo na amostra (cps)

$c$ : comprimento do padrão sintético

$A_{p}$ : atividade do radionuclídeo no padrão sintético para tempo de decaimento tp (cps)

$b$ : número de contagens da radiação de fundo sob o pico analítico (cps)

$C$ : concentração do mensurando na amostra $\left(\mathrm{mg} \mathrm{kg}^{-1}\right)$

$C R P q$ : Centro do Reator de Pesquisa

$D P$ : desvio padrão para a média de $n$ medições $\left(\mathrm{mg} \mathrm{kg}^{-1}\right)$

En : erro normalizado

GUM : Guia para expressão da incerteza de medição

$h$ : altura do padrão sintético

HPGe : Espectrômetro de raios gama com detector de germânio hiperpuro (HPGe)

$I A E A$ : Agência Internacional de Energia Atômica

INMETRO : Instituto Nacional de Metrologia: Qualidade e Tecnologia

IPEN - CNEN/SP : Instituto de Pesquisas Energéticas e Nucleares

ISO : Organização Internacional para a Padronização

$k$ : fator de abrangência da incerteza de medição; $k=2 ; a=0,05$

$L D$ : limite de detecção $\left(\mathrm{mg} \mathrm{kg}^{-1}\right)$

$L Q$ : limite de quantificação $\left(\mathrm{mg} \mathrm{kg}^{-1}\right)$

$m$ : número do ensaio da amostra, $m=1, n$

$M_{a}:$ massa da amostra $(\mathrm{kg})$

$m_{p}$ : massa do mensurando no padrão sintético $(\mathrm{mg})$

$M R$ : material de referência

$M R C$ : material de referência certificado

$n$ : número de medições

NAA : Análise por Ativação com Nêutrons Instrumental

NIST : National Institute of Standards and Technology; Intituto Nacional de Padrões e Tecnologia (EUA)

NRCC : National Research Council Canada; Conselho Nacional de Pesquisa do Canadá

$P I$ : precisão intermediária $\left(\mathrm{mg} \mathrm{kg}^{-1}\right)$

QUAM : Guia para a Quantificação da Incerteza nas medições analíticas

$r$ : limite de repetitividade $\left(\mathrm{mg} \mathrm{kg}^{-1}\right)$

$R$ : limite de reprodutibilidade $\left(\mathrm{mg} \mathrm{kg}^{-1}\right)$

$t$ : tempo real de medição da amostra (s)

$t_{đ a}$ : tempo de decaimento do radionuclídeo para medição da amostra (s)

$t_{\text {đpp }}$ : tempo de decaimento do radionuclídeo para medição do padrão (s)

$t_{1 / 2}$ : tempo de meia vida para a atividade do radionuclídeo

$U$ : incerteza expandida do resultado, $k=2\left(\mathrm{mg} \mathrm{kg}^{-1}\right)$

$U_{v}$ : incerteza expandida do valor de referência, $k=2\left(\mathrm{mg} \mathrm{kg}^{-1}\right)$

VIM : Vocabulário Internacional de Metrologia

$x$ : resultado da medição $\left(\mathrm{mg} \mathrm{kg}^{-1}\right)$

$\bar{x}$ : média dos resultados para $n$ medições

$x_{m}$ : resultado obtido para o ensaio $\mathrm{m}$

$x_{\mathrm{v}}$ : valor de referência do MR ou MRC $\left(\mathrm{mg} \mathrm{kg}^{-1}\right)$

$\alpha$ : nível de significância estatística; $\alpha=0,05 ; 95 \%$ de confiança estatística

$\lambda$ : constante de decaimento do radionuclídeo $\left(s^{-1}\right)$ 


\begin{tabular}{|c|c|c|}
\hline Centro do Reator de & MÉTODO BIO 2: Determinação da concentração & Página 4 de 13 \\
Pesquisa - CRPq, & de Co, $\mathrm{Cr}, \mathrm{Fe}, \mathrm{Rb}, \mathrm{Sc}, \mathrm{Se}$ e Zn em amostras de & POP - CRPq/002 \\
IPEN - CNEN/SP & matriz biológica (POP - CRPq/002) & Revisão: 00 \\
\hline
\end{tabular}

\section{RESPONSABILIDADES}

É de responsabilidade do analista seguir o procedimento e estabelecer práticas que garantam a segurança e saúde. É obrigação da gerência do CRPq fornecer o uso de equipamentos de monitoramento para o controle da radioatividade ao que o analista estará exposto, bem como qualquer outro equipamento de proteção individual que se faça necessário para o cumprimento das leis e acordos para a manutenção da segurança quanto a contaminação química, biológica e radioativa. É responsabilidade do analista solicitar à gerência do $\mathrm{CRPq}$ a compra dos equipamentos de proteção individual que eventualmente não encontram-se disponiveis e utilizá-los de forma correta e segura. Qualquer acidente que envolva material radioativo deverá ser imediatamente informado ao Serviço de Proteção Radiológica. Ainda, é de responsabilidade do analista fazer a verificação de todos os equipamentos utilizados bem como o registro de uso dos mesmos.

\section{PRINCÍPIO DO MÉTODO}

O método NAA consiste na irradiação da amostra e do padrão sintético (no qual a concentração do mensurando é conhecida) de maneira simultânea, em um mesmo período de tempo, geometria de espaço e de fluxo de nêutrons. Após o período de decaimento apropriado, realiza-se a medição do espectro de raios gama na amostra e no padrão sintético numa mesma configuração de deteç̧ão e em um mesmo aparelho detector. A determinação da concentração do mensurando na amostra é calculada por meio da comparação da área dos picos (atividade) obtidos para amostra e padrão sintético. A equação fundamental para o cálculo da concentração de um mensurando em NAA é apresentada a seguir (1).

$$
C_{a}=\frac{m_{p} A_{a} e^{-\lambda(t a-t p)}}{A_{p} M_{a}}
$$

onde:

$C$ é a concentração do mensurando na amostra $\left(\mathrm{mg} \mathrm{kg}^{-1}\right)$;

$m_{p}$ é a massa do mensurando no padrão $(\mathrm{mg})$;

$A_{a}$ é a atividade do radionuclídeo na amostra (cps);

$\lambda$ é a constante de decaimento do radionuclídeo $\left(\mathrm{s}^{-1}\right)$;

$t_{\text {đa }}$ é o tempo de decaimento do radionuclídeo até o momento início da medição da amostra (s);

$t_{a p}$ é o tempo de decaimento do radionuclídeo até o início da medição do padrão (s);

$M_{a}$ é a massa da amostra $(\mathrm{kg})$;

$A_{p}$ é a atividade do radionuclídeo no padrão sintético para tempo de decaimento tp (cps).

\section{EQUIPAMENTOS, VIDRARIA E REAGENTES}

\subsection{Equipamentos e vidrarias}

Estufa

Reator nuclear

Espectrômetro de raios gama com detector de germânio hiperpuro (HPGe)

Balança analítica

Máquina seladorado Sela-Pak

Aparelho deionizador de água (Mili - Q, Millipore; 18,2 $\mathrm{m} \Omega$ )

Micropipeta $(20-100 \mu \mathrm{L})$

Micropipeta $(100-1000 \mu \mathrm{L})$

Micropipeta (1000 - $5000 \mu \mathrm{L})$

Ponteira para micropipetas

Balão volumétrico calibrado de $10 \mathrm{~mL}$ Béquer de $10 \mathrm{~mL}$ 


\begin{tabular}{|c|c|c|}
\hline Centro do Reator de & MÉTODO BIO 2: Determinação da concentração & Página 5 de 13 \\
Pesquisa - CRPq, & de Co, Cr, Fe, Rb, Sc, Se e Zn em amostras de & POP - CRPq/002 \\
IPEN - CNEN/SP & matriz biológica (POP - CRPq/002) & Revisão: 00 \\
\hline
\end{tabular}

Folha de polietileno

Folha de papel filtro quantitativo

Folha de papel alumínio

Folha de papel absorvente

Baguetas de vidro

Recipiente de alumínio (coelho)

Recipiente de alumínio (panelinha)

Pinças de cabo longo

Castelo de chumbo

\subsection{Reagentes}

Ácido nítrico (10\%)

Solução padrão de Co $1000 \mathrm{mg} \mathrm{L}^{-1}$

Solução padrão de $\mathrm{Cr} 1000 \mathrm{mg} \mathrm{L}^{-1}$

Solução padrão de $\mathrm{Fe} 10000 \mathrm{mg} \mathrm{L}^{-1}$

Solução padrão de $\mathrm{Rb} 1000 \mathrm{mg} \mathrm{L}^{-1}$

Solução padrão de Sc $1000 \mathrm{mg} \mathrm{L}^{-1}$

Solução padrão de Se $10000 \mathrm{mg} \mathrm{L}^{-1}$

Solução padrão de $\mathrm{Zn} 10000 \mathrm{mg} \mathrm{L}$

\section{PROCEDIMENTO}

\subsection{Lavagem e descontaminação das vidrarias}

- Com o auxílio de um sepilho, lavar a vidraria com sabão neutro comercial (Extran $3 \%$ );

- Enxaguar três vezes com água destilada;

- Preparar uma solução de $\mathrm{HNO}_{3}(10 \%)$;

- Acondicionar a solução em um recipiente de plástico com tampa dentro de uma capela;

- Dispor a vidraria previamente lavada no recipiente plástico com a solução de $\mathrm{HNO}_{3}(10 \%)$. Essa etapa é conhecida com banho ácido;

- Aguardar por 24 horas;

- Retirar a vidraria do banho ácido, enxaguar três vezes com água destilada e três vezes com água deionizada (Mili - Q, Millipore; $18,2 \mathrm{~m} \Omega$ );

- Aguardar a secagem da vidraria sob temperatura ambiente;

- Guardar a vidraria em local adequado.

\subsection{Solução de $\mathrm{HNO}_{3}(\mathbf{1 0} \%)$ ** Procedimento dentro de capela **}

- Adicionar cerca de 1 litro de água destilada em um balão volumétrico de 2 litros;

- Dispor $200 \mathrm{~mL}$ de $\mathrm{HNO}_{3}$ concentrado em um béquer de $500 \mathrm{~mL}$ ( $\mathrm{HNO}_{3}$ concentrado é corrosivo e nocivo à saúde. Nunca realize o procedimento fora da capela);

- Com o auxílio de uma bagueta, transferir de maneira lenta e cuidadosa os $200 \mathrm{~mL}$ de $\mathrm{HNO}_{3}$ concentrado para o balão volumétrico de 2 litros (Faça de maneira devagar. Reação exotérmica);

- Completar o volume do balão volumétrico com aguá destilada até o menisco;

- Tampar o balão volumétrico e homogeneizar a solução preparada;

- Transferir a solução para um frasco âmbar, identificar a solução e armazenar em local seguro, ventilado e ao abrigo da luz solar.

\subsection{Lavagem e confeç̧ão dos invólucros de polietileno}

- As folhas de polietileno utilizadas para o preparo dos invólucros para amostras e padrões sintéticos devem ser previamente lavadas em solução de $\mathrm{HNO}_{3} 10 \%$ (v/v) por um período de 48 horas, enxaguadas com $\mathrm{H}_{2} \mathrm{O}$ destilada e deionizada (Milli-Q, Millipore; $18,2 \mathrm{~m} \Omega$ ) e secas em temperatura ambiente em capela de fluxo laminar; 


\begin{tabular}{|c|c|c|}
\hline Centro do Reator de & MÉTODO BIO 2: Determinação da concentração & Página 6 de 13 \\
Pesquisa - CRPq, & de Co, Cr, Fe, Rb, Sc, Se e Zn em amostras de & POP - CRPq/002 \\
IPEN - CNEN/SP & matriz biológica (POP - CRPq/002) & Revisão: 00 \\
\hline
\end{tabular}

- Os invólucros devem ser confeccionados em geometria retangular de $1,0 \mathrm{~cm}$ de largura por $1,5 \mathrm{~cm}$ de comprimento selado em todas as extremidades com o auxílio de uma máquina seladora. Os invólucros foram armazenados em frasco devidamente identificado e mantidos ao abrigo da luz solar e emtemperatura ambiente até o momento de sua utilização.

\subsection{Confecção das estantes e papéis filtro}

- Para a confecção das estantes se deve-se fixar duas baguetas de vidro com o auxílio de dois pedaços de fita adesiva (um pedaço em cada extremidade), de modo que permaneçam fixas e encostadas uma na outra.

- Para a confecção dos papéis filtro à serem utilizados no preparo dos padrões sintéticos, deve-se pegar uma ou mais folhas de papel filtro quantitativo e recortar de acordo com a seguinte dimensão: 2 $\mathrm{cm} \times 2,5 \mathrm{~cm}$ (h $\times$ c). Ao lado cujo comprimento é $2,5 \mathrm{~cm}$ deve-se fazer um pequeno recorte com a tesoura que servirá como marcação, medindo-se a partir da ponta em $0,5 \mathrm{~cm}$. Posteriormente, esta marcação irá indicar a parte que deverá ser descartada após o processo de pipetagem da solução de trabalho.

\subsection{Preparo dos padrões sintéticos}

- Ao balão volumétrico de $10 \mathrm{~mL}$ (calibrado) adicionar aproximadamente $1 \mathrm{~mL}$ de água deionizada (Milli - Q, Millipore; $18,2 \mathrm{~m} \Omega$ );

- Utilizando-se uma micropipeta, pipetar exatamente $1000 \mu \mathrm{L}$ de solução padrão de $\mathrm{Co}, 2000 \mu \mathrm{L}$ de solução padrão de $\mathrm{Cr}, 3000 \mu \mathrm{L}$ de solução padrão de $\mathrm{Rb}, 100 \mu \mathrm{L}$ de solução padrão de $\mathrm{Sc}, 100 \mu \mathrm{L}$ de solução padrão de $\mathrm{Se}$ e $1000 \mu \mathrm{L}$ de solução padrão de $\mathrm{Zn}$ dentro do balẫo volumétrico de $10 \mathrm{~mL}$, de modo a preparar um padrão sintético multielementar.

OBS: Deve-se manter a micropipeta na posição vertical durante todo o processo de pipetagem da solução padrão. No momento do despejo da solução pipetada dentro do balão volumétrico é importante que a ponteira da micropipeta esteja encostada na parede no balão volumétrico em uma posição abaixo da linha do menisco. Para isso, o balão volumétrico deve ser posicionado em uma posição ligeiramente inclinada, de modo que se faça um ângulo diferente de $90^{\circ}$ entre a ponteira da micropipeta e a parede do balão volumétrico. $O$ êmbolo da micropipeta nunca deve ser pressionado até o fim durante o processo de pipetagem, mas somente até a posição correspondente a trava (a solução padrão deve estar em temperatura ambiente);

- Completar o volume do balão volumétrico com água deionizada (Milli $-\mathrm{Q}$, Millipore; $18,2 \mathrm{~m} \Omega$ ) até o menisco;

- Com um pedaço de papel absorvente, secar cuidadosamente a parte acima do menisco do balão volumétrico de modo à remover gotículas de água que estejam ali adsorvidas. Em hipótese alguma o papel adsorvente pode tocar na solução que está no limite do menisco. Se isso ocorrer, descarte apropriadamente a solução e reinicie novamente o procedimento;

- Tampar o balão volumétrico e homogeneizar a solução preparada (solução de trabalho);

- Aguardar cerca de 30 minutos antes de continuar o procedimento;

- Dispor os papéis filtro recortados em geometria adequada na estante preparada com as baguetas, de modo que estes não fiquem encostados uns aos outros. A extremidade do papel filtro que conter a marcação de $0,5 \mathrm{~cm}$ deverá ser inserido no espaço que existe entre as duas baguetas. Os papéis filtro devem permanecer em posição vertical durante todo o processo de pipetagem e secagem (os processos a seguir devem ser realizados no interior de uma capela);

- Transferir uma alíquota da solução preparada para um béquer de $10 \mathrm{~mL}$ previamente limpo e seco;

- Pipetar exatamente $25 \mu \mathrm{L}$ da solução de trabalho sobre cada um dos papéis filtro dispostos nas estantes de bagueta.;

- Aguardar até que a alíquota da solução de trabalho pipetada nos papéis filtro sequem em temperatura ambiente (esse processo demora entre $6 \mathrm{~h}$ e $12 \mathrm{~h}$ );

- Aos mesmos padrões, pipetar exatamente $50 \mu \mathrm{L}$ da solução padrão de $\mathrm{Fe}\left(10000 \mathrm{mg} \mathrm{L}^{-1}\right)$; 


\begin{tabular}{|c|c|c|}
\hline $\begin{array}{c}\text { Centro do Reator de } \\
\text { Pesquisa - CRPq, }\end{array}$ & $\begin{array}{c}\text { MÉTODO BIO 2: Determinação da concentração } \\
\text { de Co, Cr, Fe, Rb, Sc, Se e Zn em amostras de }\end{array}$ & $\begin{array}{c}\text { Página } 7 \text { de 13 } \\
\text { POP - CRPq/002 } \\
\text { Revisão: } 00\end{array}$ \\
\hline
\end{tabular}

- Aguardar até que a alíquota da solução padrão de $\mathrm{Fe}$ pipetada nos papéis filtro sequem em temperatura ambiente (esse processo demora entre $6 \mathrm{~h}$ e $12 \mathrm{~h}$ ).

OBS: Deve-se tomar cuidado para que o líquido pipetado não encoste na superfície da estante de bagueta e não ultrapasse a marca do recorte de $0,5 \mathrm{~cm}$. Se isso acontecer, descarte adequadamente a folha de papel filtro.

- Com o auxílio de uma pinça, retire o papél filtro - cujo padrão de trabalho foi pipetado e já esta seco - das estantes de bagueta e com uma tesoura recorte a parte inferior do mesmo na distância de $0,5 \mathrm{~cm}$. Este $0,5 \mathrm{~cm}$ corresponde a parte do papel filtro de ficou em contato com a estante de bagueta. Esta parte deve ser descartada;

- Com a auxílio de outra pinça, dobre a folha de papel filtro (cujas dimensões devem ser $2 \mathrm{~cm} \times 2 \mathrm{~cm}$ ) ao meio tanto na largura quanto no comprimento, resultado em um padrão de geometria de $1 \mathrm{~cm} \times 1 \mathrm{~cm}$ (h $\times$ c);

- Colocar o padrão de geometria $1 \mathrm{~cm} \times 1 \mathrm{~cm}(\mathrm{~h} \times \mathrm{c})$ dentro de um invólucro de polietileno previamente preparado;

- Com o auxílio de uma seladora Sela-Pak, selar a extremidade aberta do invólucro bem rente ao padrão;

- Recortar a rebarba do invólucro acima do local que foi cuja extremidade foi selada;

- Identificar o padrão e acondicionar em local seco e ao abrigo da luz solar até o momento da análise.

\subsection{Preparo das amostras}

- Em uma balança analítica deve-se colocar um invólucro de polietileno em geometria adequada vazio (o invólucro de ter três lados selados e um lado aberto);

- Realizar a tara da massa do invólucro;

- Retirar o invólucro da balança analítica com o auxílio de uma pinça;

- Pesar em balança analítica $150 \pm 10 \mathrm{mg}$ de amostra em pó dentro do invólucro de polietileno;

- Registrar o uso da balança analítica no cademo de Registro de Uso da respectiva balança analítica;

- Anotar a massa da amostra na folha do formulário de pesagem de amostras;

- Com o auxílio de uma seladora Sela-Pak, selar a extremidade aberta do invólucro de modo que a geometria final seja idêntica à do padrão sintético $(1 \mathrm{~cm} \times 1 \mathrm{~cm})$.

- Recortar a rebarba do invólucro acima do local que foi cuja extremidade foi selada;

- Identificar a amostra e acondicionar em local seco e ao abrigo da luz solar até o momento da análise.

\subsection{Irradiação}

- Limpar a parte externa de amostras e padrões sintéticos (amostras e padrões devem ter geometria espacial idênticas: $1 \mathrm{~cm} \times 1 \mathrm{~cm}$ ) com um papel embebido em álcool etílico grau P.A. e, em seguida, com outro papel embebido em água deionizada (Milli $-\mathrm{Q}$, Millipore; $18,2 \mathrm{~m} \Omega$ );

- Secar a parte externa do invólucro com papel absorvente;

- Envolver uma capa de folha de papel alumínio em cada amostra e/ou padrão sintético, de modo que esta fique semelhante a um invólucro de papel alumínio. Deve-se usar uma mínima quantidade de papel alumínio nesta etapa;

- Identificar cada amostra e/ou padrão sintético, anotando-se o código sobre o invólucro de papel alumínio;

- Dispor amostras e padrão sintético uns sobre os outros, de maneira aleatória e de modo a formar um agrupamento;

- Envolver o agrupamento formado por amostras e padrão sintético com uma nova camada de folha de papel alumínio, de modo que estes mantenham-se fixos em uma mesma posição. A esta etapa se dá o nome de preparo do sanduiche;

- Inserir o sanduiche de amostras e padrão sintético dentro do recipiente de alumínio chamado coelho;

- Identificar o coelho com o código do experimento;

- Preencher a ficha de Solicitação para Irradiação de amostras; 


\begin{tabular}{|c|c|c|}
\hline $\begin{array}{c}\text { Centro do Reator de } \\
\text { Pesquisa - CRPq, }\end{array}$ & MÉTODO BIO 2: Determinação da concentração & Página 8 de 13 \\
IPEN - CNEN/SP & matriz biológica (POP - CRPq/002) & POP - CRPq/002 \\
Revisão: 00
\end{tabular}

- Encaminhar o coelho juntamente com a ficha de Solicitação de Irradiação de amostras corretamente preenchida e assinada para o departamento de irradiação de amostras do reator nuclear.

\subsection{Abertura do coelho}

- Ligar para o departamento de Proteção Radiológica solicitando o acompanhamento de um técnico de Radioproteção para o monitoramento das atividades de abertura do coelho;

- Com o auxílio de uma pinça de cabo longo deve-se acondicionar o coelho no aparelho de abertura de coelhos;

- Realizar a abertura do coelho acionando o aparelho de abertura de coelhos;

- Com o auxílio de uma pinça de cabo longo retirar o sanduiche do interior do coelho e acondicionar no dentro de um castelo de chumbo;

- Registrar a abertura do coelho no caderno de abertura de coelhos.

\subsection{Detecção de raios gama}

- Ir até uma capela que contenha uma barreira de proteção de chumbo;

- Colocar o castelo de chumbo contendo o sanduiche no interior da capela;

- Com o auxílio de uma pinça de cabo longo, retirar o sanduíche do castelo de chumbo;

- Desmontar o sanduíche, refazendo o processo inverso ao de montagem;

- Com o auxílio de duas pinças, retirar o invólucro de alumínio de cada uma das amostras e do padrão sintético. Deve-se ter bastante atenção nesta etapa visto que o invólucro de polietileno jamais deve ser rompido, sob o risco da ocorrência de contaminação radiológica. Apenas o invólucro de alumínio deve ser removido;

- As folhas de papel alumínio equivalentes ao sanduíche e aos invólucros de papel alumínio devem ser descartadas em lixo de resíduo radioativo;

- Colocar cada uma das amostras e do padrão sintético (de maneira individual) no centro de um recipiente de alumínio chamado panelinha;

- Fixar amostras e/ou padrão sintético exatamente no centro da panelinha com a auxílio de um pedaço de fita adesiva. Esta etapa chama-se selagem das panelinha;

- Identificar as amostra e padrão sintético;

- Colocar cada panelinha devidamente selada e identificada no interior de um castelo de chumbo e transportar até a sala de contagens;

OBS: A medição da atividade do mensurando na amostra e padrão sintético deve ser realizada 21 dias após a data de irradiação e em um mesmo espectrômetro de raios gama.

- Dispor a panelinha dentro do detector de raios gama sob configuração de contagem adequada (Prateleira 0);

- Realizar a medição da atividade do mensurando no padrão sintético por um período de 1200 segundos;

- Realizar a medição da atividade do mensurando na amostra por um período de 21600 segundos;

- Imprimir o resultado com os valores de medição para cada amostra e padrão;

- Calcular a concentração do mensurando na amostra de acordo com a equação 1.

\subsection{Descarte de amostras e padrões sintéticos}

Após o processo de medição, amostras e padrão sintético devem ser descartados em lixo de resíduo radioativo.

\section{CONTROLE DE QUALIDADE}

O controle da qualidadedo procedimento é realizado por meio da análise do material de referência interno (MR) Tecido de Mexilhão TM-1 produzido pelo IPEN - CNEN/SP. A cada nova irradiação, uma alíquota de Tecido de Mexilhäo TM-1 deve ser enviada como amostra controle e o resultado obtido para a concentração de As deve ser comparada com o valor de referência do mensurando no MR que é [Co] 


\begin{tabular}{|c|c|c|}
\hline Centro do Reator de & MÉTODO BIO 2: Determinação da concentração & Página 9 de 13 \\
Pesquisa - CRPq, & de Co, Cr, Fe, Rb, Sc, Se e Zn em amostras de & POP - CRPq/002 \\
IPEN - CNEN/SP & matriz biológica (POP - CRPq/002) & Revisão: 00 \\
\hline
\end{tabular}

$0,829 \pm 0,077 \mathrm{mg} \mathrm{kg}^{-1},[\mathrm{Cr}] 1,24 \pm 0,28 \mathrm{mg} \mathrm{kg}^{-1}$, [Fe] $593 \pm 53 \mathrm{mg} \mathrm{kg}^{-1},[\mathrm{Rb}] 4,93 \pm 0,92 \mathrm{mg} \mathrm{kg}^{-1}$, [Sc] $0,199 \pm 0,023 \mathrm{mg} \mathrm{kg}^{-1}$, [Se] 4,42 $\pm 0,45 \mathrm{mg} \mathrm{kg}^{-1} \mathrm{e}$ [Zn] 118,5 $\pm 9,5 \mathrm{mg} \mathrm{kg}^{-1}$. Os resultados das amostras controle de Tecido de Mexilhão TM-1 devem ser avaliados em função do valor de En. O critério de aceitação para os resultados é $|E n| \leq 1$. Todos os resultados obtidos nas análises de amostras controle devem ser transcritos para a Planilha "Carta Controle MÉTODO BIO-2: Determinação da concentração de $\mathrm{Co}, \mathrm{Cr}, \mathrm{Fe}, \mathrm{Rb}, \mathrm{Sc}$, Se e $\mathrm{Zn}$ em amostras de matriz biológica".

Antes de cada utilização, balanças analíticas e espectrômetros de raios gama devem ter seu funcionamento verificado em função do uso de padröes específicos. Todos os resultados das verificações devem ser registrados e arquivados em formulários específicos da qualidade.

\subsection{Validaçâo do método}

O método de medição foi validado de acordo com as exigências da norma ABNT NBR ISO/IEC 17025, seguindo-se as orientações do Guia de validação de métodos INMETRO DOQ-CGCRE-008 e da Resolução RE n 899 da ANVISA que dispõe sobre a validação de métodos de medição.

\subsection{Seletividade do método, possíveis interferentes}

A elevada seletividade do método é referente à elevada seletividade da espectrometria de raios gama. Apesar disso, possiveis interferentes não podem ser excluídos.

\subsection{Linearidade e faixa de trabalho}

A espectrometria de raios gama possui ampla faixa linear $\left(0\right.$ à $\left.1 \mathrm{~kg} \mathrm{~kg}^{-1}\right)$. Contudo, anomalias na geometria entre amostras e padrão sintético, configuração da resolução do detector e tempo morto obtido durante a medição podem gerar eventos de nẩo-linearidade às medições. Amostras típicas analisadas (MR Tecido de mexilhäo TM-1, MRC Mussel tissue-NIST SRM 2976, MRC Oyster tissueNIST SRM 1566b, MRC Fish tissue-IAEA 407 e MRC Dogfish Muscle-NRCC DORM 2) apresentaram valores de tempo morto durante a medição menores que $15 \%$. Nesta condição não foram observados efeitos de não-linearidade.

A faixa de trabalho recomendada varia entre o valor de $L Q$ até o valor de maior concentração observado no estudo de linearidade. Amostras analisadas devem atender a este requisito.

\subsection{Veracidade}

A veracidade deve ser avaliada em função do resultado obtido para a amostra controle Tecido de Mexilhão TM-1 por meio do cálculo de En (2).

$$
E n=\frac{x-x_{v}}{\sqrt{U^{2}+U_{v}^{2}}}
$$

onde:

En é o valor para erro normalizado;

$x$ é o resultado da medição $\left(\mathrm{mg} \mathrm{kg}^{-1}\right)$;

$x_{v}$ é o valor de referência $\left(\mathrm{mg} \mathrm{kg}^{-1}\right)$;

$U$ é a incerteza expandida do resultado, $k=2\left(\mathrm{mg} \mathrm{kg}^{-1}\right)$;

$U_{v}$ é a incerteza expandida do valor de referência, $k=2\left(\mathrm{mg} \mathrm{kg}^{-1}\right)$.

\subsection{Critério de aceitação}

O critério de aceitação para os resultados é $|E n| \leq 1$ 


\begin{tabular}{|c|c|c|}
\hline Centro do Reator de & MÉTODO BIO 2: Determinação da concentração & Página 10 de 13 \\
Pesquisa - CRPq, & de Co, $\mathrm{Cr}, \mathrm{Fe}, \mathrm{Rb}, \mathrm{Sc}, \mathrm{Se}$ e Zn em amostras de & POP - CRPq/002 \\
IPEN - CNEN/SP & matriz biológica (POP - CRPq/002) & Revisão: 00 \\
\hline
\end{tabular}

\subsection{Precisão}

A repetitividade do método foi determinada em função da análise de 7 amostras controle de Tecido de Mexilhão TM-1. O cálculo do resultado foi realizado de acordo com (3).

$$
r=2,8 s
$$

onde:

$r$ é o valor do limite de repetitividade $\left(\mathrm{mg} \mathrm{kg}^{-1}\right)$;

$s$ é o desvio padrão obtido para $n$ medições, $n \geq 7\left(\mathrm{mg} \mathrm{kg}^{-1}\right)$.

A precisão intermediária foi determinada em função da análise de 26 amostras controle de Tecido de Mexilhão TM-1. O cálculo do resultado foi realizado de acordo com (4).

$$
P I=\sqrt{\frac{1}{(n-1)} \sum_{m=1}^{n}\left(x_{m}-\bar{x}\right)^{2}}
$$

onde:

Pl é o valor de precisão intermediária $\left(\mathrm{mg} \mathrm{kg}^{-1}\right)$;

$n$ é o número de amostras (alíquotas);

$m$ é o número do ensaio da amostra, $m=1, n$;

$x_{m}$ é o resultado obtido para o ensaio $k$;

$\bar{x}$ é a média dos resultados para $n$ medições.

A reprodutibilidade do método foi determinada de acordo com (5).

$$
R=2,8 P I
$$

onde:

$R$ é o valor do limite de reprodutibilidade $\left(\mathrm{mg} \mathrm{kg}^{-1}\right)$;

$P /$ é o valor de precisão intermediária $\left(\mathrm{mg} \mathrm{kg}^{-1}\right)$.

\subsection{Limite de deteç̧ão}

O limite de detecção (LD) foi calculado para a análise de uma amostra controle Tecido de Mexilhão $T M-1$ de acordo com (6).

$$
L D=3,29 \frac{\sqrt{b}}{t}
$$

onde:

$L_{D}$ é a taxa de contagem correspondente ao limite de detecção do método (cps);

$b$ é o número de contagens da radiação de fundo sob o pico analítico (cps);

$t$ é o tempo real de medição da amostra (s).

O resultado obtidos para $L D$ é convertido para $\mathrm{mg} \mathrm{kg}^{-1}$ utilizando a equação geral da ativação neutrônica (1).

\subsection{Limite de quantificação}

O limite de quantificação (LQ) foi calculado para a análise de uma amostra controle Tecido de Mexilhão TM-1 de acordo com (7).

$$
L Q=10 \frac{\sqrt{b}}{t}
$$

onde:

$L_{Q}$ é a taxa de contagem correspondente ao limite de quantificação do método (cps); 


\begin{tabular}{|c|c|c|}
\hline Centro do Reator de & MÉTODO BIO 2: Determinação da concentração & Página 11 de 13 \\
Pesquisa - CRPq, & de Co, Cr, Fe, Rb, Sc, Se e Zn em amostras de & POP - CRPq/002 \\
IPEN - CNEN/SP & matriz biológica (POP - CRPq/002) & Revisão: 00 \\
\hline
\end{tabular}

b é o número de contagens da radiação de fundo sob o pico analítico (cps);

$t$ é o tempo real de medição da amostra (s).

O resultado obtidos para $L Q$ é convertido para $\mathrm{mg} \mathrm{kg}^{-1}$ utilizando a equação geral da ativação neutrônica (1).

\subsection{Incerteza de medição}

A estimativa da incerteza de medição foi realizada em função do método simulado, procedimento recomendado pelo Guia para a quantificação de incertezas de medição (EURACHEM/CITAC, 2012) e descrito passo a passo por Petroni (PETRONI, 2015). Levou-se em consideração as seguintes componentes de entrada em INAA: massa da amostra, massa do padrão sintético, atividade do radionuclídeo na amostra, atividade do radionuclídeo no padrão sintético e constante de decaimento do radionuclídeo.

\subsection{Pico analítico}

O cálculo da concentração dos mensurandos na amostra deve ser realizado para a atividade verificada nos respectivos picos analíticos:

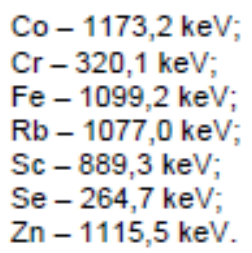

\section{CARACTERÍSTICAS DO MÉTODO DE MEDIÇÄO}

A seguir são apresentados as características correspondentes ao método de medição.

\begin{tabular}{|c|c|c|c|}
\hline \multirow{2}{*}{ Parâmetro de Validação } & \multicolumn{3}{|c|}{$\mathrm{Co}$} \\
\hline & $n$ & En & Resultado \\
\hline Limite de repetitividade & 7 & $-0,13$ & $0,037 \mathrm{mg} \mathrm{kg}^{-1}$ \\
\hline Precisão Intermediária & 28 & 0,12 & $0,045 \mathrm{mg} \mathrm{kg}^{-1}$ \\
\hline Limite de reprodutibilidade & 28 & 0,12 & $0,13 \mathrm{mg} \mathrm{kg}^{-1}$ \\
\hline Limite de detecção & 1 & $-0,27$ & $0,0083 \mathrm{mg} \mathrm{kg}^{-1}$ \\
\hline Limite de quantificação & 1 & $-0,27$ & $0,025 \mathrm{mg} \mathrm{kg}^{-1}$ \\
\hline \multirow{4}{*}{$\begin{array}{c}\text { Incerteza expandida relativa, } k=2 \\
\text { Faixa de trabalho } \\
\text { Veracidade }\end{array}$} & 5 & 0,17 & $6,1-6,2 \%$ \\
\hline & \multicolumn{3}{|c|}{$\begin{array}{c}0,025-65 \mathrm{mg} \mathrm{kg}^{-1} \\
\text { Adequada }(-1,0<E n<1,0)\end{array}$} \\
\hline & \multicolumn{3}{|c|}{$\mathrm{Cr}$} \\
\hline & $n$ & En & Resultado \\
\hline Limite de repetitividade & 7 & $-0,07$ & $0,066 \mathrm{mg} \mathrm{kg}^{-1}$ \\
\hline Precisão Intermediária & 28 & $-0,01$ & $0,14 \mathrm{mg} \mathrm{kg}^{-1}$ \\
\hline Limite de reprodutibilidade & 28 & $-0,01$ & $0,40 \mathrm{mg} \mathrm{kg}^{-1}$ \\
\hline Limite de detecção & 1 & 0,16 & $0,16 \mathrm{mg} \mathrm{kg}^{-1}$ \\
\hline Limite de quantificação & 1 & 0,16 & $0,48 \mathrm{mg} \mathrm{kg}^{-1}$ \\
\hline Incerteza expandida relativa, $k=2$ & 5 & 0,19 & $7,9-8,0 \%$ \\
\hline Faixa de trabalho & \multirow{2}{*}{\multicolumn{3}{|c|}{$\begin{array}{l}\quad 0,48-69 \mathrm{mg} \mathrm{kg}^{-1} \\
\text { Adequada }(-1,0<E n<1,0)\end{array}$}} \\
\hline Veracidade & & & \\
\hline
\end{tabular}




\begin{tabular}{|c|c|c|}
\hline Centro do Reator de & MÉTODO BIO 2: Determinação da concentração & Página 12 de 13 \\
Pesquisa - CRPq, & de Co, Cr, Fe, Rb, Sc, Se e Zn em amostras de & POP - CRPq/002 \\
IPEN - CNEN/SP & matriz biológica (POP - CRPq/002) & Revisão: 00 \\
\hline
\end{tabular}

\begin{tabular}{|c|c|c|c|}
\hline \multirow{2}{*}{ Parâmetro de validação } & \multicolumn{3}{|c|}{$\mathrm{Fe}$} \\
\hline & $n$ & $E n$ & Resultado \\
\hline Limite de repetitividade & 7 & 0,22 & $22 \mathrm{mg} \mathrm{kg}^{-1}$ \\
\hline Precisão Intermediária & 28 & 0,42 & $28 \mathrm{mg} \mathrm{kg}^{-1}$ \\
\hline Limite de reprodutibilidade & 28 & 0,42 & $78 \mathrm{mg} \mathrm{kg}^{-1}$ \\
\hline Limite de deteccão & 1 & $-0,29$ & $4.3 \mathrm{mg} \mathrm{kg}^{-1}$ \\
\hline Limite de quantificação & 1 & $-0,29$ & $20 \mathrm{mg} \mathrm{kg}^{-1}$ \\
\hline Incerteza expandida relativa, $k=2$ & 5 & $-0,14$ & $6,8-7,1 \%$ \\
\hline \multirow{4}{*}{$\begin{array}{l}\text { Faixa de trabalho } \\
\text { Veracidade }\end{array}$} & \multirow{2}{*}{\multicolumn{3}{|c|}{$\begin{array}{l}\qquad 20-79100 \mathrm{mg} \mathrm{kg}^{-1} \\
\text { Adequada }(-1,0<E n<1,0)\end{array}$}} \\
\hline & & & \\
\hline & \multicolumn{3}{|c|}{$\mathrm{Rb}$} \\
\hline & $n$ & $E n$ & Resultado \\
\hline Limite de repetitividade & 7 & 0,29 & $0,16 \mathrm{mg} \mathrm{kg}^{-1}$ \\
\hline Precisão Intermediária & 27 & $-0,37$ & $0,39 \mathrm{mg} \mathrm{kg}^{-1}$ \\
\hline Limite de reprodutibilidade & 27 & $-0,37$ & $1,1 \mathrm{mg} \mathrm{kg}^{-1}$ \\
\hline Limite de detecção & 1 & 0,14 & $0,31 \mathrm{mg} \mathrm{kg}^{-1}$ \\
\hline Limite de quantificação & 1 & 0,14 & $0,95 \mathrm{mg} \mathrm{kg}^{-1}$ \\
\hline Incerteza expandida relativa, $k=2$ & 5 & $-0,26$ & $7,1-7,4 \%$ \\
\hline \multirow{4}{*}{$\begin{array}{l}\text { Faixa de trabalho } \\
\text { Veracidade }\end{array}$} & \multirow{2}{*}{\multicolumn{3}{|c|}{$\begin{array}{l}\quad 0,95-256 \mathrm{mg} \mathrm{kg}^{-1} \\
\text { Adequada }(-1,0<E n<1,0)\end{array}$}} \\
\hline & & & \\
\hline & \multicolumn{3}{|c|}{$\mathrm{Sc}$} \\
\hline & $n$ & En & Resultado \\
\hline Limite de repetitividade & 7 & $-0,09$ & $0,0061 \mathrm{mg} \mathrm{kg}^{-1}$ \\
\hline Precisão Intermediária & 28 & $-0,11$ & $0,0078 \mathrm{mg} \mathrm{kg}^{-1}$ \\
\hline Limite de reprodutibilidade & 28 & $-0,11$ & $0,022 \mathrm{mg} \mathrm{kg}^{-1}$ \\
\hline Limite de detecção & 1 & 0,17 & $0,0092 \mathrm{mg} \mathrm{kg}^{-1}$ \\
\hline Limite de quantificação & 1 & 0,17 & $0,028 \mathrm{mg} \mathrm{kg}^{-1}$ \\
\hline Incerteza expandida relativa, $k=2$ & 5 & 0,06 & $5,3-5,9 \%$ \\
\hline \multirow{4}{*}{$\begin{array}{l}\text { Faixa de trabalho } \\
\text { Veracidade }\end{array}$} & \multirow{2}{*}{\multicolumn{3}{|c|}{$\begin{array}{c}0,028-26 \mathrm{mg} \mathrm{kg}^{-1} \\
\text { Adequada }(-1,0<E n<1,0)\end{array}$}} \\
\hline & & & \\
\hline & \multicolumn{3}{|c|}{$\mathrm{Se}$} \\
\hline & $n$ & $E n$ & Resultado \\
\hline Limite de repetitividade & 7 & $-0,09$ & $0,12 \mathrm{mg} \mathrm{kg}^{-1}$ \\
\hline Precisão Intermediária & 28 & 0,05 & $0,26 \mathrm{mg} \mathrm{kg}^{-1}$ \\
\hline Limite de reprodutibilidade & 28 & 0,05 & $0,73 \mathrm{mg} \mathrm{kg}^{-1}$ \\
\hline Limite de detecção & 1 & 0,02 & $0,18 \mathrm{mg} \mathrm{kg}^{-1}$ \\
\hline Limite de quantificação & 1 & 0,02 & $0,56 \mathrm{mg} \mathrm{kg}^{-1}$ \\
\hline Incerteza expandida relativa, $k=2$ & 5 & $-0,13$ & $8,5-9,0 \%$ \\
\hline \multirow{4}{*}{$\begin{array}{l}\text { Faixa de trabalho } \\
\text { Veracidade }\end{array}$} & \multirow{2}{*}{\multicolumn{3}{|c|}{$\begin{array}{c}\quad 0,56-64 \mathrm{mg} \mathrm{kg}^{-1} \\
\text { Adequada }(-1,0<E n<1,0)\end{array}$}} \\
\hline & & & \\
\hline & \multicolumn{3}{|c|}{ Zn } \\
\hline & $n$ & En & Resultado \\
\hline Limite de repetitividade & 7 & $-0,03$ & $4,0 \mathrm{mg} \mathrm{kg}^{-1}$ \\
\hline Precisão Intermediária & 27 & $-0,03$ & $5,4 \mathrm{mg} \mathrm{kg}^{-1}$ \\
\hline Limite de reprodutibilidade & 27 & $-0,03$ & $15 \mathrm{mg} \mathrm{kg}^{-1}$ \\
\hline Limite de detecção & 1 & 0,25 & $0,36 \mathrm{mg} \mathrm{kg}^{-1}$ \\
\hline Limite de quantificação & 1 & 0,25 & $1,1 \mathrm{mg} \mathrm{kg}^{-1}$ \\
\hline Incerteza expandida relativa, $k=2$ & 5 & 0,18 & $7,9-8,5 \%$ \\
\hline Faixa de trabalho & & $1,1-14$ & $g^{-1}, 0<0<0$ \\
\hline Veracidade & & equada (- & $\eta<1,0)$ \\
\hline
\end{tabular}

\section{REFERÊNCIAS}

ALFASSI, Z. B. Activation Analysis. CRC Press. Florida, 1990 


\begin{tabular}{|c|c|c|}
\hline Centro do Reator de & MÉTODO BIO 2: Determinação da concentração & Página 13 de 13 \\
Pesquisa - CRPq, & de Co, Cr, Fe, Rb, Sc, Se e Zn em amostras de & POP - CRPq/002 \\
IPEN - CNEN/SP & matriz biológica (POP - CRPq/002) & Revisão: 00 \\
\hline
\end{tabular}

BODE, P.; FERNANDES, E.A.N.; GREENBERG, R.R. Metrology for chemical measurements and the position of INAA. Journal of Radioanalytical and Nuclear Chemistry. 245:109-114, 2000

GREENBERG, R. R.; BODE, P.; FERNANDES, E. A. N. Neutron activation analysis: A primary method of measurement. Spectrochimica Acta Part B. 66:193-241, 2011

HAMIDATOU, L.; SLAMENE, H.; AKHAL, T.; ZOURANEN, B. Concepts, instrumentation and techniques of Neutron Activation Analysis. In: KHARFY, F. Imaging and Radioanalytical Techniques in Interdisciplinary Research - Fundamentals and Cutting Edge Applications. InTech, p. 141-177, 2013 Disponivel em: <http://www.intechopen.com/books/imaging-and-radioanalytical-techniques-ininterdisciplinary-research-fundamentals-and-cutting-edge-applications> Acesso em 18 novembro, 2014

PETRONI, R. Validação dos métodos de Análise por Ativação do Laboratório de Análise por Ativação do IPEN - CNEN/SP visando a produção de materiais de referência certificados. Dissertação de Mestrado. Universidade de São Paulo, 2015

\begin{tabular}{|c|c|c|c|}
\hline & Nome & Assinatura & Data \\
\hline Elaborado por: & & & 11 \\
\hline Aprovado por: & & & 11 \\
\hline Implantado por: & & & 1 \\
\hline \multicolumn{4}{|l|}{ Substitui POP: } \\
\hline Revisado por: & & & 1 \\
\hline \multicolumn{4}{|l|}{ Revisado por: } \\
\hline Revisado por: & & & 1 \\
\hline Desativado por: & & & $=1$ \\
\hline Razão: & & & \\
\hline
\end{tabular}

\begin{tabular}{|lll|}
\hline & Número & Destino \\
\hline Cópias & & \\
\hline
\end{tabular}




\begin{tabular}{|c|c|c|}
\hline Centro do Reator de & MÉTODO GEO 1: Determinação da & Página 1 de 12 \\
Pesquisa - CRPq, & concentração de As e Sb em amostras de & POP - CRPq/101 \\
IPEN - CNEN/SP & matriz biológica (POP - CRPq/101) & Revisão: 00 \\
\hline
\end{tabular}

\title{
MÉTODO GEO 1: Determinação da concentração de As e Sb em amostras de matriz geológica
}

\begin{abstract}
1. INTRODUÇÄO
O método de Análise por Ativação com Nêutrons (NAA) se baseia na produção e posterior identificação de radionuclídeos artificiais a partir de elementos naturalmente estáveis. Esse processo ocorre por meio do bombardeamento com nêutrons no material a ser analisado (amostra), resultando em reações nucleares características para cada elemento. Em NAA, o produto da reação nuclear que é medido é a emissão de raios gama provenientes do decaimento radioativo dos radionuclídeos formados durante 0 processo de bombardeamento com nêutrons (BODE et al., 2000).
\end{abstract}

Em NAA, amostras e padrões são irradiados sob um fluxo de nêutrons térmicos provenientes de um reator nuclear. A sequência de eventos que ocorrem numa reação nuclear típica se inicia quando um nêutron interage com um núcleo alvo por meio de uma colisão inelástica, formando um núcleo composto num estado excitado. A energia de excitação do núcleo composto é devida à energia de ligação do nêutron com o núcleo. $O$ núcleo composto formado quase que instantaneamente adquire uma configuração mais estável por meio da emissão de raios gama prontos, do inglês, prompt gamma rays. Em muitos casos, esta nova configuração do núcleo no estado passa por outras vias de decaimento por emissão de raios gama retardados, do inglês, delayed gamma rays (ALFASSI, 1990).

O sistema de deteç̧ão de raios gama é constituido basicamente por um detector semicondutor de germânio hiperpuro (HPGe) associado ao analisador de multi canal (MCA) e a um computador responsável pela análise dos dados obtidos durante o processo de medição, integração da área dos picos analíticos e geração do espectro com os resultados da medição dos raios gama. Esse sistema qualifica a técnica como bastante seletiva devido as característicvas do processo de deteç̧ão de raios gama.

NAA é uma técnica multielementar capaz de detectar e quantificar dezenas de elementos em uma única rodada de experimentos é independente de efeitos de matriz e é considerada uma técnica não destrutiva, uma vez que não requer processos de digestão das amostras, fato que contribui para a diminuição do risco de contaminação. Apresenta-se ainda uma técnica muito competitiva para a determinação do teor de elementos traço em matrizes ambientais, apresentando elevado nível de exatidão para a medição de muitos elementos (GREENBERG et al., 2011).

Outra grande vantagem da técnica está no fato da não obrigatoriedade de se analisar o branco analítico, pois não há utilização de reagentes para digestão da amostra, processos de extração ou separação de elementos. Por esse motivo, faz-se seguro afirmar que não há possibilidade de introdução de contaminantes após a irradiação nas amostras, exceto por contaminação de outro material radioativo (HAMIDATOU et al., 2013).

\section{APLICAÇÄO DO MÉTODO}

Este documento descreve o método para determinação da concentração total de As em amostras de matriz biológica por meio da técnica de Análise por Ativação com Nêutrons.

\section{REFERÊNCIAS NORMATIVAS}

ABNT, ASSOCIAÇÃO BRASILEIRA DE NORMAS TÉCNICAS. Sistemas de Gestão da Qualidade Fundamentos e vocabulário. Rio de Janeiro: ABNT, 2005 (ABNT NBR ISO 9000)

ABNT, ASSOCIAÇÃO BRASILEIRA DE NORMAS TÉCNICAS. Requisitos gerais para a competência de laboratórios de ensaio e calibração. 2 ed. corrigida, Rio de Janeiro: ABNT, 2006 (ABNT NBR ISO/IEC 17025:2005) 


\begin{tabular}{|c|c|c|}
\hline $\begin{array}{c}\text { Centro do Reator de } \\
\text { Pesquisa - CRPq, } \\
\text { IPEN - CNEN/SP }\end{array}$ & MÉTODO GEO 1: Determinação da & Página 2 de 12 \\
concentração de As e Sb em amostras de & POP - CRPq/101 \\
Revisão: 00
\end{tabular}

ABNT, ASSOCIAÇÃO BRASILEIRA DE NORMAS TÉCNICAS. Sistemas de Gestão da Qualidade Requisitos. 2 ed. corrigida, Rio de Janeiro: ABNT, 2009 (ABNT NBR ISO 9001)

ABNT, ASSOCIAÇÃO BRASILEIRA DE NORMAS TÉCNICAS. Gestão para o sucesso sustentado de uma organização - Uma abordagem da gestâo da qualidade. 2 ed. corrigida Rio de Janeiro: ABNT, 2010 (ABNT NBR ISO 9004)

ANVISA, AGÊNCIA NACIONAL DE VIGILÂNCIA SANITÁRIA. Guia Para Qualidade em Química Analítica - Uma Assistência de Acreditação. $1^{20}$ ed. Brasília, 2004

BRASIL. Resolução RE $n^{\circ} 899$, de 29 de maio de 2003. ANVISA, AGÊNCIA NACIONAL DE VIGILÂNCIA SANITÁRIA, 2003. Disponivel em:

<http://portal.anvisa.gov.br/wps/wcm/connect/4983b0004745975da005f43fbc4c6735/RE_899_2003_Det ermina+a+publica\%C3\%A7\%C3\%A30+do+Guia+para+valida\%C3\%A7\%C3\%A30+de+m\%C3\%A9todos +anal\%C3\%ADticos+e+bioanal\%C3\%ADticos.pdf?MOD=AJPERES> Acesso em 18 junho, 2015

CURRIE, L. A. Nomenclature in evaluation of analytical methods including detection and quantification capabilities (IUPAC Recommendations 1995). Analytical Chimic Acta, 391:105-126, 1999

EURACHEM. The fitness for purpose of analytical methods. A laboratory guide to method validation and related topics, 1998. Disponivel em:

<http://www.eurachem.org/images/stories/Guides/pdf/valid.pdf> Acesso em: 18 junho, 2015

EURACHEM/CITAC. Quantifying uncertainty in analytical measurement. EURACHEM/CITAC Guide CG 4, 2012. Disponivel em: <http//www.citac.cc/QUAM2012_P1.pdf> Acesso em: 18 junho, 2015 (QUAM:2012)

IAEA. International atomic Energy Agency. Use of research reactors for neutron activation analysis. Vienna, 2001 Disponivel em : <http://www-pub.iaea.org/MTCD/publications/PDF/te_1215_pm.pdf> Acesso em 18 junho, 2015 (IAEA-TECDOC 1215)

IAEA. International atomic Energy Agency. Uncertainty evaluation in instrumental and radiochemical neutron activation analysis. Vienna, 2004 Disponivel em <http://www-pub.iaea.org/MTCD/publications/PDF/te_1401_web.pdfs Acesso em 18 junho, 2015 (IAEA-TECDOC1401)

INMETRO, INSTITUTO NACIONAL DE METROLOGIA, QUALIDADE E TECNOLOGIA. Orientação sobre validação de métodos analíticos. Rio de Janeiro, Fev. 2010. Disponível em: <http://www.inmetro.gov.br/Sidoq/Arquivos/CGCRE/DOQ/DOQ-CGCRE-8_03.pdf>, Acesso em: 18 junho, 2015 (DOQ-CGCRE-008)

INMETRO, INSTITUTO NACIONAL DE METROLOGIA, QUALIDADE E TECNOLOGIA. Vocabulário Internacional de Metrologia: conceitos fundamentais e gerais e termos associados. 1ed Lusobrasileira, Rio de Janeiro: INMETRO, 2012. Disponivel em:

<http://www.inmetro.gov.br/inovacao/publicacoes/vim_2012.pdf>, Acesso em: 18 junho, 2015 (VIM)

INMETRO, INSTITUTO NACIONAL DE METROLOGIA, QUALIDADE E TECNOLOGIA. Guia para a expressão da incerteza de medição. 1ed Luso-brasileira. Rio de Janeiro: INMETRO, 2012. (ISO GUM)

ISO, INTERNATIONAL ORGANIZATION OF STANDADIZATION. Accuracy (trueness and precision) of measurement methods and results -- Part 1: General principles and definitions. Geneva, 2012 


\begin{tabular}{|l|c|c|}
\hline Centro do Reator de & MÉTODO GEO 1: Determinação da & Página 3 de 12 \\
Pesquisa - CRPq, & concentração de As e Sb em amostras de & POP - CRPq/101 \\
IPEN - CNEN/SP & matriz biológica (POP - CRPq/101) & Revisão: 00 \\
\hline
\end{tabular}

ISO, INTERNATIONAL ORGANIZATION OF STANDADIZATION. Accuracy (trueness and precision) of measurement methods and results- Part 3: Intermediate measures of the precision of a standard measurement method. Geneva, 2013

ISO, INTERNATIONAL ORGANIZATION OF STANDADIZATION. Accuracy (trueness and precision) of measurement methods and results - Practical guidance for the use of ISO 5725:1994 in designing, implementing and statistically analysing interlaboratory repeatability and reproducibility results. Geneva, 2005

\section{SIMBOLOS, SIGLAS E ABREVIAÇÕES}

ABNT : Associação Brasileira de Normas Técnicas ANVISA : Agência Nacional de Vigilância Sanitária

$A_{\mathrm{a}}$ : atividade do radionuclídeo na amostra (cps)

$c$ : comprimento do padrão sintético

$A_{p}$ : atividade do radionuclídeo no padrão sintético para tempo de decaimento tp (cps)

$b$ : número de contagens da radiação de fundo sob o pico analítico (cps)

$C$ : concentração do mensurando na amostra $\left(\mathrm{mg} \mathrm{kg}^{-1}\right)$

$C R P q$ : Centro do Reator de Pesquisa

$D P$ : desvio padrão para a média de $n$ medições $\left(\mathrm{mg} \mathrm{kg}^{-1}\right)$

En : erro normalizado

GUM : Guia para expressão da incerteza de medição

$h$ : altura do padrão sintético

$\mathrm{HPGe}$ : Espectrômetro de raios gama com detector de germânio hiperpuro (HPGe)

IAEA : Agência Internacional de Energia Atômica

INMETRO : Instituto Nacional de Metrologia: Qualidade e Tecnologia

IPEN - CNEN/SP : Instituto de Pesquisas Energéticas e Nucleares

ISO : Organização Internacional para a Padronização

$k$ : fator de abrangência da incerteza de medição; $k=2 ; a=0,05$

$L D$ : limite de detecção $\left(\mathrm{mg} \mathrm{kg}^{-1}\right)$

$L Q$ : limite de quantificação $\left(\mathrm{mg} \mathrm{kg}^{-1}\right)$

$m$ : número do ensaio da amostra, $m=1, n$

$M_{\mathrm{a}}$ : massa da amostra $(\mathrm{kg})$

$m_{p}$ : massa do mensurando no padrão sintético $(\mathrm{mg})$

$M R$ : material de referência

$M R C$ : material de referência certificado

$n$ : número de medições

NAA : Análise por Ativação com Nêutrons Instrumental

NIST : National Institute of Standards and Technology; Intituto Nacional de Padrões e Tecnologia (EUA)

NRCC : National Research Council Canada; Conselho Nacional de Pesquisa do Canadá

$P I$ : precisão intermediária $\left(\mathrm{mg} \mathrm{kg}^{-1}\right)$

QUAM : Guia para a Quantificação da Incerteza nas medições analíticas

$r$ : limite de repetitividade $\left(\mathrm{mg} \mathrm{kg}^{-1}\right)$

$R$ : limite de reprodutibilidade $\left(\mathrm{mg} \mathrm{kg}^{-1}\right)$

$t$ : tempo real de medição da amostra (s)

$t_{\text {đa }}$ : tempo de decaimento do radionuclídeo para medição da amostra (s)

$t_{a p}$ : tempo de decaimento do radionuclídeo para medição do padrão (s)

$t_{1 / 2}$ : tempo de meia vida para a atividade do radionuclídeo

$U$ : incerteza expandida do resultado, $k=2\left(\mathrm{mg} \mathrm{kg}^{-1}\right)$

$U_{v}$ : incerteza expandida do valor de referência, $k=2\left(\mathrm{mg} \mathrm{kg}^{-1}\right)$

VIM : Vocabulário Internacional de Metrologia

$x$ : resultado da medição $\left(\mathrm{mg} \mathrm{kg}^{-1}\right)$

$\bar{x}$ : média dos resultados para $n$ medições

$x_{m}$ : resultado obtido para o ensaio $m$

$x_{\mathrm{v}}$ : valor de referência do MR ou MRC $\left(\mathrm{mg} \mathrm{kg}^{-1}\right)$

$\alpha$ : nivel de significância estatística; $\alpha=0,05 ; 95 \%$ de confiança estatística

$\lambda$ : constante de decaimento do radionuclídeo $\left(\mathrm{s}^{-1}\right)$ 


\begin{tabular}{|c|c|c|}
\hline Centro do Reator de & MÉTODO GEO 1: Determinação da & Página 4 de 12 \\
$\begin{array}{c}\text { Pesquisa - CRPq, } \\
\text { IPEN - CNEN/SP }\end{array}$ & concentração de As e Sb em amostras de & POP - CRPq/101 \\
matriz biológica (POP - CRPq/101) & Revisão: 00 \\
\hline
\end{tabular}

\section{RESPONSABILIDADES}

É de responsabilidade do analista seguir o procedimento e estabelecer práticas que garantam a segurança e saúde. É obrigação da gerência do $\mathrm{CRPq}$ fornecer o uso de equipamentos de monitoramento para o controle da radioatividade ao que $o$ analista estará exposto, bem como qualquer outro equipamento de proteção individual que se faça necessário para o cumprimento das leis e acordos para a manutenção da segurança quanto a contaminação química, biológica e radioativa. É responsabilidade do analista solicitar à gerência do CRPq a compra dos equipamentos de proteção individual que eventualmente não encontram-se disponiveis e utilizá-los de forma correta e segura. Qualquer acidente que envolva material radioativo deverá ser imediatamente informado ao Serviço de Proteção Radiológica. Ainda, é de responsabilidade do analista fazer a verificação de todos os equipamentos utilizados bem como o registro de uso dos mesmos.

\section{PRINCÍPIO DO MÉTODO}

O método NAA consiste na irradiação da amostra e do padrão sintético (no qual a concentração do mensurando é conhecida) de maneira simultânea, em um mesmo período de tempo, geometria de espaço e de fluxo de nêutrons. Após o período de decaimento apropriado, realiza-se a medição do espectro de raios gama na amostra e no padrão sintético numa mesma configuração de deteç̧ão e em um mesmo aparelho detector. A determinação da concentração do mensurando na amostra é calculada por meio da comparação da área dos picos (atividade) obtidos para amostra e padrão sintético. A equação fundamental para o cálculo da concentração de um mensurando em NAA é apresentada a seguir (1).

$$
C_{a}=\frac{m_{p} A_{a} e^{-\lambda(t a-t p)}}{A_{p} M_{a}}
$$

onde:

$C$ é a concentração do mensurando na amostra $\left(\mathrm{mg} \mathrm{kg}^{-1}\right)$;

$m_{\rho}$ é a massa do mensurando no padrão $(\mathrm{mg})$;

$A_{a}$ é a atividade do radionuclídeo na amostra (cps);

$\lambda$ é a constante de decaimento do radionuclídeo $\left(\mathrm{s}^{-1}\right)$;

$t_{\text {da }}$ é o tempo de decaimento do radionuclídeo até o momento início da medição da amostra (s);

$t_{a p}$ é o tempo de decaimento do radionuclídeo até o início da medição do padrão (s);

$M_{a}$ é a massa da amostra $(\mathrm{kg})$;

$A_{p}$ é a atividade do radionuclídeo no padrão sintético para tempo de decaimento tp (cps).

\section{EQUIPAMENTOS, VIDRARIA E REAGENTES}

\subsection{Equipamentos e vidrarias}

Estufa

Reator nuclear

Espectrômetro de raios gama com detector de germânio hiperpuro (HPGe)

Balança analítica

Máquina seladorado Sela-Pak

Aparelho deionizador de água (Mili - Q, Millipore; 18,2 m 2 )

Micropipeta $(20-100 \mu \mathrm{L})$

Micropipeta (100 - $1000 \mu \mathrm{L})$

Micropipeta (1000 - $5000 \mu \mathrm{L})$

Ponteira para micropipetas

Balão volumétrico calibrado de $10 \mathrm{~mL}$

Béquer de $10 \mathrm{~mL}$ 


\begin{tabular}{|c|c|c|}
\hline Centro do Reator de & MÉTODO GEO 1: Determinação da & Página 5 de 12 \\
Pesquisa - CRPq, & concentração de As e Sb em amostras de & POP - CRPq/101 \\
IPEN - CNEN/SP & matriz biológica (POP - CRPq/101) & Revisão: 00 \\
\hline
\end{tabular}

Folha de polietileno

Folha de papel filtro quantitativo

Folha de papel alumínio

Folha de papel absorvente

Baguetas de vidro

Recipiente de alumínio (coelho)

Recipiente de alumínio (panelinha)

Pinças de cabo longo

Castelo de chumbo

\subsection{Reagentes}

Ácido nítrico (10\%)

Solução padrão de As $1000 \mathrm{mg} \mathrm{L}^{-1}$

Solução padrão de Sb $1000 \mathrm{mg} \mathrm{L}^{-1}$

\section{PROCEDIMENTO}

\subsection{Lavagem e descontaminação das vidrarias}

- Com o auxílio de um sepilho, lavar a vidraria com sabão neutro comercial (Extran $3 \%$ );

- Enxaguar três vezes com água destilada;

- Preparar uma solução de $\mathrm{HNO}_{3}(10 \%)$;

- Acondicionar a solução em um recipiente de plástico com tampa dentro de uma capela;

- Dispor a vidraria previamente lavada no recipiente plástico com a solução de $\mathrm{HNO}_{3}(10 \%)$. Essa etapa é conhecida com banho ácido;

- Aguardar por 24 horas;

- Retirar a vidraria do banho ácido, enxaguar três vezes com água destilada e três vezes com água deionizada (Mili $-Q$, Millipore; $18,2 \mathrm{~m} \Omega$ );

- Aguardar a secagem da vidraria sob temperatura ambiente;

- Guardar a vidraria em local adequado.

\subsection{Solução de $\mathrm{HNO} 3(10 \%)$ ** Procedimento dentro de capela **}

- Adicionar cerca de 1 litro de água destilada em um balão volumétrico de 2 litros;

- Dispor $200 \mathrm{~mL}$ de $\mathrm{HNO}_{3}$ concentrado em um béquer de $500 \mathrm{~mL}$ ( $\mathrm{HNO}_{3}$ concentrado é corrosivo e nocivo à saúde. Nunca realize o procedimento fora da capela);

- Com o auxílio de uma bagueta, transferir de maneira lenta e cuidadosa os $200 \mathrm{~mL}$ de $\mathrm{HNO}_{3}$ concentrado para o balão volumétrico de 2 litros (Faça de maneira devagar. Reação exotérmica);

- Completar o volume do balão volumétrico com aguá destilada até o menisco;

- Tampar o balão volumétrico e homogeneizar a solução preparada;

- Transferir a solução para um frasco âmbar, identificar a solução e armazenar em local seguro, ventilado e ao abrigo da luz solar.

\subsection{Lavagem e confecção dos invólucros de polietileno}

- As folhas de polietileno utilizadas para o preparo dos invólucros para amostras e padrões sintéticos devem ser previamente lavadas em solução de $\mathrm{HNO}_{3} 10 \%$ (v/v) por um período de 48 horas, enxaguadas com $\mathrm{H}_{2} \mathrm{O}$ destilada e deionizada (Milli-Q, Millipore; $18,2 \mathrm{~m} \Omega$ ) e secas em temperatura ambiente em capela de fluxo laminar;

- Os invólucros devem ser confeccionados em geometria retangular de $1,0 \mathrm{~cm}$ de largura por $1,5 \mathrm{~cm}$ de comprimento selado em todas as extremidades com o auxílio de uma máquina seladora. Os invólucros foram armazenados em frasco devidamente identificado e mantidos ao abrigo da luz solar $e$ emtemperatura ambiente até o momento de sua utilização. 


\begin{tabular}{|c|c|c|}
\hline $\begin{array}{c}\text { Centro do Reator de } \\
\text { Pesquisa - CRPq, }\end{array}$ & MÉTODO GEO 1: Determinação da & Página 6 de 12 \\
IPEN - CNEN/SP & concentração de As e Sb em amostras de & POP - CRPq/101 \\
matriz biológica (POP - CRPq/101) & Revisão: 00 \\
\hline
\end{tabular}

\subsection{Confecção das estantes e papéis filtro}

- Para a confeç̧ão das estantes se deve-se fixar duas baguetas de vidro com o auxílio de dois pedaços de fita adesiva (um pedaço em cada extremidade), de modo que permaneçam fixas e encostadas uma na outra.

- Para a confecção dos papéis filtro à serem utilizados no preparo dos padrões sintéticos, deve-se pegar uma ou mais folhas de papel filtro quantitativo e recortar de acordo com a seguinte dimensão: 2 $\mathrm{cm} \times 2,5 \mathrm{~cm}$ (h $\times$ c). Ao lado cujo comprimento é $2,5 \mathrm{~cm}$ deve-se fazer um pequeno recorte com a tesoura que servirá como marcação, medindo-se a partir da ponta em $0,5 \mathrm{~cm}$. Posteriormente, esta marcação irá indicar a parte que deverá ser descartada após o processo de pipetagem da solução de trabalho.

\subsection{Preparo dos padróes sintéticos}

- Ao balão volumétrico de $10 \mathrm{~mL}$ (calibrado) adicionar aproximadamente $5 \mathrm{~mL}$ de água deionizada (Milli-Q, Millipore; $18,2 \mathrm{~m} \Omega$ );

- Pipetar exatamente $1000 \mu \mathrm{L}$ de solução padrão de $\mathrm{As}\left(1000 \mathrm{mg} \mathrm{L}^{-1}\right)$ e $500 \mu \mathrm{L}$ de solução padrão de $\mathrm{Sb}\left(1000 \mathrm{mg} \mathrm{L}^{-1}\right)$ dentro do balão volumétrico de $10 \mathrm{~mL}$.

OBS: Deve-se manter a micropipeta na posição vertical durante todo o processo de pipetagem da solução padrão. No momento do despejo da solução pipetada dentro do balão volumétrico é importante que a ponteira da micropipeta esteja encostada na parede no balão volumétrico em uma posição abaixo da linha do menisco. Para isso, o balão volumétrico deve ser posicionado em uma posição ligeiramente inclinada, de modo que se faça um ângulo diferente de $90^{\circ}$ entre a ponteira da micropipeta e a parede do balão volumétrico. O êmbolo da micropipeta nunca deve ser pressionado até o fim durante o processo de pipetagem, mas somente até a posição correspondente a trava (a solução padrão deve estar em temperatura ambiente).

- Completar o volume do balão volumétrico com água deionizada (Milli $-\mathrm{Q}$, Millipore; $18,2 \mathrm{~m} \Omega$ ) até o menisco;

- Com um pedaço de papel absorvente, secar cuidadosamente a parte acima do menisco do balão volumétrico de modo à remover gotículas de água que estejam ali adsorvidas. Em hipótese alguma o papel adsorvente pode tocar na solução que está no limite do menisco. Se isso ocorrer, descarte apropriadamente a solução e reinicie novamente o procedimento;

- Tampar o balão volumétrico e homogeneizar a solução preparada (solução de trabalho);

- Aguardar cerca de 30 minutos antes de continuar o procedimento;

- Dispor os papéis filtro recortados em geometria adequada na estante preparada com as baguetas, de modo que estes não fiquem encostados uns aos outros. A extremidade do papel filtro que conter a marcação de $0,5 \mathrm{~cm}$ deverá ser inserido no espaço que existe entre as duas baguetas. Os papéis filtro devem permanecer em posição vertical durante todo o processo de pipetagem e secagem (os processos a seguir devem ser realizados no interior de uma capela);

- Transferir uma alíquota da solução preparada para um béquer de $10 \mathrm{~mL}$ previamente limpo e seco;

- Pipetar exatamente $25 \mu \mathrm{L}$ da solução de trabalho sobre cada um dos papéis filtro dispostos nas estantes de bagueta. Deve-se tomar cuidado para que o líquido pipetado não encoste na superfície da estante de bagueta e não ultrapasse a marca do recorte de $0,5 \mathrm{~cm}$. Se isso acontecer, descarte adequadamente a folha de papel filtro;

- Aguardar até que a alíquota da solução de trabalho pipetada nos papéis filtro sequem em temperatura ambiente (esse processo demora entre $6 \mathrm{~h}$ e $12 \mathrm{~h}$ );

- Com o auxílio de uma pinça, retire o papél filtro - cujo padrão de trabalho foi pipetado e já esta seco - das estantes de bagueta e com uma tesoura recorte a parte inferior do mesmo na distância de $0,5 \mathrm{~cm}$. Este $0,5 \mathrm{~cm}$ corresponde a parte do papel filtro de ficou em contato com a estante de bagueta. Esta parte deve ser descartada;

- Com a auxílio de outra pinça, dobre a folha de papel filtro (cujas dimensões devem $s e r 2 \mathrm{~cm} \times 2 \mathrm{~cm}$ ) ao meio tanto na largura quanto no comprimento, resultado em um padrão de geometria de $1 \mathrm{~cm} \times 1 \mathrm{~cm}$ $(\mathrm{h} \times \mathrm{c})$; 


\begin{tabular}{|c|c|c|}
\hline Centro do Reator de & MÉTODO GEO 1: Determinação da & Página 7 de 12 \\
Pesquisa - CRPq, & concentração de As e Sb em amostras de & POP - CRPq/101 \\
IPEN - CNEN/SP & matriz biológica (POP - CRPq/101) & Revisão: 00 \\
\hline
\end{tabular}

- Colocar o padrão de geometria $1 \mathrm{~cm} \times 1 \mathrm{~cm}(\mathrm{~h} \times \mathrm{c}$ ) dentro de um invólucro de polietileno previamente preparado;

- Com o auxílio de uma seladora Sela-Pak, selar a extremidade aberta do invólucro bem rente ao padrão;

- Recortar a rebarba do invólucro acima do local que foi cuja extremidade foi selada;

- Identificar o padrão e acondicionar em local seco e ao abrigo da luz solar até o momento da análise.

\subsection{Preparo das amostras}

- Em uma balança analítica deve-se colocar um invólucro de polietileno em geometria adequada vazio

(o invólucro de ter três lados selados e um lado aberto);

- Realizar a tara da massa do invólucro;

- Retirar o invólucro da balança analítica com o auxílio de uma pinça;

- Pesar em balança analítica $150 \pm 10 \mathrm{mg}$ de amostra em pó dentro do invólucro de polietileno;

- Registrar o uso da balança analítica no cademo de Registro de Uso da respectiva balança analítica;

- Anotar a massa da amostra na folha do formulário de pesagem de amostras;

- Com o auxílio de uma seladora Sela-Pak, selar a extremidade aberta do invólucro de modo que a geometria final seja idêntica à do padrão sintético $(1 \mathrm{~cm} \times 1 \mathrm{~cm})$.

- Recortar a rebarba do invólucro acima do local que foi cuja extremidade foi selada;

- Identificar a amostra e acondicionar em local seco e ao abrigo da luz solar até o momento da análise.

\subsection{Irradiação}

- Limpar a parte externa de amostras e padrões sintéticos (amostras e padrões devem ter geometria espacial idênticas: $1 \mathrm{~cm} \times 1 \mathrm{~cm}$ ) com um papel embebido em álcool etílico grau P.A. e, em seguida, com outro papel embebido em água deionizada (Milli $-\mathrm{Q}$, Millipore; $18,2 \mathrm{~m} \Omega$ );

- Secar a parte externa do invólucro com papel absorvente;

- Envolver uma capa de folha de papel alumínio em cada amostra e/ou padrão sintético, de modo que esta fique semelhante a um invólucro de papel alumínio. Deve-se usar uma mínima quantidade de papel alumínio nesta etapa;

- Identificar cada amostra e/ou padrão sintético, anotando-se o código sobre o invólucro de papel alumínio;

- Dispor amostras e padrão sintético uns sobre os outros, de maneira aleatória e de modo a formar um agrupamento;

- Envolver o agrupamento formado por amostras e padrão sintético com uma nova camada de folha de papel alumínio, de modo que estes mantenham-se fixos em uma mesma posição. A esta etapa se dá o nome de preparo do sanduiche;

- Inserir o sanduiche de amostras e padrão sintético dentro do recipiente de alumínio chamado coelho;

- Identificar o coelho com o código do experimento;

- Preencher a ficha de Solicitação para Irradiação de amostras;

- Encaminhar o coelho juntamente com a ficha de Solicitação de Irradiação de amostras corretamente preenchida e assinada para o departamento de irradiação de amostras do reator nuclear.

\subsection{Abertura do coe/ho}

- Ligar para o departamento de Proteção Radiológica solicitando o acompanhamento de um técnico de Radioproteção para o monitoramento das atividades de abertura do coelho;

- Com o auxílio de uma pinça de cabo longo deve-se acondicionar o coelho no aparelho de abertura de coelhos;

- Realizar a abertura do coelho acionando o aparelho de abertura de coelhos;

- Com o auxílio de uma pinça de cabo longo retirar o sanduiche do interior do coelho e acondicionar no dentro de um castelo de chumbo;

- Registrar a abertura do coelho no caderno de abertura de coelhos. 


\begin{tabular}{|c|c|c|}
\hline Centro do Reator de & MÉTODO GEO 1: Determinação da & Página 8 de 12 \\
Pesquisa - CRPq, & concentração de As e Sb em amostras de & POP - CRPq/101 \\
IPEN - CNEN/SP & matriz biológica (POP - CRPq/101) & Revisão: 00 \\
\hline
\end{tabular}

\subsection{Detecção de raios gama}

- Ir até uma capela que contenha uma barreira de proteção de chumbo;

- Colocar o castelo de chumbo contendo o sanduíche no interior da capela;

- Com o auxílio de uma pinça de cabo longo, retirar o sanduíche do castelo de chumbo;

- Desmontar o sanduíche, refazendo o processo inverso ao de montagem;

- Com o auxílio de duas pinças, retirar o invólucro de alumínio de cada uma das amostras e do padrão sintético. Deve-se ter bastante atenção nesta etapa visto que o invólucro de polietileno jamais deve ser rompido, sob o risco da ocorrência de contaminação radiológica. Apenas o invólucro de alumínio deve ser removido;

- As folhas de papel alumínio equivalentes ao sanduíche e aos invólucros de papel alumínio devem ser descartadas em lixo de residuo radioativo;

- Colocar cada uma das amostras e do padrão sintético (de maneira individual) no centro de um recipiente de alumínio chamado panelinha;

- Fixar amostras e/ou padrão sintético exatamente no centro da panelinha com a auxílio de um pedaço de fita adesiva. Esta etapa chama-se selagem das panelinha;

- Identificar as amostra e padrão sintético;

- Colocar cada panelinha devidamente selada e identificada no interior de um castelo de chumbo e transportar até a sala de contagens:

OBS: A medição da atividade do mensurando na amostra e padrão sintético deve ser realizada 7 dias após a data de irradiação e em um mesmo espectrômetro de raios gama. Amostras cuja irradiação tenha sido realizada em um período menor que 7 dias ou maior que 9 dias não devem ser analisadas.

- Dispor a panelinha dentro do detector de raios gama sob configuração de contagem adequada (Prateleira 1);

- Realizar a medição da atividade do mensurando no padrão sintético por um período de 1200 segundos;

- Realizar a medição da atividade do mensurando na amostra por um período de 3600 segundos;

- Imprimir o resultado com os valores de medição para cada amostra e padrão;

- Calcular a concentração do mensurando na amostra de acordo com a equação 1.

\subsection{Descarte de amostras e padrões sintéticos}

Após o processo de medição, amostras e padrão sintético devem ser descartados em lixo de resíduo radioativo.

\section{CONTROLE DE QUALIDADE}

O controle da qualidadedo procedimento é realizado por meio da análise do material de referência certificado (MRC) Marine Sediment NIST SRM 2702 produzido pelo National Institute of Standards and Technology (NIST). A cada nova irradiação, uma aliquota de Tecido de Mexilhão TM-1 deve ser enviada como amostra controle e o resultado obtido para a concentração de As deve ser comparada com o valor de referência do mensurando no MRC que são [As] 45,3 $\pm 1,8 \mathrm{mg} \mathrm{kg}^{-1}$ e [Sb] $5,60 \pm 0,24 \mathrm{mg} \mathrm{kg}^{-1}$. Os resultados das amostras controle de Marine Sediment NIST SRM 2702 devem ser avaliados em função do valor de $E n$. O critério de aceitação para os resultados é $|E n| \leq 1$. Todos os resultados obtidos nas análises de amostras controle devem ser transcritos para a Planilha "Carta Controle MÉTODO GEO-1. Determinaçäo da concentraçäo de As e Sb em amostras de matriz biológica".

Antes de cada utilização, balanças analíticas e espectrômetros de raios gama devem ter seu funcionamento verificado em função do uso de padröes específicos. Todos os resultados das verificações devem ser registrados e arquivados em formulários específicos da qualidade. 


\begin{tabular}{|c|c|c}
\hline Centro do Reator de & MÉTODO GEO 1: Determinação da & Página 9 de 12 \\
Pesquisa - CRPq, & concentração de As e Sb em amostras de & POP - CRPq/101 \\
IPEN - CNEN/SP & matriz biológica (POP - CRPq/101) & Revisão: 00 \\
\hline
\end{tabular}

\subsection{Validação do método}

O método de medição foi validado de acordo com as exigências da norma ABNT NBR ISO/IEC 17025 seguindo-se as orientações do Guia de validação de métodos INMETRO DOQ-CGCRE-008 e da Resolução RE n 899 da ANVISA que dispõe sobre a validação de métodos de medição.

\subsection{Seletividade do método, possíveis interferentes}

A elevada seletividade do método é referente à elevada seletividade da espectrometria de raios gama. Apesar disso, possiveis interferentes não podem ser excluídos.

\subsection{Linearidade e faixa de trabalho}

A espectrometria de raios gama possui ampla faixa linear $\left(0\right.$ à $\left.1 \mathrm{~kg} \mathrm{~kg}^{-1}\right)$. Contudo, anomalias na geometria entre amostras e padrão sintético, configuração da resolução do detector e tempo morto obtido durante a medição podem gerar eventos de não-linearidade às medições. Amostras típicas analisadas (MRC Marine Sediment NIST SRM 2702, MRC Estuarine Sediment NIST SRM 1646a, MRC Marine Sediment NRCC MESS-3, MRC River Sediment NIST SRM 8704 e MRC Estuarine Sediment BCR 667) apresentaram valores de tempo morto durante a medição menores que $10 \%$. Nesta condição não foram observados efeitos de não-linearidade.

A faixa de trabalho recomendada varia entre o valor de $L Q$ até o valor de maior concentração observado no estudo de linearidade. Amostras analisadas devem atender a este requisito.

\subsection{Veracidade}

A veracidade deve ser avaliada em função do resultado obtido para a amostra controle Marine Sediment NIST SRM 2702 por meio do cálculo de En (2).

$$
E n=\frac{x-x_{v}}{\sqrt{U^{2}+U_{v}^{2}}}
$$

onde:

En é o valor para erro normalizado;

$x$ é o resultado da medição $\left(\mathrm{mg} \mathrm{kg}^{-1}\right)$;

$x_{\mathrm{y}}$ é o valor de referência $\left(\mathrm{mg} \mathrm{kg}^{-1}\right)$;

$U$ é a incerteza expandida do resultado, $k=2\left(\mathrm{mg} \mathrm{kg}^{-1}\right)$;

$U_{v}$ é a incerteza expandida do valor de referência, $k=2\left(\mathrm{mg} \mathrm{kg}^{-1}\right)$.

\subsection{Critério de aceitação}

$O$ critério de aceitação para os resultados é $|E n| \leq 1$

\subsection{Precisão}

A repetitividade do método foi determinada em função da análise de 7 amostras controle de Marine Sediment NIST SRM 2702. O cálculo do resultado foi realizado de acordo com (3).

$$
r=2,8 s
$$

onde:

$r$ é o valor do limite de repetitividade $\left(\mathrm{mg} \mathrm{kg}^{-1}\right)$;

$s$ é o desvio padrão obtido para $n$ medições, $n \geq 7\left(\mathrm{mg} \mathrm{kg}^{-1}\right)$.

A precisão intermediária foi determinada em função da análise de 26 amostras controle de Marine Sediment NIST SRM 2702. O cálculo do resultado foi realizado de acordo com (4). 


\begin{tabular}{|l|c|c|}
\hline $\begin{array}{c}\text { Centro do Reator de } \\
\text { Pesquisa - CRPq, }\end{array}$ & MÉTODO GEO 1: Determinação da & Página 10 de 12 \\
IPEN - CNEN/SP & concentração de As e Sb em amostras de & POP - CRPq/101 \\
Revisão: 00
\end{tabular}

$$
P I=\sqrt{\frac{1}{(n-1)} \sum_{m=1}^{n}\left(x_{m}-\bar{x}\right)^{2}}
$$

onde:

Pl é o valor de precisão intermediária $\left(\mathrm{mg} \mathrm{kg}^{-1}\right)$;

$n$ é o número de amostras (alíquotas);

$m$ é o número do ensaio da amostra, $m=1, n$;

$x_{m}$ é o resultado obtido para o ensaio $k$;

$\bar{x}$ é a média dos resultados para $n$ medições.

A reprodutibilidade do método foi determinada de acordo com (5).

$$
R=2,8 P I
$$

onde:

$R$ é o valor do limite de reprodutibilidade $\left(\mathrm{mg} \mathrm{kg}^{-1}\right)$;

Pl é o valor de precisão intermediária $\left(\mathrm{mg} \mathrm{kg}^{-1}\right)$.

\subsection{Limite de deteç̧ão}

O limite de detecção (LD) foi calculado para a análise de uma amostra controle Tecido de Mexilhão $T M-1$ de acordo com (6).

$$
L D=3,29 \frac{\sqrt{b}}{t}
$$

onde:

$L_{D}$ é a taxa de contagem correspondente ao limite de detecção do método (cps);

$b$ é o número de contagens da radiação de fundo sob o pico analítico (cps);

$t$ é o tempo real de medição da amostra (s).

O resultado obtidos para $L D$ é convertido para $\mathrm{mg} \mathrm{kg}^{-1}$ utilizando a equação geral da ativação neutrônica (1).

\subsection{Limite de quantificação}

O limite de quantificação (LQ) foi calculado para a análise de uma amostra controle Tecido de Mexilhão TM-1 de acordo com (7).

$$
L Q=10 \frac{\sqrt{b}}{t}
$$

onde:

$L_{Q}$ é a taxa de contagem correspondente ao limite de quantificação do método (cps); $b$ é o número de contagens da radiação de fundo sob o pico analítico (cps); $t$ é o tempo real de medição da amostra (s).

O resultado obtidos para $L Q$ é convertido para $\mathrm{mg} \mathrm{kg}^{-1}$ utilizando a equação geral da ativação neutrônica (1).

\subsection{Incerteza de medição}

A estimativa da incerteza de medição foi realizada em função do método simulado, procedimento recomendado pelo Guia para a quantificação de incertezas de medição (EURACHEM/CITAC, 2012) e descrito passo a passo por Petroni (PETRONI, 2015). Levou-se em consideração as seguintes componentes de entrada em INAA: massa da amostra, massa do padrão sintético, atividade do radionuclídeo na amostra, atividade do radionuclídeo no padrão sintético e constante de decaimento do radionuclídeo. 


\begin{tabular}{|c|c|c|}
\hline Centro do Reator de & MÉTODO GEO 1: Determinação da & Página 11 de 12 \\
Pesquisa - CRPq, & concentração de As e Sb em amostras de & POP - CRPq/101 \\
IPEN - CNEN/SP & matriz biológica (POP - CRPq/101) & Revisão: 00 \\
\hline
\end{tabular}

\subsection{Pico analítico}

O cálculo da concentração dos mensurandos na amostra deve ser realizado para a atividade verificada nos respectivos picos analíticos:

As - $559,1 \mathrm{keV}$;

$\mathrm{Sb}-564,2 \mathrm{keV}$.

\section{CARACTERÍSTICAS DO MÉTODO DE MEDIÇÄO}

A seguir são apresentados as características correspondentes ao método de medição.

\begin{tabular}{|c|c|c|c|}
\hline \multirow{2}{*}{ Parâmetro de Validação } & \multicolumn{3}{|c|}{ As } \\
\hline & $n$ & En & Resultado \\
\hline Limite de repetitividade & 7 & 0,50 & $0,72 \mathrm{mg} \mathrm{kg}^{-1}$ \\
\hline Precisão Intermediária & 28 & 0,05 & $1,3 \mathrm{mg} \mathrm{kg}^{-1}$ \\
\hline Limite de reprodutibilidade & 28 & 0,05 & $3,6 \mathrm{mg} \mathrm{kg}^{-1}$ \\
\hline Limite de detecção & 5 & $-0,32$ & $0,59 \mathrm{mg} \mathrm{kg}^{-1}$ \\
\hline Limite de quantificação & 5 & $-0,32$ & $1,8 \mathrm{mg} \mathrm{kg}^{-1}$ \\
\hline \multirow{5}{*}{$\begin{array}{c}\text { Incerteza expandida relativa, } k=2 \\
\text { Faixa de trabalho } \\
\text { Veracidade }\end{array}$} & 5 & $-0,32$ & $3,7-4,2 \%$ \\
\hline & \multirow{2}{*}{\multicolumn{3}{|c|}{$\begin{array}{c}1,8-69 \mathrm{mg} \mathrm{kg}^{-1} \\
\text { Adequada }(-1,0<E n<1,0)\end{array}$}} \\
\hline & & & \\
\hline & \multicolumn{3}{|c|}{$\mathrm{Sb}$} \\
\hline & $n$ & $E n$ & Resultado \\
\hline Limite de repetitividade & 7 & $-0,24$ & $0,16 \mathrm{mg} \mathrm{kg}^{-1}$ \\
\hline Precisão Intermediária & 28 & 0,01 & $0,34 \mathrm{mg} \mathrm{kg}^{-1}$ \\
\hline Limite de reprodutibilidade & 28 & 0,01 & $0,96 \mathrm{mg} \mathrm{kg}^{-1}$ \\
\hline Limite de detecção & 5 & 0,06 & $0,089 \mathrm{mg} \mathrm{kg}^{-1}$ \\
\hline Limite de quantificação & 5 & 0,06 & $0,27 \mathrm{mg} \mathrm{kg}^{-1}$ \\
\hline Incerteza expandida relativa, $k=2$ & 5 & 0,06 & $3,3-4,6 \%$ \\
\hline Faixa de trabalho & \multirow{2}{*}{\multicolumn{3}{|c|}{$\begin{array}{l}\quad 0,27-35 \mathrm{mg} \mathrm{kg}^{-1} \\
\text { Adequada }(-1,0<E n<1,0)\end{array}$}} \\
\hline Veracidade & & & \\
\hline
\end{tabular}

\section{REFERÊNCIAS}

ALFASSI, Z. B. Activation Analysis. CRC Press. Florida, 1990

BODE, P.; FERNANDES, E.A.N.; GREENBERG, R.R. Metrology for chemical measurements and the position of INAA. Journal of Radioanalytical and Nuclear Chemistry. 245:109-114, 2000

GREENBERG, R. R.; BODE, P.; FERNANDES, E. A. N. Neutron activation analysis: A primary method of measurement. Spectrochimica Acta Part B. 66:193-241, 2011

HAMIDATOU, L.; SLAMENE, H.; AKHAL, T.; ZOURANEN, B. Concepts, instrumentation and techniques of Neutron Activation Analysis. In: KHARFY, F. Imaging and Radioanalytical Techniques in Interdisciplinary Research - Fundamentals and Cutting Edge Applications. InTech, p. 141-177, 2013 Disponivel em: <http://www.intechopen.com/books/imaging-and-radioanalytical-techniques-ininterdisciplinary-research-fundamentals-and-cutting-edge-applications> Acesso em 18 novembro, 2014

PETRONI, R. Validação dos métodos de Análise por Ativação do Laboratório de Análise por Ativação do IPEN - CNEN/SP visando a produção de materiais de referência certificados. Dissertação de Mestrado. Universidade de São Paulo, 2015 


\begin{tabular}{|c|c|c|}
\hline Centro do Reator de & MÉTODO GEO 1: Determinação da & Página 12 de 12 \\
Pesquisa - CRPq, & concentração de As e Sb em amostras de & POP - CRPq/101 \\
IPEN - CNEN/SP & matriz biológica (POP - CRPq/101) & Revisão: 00 \\
\hline
\end{tabular}

\begin{tabular}{|c|c|c|c|}
\hline & Nome & Assinatura & Data \\
\hline Elaborado por: & & & 11 \\
\hline Aprovado por: & & & 11 \\
\hline Implantado por: & & & 11 \\
\hline \multicolumn{4}{|l|}{ Substitui POP: } \\
\hline Revisado por: & & & 11 \\
\hline Revisado por: & & & $=1$ \\
\hline Revisado por: & & & 1.1. \\
\hline Desativado por: & & & 1.1. \\
\hline
\end{tabular}

\begin{tabular}{|ll}
\hline & Número \\
\hline
\end{tabular}




\begin{tabular}{|c|c|c|}
\hline Centro do Reator de & MÉTODO GEO 2: Determinação da concentração & Página 1 de 12 \\
Pesquisa - CRPq, & de Co, Cr, Fe, Sc e Zn em amostras de matriz & POP - CRPq/102 \\
IPEN - CNEN/SP & geológica (POP - CRPq/102) & Revisão: 00 \\
\hline
\end{tabular}

\section{MÉTODO GEO 2: Determinação da concentração de $\mathrm{Co}, \mathrm{Cr}, \mathrm{Fe}, \mathrm{Sc}$ e $\mathrm{Zn}$ em amostras de matriz biológica}

\section{INTRODUÇÃO}

O método de Análise por Ativação com Nêutrons (NAA) se baseia na produção e posterior identificação de radionuclídeos artificiais a partir de elementos naturalmente estáveis. Esse processo ocorre por meio do bombardeamento com nêutrons no material a ser analisado (amostra), resultando em reações nucleares características para cada elemento. Em NAA, o produto da reação nuclear que é medido é a emissão de raios gama provenientes do decaimento radioativo dos radionuclídeos formados durante 0 processo de bombardeamento com nêutrons (BODE et al., 2000).

Em NAA, amostras e padrões são irradiados sob um fluxo de nêutrons térmicos provenientes de um reator nuclear. A sequência de eventos que ocorrem numa reação nuclear típica se inicia quando um nêutron interage com um núcleo alvo por meio de uma colisão inelástica, formando um núcleo composto num estado excitado. A energia de excitação do núcleo composto é devida à energia de ligação do nêutron com o núcleo. O núcleo composto formado quase que instantaneamente adquire uma configuração mais estável por meio da emissão de raios gama prontos, do inglês, prompt gamma rays. Em muitos casos, esta nova configuração do núcleo no estado passa por outras vias de decaimento por emissão de raios gama retardados, do inglês, delayed gamma rays (ALFASSI, 1990).

O sistema de deteç̧ão de raios gama é constituido basicamente por um detector semicondutor de germânio hiperpuro (HPGe) associado ao analisador de multi canal (MCA) e a um computador responsável pela análise dos dados obtidos durante o processo de medição, integração da área dos picos analíticos e geração do espectro com os resultados da medição dos raios gama. Esse sistema qualifica a técnica como bastante seletiva devido as característicvas do processo de detecção de raios gama.

NAA é uma técnica multielementar capaz de detectar e quantificar dezenas de elementos em uma única rodada de experimentos é independente de efeitos de matriz e é considerada uma técnica não destrutiva, uma vez que não requer processos de digestão das amostras, fato que contribui para a diminuição do risco de contaminação. Apresenta-se ainda uma técnica muito competitiva para a determinação do teor de elementos traço em matrizes ambientais, apresentando elevado nível de exatidão para a medição de muitos elementos (GREENBERG et al., 2011).

Outra grande vantagem da técnica está no fato da não obrigatoriedade de se analisar o branco analítico, pois não há utilização de reagentes para digestão da amostra, processos de extração ou separação de elementos. Por esse motivo, faz-se seguro afirmar que não há possibilidade de introdução de contaminantes após a irradiação nas amostras, exceto por contaminação de outro material radioativo (HAMIDATOU et al., 2013).

\section{APLICAÇÄO DO MÉTODO}

Este documento descreve o método para determinação da concentração total de As em amostras de matriz biológica por meio da técnica de Análise por Ativação com Nêutrons.

\section{REFERÊNCIAS NORMATIVAS}

ABNT, ASSOCIAÇÃO BRASILEIRA DE NORMAS TÉCNICAS. Sistemas de Gestão da Qualidade Fundamentos e vocabulário. Rio de Janeiro: ABNT, 2005 (ABNT NBR ISO 9000)

ABNT, ASSOCIAÇÃO BRASILEIRA DE NORMAS TÉCNICAS. Requisitos gerais para a competência de laboratórios de ensaio e calibração. 2 ed. corrigida, Rio de Janeiro: ABNT, 2006 (ABNT NBR ISO/IEC 17025:2005) 


\begin{tabular}{|c|c|c|}
\hline Centro do Reator de & MÉTODO GEO 2: Determinação da concentração & Página 2 de 12 \\
Pesquisa - CRPq, & de Co, Cr, Fe, Sc e Zn em amostras de matriz & POP - CRPq/102 \\
IPEN - CNEN/SP & geológica (POP - CRPq/102) & Revisão: 00 \\
\hline
\end{tabular}

ABNT, ASSOCIAÇÃO BRASILEIRA DE NORMAS TÉCNICAS. Sistemas de Gestão da Qualidade Requisitos. 2 ed. corrigida, Rio de Janeiro: ABNT, 2009 (ABNT NBR ISO 9001)

ABNT, ASSOCIAÇÃO BRASILEIRA DE NORMAS TÉCNICAS. Gestão para o sucesso sustentado de uma organização - Uma abordagem da gestâo da qualidade. 2 ed. corrigida Rio de Janeiro: ABNT, 2010 (ABNT NBR ISO 9004)

ANVISA, AGÊNCIA NACIONAL DE VIGILÂNCIA SANITÁRIA. Guia Para Qualidade em Química Analítica - Uma Assistência de Acreditação. $1^{\text {a }}$ ed. Brasília, 2004

BRASIL. Resolução RE $n^{\circ} 899$, de 29 de maio de 2003. ANVISA, AGÊNCIA NACIONAL DE VIGILÂNCIA SANITÁRIA, 2003. Disponivel em:

<http://portal.anvisa.gov.br/wps/wcm/connect/4983b0004745975da005f43fbc4c6735/RE_899_2003_Det ermina+a+publica \%C3\%A7\% $3 \%$ A3o+do+Guia+para+valida\%C3\%A7\%C3\%A3o+de+m\%C3\%A9todos + anal\%C3\%ADticos+e+bioanal\%C3\%ADticos.pdf?MOD=AJPERES> Acesso em 18 junho, 2015

CURRIE, L. A. Nomenclature in evaluation of analytical methods including detection and quantification capabilities (IUPAC Recommendations 1995). Analytical Chimic Acta, 391:105-126, 1999

EURACHEM. The fitness for purpose of analytical methods. A laboratory guide to method validation and related topics, 1998. Disponivel em:

<http://www.eurachem.org/images/stories/Guides/pdf/valid.pdf> Acesso em: 18 junho, 2015

EURACHEM/CITAC. Quantifying uncertainty in analytical measurement. EURACHEM/CITAC Guide CG 4, 2012. Disponivel em: <http://www.citac.cc/QUAM2012_P1.pdf> Acesso em: 18 junho, 2015 (QUAM:2012)

IAEA. International atomic Energy Agency. Use of research reactors for neutron activation analysis. Vienna, 2001 Disponivel em : <http://www-pub.iaea.org/MTCD/publications/PDF/te_1215_prn.pdf> Acesso em 18 junho, 2015 (IAEA-TECDOC 1215)

IAEA. International atomic Energy Agency. Uncertainty evaluation in instrumental and radiochemical neutron activation analysis. Vienna, 2004 Disponivel em : <http://www-pub.iaea.org/MTCD/publications/PDF/te_1401_web.pdf> Acesso em 18 junho, 2015 (IAEA-TECDOC1401)

INMETRO, INSTITUTO NACIONAL DE METROLOGIA, QUALIDADE E TECNOLOGIA. Orientação sobre validação de métodos analíticos. Rio de Janeiro, Fev. 2010. Disponível em: <http://www.inmetro.gov.br/Sidoq/Arquivos/CGCRE/DOQ/DOQ-CGCRE-8_03.pdf>, Acesso em: 18 junho, 2015 (DOQ-CGCRE-008)

INMETRO, INSTITUTO NACIONAL DE METROLOGIA, QUALIDADE E TECNOLOGIA. Vocabulário Internacional de Metrologia: conceitos fundamentais e gerais e termos associados. 1ed Lusobrasileira, Rio de Janeiro: INMETRO, 2012. Disponivel em:

<http://www.inmetro.gov.br/inovacao/publicacoes/vim_2012.pdf>, Acesso em: 18 junho, 2015 (VIM)

INMETRO, INSTITUTO NACIONAL DE METROLOGIA, QUALIDADE E TECNOLOGIA. Guia para a expressão da incerteza de medição. 1ed Luso-brasileira. Rio de Janeiro: INMETRO, 2012. (ISO GUM)

ISO, INTERNATIONAL ORGANIZATION OF STANDADIZATION. Accuracy (trueness and precision) of measurement methods and results-- Part 1: General principles and definitions. Geneva, 2012 


\begin{tabular}{|c|c|c|}
\hline Centro do Reator de & MÉTODO GEO 2: Determinação da concentração & Página 3 de 12 \\
Pesquisa - CRPq, & de Co, Cr, Fe, Sc e Zn em amostras de matriz & POP - CRPq/102 \\
IPEN - CNEN/SP & geológica (POP - CRPq/102) & Revisão: 00 \\
\hline
\end{tabular}

ISO, INTERNATIONAL ORGANIZATION OF STANDADIZATION. Accuracy (trueness and precision) of measurement methods and results- Part 3: Intermediate measures of the precision of a standard measurement method. Geneva, 2013

ISO, INTERNATIONAL ORGANIZATION OF STANDADIZATION. Accuracy (trueness and precision) of measurement methods and results - Practical guidance for the use of ISO 5725:1994 in designing, implementing and statistically analysing interlaboratory repeatability and reproducibility results. Geneva, 2005

\section{SIMBOLOS, SIGLAS E ABREVIAÇÕES}

ABNT : Associação Brasileira de Normas Técnicas ANVISA : Agência Nacional de Vigilância Sanitária

$A_{a}:$ atividade do radionuclídeo na amostra (cps)

$c$ : comprimento do padrão sintético

$A_{p}$ : atividade do radionuclídeo no padrão sintético para tempo de decaimento tp (cps)

$b$ : número de contagens da radiação de fundo sob o pico analítico (cps)

$C$ : concentração do mensurando na amostra $\left(\mathrm{mg} \mathrm{kg}^{-1}\right)$

$C R P q$ : Centro do Reator de Pesquisa

$D P$ : desvio padrão para a média de $n$ medições $\left(\mathrm{mg} \mathrm{kg}^{-1}\right)$

En : erro normalizado

GUM : Guia para expressão da incerteza de medição

$h$ : altura do padrão sintético

$\mathrm{HPGe}$ : Espectrômetro de raios gama com detector de germânio hiperpuro (HPGe)

IAEA : Agência Internacional de Energia Atômica

INMETRO : Instituto Nacional de Metrologia: Qualidade e Tecnologia

IPEN - CNEN/SP : Instituto de Pesquisas Energéticas e Nucleares

ISO : Organização Internacional para a Padronização

$k$ : fator de abrangência da incerteza de medição; $k=2 ; a=0,05$

$L D$ : limite de deteç̧ão $\left(\mathrm{mg} \mathrm{kg}^{-1}\right)$

$L Q$ : limite de quantificação $\left(\mathrm{mg} \mathrm{kg}^{-1}\right)$

$m$ : número do ensaio da amostra, $m=1, n$

$M_{a}$ : massa da amostra $(\mathrm{kg})$

$m_{0}$ : massa do mensurando no padrão sintético $(\mathrm{mg})$

$M R$ : material de referência

$M R C$ : material de referência certificado

$n$ : número de medições

NAA : Análise por Ativação com Nêutrons Instrumental

NIST : National Institute of Standards and Technology; Intituto Nacional de Padrões e Tecnologia (EUA)

NRCC : National Research Council Canada; Conselho Nacional de Pesquisa do Canadá

$P I$ : precisão intermediária $\left(\mathrm{mg} \mathrm{kg}^{-1}\right)$

QUAM : Guia para a Quantificação da Incerteza nas medições analíticas

$r$ : limite de repetitividade $\left(\mathrm{mg} \mathrm{kg}^{-1}\right)$

$R$ : limite de reprodutibilidade $\left(\mathrm{mg} \mathrm{kg}^{-1}\right)$

$t:$ tempo real de medição da amostra (s)

$t_{\text {da }}$ : tempo de decaimento do radionuclídeo para medição da amostra (s)

$t_{đ p}$ : tempo de decaimento do radionuclídeo para medição do padrão (s)

$t_{1 / 2}$ : tempo de meia vida para a atividade do radionuclídeo

$U$ : incerteza expandida do resultado, $k=2\left(\mathrm{mg} \mathrm{kg}^{-1}\right)$

$U_{v}$ : incerteza expandida do valor de referência, $k=2\left(\mathrm{mg} \mathrm{kg}^{-1}\right)$

VIM : Vocabulário Internacional de Metrologia

$x$ : resultado da medição $\left(\mathrm{mg} \mathrm{kg}^{-1}\right)$

$\bar{x}$ : média dos resultados para $n$ medições

$x_{m}$ : resultado obtido para o ensaio $m$

$x_{v}$ : valor de referência do MR ou MRC $\left(\mathrm{mg} \mathrm{kg}^{-1}\right)$

$\alpha$ : nivel de significância estatística; $\alpha=0,05 ; 95 \%$ de confiança estatística

$\lambda$ : constante de decaimento do radionuclídeo $\left(\mathrm{s}^{-1}\right)$ 


\begin{tabular}{|c|c|c|}
\hline Centro do Reator de & MÉTODO GEO 2: Determinação da concentração & Página 4 de 12 \\
Pesquisa - CRPq, & de Co, Cr, Fe, Sc e Zn em amostras de matriz & POP - CRPq/102 \\
IPEN - CNEN/SP & geológica (POP - CRPq/102) & Revisão: 00 \\
\hline
\end{tabular}

\section{RESPONSABILIDADES}

É de responsabilidade do analista seguir o procedimento e estabelecer práticas que garantam a segurança e saúde. É obrigação da gerência do $\mathrm{CRPq}$ fornecer o uso de equipamentos de monitoramento para o controle da radioatividade ao que o analista estará exposto, bem como qualquer outro equipamento de proteção individual que se faça necessário para o cumprimento das leis e acordos para a manutenção da segurança quanto a contaminação química, biológica e radioativa. É responsabilidade do analista solicitar à gerência do CRPq a compra dos equipamentos de proteção individual que eventualmente não encontram-se disponiveis e utilizá-los de forma correta e segura. Qualquer acidente que envolva material radioativo deverá ser imediatamente informado ao Serviço de Proteção Radiológica. Ainda, é de responsabilidade do analista fazer a verificação de todos os equipamentos utilizados bem como o registro de uso dos mesmos.

\section{PRINCÍPIO DO MÉTODO}

O método NAA consiste na irradiação da amostra e do padrão sintético (no qual a concentração do mensurando é conhecida) de maneira simultânea, em um mesmo período de tempo, geometria de espaço e de fluxo de nêutrons. Após o período de decaimento apropriado, realiza-se a medição do espectro de raios gama na amostra e no padrão sintético numa mesma configuração de deteç̧ão e em um mesmo aparelho detector. A determinação da concentração do mensurando na amostra é calculada por meio da comparação da área dos picos (atividade) obtidos para amostra e padrão sintético. A equação fundamental para o cálculo da concentração de um mensurando em NAA é apresentada a seguir (1).

$$
C_{a}=\frac{m_{p} A_{a} e^{-\lambda(t a-t p)}}{A_{p} M_{Q}}
$$

onde:

$C$ é a concentração do mensurando na amostra $\left(\mathrm{mg} \mathrm{kg}^{-1}\right)$;

$m_{p}$ é a massa do mensurando no padrão $(\mathrm{mg})$;

$A_{a}$ é a atividade do radionuclídeo na amostra (cps);

$\lambda$ é a constante de decaimento do radionuclídeo $\left(\mathrm{s}^{-1}\right)$;

$t_{\varpi a}$ é o tempo de decaimento do radionuclídeo até o momento início da medição da amostra (s);

$t_{\text {ap }}$ é o tempo de decaimento do radionuclídeo até o início da medição do padrão (s);

$M_{a}$ é a massa da amostra $(\mathrm{kg})$;

$A_{p}$ é a atividade do radionuclídeo no padrão sintético para tempo de decaimento tp (cps).

\section{EQUIPAMENTOS, VIDRARIA E REAGENTES}

\subsection{Equipamentos e vidrarias}

Estufa

Reator nuclear

Espectrômetro de raios gama com detector de germânio hiperpuro (HPGe)

Balança analítica

Máquina seladorado Sela-Pak

Aparelho deionizador de água (Mili - Q, Millipore; 18,2 m $\Omega$ )

Micropipeta $(20-100 \mu \mathrm{L})$

Micropipeta $(100-1000 \mu \mathrm{L})$

Micropipeta (1000 - $5000 \mu \mathrm{L})$

Ponteira para micropipetas

Balão volumétrico calibrado de $10 \mathrm{~mL}$

Béquer de $10 \mathrm{~mL}$ 


\begin{tabular}{|c|c|c|}
\hline Centro do Reator de & MÉTODO GEO 2: Determinação da concentração & Página 5 de 12 \\
Pesquisa - CRPq, & de Co, Cr, Fe, Sc e Zn em amostras de matriz & POP - CRPq/102 \\
IPEN - CNEN/SP & geológica (POP - CRPq/102) & Revisão: 00 \\
\hline
\end{tabular}

Folha de polietileno

Folha de papel filtro quantitativo

Folha de papel alumínio

Folha de papel absorvente

Baguetas de vidro

Recipiente de alumínio (coelho)

Recipiente de alumínio (panelinha)

Pinças de cabo longo

Castelo de chumbo

\subsection{Reagentes}

Ácido nítrico (10\%)

Solução padrão de Co $1000 \mathrm{mg} \mathrm{L}^{-1}$

Solução padrão de $\mathrm{Cr} 1000 \mathrm{mg} \mathrm{L}^{-1}$

Solução padrão de $\mathrm{Fe} 10000 \mathrm{mg} \mathrm{L}^{-1}$

Solução padrão de $\mathrm{Sc} 1000 \mathrm{mg} \mathrm{L}^{-1}$

Solução padrão de $\mathrm{Zn} 10000 \mathrm{mg} \mathrm{L}^{-1}$

\section{PROCEDIMENTO}

\subsection{Lavagem e descontaminação das vidrarias}

- Com o auxílio de um sepilho, lavar a vidraria com sabão neutro comercial (Extran 3\%);

- Enxaguar três vezes com água destilada;

- Preparar uma solução de $\mathrm{HNO}_{3}(10 \%)$;

- Acondicionar a solução em um recipiente de plástico com tampa dentro de uma capela;

- Dispor a vidraria previamente lavada no recipiente plástico com a solução de $\mathrm{HNO}_{3}(10 \%)$. Essa etapa é conhecida com banho ácido;

- Aguardar por 24 horas;

- Retirar a vidraria do banho ácido, enxaguar três vezes com água destilada e três vezes com água deionizada (Mili $-Q$, Millipore; 18,2 $\mathrm{m} \Omega$ );

- Aguardar a secagem da vidraria sob temperatura ambiente;

- Guardar a vidraria em local adequado.

\subsection{Solução de $\mathrm{HNO} 3(10 \%)$ ** Procedimento dentro de capela **}

- Adicionar cerca de 1 litro de água destilada em um balão volumétrico de 2 litros;

- Dispor $200 \mathrm{~mL}$ de $\mathrm{HNO}_{3}$ concentrado em um béquer de $500 \mathrm{~mL}\left(\mathrm{HNO}_{3}\right.$ concentrado é corrosivo e nocivo à saúde. Nunca realize o procedimento fora da capela);

- Com o auxílio de uma bagueta, transferir de maneira lenta e cuidadosa os $200 \mathrm{~mL}$ de $\mathrm{HNO}_{3}$ concentrado para o balão volumétrico de 2 litros (Faça de maneira devagar. Reação exotérmica);

- Completar o volume do balão volumétrico com aguá destilada até o menisco;

- Tampar o balão volumétrico e homogeneizar a solução preparada;

- Transferir a solução para um frasco âmbar, identificar a solução e armazenar em local seguro, ventilado e ao abrigo da luz solar.

\subsection{Lavagem e confecção dos invólucros de polietileno}

- As folhas de polietileno utilizadas para o preparo dos invólucros para amostras e padrões sintéticos devem ser previamente lavadas em solução de $\mathrm{HNO}_{3} 10 \%(\mathrm{v} / \mathrm{v})$ por um período de 48 horas, enxaguadas com $\mathrm{H}_{2} \mathrm{O}$ destilada e deionizada (Milli-Q, Millipore; $18,2 \mathrm{~m} \Omega$ ) e secas em temperatura ambiente em capela de fluxo laminar;

- Os invólucros devem ser confeccionados em geometria retangular de $1,0 \mathrm{~cm}$ de largura por $1,5 \mathrm{~cm}$ de comprimento selado em todas as extremidades com 0 auxílio de uma máquina seladora. Os 


\begin{tabular}{|c|c|c|}
\hline Centro do Reator de & MÉTODO GEO 2: Determinação da concentração & Página 6 de 12 \\
Pesquisa - CRPq, & de Co, Cr, Fe, Sc e Zn em amostras de matriz & POP - CRPq/102 \\
IPEN - CNEN/SP & geológica (POP - CRPq/102) & Revisão: 00 \\
\hline
\end{tabular}

invólucros foram armazenados em frasco devidamente identificado e mantidos ao abrigo da luz solar e emtemperatura ambiente até o momento de sua utilização.

\subsection{Confecção das estantes e papéis filtro}

- Para a confecção das estantes se deve-se fixar duas baguetas de vidro com o auxílio de dois pedaços de fita adesiva (um pedaço em cada extremidade), de modo que permaneçam fixas e encostadas uma na outra.

- Para a confecção dos papéis filtro à serem utilizados no preparo dos padrões sintéticos, deve-se pegar uma ou mais folhas de papel filtro quantitativo e recortar de acordo com a seguinte dimensão: 2 $\mathrm{cm} \times 2,5 \mathrm{~cm}$ (h $\times$ c). Ao lado cujo comprimento é $2,5 \mathrm{~cm}$ deve-se fazer um pequeno recorte com a tesoura que servirá como marcação, medindo-se a partir da ponta em $0,5 \mathrm{~cm}$. Posteriormente, esta marcação irá indicar a parte que deverá ser descartada após o processo de pipetagem da solução de trabalho.

\subsection{Preparo dos padrões sintéticos}

- Ao balão volumétrico de $10 \mathrm{~mL}$ (calibrado) adicionar aproximadamente $3 \mathrm{~mL}$ de água deionizada (Milli-Q, Millipore; 18,2 $\mathrm{m} \Omega$ );

- Utilizando-se uma micropipeta, pipetar exatamente $1000 \mu \mathrm{L}$ de solução padrão de Co, $2000 \mu \mathrm{L}$ de solução padrão de $\mathrm{Cr}, 100 \mu \mathrm{L}$ de solução padrão de $\mathrm{Sc}$ e $1000 \mu \mathrm{L}$ de solução padrão de $\mathrm{Zn}$ dentro do balão volumétrico de $10 \mathrm{~mL}$, de modo a preparar um padrão sintético multielementar.

OBS: Deve-se manter a micropipeta na posição vertical durante todo o processo de pipetagem da solução padrão. No momento do despejo da solução pipetada dentro do balão volumétrico é importante que a ponteira da micropipeta esteja encostada na parede no balão volumétrico em uma posição abaixo da linha do menisco. Para isso, o balão volumétrico deve ser posicionado em uma posição ligeiramente inclinada, de modo que se faça um ângulo diferente de $90^{\circ}$ entre a ponteira da micropipeta e a parede do balão volumétrico. O êmbolo da micropipeta nunca deve ser pressionado até o fim durante o processo de pipetagem, mas somente até a posição correspondente a trava (a solução padrão deve estar em temperatura ambiente);

- Completar o volume do balão volumétrico com água deionizada (Milli - Q, Millipore; $18,2 \mathrm{~m} \Omega$ ) até o menisco;

- Com um pedaço de papel absorvente, secar cuidadosamente a parte acima do menisco do balão volumétrico de modo à remover gotículas de água que estejam ali adsorvidas. Em hipótese alguma o papel adsorvente pode tocar na solução que está no limite do menisco. Se isso ocorrer, descarte apropriadamente a solução e reinicie novamente o procedimento;

- Tampar o balão volumétrico e homogeneizar a solução preparada (solução de trabalho);

- Aguardar cerca de 30 minutos antes de continuar o procedimento;

- Dispor os papéis filtro recortados em geometria adequada na estante preparada com as baguetas, de modo que estes não fiquem encostados uns aos outros. A extremidade do papel filtro que conter a marcação de $0,5 \mathrm{~cm}$ deverá ser inserido no espaço que existe entre as duas baguetas. Os papéis filtro devem permanecer em posição vertical durante todo o processo de pipetagem e secagem (os processos a seguir devem ser realizados no interior de uma capela);

- Transferir uma alíquota da solução preparada para um béquer de $10 \mathrm{~mL}$ previamente limpo e seco;

- Pipetar exatamente $25 \mu \mathrm{L}$ da solução de trabalho sobre cada um dos papéis filtro dispostos nas estantes de bagueta.;

- Aguardar até que a alíquota da solução de trabalho pipetada nos papéis filtro sequem em temperatura ambiente (esse processo demora entre $6 \mathrm{~h} \mathrm{e} 12 \mathrm{~h}$ );

- Aos mesmos padrões, pipetar exatamente $50 \mu \mathrm{L}$ da solução padrão de $\mathrm{Fe}\left(10000 \mathrm{mg} \mathrm{L}^{-1}\right)$;

- Aguardar até que a alíquota da solução padrão de $\mathrm{Fe}$ pipetada nos papéis filtro sequem em temperatura ambiente (esse processo demora entre $6 \mathrm{~h}$ e $12 \mathrm{~h}$ ). 


\begin{tabular}{|c|c|c|}
\hline Centro do Reator de & MÉTODO GEO 2: Determinação da concentração & Página 7 de 12 \\
Pesquisa - CRPq, & de Co, Cr, Fe, Sc e Zn em amostras de matriz & POP - CRPq/102 \\
IPEN - CNEN/SP & geológica (POP - CRPq/102) & Revisão: 00 \\
\hline
\end{tabular}

OBS: Deve-se tomar cuidado para que o líquido pipetado não encoste na superfície da estante de bagueta e não ultrapasse a marca do recorte de $0,5 \mathrm{~cm}$. Se isso acontecer, descarte adequadamente a follha de papel filtro.

- Com o auxílio de uma pinça, retire o papél filtro - cujo padrão de trabalho foi pipetado e já esta seco - das estantes de bagueta e com uma tesoura recorte a parte inferior do mesmo na distância de $0,5 \mathrm{~cm}$. Este $0,5 \mathrm{~cm}$ corresponde a parte do papel filtro de ficou em contato com a estante de bagueta. Esta parte deve ser descartada;

- Com a auxílio de outra pinça, dobre a folha de papel filtro (cujas dimensões devem $s e r 2 \mathrm{~cm} \times 2 \mathrm{~cm}$ ) ao meio tanto na largura quanto no comprimento, resultado em um padrão de geometria de $1 \mathrm{~cm} \times 1 \mathrm{~cm}$ (h $\times$ c);

- Colocar o padrão de geometria $1 \mathrm{~cm} \times 1 \mathrm{~cm}(\mathrm{~h} \times \mathrm{c}$ ) dentro de um invólucro de polietileno previamente preparado;

- Com o auxílio de uma seladora Sela-Pak, selar a extremidade aberta do invólucro bem rente ao padrão:

- Recortar a rebarba do invólucro acima do local que foi cuja extremidade foi selada;

- Identificar o padrão e acondicionar em local seco e ao abrigo da luz solar até o momento da análise.

\subsection{Preparo das amostras}

- Em uma balança analítica deve-se colocar um invólucro de polietileno em geometria adequada vazio (o invólucro de ter três lados selados e um lado aberto);

- Realizar a tara da massa do invólucro;

- Retirar o invólucro da balança analítica com o auxílio de uma pinça;

- Pesar em balança analítica $150 \pm 10 \mathrm{mg}$ de amostra em pó dentro do invólucro de polietileno;

- Registrar o uso da balança analítica no caderno de Registro de Uso da respectiva balança analítica;

- Anotar a massa da amostra na folha do formulário de pesagem de amostras;

- Com o auxílio de uma seladora Sela-Pak, selar a extremidade aberta do invólucro de modo que a geometria final seja idêntica à do padrão sintético $(1 \mathrm{~cm} \times 1 \mathrm{~cm})$.

- Recortar a rebarba do invólucro acima do local que foi cuja extremidade foi selada;

- Identificar a amostra e acondicionar em local seco e ao abrigo da luz solar até o momento da análise.

\subsection{Irradiação}

- Limpar a parte externa de amostras e padrões sintéticos (amostras e padrões devem ter geometria espacial idênticas: $1 \mathrm{~cm} \times 1 \mathrm{~cm}$ ) com um papel embebido em álcool etílico grau P.A. e, em seguida, com outro papel embebido em água deionizada (Milli $-\mathrm{Q}$, Millipore; $18,2 \mathrm{~m} \Omega$ );

- Secar a parte externa do invólucro com papel absorvente;

- Envolver uma capa de folha de papel alumínio em cada amostra e/ou padrão sintético, de modo que esta fique semelhante a um invólucro de papel alumínio. Deve-se usar uma mínima quantidade de papel alumínio nesta etapa;

- Identificar cada amostra e/ou padrão sintético, anotando-se o código sobre o invólucro de papel alumínio;

- Dispor amostras e padrão sintético uns sobre os outros, de maneira aleatória e de modo a formar um agrupamento;

- Envolver o agrupamento formado por amostras e padrão sintético com uma nova camada de folha de papel alumínio, de modo que estes mantenham-se fixos em uma mesma posição. A esta etapa se dá o nome de preparo do sanduíche;

- Inserir o sanduíche de amostras e padrão sintético dentro do recipiente de alumínio chamado coelho;

- Identificar o coelho com o código do experimento;

- Preencher a ficha de Solicitação para Irradiação de amostras;

- Encaminhar o coelho juntamente com a ficha de Solicitação de Irradiação de amostras corretamente preenchida e assinada para o departamento de irradiação de amostras do reator nuclear. 


\begin{tabular}{|c|c|c|}
\hline Centro do Reator de & MÉTODO GEO 2: Determinação da concentração & Página 8 de 12 \\
Pesquisa - CRPq, & de Co, Cr, Fe, Sc e Zn em amostras de matriz & POP - CRPq/102 \\
IPEN - CNEN/SP & geológica (POP - CRPq/102) & Revisão: 00 \\
\hline
\end{tabular}

\subsection{Abertura do coelho}

- Ligar para o departamento de Proteção Radiológica solicitando o acompanhamento de um técnico de Radioproteção para o monitoramento das atividades de abertura do coelho;

- Com o auxílio de uma pinça de cabo longo deve-se acondicionar o coelho no aparelho de abertura de coelhos;

- Realizar a abertura do coelho acionando o aparelho de abertura de coelhos;

- Com o auxílio de uma pinça de cabo longo retirar o sanduiche do interior do coelho e acondicionar no dentro de um castelo de chumbo;

- Registrar a abertura do coelho no caderno de abertura de coelhos.

\subsection{Detecção de raios gama}

- Ir até uma capela que contenha uma barreira de proteção de chumbo;

- Colocar o castelo de chumbo contendo o sanduíche no interior da capela;

- Com o auxílio de uma pinça de cabo longo, retirar o sanduíche do castelo de chumbo;

- Desmontar o sanduiche, refazendo o processo inverso ao de montagem;

- Com o auxílio de duas pinças, retirar o invólucro de alumínio de cada uma das amostras e do padrão sintético. Deve-se ter bastante atenção nesta etapa visto que o invólucro de polietileno jamais deve ser rompido, sob o risco da ocorrência de contaminação radiológica. Apenas o invólucro de alumínio deve ser removido;

- As folhas de papel alumínio equivalentes ao sanduíche e aos invólucros de papel alumínio devem ser descartadas em lixo de resíduo radioativo;

- Colocar cada uma das amostras e do padrão sintético (de maneira individual) no centro de um recipiente de alumínio chamado panelinha;

- Fixar amostras e/ou padrão sintético exatamente no centro da panelinha com a auxílio de um pedaço de fita adesiva. Esta etapa chama-se selagem das panelinha;

- Identificar as amostra e padrão sintético;

- Colocar cada panelinha devidamente selada e identificada no interior de um castelo de chumbo e transportar até a sala de contagens;

OBS: A medição da atividade do mensurando na amostra e padrão sintético deve ser realizada 21 dias após a data de irradiação e em um mesmo espectrômetro de raios gama.

- Dispor a panelinha dentro do detector de raios gama sob configuração de contagem adequada (Prateleira 0);

- Realizar a medição da atividade do mensurando no padrão sintético por um período de 1200 segundos;

- Realizar a medição da atividade do mensurando na amostra por um período de 21600 segundos;

- Imprimir o resultado com os valores de medição para cada amostra e padrão;

- Calcular a concentração do mensurando na amostra de acordo com a equação 1.

\subsection{Descarte de amostras e padrões sintéticos}

Após o processo de medição, amostras e padrão sintético devem ser descartados em lixo de resíduo radioativo.

\section{CONTROLE DE QUALIDADE}

O controle da qualidadedo procedimento é realizado por meio da análise do material de referência interno (MRC) Marine Sediment NIST SRM 2702 produzido pelo National Institute of Standards and Technology (NIST). A cada nova irradiação, uma alíquota de Marine Sediment NIST SRM 2702 deve ser enviada como amostra controle e o resultado obtido para a concentração de As deve ser comparada com o valor de referência do mensurando no MR que é [Co] $27,76 \pm 0,58 \mathrm{mg} \mathrm{kg}^{-1},[\mathrm{Cr}] 352 \pm 22 \mathrm{mg} \mathrm{kg}^{-1}$, [Fe] $79100 \pm 2400 \mathrm{mg} \mathrm{kg}^{-1}$, [Sc] $25,9 \pm 1,1 \mathrm{mg} \mathrm{kg}^{-1} \mathrm{e}[\mathrm{Zn}] 485,3 \pm 4,2 \mathrm{mg} \mathrm{kg}^{-1}$. Os resultados das amostras controle de Marine Sediment NIST SRM 2702 devem ser avaliados em função do valor de En. $O$ critério de aceitação para os resultados é $|E n| \leq 1$. Todos os resultados obtidos nas análises de 


\begin{tabular}{|c|c|c|}
\hline Centro do Reator de & MÉTODO GEO 2: Determinação da concentração & Página 9 de 12 \\
Pesquisa - CRPq, & de Co, Cr, Fe, Sc e Zn em amostras de matriz & POP - CRPq/102 \\
IPEN - CNEN/SP & geológica (POP - CRPq/102) & Revisão: 00 \\
\hline
\end{tabular}

amostras controle devem ser transcritos para a Planilha ${ }^{a}$ Carta Controle MÉTODO GEO-2: Determinaçäo da concentraçäo de $\mathrm{Co}, \mathrm{Cr}$, $\mathrm{Fe}$, Sc e $\mathrm{Zn}$ em amostras de matriz geológica".

Antes de cada utilização, balanças analíticas e espectrômetros de raios gama devem ter seu funcionamento verificado em função do uso de padröes específicos. Todos os resultados das verificações devem ser registrados e arquivados em formulários específicos da qualidade.

\subsection{Validação do método}

O método de medição foi validado de acordo com as exigências da norma ABNT NBR ISO/IEC 17025, seguindo-se as orientações do Guia de validação de métodos INMETRO DOQ-CGCRE-008 e da Resolução RE n 899 da ANVISA que dispõe sobre a validação de métodos de medição.

\subsection{Seletividade do método, possíveis interferentes}

A elevada seletividade do método é referente à elevada seletividade da espectrometria de raios gama. Apesar disso, possiveis interferentes não podem ser excluídos.

\subsection{Linearidade e faixa de trabalho}

A espectrometria de raios gama possui ampla faixa linear ( 0 à $1 \mathrm{~kg} \mathrm{~kg}^{-1}$ ). Contudo, anomalias na geometria entre amostras e padrão sintético, configuração da resolução do detector e tempo morto obtido durante a medição podem gerar eventos de nẩo-linearidade às medições. Amostras típicas analisadas (MRC Marine Sediment NIST SRM 2702, MRC Estuarine Sediment NIST SRM 1646a, MRC Marine Sediment NRCC MESS-3, MRC River Sediment NIST SRM 8704 e MRC Estuarine Sediment BCR 667) apresentaram valores de tempo morto durante a medição menores que $15 \%$. Nesta condição não foram observados efeitos de não-linearidade.

A faixa de trabalho recomendada varia entre o valor de $L Q$ até o valor de maior concentração observado no estudo de linearidade. Amostras analisadas devem atender a este requisito.

\subsection{Veracidade}

A veracidade deve ser avaliada em função do resultado obtido para a amostra controle Marine Sediment NIST SRM 2702 por meio do cálculo de En (2).

onde:

$$
E n=\frac{x-x_{v}}{\sqrt{U^{2}+U_{v}^{2}}}
$$

En é o valor para erro normalizado;

$x$ é o resultado da medição $\left(\mathrm{mg} \mathrm{kg}^{-1}\right)$;

$x_{\mathrm{v}}$ é o valor de referência $\left(\mathrm{mg} \mathrm{kg}^{-1}\right)$;

$U$ é a incerteza expandida do resultado, $k=2\left(\mathrm{mg} \mathrm{kg}^{-1}\right)$;

$U_{v}$ é a incerteza expandida do valor de referência, $k=2\left(\mathrm{mg} \mathrm{kg}^{-1}\right)$.

\subsection{Critério de aceitação}

O critério de aceitação para os resultados é $|E n| \leq 1$

\subsection{Precisão}

A repetitividade do método foi determinada em função da análise de 7 amostras controle de Marine Sediment NIST SRM 2702. O cálculo do resultado foi realizado de acordo com (3).

$$
r=2,8 s
$$

onde:

ré o valor do limite de repetitividade $\left(\mathrm{mg} \mathrm{kg}^{-1}\right)$; 


\begin{tabular}{|c|c|c|}
\hline Centro do Reator de & MÉTODO GEO 2: Determinação da concentração & Página 10 de 12 \\
Pesquisa - CRPq, & de Co, Cr, Fe, Sc e Zn em amostras de matriz & POP - CRPq/102 \\
IPEN - CNEN/SP & geológica (POP - CRPq/102) & Revisão: 00 \\
\hline
\end{tabular}

$s$ é o desvio padrão obtido para $n$ medições, $n \geq 7\left(\mathrm{mg} \mathrm{kg}^{-1}\right)$.

A precisão intermediária foi determinada em função da análise de 28 amostras controle de Marine Sediment NIST SRM 2702. O cálculo do resultado foi realizado de acordo com (4).

$$
P I=\sqrt{\frac{1}{(n-1)} \sum_{m=1}^{n}\left(x_{m}-\bar{x}\right)^{2}}
$$

onde:

Pl é o valor de precisão intermediária $\left(\mathrm{mg} \mathrm{kg}^{-1}\right)$;

$n$ é o número de amostras (alíquotas);

$m$ é o número do ensaio da amostra, $m=1, n$;

$x_{m}$ é o resultado obtido para o ensaio $k$;

$\bar{x}$ é a média dos resultados para $n$ medições.

A reprodutibilidade do método foi determinada de acordo com (5).

$$
R=2,8 P I
$$

onde:

$R$ é o valor do limite de reprodutibilidade $\left(\mathrm{mg} \mathrm{kg}^{-1}\right)$;

$P$ l é o valor de precisão intermediária $\left(\mathrm{mg} \mathrm{kg}^{-1}\right)$.

\subsection{Limite de deteç̧ão}

O limite de deteç̧ão (LD) foi calculado para a análise de uma amostra controle Tecido de Mexilhão $T M-1$ de acordo com (6).

$$
L D=3,29 \frac{\sqrt{b}}{t}
$$

onde:

Loé a taxa de contagem correspondente ao limite de deteç̧ão do método (cps);

$b$ é o número de contagens da radiação de fundo sob o pico analítico (cps);

$t$ é o tempo real de medição da amostra (s).

O resultado obtidos para $L D$ é convertido para $\mathrm{mg} \mathrm{kg}^{-1}$ utilizando a equação geral da ativação neutrônica (1).

\subsection{Limite de quantificação}

O limite de quantificação (LQ) foi calculado para a análise de uma amostra controle Tecido de Mexilhão TM-1 de acordo com (7).

$$
L Q=10 \frac{\sqrt{b}}{t}
$$

onde:

$L_{Q}$ é a taxa de contagem correspondente ao limite de quantificação do método (cps);

$b$ é o número de contagens da radiação de fundo sob o pico analítico (cps);

$t$ é o tempo real de medição da amostra (s).

O resultado obtidos para $L Q$ é convertido para $\mathrm{mg} \mathrm{kg}^{-1}$ utilizando a equação geral da ativação neutrônica (1). 


\begin{tabular}{|c|c|c|}
\hline Centro do Reator de & MÉTODO GEO 2: Determinação da concentração & Página 11 de 12 \\
Pesquisa - CRPq, & de Co, Cr, Fe, Sc e Zn em amostras de matriz & POP - CRPq/102 \\
IPEN - CNEN/SP & geológica (POP - CRPq/102) & Revisão: 00 \\
\hline
\end{tabular}

\subsection{Incerteza de medição}

A estimativa da incerteza de medição foi realizada em função do método simulado, procedimento recomendado pelo Guia para a quantificação de incertezas de medição (EURACHEM/CITAC, 2012) e descrito passo a passo por Petroni (PETRONI, 2015). Levou-se em consideração as seguintes componentes de entrada em INAA: massa da amostra, massa do padrão sintético, atividade do radionuclídeo na amostra, atividade do radionuclídeo no padrão sintético e constante de decaimento do radionuclídeo.

\subsection{Pico analítico}

O cálculo da concentração dos mensurandos na amostra deve ser realizado para a atividade verificada nos respectivos picos analíticos:

$$
\begin{aligned}
& \mathrm{Co}-1173,2 \mathrm{keV} ; \\
& \mathrm{Cr}-320,1 \mathrm{keV} ; \\
& \mathrm{Fe}-1099,2 \mathrm{keV} \\
& \mathrm{Sc}-889,3 \mathrm{keV} \\
& \mathrm{Zn}-1115,5 \mathrm{keV}
\end{aligned}
$$

\begin{tabular}{|c|c|c|c|}
\hline \multirow{2}{*}{ Parâmetro de Validação } & \multicolumn{3}{|c|}{$\mathrm{Co}$} \\
\hline & $n$ & En & Resultado \\
\hline Limite de repetitividade & 7 & $-0,13$ & $0,87 \mathrm{mg} \mathrm{kg}^{-1}$ \\
\hline Precisão Intermediária & 28 & 0,12 & $1,1 \mathrm{mg} \mathrm{kg}^{-1}$ \\
\hline Limite de reprodutibilidade & 28 & 0,12 & $3,2 \mathrm{mg} \mathrm{kg}^{-1}$ \\
\hline Limite de detecção & 1 & 0,08 & $0,17 \mathrm{mg} \mathrm{kg}^{-1}$ \\
\hline Limite de quantificação & 1 & 0,08 & $0,51 \mathrm{mg} \mathrm{kg}^{-1}$ \\
\hline \multirow{5}{*}{$\begin{array}{c}\text { Incerteza expandida relativa, } k=2 \\
\text { Faixa de trabalho } \\
\text { Veracidade }\end{array}$} & 5 & 0,17 & $6,9-7,0 \%$ \\
\hline & \multirow{2}{*}{\multicolumn{3}{|c|}{$\begin{array}{l}\quad 0,51-65 \mathrm{mg} \mathrm{kg}^{-1} \\
\text { Adequada }(-1,0<E n<1,0)\end{array}$}} \\
\hline & & & \\
\hline & \multicolumn{3}{|c|}{$\mathrm{Cr}$} \\
\hline & $n$ & $E n$ & Resultado \\
\hline Limite de repetitividade & 7 & $-0,07$ & $9,8 \mathrm{mg} \mathrm{kg}^{-1}$ \\
\hline Precisão Intermediária & 28 & $-0,01$ & $16 \mathrm{mg} \mathrm{kg}^{-1}$ \\
\hline Limite de reprodutibilidade & 28 & $-0,01$ & $44 \mathrm{mg} \mathrm{kg}^{-1}$ \\
\hline Limite de detecção & 1 & 0,10 & $1,4 \mathrm{mg} \mathrm{kg}^{-1}$ \\
\hline \multirow{6}{*}{$\begin{array}{l}\text { Limite de quantificação } \\
\text { Incerteza expandida relativa, } k=2 \\
\text { Faixa de trabalho } \\
\text { Veracidade }\end{array}$} & 1 & 0,10 & $4,3 \mathrm{mg} \mathrm{kg}^{-1}$ \\
\hline & 5 & 0,19 & $8,7-9,3 \%$ \\
\hline & \multirow{2}{*}{\multicolumn{3}{|c|}{$\begin{array}{c}4,3-69 \mathrm{mg} \mathrm{kg}^{-1} \\
\text { Adequada }(-1,0<E n<1,0)\end{array}$}} \\
\hline & & & \\
\hline & \multicolumn{3}{|c|}{$\mathrm{Fe}$} \\
\hline & $n$ & $E n$ & Resultado \\
\hline Limite de repetitividade & 7 & 0,22 & $1239 \mathrm{mg} \mathrm{kg}^{-1}$ \\
\hline Precisão Intermediária & 28 & 0,42 & $3196 \mathrm{mg} \mathrm{kg}^{-1}$ \\
\hline Limite de reprodutibilidade & 28 & 0,42 & $8948 \mathrm{mg} \mathrm{kg}^{-1}$ \\
\hline Limite de detecção & 1 & 0,01 & $137 \mathrm{mg} \mathrm{kg}^{-1}$ \\
\hline Limite de quantificação & 1 & 0,01 & $418 \mathrm{mg} \mathrm{kg}^{-1}$ \\
\hline Incerteza expandida relativa, $k=2$ & 5 & $-0,14$ & $7,3-7,9 \%$ \\
\hline Faixa de trabalho & \multirow{2}{*}{\multicolumn{3}{|c|}{$\begin{array}{c}418-79100 \mathrm{mg} \mathrm{kg}^{-1} \\
\text { Adequada }(-1,0<E n<1,0)\end{array}$}} \\
\hline Veracidade & & & \\
\hline
\end{tabular}

\section{CARACTERÍSTICAS DO MÉTODO DE MEDIÇÄO}

A seguir são apresentados as características correspondentes ao método de medição. 


\begin{tabular}{|c|c|c|}
\hline $\begin{array}{c}\text { Centro do Reator de } \\
\text { Pesquisa - CRPq, } \\
\text { IPEN - CNEN/SP }\end{array}$ & $\begin{array}{c}\text { MÉTODO GEO 2: Determinação da concentração } \\
\text { de Co, Cr, Fe, Sc e Zn em amostras de matriz }\end{array}$ & $\begin{array}{c}\text { Página 12 de 12 } \\
\text { POP - CRPq/102 } \\
\text { Revisão: 00 }\end{array}$ \\
\hline
\end{tabular}

\begin{tabular}{|c|c|c|c|}
\hline \multirow{2}{*}{ Parâmetro de validação } & \multicolumn{3}{|c|}{ Sc } \\
\hline & $n$ & $E n$ & Resultado \\
\hline Limite de repetitividade & 7 & $-0,09$ & $0,37 \mathrm{mg} \mathrm{kg}^{-1}$ \\
\hline Precisão Intermediária & 28 & $-0,11$ & $1,1 \mathrm{mg} \mathrm{kg}^{-1}$ \\
\hline Limite de reprodutibilidade & 28 & $-0,11$ & $3,1 \mathrm{mg} \mathrm{kg}^{-1}$ \\
\hline Limite de detecção & 5 & 0,33 & $0,023 \mathrm{mg} \mathrm{kg}^{-1}$ \\
\hline Limite de quantificação & 1 & 0,33 & $0,070 \mathrm{mg} \mathrm{kg}^{-1}$ \\
\hline \multirow{5}{*}{$\begin{array}{c}\text { Incerteza expandida relativa, } k=2 \\
\text { Faixa de trabalho } \\
\text { Veracidade }\end{array}$} & 1 & 0,06 & $5,0-5,2 \%$ \\
\hline & \multirow{2}{*}{\multicolumn{3}{|c|}{$\begin{array}{c}0,070-26 \mathrm{mg} \mathrm{kg}^{-1} \\
\text { Adequada }(-1,0<E n<1,0)\end{array}$}} \\
\hline & & & \\
\hline & \multicolumn{3}{|c|}{$\mathrm{Zn}$} \\
\hline & $n$ & En & Resultado \\
\hline Limite de repetitividade & 7 & $-0,03$ & $14 \mathrm{mg} \mathrm{kg}^{-1}$ \\
\hline Precisão Intermediária & 27 & $-0,03$ & $62 \mathrm{mg} \mathrm{kg}^{-1}$ \\
\hline Limite de reprodutibilidade & 27 & $-0,03$ & $174 \mathrm{mg} \mathrm{kg}^{-1}$ \\
\hline Limite de detecção & 1 & 0,05 & $5,3 \mathrm{mg} \mathrm{kg}^{-1}$ \\
\hline Limite de quantificação & 1 & 0,05 & $16 \mathrm{mg} \mathrm{kg}^{-1}$ \\
\hline Incerteza expandida relativa, $k=2$ & 5 & 0,18 & $9,7-11,4 \%$ \\
\hline Faixa de trabalho & \multirow{2}{*}{\multicolumn{3}{|c|}{$\begin{array}{c}16-1424 \mathrm{mg} \mathrm{kg}^{-1} \\
\text { Adequada }(-1,0<E n<1,0)\end{array}$}} \\
\hline Veracidade & & & \\
\hline
\end{tabular}

\section{REFERÊNCIAS}

ALFASSI, Z. B. Activation Analysis. CRC Press. Florida, 1990

BODE, P.; FERNANDES, E.A.N.; GREENBERG, R.R. Metrology for chemical measurements and the position of INAA. Journal of Radioanalytical and Nuclear Chemistry. 245:109-114, 2000

GREENBERG, R. R.; BODE, P.; FERNANDES, E. A. N. Neutron activation analysis: A primary method of measurement. Spectrochimica Acta Part B. 66:193-241, 2011

HAMIDATOU, L.; SLAMENE, H.; AKHAL, T.; ZOURANEN, B. Concepts, instrumentation and techniques of Neutron Activation Analysis. In: KHARFY, F. Imaging and Radioanalytical Techniques in Interdisciplinary Research - Fundamentals and Cutting Edge Applications. InTech, p. 141-177, 2013 Disponivel em: $\quad$ http://www.intechopen.com/books/imaging-and-radioanalytical-techniques-ininterdisciplinary-research-fundamentals-and-cutting-edge-applications> Acesso em 18 novembro, 2014

PETRONI, R. Validação dos métodos de Análise por Ativação do Laboratório de Análise por Ativação do IPEN - CNEN/SP visando a produção de materiais de referência certificados. Dissertação de Mestrado. Universidade de São Paulo, 2015

\begin{tabular}{|c|c|c|c|}
\hline & Nome & Assinatura & Data \\
\hline Elaborado por: & & & $1-1$ \\
\hline Aprovado por: & & & 1 \\
\hline Implantado por: & & & 1 \\
\hline \multicolumn{4}{|l|}{ Substitui POP: } \\
\hline Revisado por: & & & 1 \\
\hline Revisado por: & & & 1 \\
\hline Revisado por: & & & 1 \\
\hline Desativado por: & & & 1 \\
\hline Razão: & & & \\
\hline
\end{tabular}

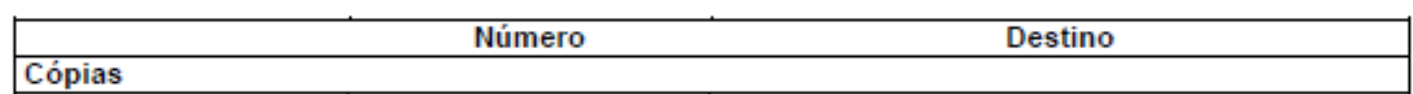




\section{REFERÊNCIAS BIBLIOGRÁFICAS}

ABNT, ASSOCIAÇÃO BRASILEIRA DE NORMAS TÉCNICAS. Termos $\boldsymbol{e}$ definições relacionados com materiais de referência. 1 ed. Rio de Janeiro: ABNT, 2000 (ABNT ISO Guia 30)

ABNT, ASSOCIAÇÃO BRASILEIRA DE NORMAS TÉCNICAS. Diretrizes para auditoria de sistemas de gestão da qualidade e/ou ambiental. Rio de Janeiro: ABNT, 2002 (ABNT NBR ISO 19011)

ABNT, ASSOCIAÇÃO BRASILEIRA DE NORMAS TÉCNICAS. Materiais de Referência - Conteúdo de certificados e rótulos. 2 ed. Rio de Janeiro: ABNT, 2004 (ABNT ISO Guia 31)

ABNT, ASSOCIAÇÃO BRASILEIRA DE NORMAS TÉCNICAS. Sistemas de Gestão da Qualidade - Fundamentos e vocabulário. Rio de Janeiro: ABNT, 2005 (ABNT NBR ISO 9000)

ABNT, ASSOCIAÇÃO BRASILEIRA DE NORMAS TÉCNICAS. Requisitos gerais para a competência de laboratórios de ensaio e calibração. 2 ed. corrigida, Rio de Janeiro: ABNT, 2006 (ABNT NBR ISO/IEC 17025:2005)

ABNT, ASSOCIAÇÃO BRASILEIRA DE NORMAS TÉCNICAS. Sistemas de Gestão da Qualidade - Requisitos. 2 ed. corrigida, Rio de Janeiro: ABNT, 2009 (ABNT NBR ISO 9001)

ABNT, ASSOCIAÇÃO BRASILEIRA DE NORMAS TÉCNICAS. Gestão para o sucesso sustentado de uma organização - Uma abordagem da gestão da qualidade. 2 ed. corrigida Rio de Janeiro: ABNT, 2010 (ABNT NBR ISO 9004) 
ABNT, ASSOCIAÇÃO BRASILEIRA DE NORMAS TÉCNICAS. Avaliação da conformidade - Requisitos gerais para ensaios de proficiência. Rio de Janeiro: ABNT, 2011 (ABNT NBR ISO/IEC 17043)

ALFASSI, Z. B. Activation Analysis. CRC Press. Florida, 1990

ANVISA, AGÊNCIA NACIONAL DE VIGILÂNCIA SANITÁRIA. Guia Para Qualidade em Química Analítica - Uma Assistência de Acreditação. 1a ed. Brasília, 2004

ANVISA, AGÊNCIA NACIONAL DE VIGILÂNCIA SANITÁRIA. Seleção, uso $\boldsymbol{e}$ interpretação de programas de ensaios de proficiência (EP) por laboratórios, Brasília: ANVISA, 2005 (Série Acreditação; 2)

ÁVILA, A. K.; ARAÚJO, T. O.; COUTO, P. R. G.; BORGES, R. M. H. Comparação da estimativa de incerteza de medição na determinação de cobre por espectrometria de absorção atômica com chama por diluição gravimétrica e volumétrica. 2014 Disponível em: <http://www.inmetro.gov.br/inovacao/artigos/ docs/55.pdf> Acesso em: 15 junho 2015

BALLA, M.; MOLNÁR, Z.; KOROS, A. Uncertainty budget and validation of NAA using Reference Materials. Journal of Radioanalytical and Nuclear Chemistry. v. 259, p. 395-400, 2004

BLAAUW, M.; GELSEMA, S. J.; The influence of peak area determination bias in gamma-ray spectrometry in the presence of true coincidence summing. Nuclear Instruments and Methods in Physics Research A. v. 422, p. 417-422, 1999

BODE, P.; GOEIJ, J. M. Activation analysis. In: MEYERS, R. A. Encyclopedia of Environmental Analysis and Remediation. John Wiley \& Sons Inc., 1998

BODE, P.; FERNANDES, E.A.N.; GREENBERG, R.R. Metrology for chemical measurements and the position of INAA. Journal of Radioanalytical and Nuclear Chemistry. v. 245, p. 109-114, 2000 
BODE, P.; BLAAUW, M. Performance and robustness of a multi-user, multispectrometer system for INAA. Journal of Radionalytical and Nuclear Chemistry. v. 291, p. 299-305, 2012

BOX, G. E. P.; HUNTER, W. G.; HUNTER, J. S. Statistics for experimenters. John Wiley \& Sons, Inc. New York, 2005

BRASIL. Resolução RE no 899, de 29 de maio de 2003. Agencia Nacional de Vigilância Sanitária (ANVISA), 2003 Disponível em:

http://portal.anvisa.gov.br/wps/wcm/connect/4983b0004745975da005f43fbc4c6735/RE _899_2003_Determina+a+publica\%C3\%A7\%C3\%A3o+do+Guia+para+valida\%C3\%A 7\% $3 \%$ A3o+de+m\% $3 \%$ A 9 todos+anal\%C3\%ADticos+e+bioanal\%C3\%ADticos.pdf? MOD=AJPERES $>$ Acesso em: 15 junho 2015

BRITO, N. M. Resíduos de pesticidas organoclorados (OC) e organofosforados (OF) em matriz de coco: metodologia e aplicação. 2001. Dissertação (Mestrado) Universidade Estadual Paulista. São Paulo

BUTTON, S.T. Metodologia para planejamento experimental e análise de resultado.Universidade Estadual de Campinas. São Paulo, 2001

CASTRO, L.; MOREIRA, E. G.; MAIHARA, V. A.; VASCONCELlOS, M. B. A. Bovine kidney reference material preparation proposal to be used in quality assurance of chemical measurements in meat products. In: International Nuclear Chemistry Congress, 2014. Maresias. Abstract book. Disponível em: <http://www.acquacon.com.br/4thincc/program.pdf> Acesso em: 15 junho 2015

CHENG, T. C. E.; PODOLSKY, S. Just-in-time manufacturing: an introduction. $2^{\text {a }}$ ed. London: Chapman \& Hall, 1996

CHU, S. F. Y.; EKSTROM, L. P.; FIRESTONE, R. B. The Lund/LBNL nuclear data search, version 2.0, 1999. Disponível em: <http://nucleardata.nuclear.lu.se/toi/> Acesso em: 15 junho 2015

CLEWER, A. G.; SCANISBRICK, D. H. Practical Statistics and Experimental Design for Plant and Crop Science. John Wiley \& Sons. Chichester, 2011 
COUTO, P.R.G. Estimativa da incerteza da massa específica da gasolina pelo ISO GUM 95 e Método de Monte-Carlo e seu impacto na transferência de custódia. Dissertação (Mestrado) - Universidade Federal do Rio de Janeiro, 2006

COUTO, P. R. G.; SILVA, M. A. S. Metodologia para comparação dos resultados, calibrações de padrões digitais de pressão e estimativa das incertezas seguindo as recomendações do ISO GUM 95 e o método de simulação de Monte Carlo. In:V Congresso Latino Americano de Metrologia (V METROSUL). Curitiba, 2007

CURRIE, L. A. Nomenclature in evaluation of analytical methods including detection and quantification capabilities (IUPAC Recommendations 1995). Analytical Chim Acta, v. 391, p. 105-126, 1999

DE SOETE, D.; GIJELS, R.; HOSTE, J. Neutron activation analysis. WileyInterscience, London, 1972

EHMANN, W. D.; VANCE, D. E. Radiochemistry and nuclear methods of analysis. New York, John Wiley \& Sons, Inc., 1991

ENGELHARD T, FELLER E, NIZRI Z. A comparison of the complimentary and different issues in ISO/IEC 17025 and OECD GLP. Accreditation and Quality Assurance. v. 8, 2003

ERIKSSON, L.; JOHASSON, E.; KETTANEH-WOLD, N.; WIKTROM C.; WOLD, S. Design of experiments: principles and applications. MKS Umetrics. Umea, 2008

EURACHEM. The fitness for purpose of analytical methods. A laboratory guide to method validation and related topics, 1998. Disponível em: <http://www.eurachem.org/images/stories/Guides/pdf/valid.pdf> Acesso em: 15 junho 2015

EURACHEM/CITAC. Quantifying uncertainty in analytical measurement. EURACHEM/CITAC Guide CG 4, 2012. Disponível em: <http://www.citac.cc/QUAM2012_P1.pdf> Acesso em: 15 junho 2015 (QUAM:2012) 
FELDSINE P, ABEYTA C, ANDREWS WH. AOAC. International Methods Committee Guidelines for Validation of Qualitative and Quantitative Food Microbiological Official Methods Analysis, 2002

FOX, A. GLP Regulation vs. ISO 17025 Requirements: how do they differ? Accreditation and Quality Assurance. v.8, p. 303, 2003

GREENBERG, R. R. Pushing the limits of NAA: accuracy, uncertainty and detection limits. Journal of Radioanalytical and Nuclear Chemistry. v. 278, p. 231-240, 2008

GREENBERG, R. R.; BODE, P.; FERNANDES, E. A. N. Neutron Activation Analysis: a primary method of measurement. Spectrochimica Acta Part B. v. 66, p. 193-241, 2011

HAIR, J. F.; BLACK, D. C.; BABIN, B. J.; ANDERSON, R. E.; TATHAM, R. L. Análise multivariada de dados. Bookman Companhia Editora. Porto Alegre, 2009

HAMIDATOU, L.; SLAMENE, H.; AKHAL, T.; ZOURANEN, B. Concepts, instrumentation and techniques of Neutron Activation Analysis. In: KHARFY, F. Imaging and Radioanalytical Techniques in Interdisciplinary Research - Fundamentals and Cutting Edge Applications. InTech, p. 141-177, 2013 Disponível em: $<$ http://www.intechopen.com/books/imaging-and-radioanalytical-techniques-ininterdisciplinary-research-fundamentals-and-cutting-edge-applications> Acesso em: 15 junho 2015

HARRIS, D. C. Exploring chemical analysis. W H Freeman \& Co, 1996

HIRANO, H. JIT Implementation Manual - The complete guide to just-in-time manufacturing: volume 1 - the just-in-time production system. Boca Raton: CRC Press, 2009

HUBER L. Validation on qualification in analytical laboratories. Interpharm. Informa Healthcare. Nova York. 1 ${ }^{\text {a }}$ Edição, 2007

IAEA. International atomic Energy Agency. Practical aspects of operating a neutron activation analysis laboratory. Vienna, 1990 (IAEA-TECDOC 564) 
IAEA. International atomic Energy Agency. Use of research reactors for neutron activation analysis. Vienna, 2001 Disponível em :

< http://www-pub.iaea.org/MTCD/publications/PDF/te_1215_prn.pdf > Acesso em: 15 junho 2015 (IAEA-TECDOC 1215)

IAEA. International atomic Energy Agency. Uncertainty evaluation in instrumental and radio-chemical neutron activation analysis. Vienna, 2004 Disponível em : <http://www-pub.iaea.org/MTCD/publications/PDF/te_1401_web.pdf> Acesso em: 15 junho 2015 (IAEA-TECDOC1401)

IAEA. International atomic Energy Agency. Regional cooperation agreement for the promotion of nuclear science and technology in Latin America and the Caribbean Contribution to sustainable development - 1984-2009. Vienna, 2010. Disponível em: <http://www.iaea.org/technicalcooperation/documents/Brochures/Sus-dev-19842009_eng.pdf> Acesso em: 15 junho 2015

INMETRO, INSTITUTO NACIONAL DE METROLOGIA, QUALIDADE E TECNOLOGIA. Orientação sobre validação de métodos analíticos. Rio de Janeiro, Fev. 2010. Disponível em:

<http://www.inmetro.gov.br/Sidoq/Arquivos/CGCRE/DOQ/DOQ-CGCRE-8_03.pdf>, Acesso em: 15 junho 2015 (DOQ-CGCRE-008)

INMETRO, INSTITUTO NACIONAL DE METROLOGIA, QUALIDADE E TECNOLOGIA. O movimento da qualidade no Brasil. São Paulo: Essencial Idea Publishing, 2011a

INMETRO, INSTITUTO NACIONAL DE METROLOGIA, QUALIDADE E TECNOLOGIA. Princípios das Boas Práticas de Laboratório - BPL, 2011b Disponível em: < http://www.inmetro.gov.br/sidoq/arquivos/Dicla/NIT/NIT-Dicla35_02.pdf > Acesso em: 15 junho 2015 (NIT-DICLA-035)

INMETRO, INSTITUTO NACIONAL DE METROLOGIA, QUALIDADE E TECNOLOGIA. Vocabulário Internacional de Metrologia: conceitos fundamentais $e$ gerais e termos associados. 1ed Luso-brasileira, Rio de Janeiro: INMETRO, 2012a. 
Disponível em: http://www.inmetro.gov.br/inovacao/publicacoes/vim_2012.pdf>, Acesso em: 15 junho, 2015 (VIM)

INMETRO, INSTITUTO NACIONAL DE METROLOGIA, QUALIDADE E TECNOLOGIA. Orientação sobre a análise crítica da documentação associada aos Materiais de Referência adquiridos. Rio de Janeiro: INMETRO, 2012b (DOQ-CGCRE-033)

INMETRO, INSTITUTO NACIONAL DE METROLOGIA, QUALIDADE E TECNOLOGIA. Guia para a expressão da incerteza de medição. 1ed Luso-brasileira. Rio de Janeiro: INMETRO, 2012c (ISO GUM)

INMETRO, INSTITUTO NACIONAL DE METROLOGIA, QUALIDADE E TECNOLOGIA. Reconhecimento da conformidade aos princípios BPL, 2014 Disponível em:

<http://www.inmetro.gov.br/monitoramento_BPL/reconhecimento_BPL.asp\#info> Acesso em: 15 junho 2015

IPEN, INSTITUTO DE PESQUISAS ENERGÉTICAS E NUCLEARES. Centro de Reator de Pesquisas, 2014. Disponível em: < https://www.ipen.br/sitio/?idc=192> Acesso em: 25 dezembro, 2014

IPEN, INSTITUTO DE PESQUISAS ENERGÉTICAS E NUCLEARES. LAN. Laboratório de Análise por Ativação Neutrônica, 2015. Disponível em: < https://www.ipen.br/portal_por/portal/interna.php?secao_id=715> Acesso em: 15 junho 2015

ISO, INTERNATIONAL ORGANIZATION OF STANDADIZATION. Accuracy (trueness and precision) of measurement methods and results - Practical guidance for the use of ISO 5725:1994 in designing, implementing and statistically analysing interlaboratory repeatability and reproducibility results. Geneva, 2005

ISO, INTERNATIONAL ORGANIZATION OF STANTARDIZATION. Reference materials - General and statistical principles for certification. Geneva: 2006 (ISO Guide 35) 
ISO, INTERNATIONAL ORGANIZATION OF STANDADIZATION. Accuracy (trueness and precision) of measurement methods and results-- Part 1: General principles and definitions. Geneva, 2012

ISO, INTERNATIONAL ORGANIZATION OF STANDADIZATION. Accuracy (trueness and precision) of measurement methods and results- Part 3: Intermediate measures of the precision of a standard measurement method. Geneva, 2013

IZADYAR, S.; FATEMI, S.; MOUSAVAND, T. Synthesis and modification of nanosized $\mathrm{TiO} 2$ for photo-degradation process under visible light irradiation; a PlacketBurman experimental design. Materials Research Bulletin, v. 48, p. 3196-3203, 2013

JONES, E. C. Quality management for organizations using lean Six Sigma techniques. Boca Raton: CRC Press, 2014

JURAN, J.M.; GRYNA, JR., F. M.; BINGHAM JR., R. S. Quality control handbook. McGraw-Hill. Cap New York,1951

KENNEDy, J. H. Analytical Chemistry: Practice. 2 ed. Santa Barbara: Harcourt Brace, 1990

KONIECZKA, P.; NAMIESNIK, J. Quality assurance and quality control in the analytical chemical laboratory: A practical approach. Boca Raton: CRC Press, 2009

LOPES, L.; SANTOS, S. C. A. Estatística Básica Aplicada para Laboratório. Universidade Corporativa Petrobras, Salvador, 2008

MARTÍNEZ, H. D. R. Analyzing interactions of fitted models, 2013 Disponível em: <http://cran.r-project.org/web/packages/phia/vignettes/phia.pdf> Acesso em: 15 junho 2015

MATSUBARA, T. C. M. Estudo sobre a determinação de antimônio em amostras ambientais pelo método de análise por ativação com nêutrons. Validação da metodologia e determinação da incerteza de medição. 2011 Dissertação (Mestrado) Instituto de Pesquisas Energéticas e Nucleares, São Paulo. 
MELO, J. C. Otimização da produção de biodiesel. Dissertação (Mestrado) Universidade Federal do Pernambuco, 2007

MERMET, J. M.; OTTO, M.; VALCÁRCEL, M. Analytical chemistry: a modern approach to analytical science. Weinhein: Wiley-VCH, 2004

MONTGOMERY, D. C. Design and analysis of experiments. John Wiley \& Sons, Inc. New York, 1991

MOREIRA, E. G.; VASCONCELLOS, M. B. A.; SAIKI, M. Uncertainty assessment in instrumental neutron activation analysis of biological materials. Journal of Radioanaytical and Nuclear Chemistry. v. 269, p. 377-382, 2006

MOREIRA, E. G. Preparo e certificação de um material de referência de mexilhão Perna perna (Linnaeus, 1758). 2010. Tese (Doutorado) - Instituto de Pesquisas Energéticas e Nucleares, São Paulo

NIST, National Institute of Standards e Technology. Standard Reference Material 1646a: Estuarine sediment (Certificate of Analysis). National Institute of Standards \& Technology, 2004

NIST, National Institute of Standards e Technology. Standard Reference Material 1566b: Oyster tissue (Certificate of Analysis). National Institute of Standards \& Technology, 2011

NIST, National Institute of Standards e Technology. Standard Reference Material 2702: Marine sediment (Certificate of Analysis). National Institute of Standards \& Technology, 2012

NIST/SEMANTECH. e-Handbook of Statistical Method. 2013. Disponível em: <http://www.itl.nist.gov/div898/handbook/> Acesso em: 01 dezembro, 2014

NRCC, National Research Council Canada. Standard Reference Material HISS-1, MESS-3 and PACS-2: Marine sediment (Certificate of Analysis). National Research Council Canada, 2012 
PEREIRA-FILHO, E.; POPPI, R. J.; ARRUDA, M. A. Z. Employment of factorial design for optimization of pirolysis and atomization temperatures for $\mathrm{Al}, \mathrm{Cd}, \mathrm{Ni}$ and $\mathrm{Pb}$ determination by ET AAS. Química Nova, v. 25, p. 246-253, 2002

PETERS F.T.; DRUMMER O. H.; MUSSHOFF F. Validation of new methods. Forensic Science International. v. 165, 2007

PORTAL ACTION. 2015 Disponível em:

$<$ http://www.portalaction.com.br/content/download-action> Acesso em: 15 junho, 2015

PRICHARD, E.; BARWICK, V. Quality assurance in analytical chemistry. Teddington, Wiley-LGC, 2008

REYNIER, N.; BLAIS, J. F.; MERCIER, G. Optimization of arsenic and pentachlorophenol removal from soil using an experimental design methodology. Journal of soils and sediments, v. 13, p. 1189-1200, 2013

RIBEIRO, H. A Bíblia do 5s. Salvador: Casa da Qualidade, 2006

STOCKL D.; D'HONDT H.; THIENPONT L. M. Validation across the disciplinesCritical investigation of Major Validation Criteria and Associated Experimental Protocols. Journal of Chromatography B. v. 877, 2009

TAVARES, K. S. Validação de métodos de análises cromatográficos: determinação de HCl. Dissertação (Mestrado) - Universidade de Aveiro, Aveiro, 2012 Disponível em: <https://ria.ua.pt/bitstream/10773/9302/1/253049.pdf> Acesso em: 15 junho 2015

TAVERNIERS I.; BLOCKSTAELE E. V.; DE LOOSE M. Trends in quality in the analytical laboratory. 1. Traceability and measurement uncertainty of analytical results. Trends in Analytical Chemistry. v. 23, n. 7, 2004

TEÓFILO, R. F.; FERREIRA, M. M. C. Chemometrics II: Spreadsheets for experimental design calculations, a tutorial, Química Nova, v. 29, p. 338-350, 2006

THOMPSON, M.; ELLISON, S. L. R.; WOOD, R. Harmonized guidelines for single laboratory validation of methods of analysis. (IUPAC Technical Report). Pure and Applied Chemistry. v. 74, n. 5, 2002 
THOMPSON, M.; ELLISON, S. L. R.; WOOD, R. The International Harmonized protocol for the proficiency testing of analytical chemistry laboratories. Pure and Applied Chemistry. v. 78, p. 145-196. 2006

WALSH, M. C. Moving from official to traceable methods. Trac Trends in Analytical Chemistry. v. 18, p. 616-623, 1999

YE, K. Q.; HAMADA, M.; WU, C. F. J. A Step-Down lenth method for analyzing unreplicated factorial designs. Journal of Quality Technology. v.33, p.140-152, 2001

ZHAG, W. L.; ZHANG, Z. B.; CAO, X. H.; LIU, Y. H. Uranium adsorption studies on hydrothermal carbon produced by chitosan using statistical design method. Journal of Radioanalytical and Nuclear Chemistry. v. 301, p.197-205, 2014

ZSCHUNKE, A. Reference materials in analytical chemistry - a guide for selection and use. Berlin: Springer, 2000 